\title{
Chemical and physical modification of petroleum, coal-tar, and coal-extract pitches by air-blowing
}

Nathan D. King

West Virginia University

Follow this and additional works at: https://researchrepository.wvu.edu/etd

\section{Recommended Citation}

King, Nathan D., "Chemical and physical modification of petroleum, coal-tar, and coal-extract pitches by air-blowing" (2004). Graduate Theses, Dissertations, and Problem Reports. 1754.

https://researchrepository.wvu.edu/etd/1754

This Thesis is protected by copyright and/or related rights. It has been brought to you by the The Research Repository @ WVU with permission from the rights-holder(s). You are free to use this Thesis in any way that is permitted by the copyright and related rights legislation that applies to your use. For other uses you must obtain permission from the rights-holder(s) directly, unless additional rights are indicated by a Creative Commons license in the record and/ or on the work itself. This Thesis has been accepted for inclusion in WVU Graduate Theses, Dissertations, and Problem Reports collection by an authorized administrator of The Research Repository @ WVU. For more information, please contact researchrepository@mail.wvu.edu. 


\title{
Chemical and Physical Modification of Petroleum, Coal-Tar, and Coal- Extract Pitches by Air-Blowing
}

\author{
Nathan D. King \\ Thesis submitted to the \\ College of Engineering and Mineral Resources \\ At West Virginia University \\ in partial fulfillment of the requirements \\ for the degree of \\ Master of Science \\ in \\ Chemical Engineering
}

\author{
Peter G. Stansberry, Ph.D., Chair \\ Alfred H. Stiller, Ph.D. \\ John W. Zondlo, Ph.D. \\ Department of Chemical Engineering \\ Morgantown, West Virginia
}

2004

Keywords: Coal, extract, pitch, air-blowing, oxidation 


\title{
ABSTRACT \\ Chemical and Physical Modification of Petroleum, Coal-tar, and Coal-extract Pitches by Air-blowing
}

\begin{abstract}
Nathan King
Treatment by air-blowing was pursued as a process to modify the properties of pitches. The focus of this research was to compare the effects of air-blowing a coalextract pitch with a petroleum pitch and coal-tar binder pitch. Hydrogenation of a bituminous coal in tetralin was used to produce the coal-extract pitch. The three pitches were air-blown in a 1-liter autoclave at temperatures of $250^{\circ} \mathrm{C}, 275^{\circ} \mathrm{C}$, and $300^{\circ} \mathrm{C}$ for various time periods. The air-blown pitches were then characterized by softening point, coke yield, solubility, viscosity, density, elemental analysis, thermogravimetric analysis, FTIR, and optical texture. The results showed that air-blowing was a very effective way to increase the softening point, coke yield, density, and viscosity for all of the materials. The viscosity of the pitches was described well using the WLF model. Air blowing increased the carbon-to-hydrogen ratio, but little oxygen was incorporated into the pitch product. van Krevelen diagrams indicated that the coal-extract, petroleum, and coal-tar pitch each followed different mechanisms during the course of air blowing, emphasizing that compositional details must be considered in describing reaction details. Kinetic modeling of the air-blowing process showed an activation energy of approximately 16 $\mathrm{kcal} / \mathrm{mol}$ for all three pitches. The optical texture of all of the pitches was purely isotropic before and after air-blowing treatment. The pitches were carbonized and their respective green cokes displayed a highly anisotropic structure.
\end{abstract}




\section{Acknowledgements}

I would like to express my appreciation to the members of my thesis committee, Drs. Peter Stansberry, Alfred Stiller, and John Zondlo, who each gave valuable time, assistance, and support during this study. I am especially indebted to my advisor and committee chair, Dr. Peter Stansberry, who has worked countless hours assisting me, and who has been a true mentor for all areas of my academic and professional development. Additionally, I wish to thank my family for their help, guidance, and encouragement. A sincere thanks to all the other people named and not named who have helped me with the project by supplying valuable resources and assistance, Dr. Chong Chen, Liviu Magean, Mitchell Clendenin, and Jim Bowers. I also wish to extend a special thanks to the Department of Energy for supporting this research project and providing the necessary funds. 


\section{Table of Contents}

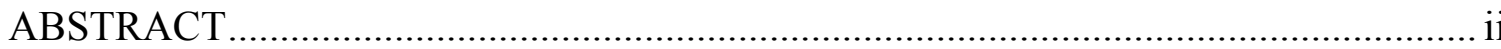

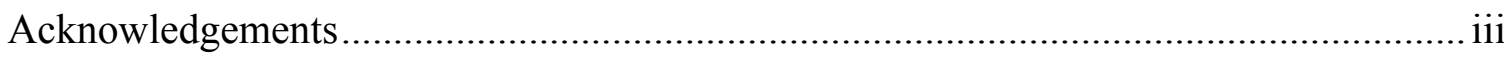

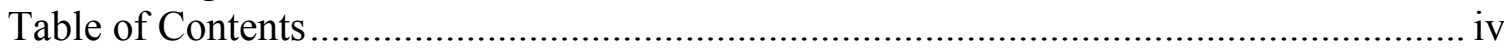

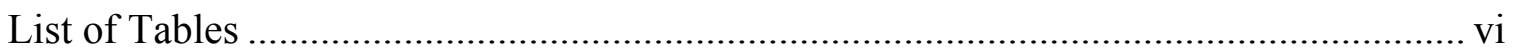

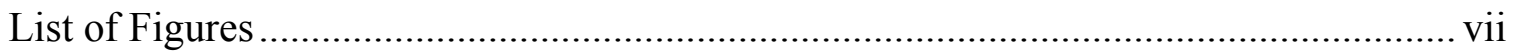

Chapter 1 - Introduction....................................................................................... 1

1.1 Tar and Pitch: Opening Comments ................................................................ 1

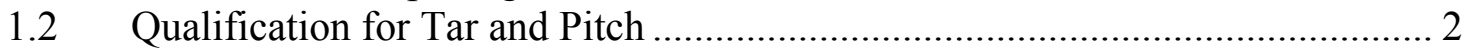

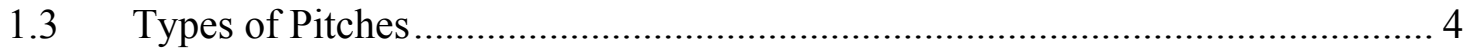

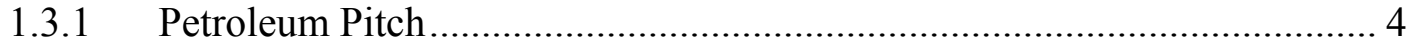

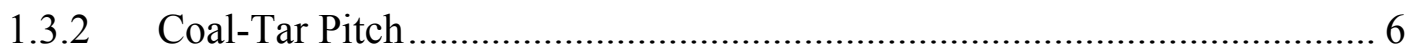

1.3.3 Coal-Extract Pitch........................................................................... 9

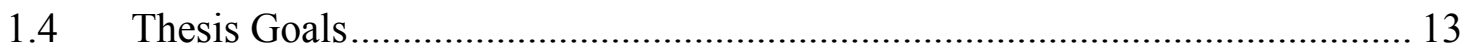

Chapter 2 - Literature Review.................................................................................. 16

2.1 Modification of Pitch Properties by Air Blowing......................................... 16

2.1.1 Effects on Softening Point ................................................................. 16

2.1.2 Effects on Coke Yield ....................................................................... 18

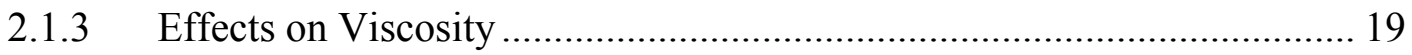

2.2 Williams, Landel, and Ferry Viscosity Model........................................... 20

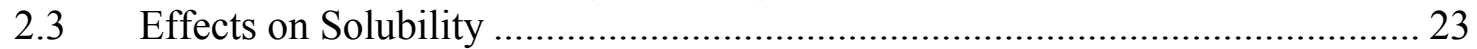

2.4 Effects of Air-blowing on Chemical Changes and Mechanisms ...................... 24

2.4.1 Reaction Pathways ...................................................................... 24

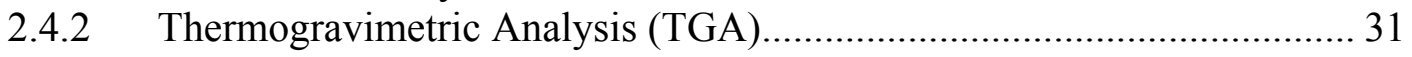

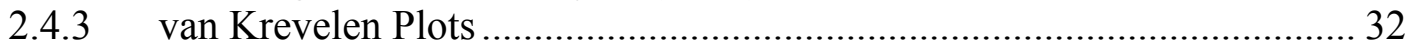

2.5 Effects of Air-blowing on Optical Activity ................................................. 36

Chapter 3 - Experimental Procedure ........................................................................ 37

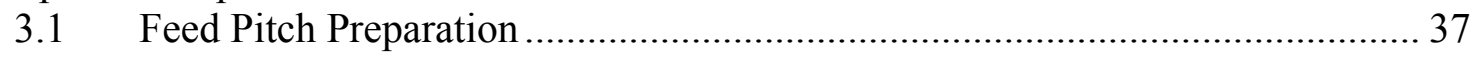

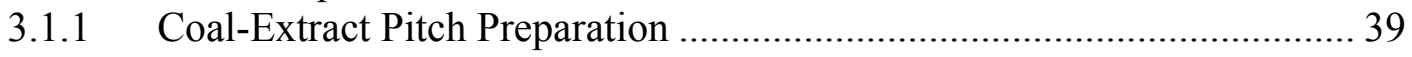

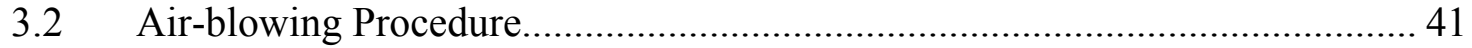

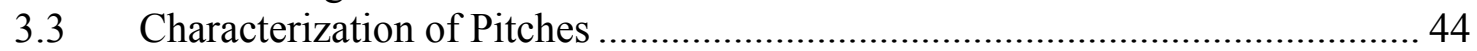

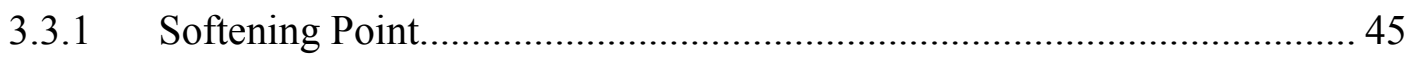

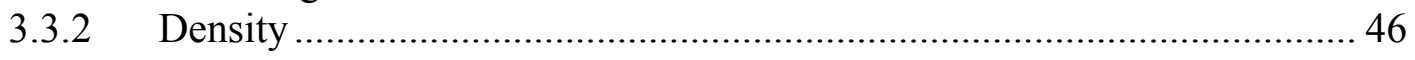

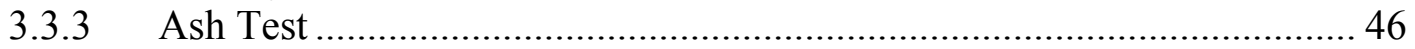

3.3.4 Conradson Carbon Test....................................................................... 47

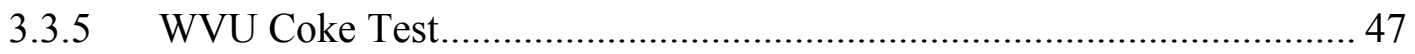

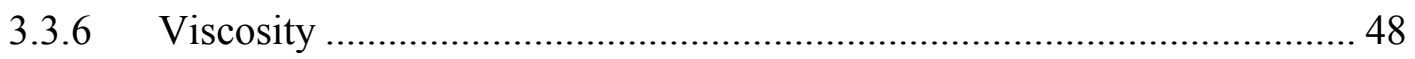

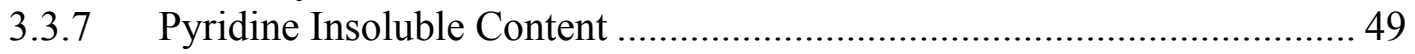

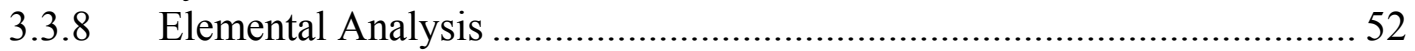

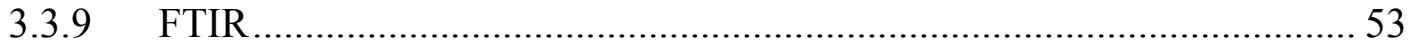

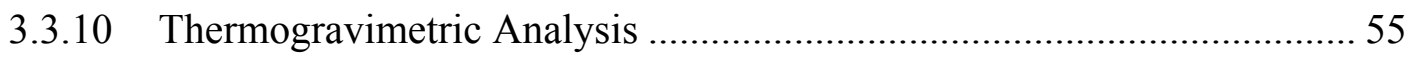

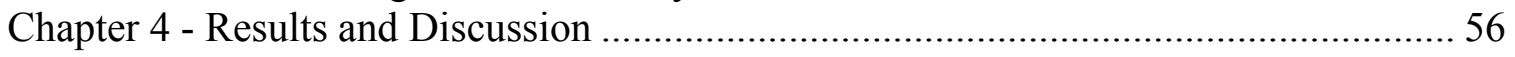

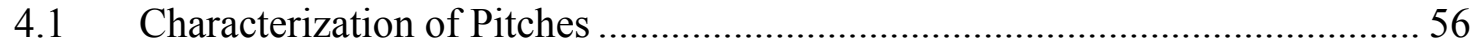

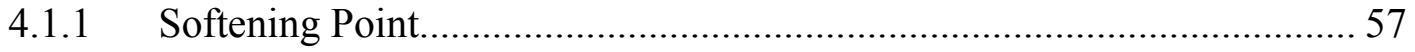

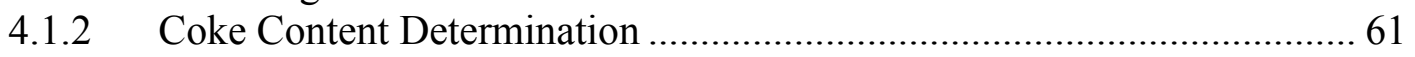




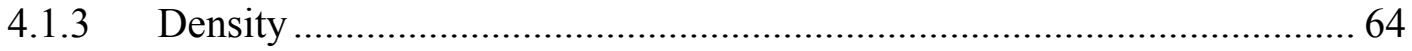

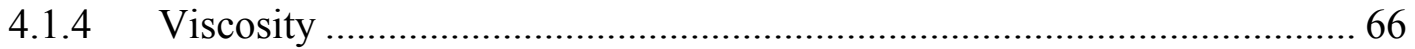

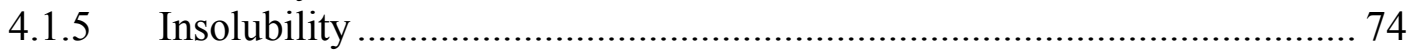

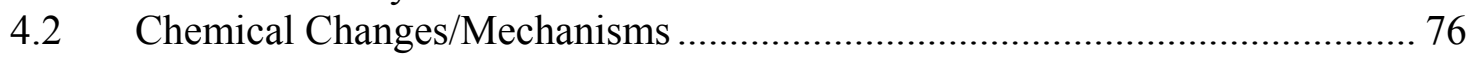

4.2.1 Kinetic Modeling ........................................................................... 76

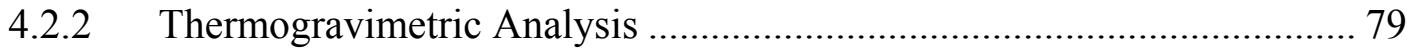

4.2.3 Elemental Analysis and van Krevelen Plots ......................................... 89

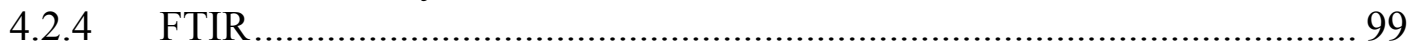

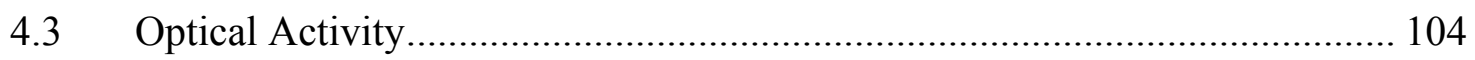

Chapter 5 - Conclusions and Recommendations ..................................................... 105

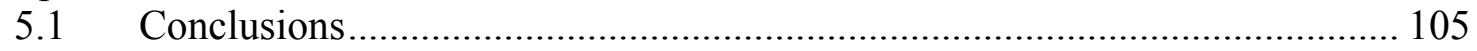

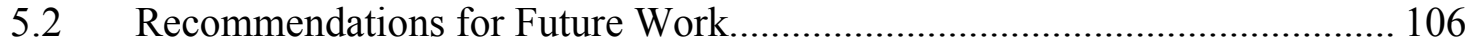

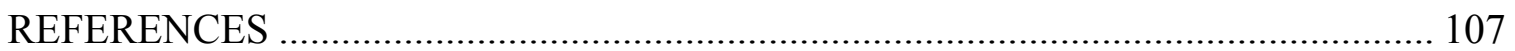

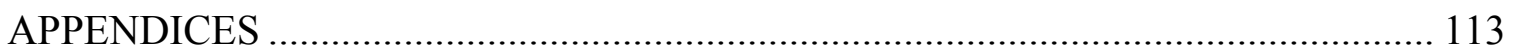

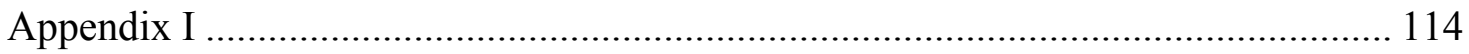

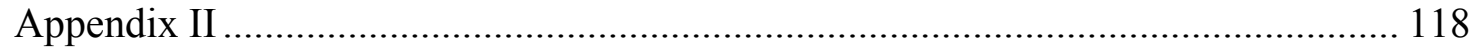

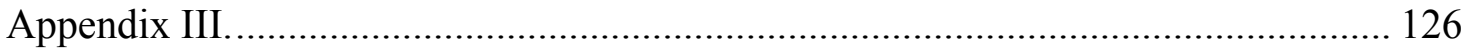

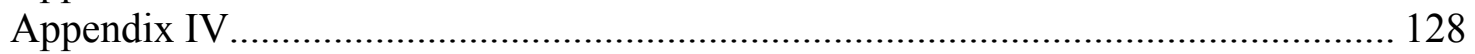

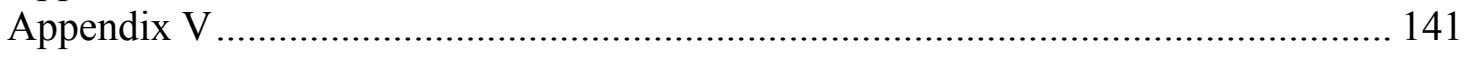

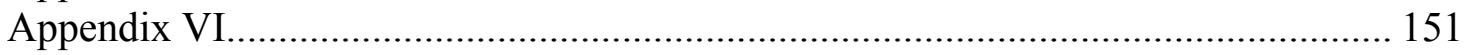

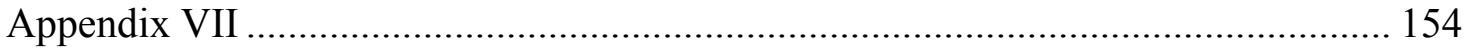




\section{List of Tables}

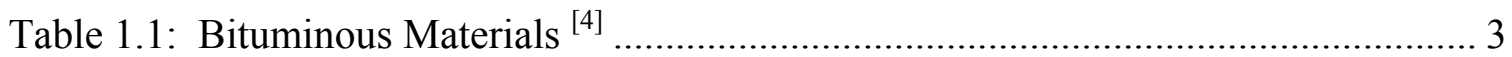

Table 1.2: Typical boiling point ranges of crude oil fractions ${ }^{[11]}$................................... 5

Table 1.3: Coal-tar distillation fractions .................................................................. 9

Table 1.4: Nominal product distribution from solvent extraction of coal with middle oil [29]

Table 1.5: Methods used for modification of pitch composition and properties ............. 14

Table 2.1: Coke yield (wt \%) for air-blown pitch A and pitch B ................................ 19

Table 3.1: A240 Petroleum Pitch properties............................................................ 37

Table 3.2: Koppers Coal-Tar Pitch Properties ........................................................... 39

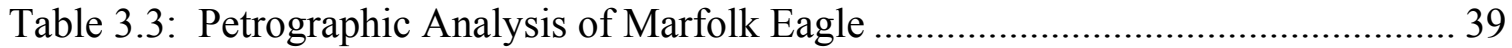

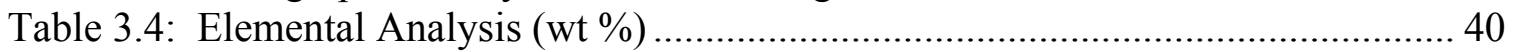

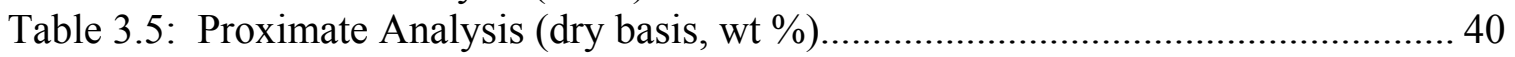

Table 3.6: Time to reach air-blowing temperature after pitch became molten............... 43

Table 3.7: Air oxidation reaction times and temperatures of the three pitches ............... 44

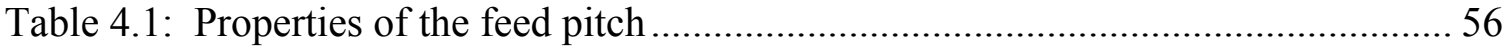

Table 4.2: Activation energies for the air-blowing of three types of pitches ................. 77 


\section{List of Figures}

Figure 1.1: Basic flow diagram of a modern petroleum refinery. ${ }^{[17]}$.............................. 6

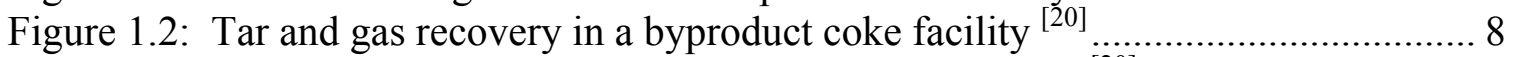

Figure 1.3: Process flow diagram for a coal-tar distillation plant ${ }^{[20]}$.............................. 9

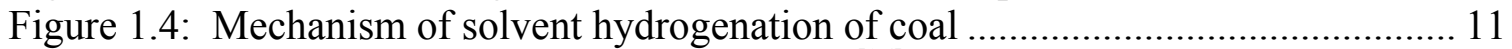

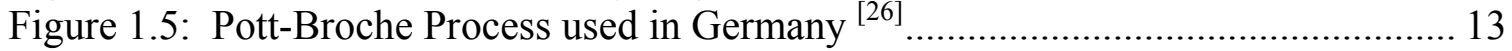

Figure 2.1: Softening point of coal-tar (NP80-1), hydrogenated coal-tar (NHP-1) and petroleum pitches (A60-1) during air-blowing at $330^{\circ} \mathrm{C}^{[34]}$................................ 17

Figure 2.2: Shear stress response upon start up of shear flow for the parent pitch and the air-blown pitches ${ }^{[37]}$

Figure 2.3: Plot of $(\mathrm{T}-\mathrm{Tr})$ vs. Log AT for a range of mesophase-containing pitches ${ }^{[42]}$

Figure 2.4: Variation of toluene insoluble content of coal-tar pitch with increased reaction time at four various temperatures....................................................... 24

Figure 2.5: Oxidation schemes of coal-tar and petroleum pitches. (a) Coal-tar pitch (b) Hydrogenated coal-tar pitch (c) Petroleum pitch [34] ............................................ 26

Figure 2.6: Dependency of TI Yields from coal-tar pitch on gas flow rate in air and

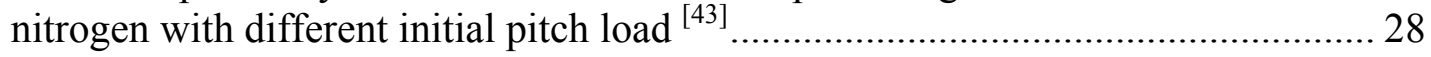

Figure 2.7: Relative carbonization of petroleum feedstocks at a heat treatment temperature of $723 \mathrm{~K}$

Figure 2.8: First-order plots for pyridine insolubles formation fromVR2 pentane insolubles 30

Figure 2.9: Arrhenius plot for VR2 pentane insolubles 30

Figure 2.10: Thermogravimetric (TGA) data for pyrolysis products of A240 petroleum

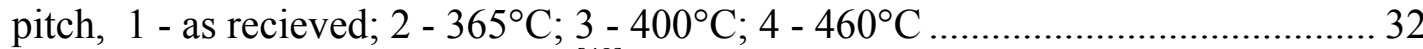

Figure 2.11: $\mathrm{H} / \mathrm{C}$ versus $\mathrm{O} / \mathrm{C}$ diagram ${ }^{[48]}$.................................................................. 33

Figure 2.12: H/C versus O/C for I) Wood, II) Cellulose, III) Lignin, IV) Peat, V) Lignite, VI) Low rank bituminous coal, VII) Medium rank bituminous coal, VIII) High rank bituminous coal, IX) Semi-anthracite, X) Anthracite ${ }^{[47]}$

Figure 2.13: van Krevelen diagrams showing oxidation paths of various organic

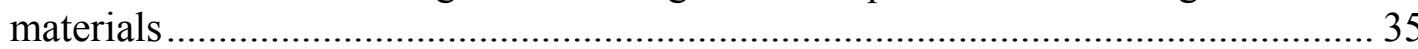

Figure 3.1: Rotary Evaporator ............................................................................ 38

Figure 3.2: Diagram of the 1-liter autoclave used in air-blowing experiments .............. 42

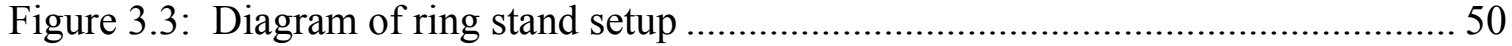

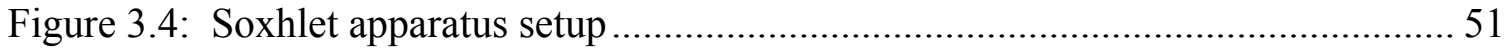

Figure 3.5: Diagram of Spectra-tech pellet apparatus ............................................... 54

Figure 4.1: Softening point effects of nitrogen and air-blowing at $300^{\circ} \mathrm{C}$ on the petroleum pitch, A240

Figure 4.2: Softening point effects of nitrogen and air-blowing at $300^{\circ} \mathrm{C}$ on the Koppers coal-tar pitch 58

Figure 4.3: Softening point temperatures of petroleum, coal-tar, and coal-extract feed and air-blown pitches at reaction temperatures of $250^{\circ} \mathrm{C}, 275^{\circ} \mathrm{C}, 300^{\circ} \mathrm{C} \mathrm{\ldots .............} 60$

Figure 4.4: Softening points of air-blown reaction at $300^{\circ} \mathrm{C}$ for all three pitches.......... 61 Figure 4.5: Conradson coke yield of petroleum, coal-tar, and coal-extract pitches airblown for various periods at 250,275 , and $300^{\circ} \mathrm{C}$ 
Figure 4.6: WVU coke yield of A240 petroleum pitch, Koppers coal-tar pitch, and WVU

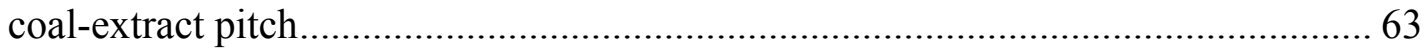

Figure 4.7: Density of petroleum, coal-tar, and coal-extract pitches air-blown at 250, $275,300^{\circ} \mathrm{C}$.

Figure 4.8: Temperature dependence of viscosity for $\mathrm{A} 240$ petroleum pitch at $250^{\circ} \mathrm{C}$, $275^{\circ} \mathrm{C}$, and $300^{\circ} \mathrm{C}$

Figure 4.9: Temperature dependence of viscosity for Koppers coal-tar pitch at $250^{\circ} \mathrm{C}$, $275^{\circ} \mathrm{C}$, and $300^{\circ} \mathrm{C}$

Figure 4.10: Temperature dependence of viscosity for WVU coal-extract pitch (CEP) at

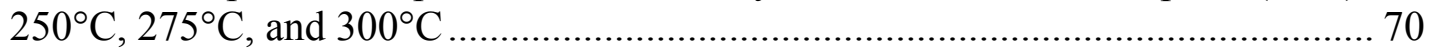

Figure 4.11: WFL model of A240 petroleum pitch at $250^{\circ} \mathrm{C}, 275^{\circ} \mathrm{C}$, and $300^{\circ} \mathrm{C} \ldots \ldots \ldots . .71$

Figure 4.12: WFL model of Koppers coal-tar pitch (CTP) at $250^{\circ} \mathrm{C}, 275^{\circ} \mathrm{C}$, and $300^{\circ} \mathrm{C} 72$ Figure 4.13: WFL model of WVU coal-extract pitch (CTP) at $250^{\circ} \mathrm{C}, 275^{\circ} \mathrm{C}$, and $300^{\circ} \mathrm{C}$

Figure 4.14: Pyridine insoluble content of A240 petroleum pitch................................... 74

Figure 4.15: Pyridine insoluble content of Koppers coal-tar pitch ................................. 75

Figure 4.16: Pyridine insoluble content of WVU coal-extract pitch .............................. 76

Figure 4.17: Rate constant data for the air-blowing kinetics of petroleum pitch A240, coal-tar pitch, and coal-extract pitch................................................................... 78

Figure 4.18: Activation Energies for the air-blowing of petroleum pitch A240, coal-tar

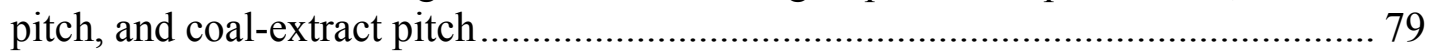

Figure 4.19: Petroleum pitch weight loss for air-blowing at $250^{\circ} \mathrm{C}, 275^{\circ} \mathrm{C}$, and $300^{\circ} \mathrm{C} .81$ Figure 4.20: Coal-tar pitch weight loss for air-blowing at $250^{\circ} \mathrm{C}, 275^{\circ} \mathrm{C}$, and $300^{\circ} \mathrm{C} \ldots 82$ Figure 4.21: Coal-extract weight loss for air-blowing at $250^{\circ} \mathrm{C}, 275^{\circ} \mathrm{C}$, and $300^{\circ} \mathrm{C} \ldots . .83$ Figure 4.22: Volatile fraction remaining for $\mathrm{AB} \mathrm{A} 240$ at $250^{\circ} \mathrm{C}, 275^{\circ} \mathrm{C}$, and $300^{\circ} \mathrm{C} \ldots . .86$ Figure 4.23: Volatile fraction remaining for $\mathrm{AB} \mathrm{CTP}$ at $250^{\circ} \mathrm{C}, 275^{\circ} \mathrm{C}$, and $300^{\circ} \mathrm{C} \ldots \ldots . .87$ Figure 4.24: Volatile fraction for $\mathrm{AB}$ Coal-extract at $250^{\circ} \mathrm{C}, 275^{\circ} \mathrm{C}$, and $300^{\circ} \mathrm{C}$.......... 88 Figure 4.25: C-H Atomic Ratio vs AB Time A240 …………….............................. 90

Figure 4.26: C-H Atomic Ratio vs AB Time CTP...................................................... 91

Figure 4.27: C-H Atomic Ratio versus air-blown time for coal-extract .......................... 92

Figure 4.28: Oxygen content for air-blown petroleum pitch .......................................... 93

Figure 4.29: Oxygen content for air-blown coal-tar pitch .............................................. 94

Figure 4.30: Oxygen content for air-blown coal-extract pitch ....................................... 95

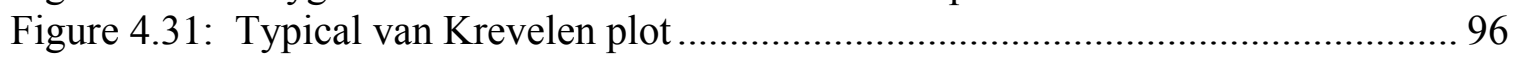

Figure 4.32: van Krevelen plot for A240 petroleum pitch............................................. 97

Figure 4.33: van Krevelen plot for coal-tar pitch ....................................................... 98

Figure 4.34: van Krevelen plot for coal-extract pitch.................................................... 99

Figure 4.35: Elemental Analysis and FTIR comparison for the three air blown pitches at $250^{\circ} \mathrm{C}$ 101

Figure 4.36: Elemental Analysis and FTIR comparison for the three air blown pitches at $275^{\circ} \mathrm{C}$ 102

Figure 4.37: Elemental Analysis and FTIR comparison for the three air blown pitches at $300^{\circ} \mathrm{C}$ 103 


\section{Chapter 1 - Introduction}

\subsection{Tar and Pitch: Opening Comments}

Mankind has used bituminous materials since antiquity. In the Book of Genesis 6.12 Noah is instructed to "...make rooms in the ark and cover it inside and out with pitch" and in Exodus 2.3 is told of the infant Moses who was spared from the death decree of Pharaoh by Levi's wife “... when she could hide him no longer, she took for him a basket of bulrushes and daubed it with bitumen and pitch..." And in Sirach 13.1 is stated ruefully, "He who touches pitch blackens his hand." Sadly, no mention is made in these biblical accounts from whence or how bitumen and pitch were made. Nonetheless, these types of materials were long ago recognized by early civilization for their superior waterproofing and preservative effects on wood, cordage, and rigging. Indeed, discovery of America by fifteenth-century mariners might have been delayed were it not for wooden ships made seaworthy by tarring.

Both academic and commercial interests in bituminous materials grew rapidly in the $17^{\text {th }}$ through the $19^{\text {th }}$ centuries particularly with respect to byproducts of coal carbonization. Michael Faraday first isolated benzene, a component of coal-tar, in 1825, and later Kekule described the resonance-stabilized structure of benzene in 1865. Both discoveries contributed greatly to the foundation of modern organic chemistry [1]. For soon thereafter benzene and the many other chemicals from coal-tars were to become commercial feeds for the synthetic dyes, plastics, disinfectants, and explosives industries.

In current times, coal-based as well as petroleum-based tars and other related substances continue to provide in no small measure to modern society. For example, coal-tars are processed into paints and coatings, pipeline enamels and fiber saturants, 
pitch cokes and carbon electrodes, binders and impregnants, road and roofing tars, industrial fuels and chemicals, and wood preserving oils [2]. Likewise, in addition to fuels and chemicals, petroleum is processed into asphalts for home and road building, tars for carbon black and binder pitch, and precursors for calcined coke [3].

\subsection{Qualification for Tar and Pitch}

Unfortunately, all too frequently there is uncertainty as to what constitutes pitch. To the average layperson any dark, often strong smelling, viscous organic liquid, would in all likelihood be referred to as tar. But such labels often are used indiscriminately and interchangeably, can be misleading and vague, and provide little indication as to practical application. Some of the nomenclature evolved over many years to become customary terminology, the materials often acquired trivial names, frequently coined to distinguish one product from another that, despite apparent similarities, perform differently. It is not uncommon for descriptive terms used by petroleum engineers, for example, to seem confusing or contradictory to the coal-tar researcher. Understandably, there is some justification to prevent confusion in terminology and to establish nomenclature and terms on a rational basis in categorizing tar-like materials.

Since this thesis is concerned with the development and characterization of pitches, it is naturally important to establish those characteristics that distinguish these materials from others. To begin with, tars and pitches are members of a broad range of naturally occurring or man-made substances known as bituminous materials [4]. Table 1.1 indicates some of the major groups, which include humuliths, asphalts, and resins. Although not indicated in the table, each major group is subdivided into several other 
classes of substances in that, for example, lignite, subbituminous coal, bituminous coal, and anthracite would fall under the humuliths group.

Table 1.1: Bituminous Materials ${ }^{\text {[4] }}$

\begin{tabular}{lll}
\hline \multicolumn{1}{c}{ Native } & Manufactured & Other \\
\hline Petroleums & Waxes & mineral oils \\
mineral waxes & Asphalts & Resins \\
Asphalts & Tars & Asphaltenes \\
Asphaltites & Pitches & \\
Asphaltoids & & \\
Bituminous rocks & & \\
Humuliths & & \\
\hline
\end{tabular}

Most importantly, however, are two necessary criteria or distinguishing features that set tar and pitch apart from all other bituminous materials. First, they are not found, under normal circumstances, in nature but rather are manufactured. Second, they are obtained as condensed products from destructive distillation or thermal decomposition of organic precursors: distillation of wood generates wood tars, coking of coal produces coal-tars, and simple cracking of petroleum makes gas oil or thermal tars. Each tar has its own unique composition and behavior. Only after the tars are collected and then distilled or otherwise processed to remove the more volatile components can the remaining heaviest material be properly called pitch. In simple words pitches are derived from tars that are derived from thermally degraded organic feeds. Thus it should be apparent that conventional distillation residues of petroleum and certain solvent extracts of coal are neither tar nor pitch since thermal degradation has not taken place in any prior processing step.

Tars are made by a wide range of methods. Each particular process design is dependent primarily on the feed material, i.e., whether pine wood, bone, or coal, and the 
intended primary product, i.e., whether synthesis gas, water gas, or metallurgical coke. Excellent details on process developments, feed characteristics, and product distributions are found in the literature [5-10]. In the United States, current domestic sources of tar are produced predominantly from commercial petroleum cracking and high-temperature coal carbonization operations [11]. Additionally, there also is a resurgence in efforts to convert coal directly into pitch-like feeds by solvent refining or direct coal liquefaction processes [12-14].

\subsection{Types of Pitches}

Pitches fall into one of two families depending on the extent of long-range molecular order: anisotropic or isotropic pitch. The former is a liquid crystalline form of pitch derived by thermal or catalytic polymerization of aromatic molecules. The production, characterization, and utilization of mesophasic pitches are beyond the scope of this thesis and will not be discussed specifically further. The subject is well covered elsewhere in the literature [15]. On the other hand, isotropic pitches find broader industrial utility and thus attention will be given to their precursors and production. In particular, two commercial pitches, a petroleum-derived pitch, and byproduct coke-oven coal-tar binder pitch, will be addressed. In addition, pitch derived by solvent extraction of coal, a potential surrogate to conventional materials, will be discussed.

\subsubsection{Petroleum Pitch}

The production of the pitch begins with the distillation of crude oil in a petroleum refinery [16-18]. Crude oil is heated and fed into a fractionator, normally an atmospheric 
distillation column, in which the components are separated by boiling point to recover butanes and lighter hydrocarbons, light naphtha, heavy naphtha, kerosene, atmospheric gas oil, and reduced crude. The reduced crude is then sent to a vacuum distillation tower to recover more naphtha, a vacuum gas oil stream, and a vacuum reduced crude bottoms or residua. Typically distillation cuts are shown in Table 1.2.

Table 1.2: Typical boiling point ranges of crude oil fractions ${ }^{[11]}$

\begin{tabular}{cc}
\hline Fraction & Boiling Ranges, ${ }^{\circ} \mathrm{C}$ \\
\hline Butanes and Lighter & $32-88$ \\
Light Naphtha & $88-193$ \\
Heavy Naphtha & $193-271$ \\
Kerosene & $271-321$ \\
Light Gas Oil & $321-427$ \\
Atmospheric Gas Oil & $610-427$ \\
Vacuum Gas Oil & $427-566$ \\
Residua & $566+$ \\
\hline
\end{tabular}

To maximize profits, the refinery usually upgrades higher-boiling gas-oil distillates into lower-boiling naphtha distillates, or gasoline. This can be accomplished by sending the gas oils to a fluid catalytic cracking (FCC) unit in which heavy molecules are broken down into lower molecular weight compounds boiling within the naphtha range. Note that catalytic cracking of gas oil is considered a thermal decomposition process. After catalytic cracking, the light products are sent to a fractionator to separate the components by distillation. The heaviest fraction is then sent to a clarifier to remove entrained catalysts particles. Once most of the catalyst fines have been removed, the remaining heavy hydrocarbon product is called clarified cycle oil, also known as decant oil or slurry oil. A flow diagram of basic processes in a refinery is shown in Figure 1.1. 


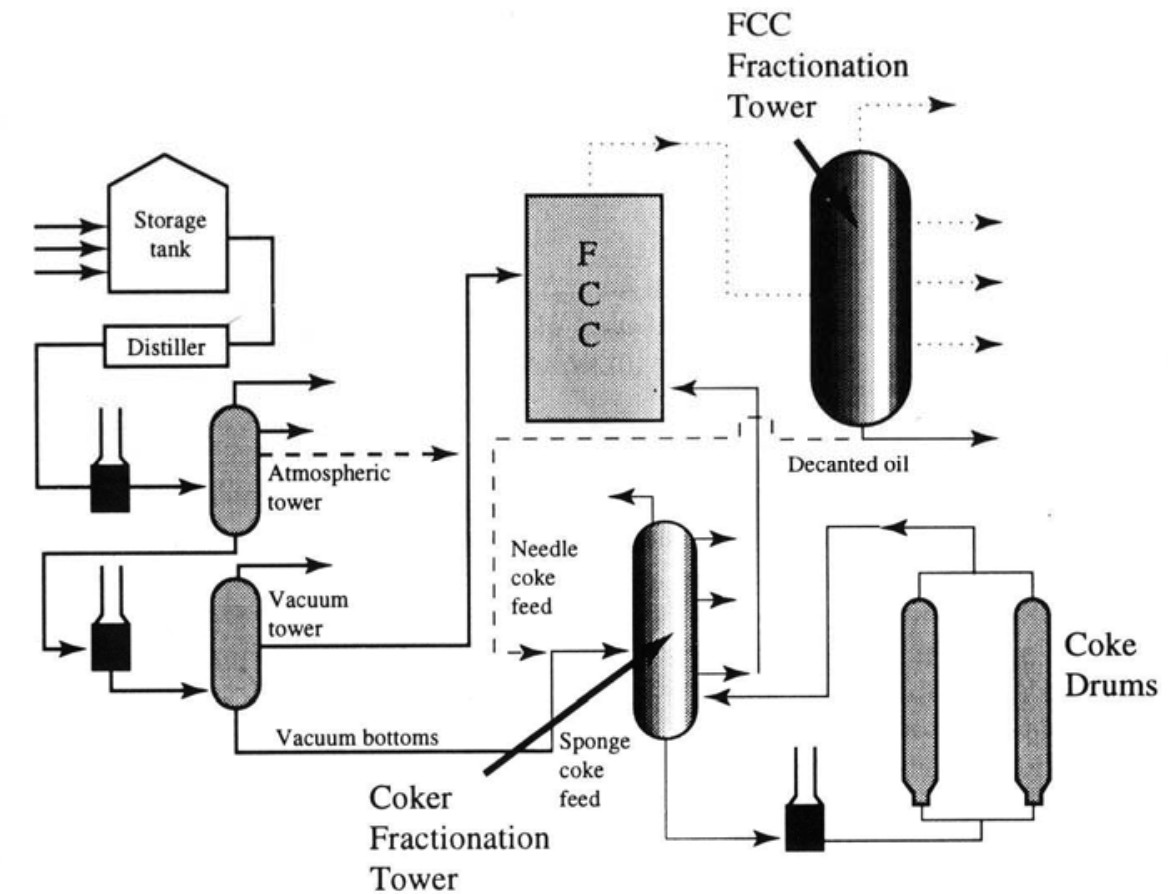

Figure 1.1: Basic flow diagram of a modern petroleum refinery. ${ }^{[17]}$

The decant oil can be sent to a delayed coker unit to generate even more naphtha distillate and, if certain compositional requirements are met, a high-quality green needle coke. Alternatively, the decant oil can be further processed into petroleum-based pitch. An example of such a pitch is produced by Marathon-Ashland Petroleum, marketed under the name A240. The exact procedures used to produce the A240 pitch remain proprietary, thus details are not available publicly, but they probably entail solvent extraction, thermal soaking, thermal-chemical modification, or any combination thereof [16].

\subsubsection{Coal-Tar Pitch}

A modern byproduct coke plant is made up of extensive hardware for the hightemperature carbonization of coal and recovery of evolved gases, oils, tars, and other 
useful chemicals [19]. The coke plant is made up of several brick-lined ovens arranged into batteries in which each coke oven is a long and narrow rectangular chamber ranging in size from 35 to 45 feet long, 9 to 15 feet high, and 1 to 2 feet wide. The walls of the oven are maintained between about 1000 to $1100^{\circ} \mathrm{C}$ by the combustion of fuel gas that is generated by the carbonizing coal itself. On top of each oven are along its length several evenly spaced holes sealed with removable lids. During charging, the lids are removed and coal is dropped through the openings by means of a coal-charging or larry car to initiate the coking cycle. Immediately after filling the oven with coal the lids are replaced. After several hours the coal has been carbonized completely. Finally, the two ends of the oven are opened, and the coke pushed out to cool on a loading platform by means of a large pusher arm and the oven made ready for another cycle.

Within the incandescent oven environment, the coal nearly immediately starts to decompose thermally upon introduction. The passage of decomposition products and volatiles through the hot coke bed, oven walls, and ceiling causes extensive cracking to occur. These products are removed from each individual oven by means of an ascension pipe that extends from the roof of the oven to a gas-collecting main. Within the top portion of the ascension pipe are sprays of flushing liquor, a dilute ammonia solution, to condense tar from the gas. Within the collecting main about $70 \%$ of the tar, called heavy tar, is condensed. The gas and vapors, heavy tar and flushing liquor leave the collecting main at about $100^{\circ} \mathrm{C}$ and are sent to a downcomer to effect gas-liquid separation. One exit stream of the downcomer contains the heavy tar and flushing liquor, which are sent to a decanter. The decanter separates the heavy tar from the flushing liquor by gravity so that the heavy tar can be pumped to storage and the flushing liquor recycled. The 
remaining $30 \%$ of the tar is carried along with the coke oven gas through the other exit stream of the downcomer to a primary cooler to condense most of the light tar from the gas stream. Further operations are required to recover additional light tar and to purify the gas for heat generation on site or for sale. Figure 1.2 shows an overview of the main process flows encountered in a byproduct coke facility.

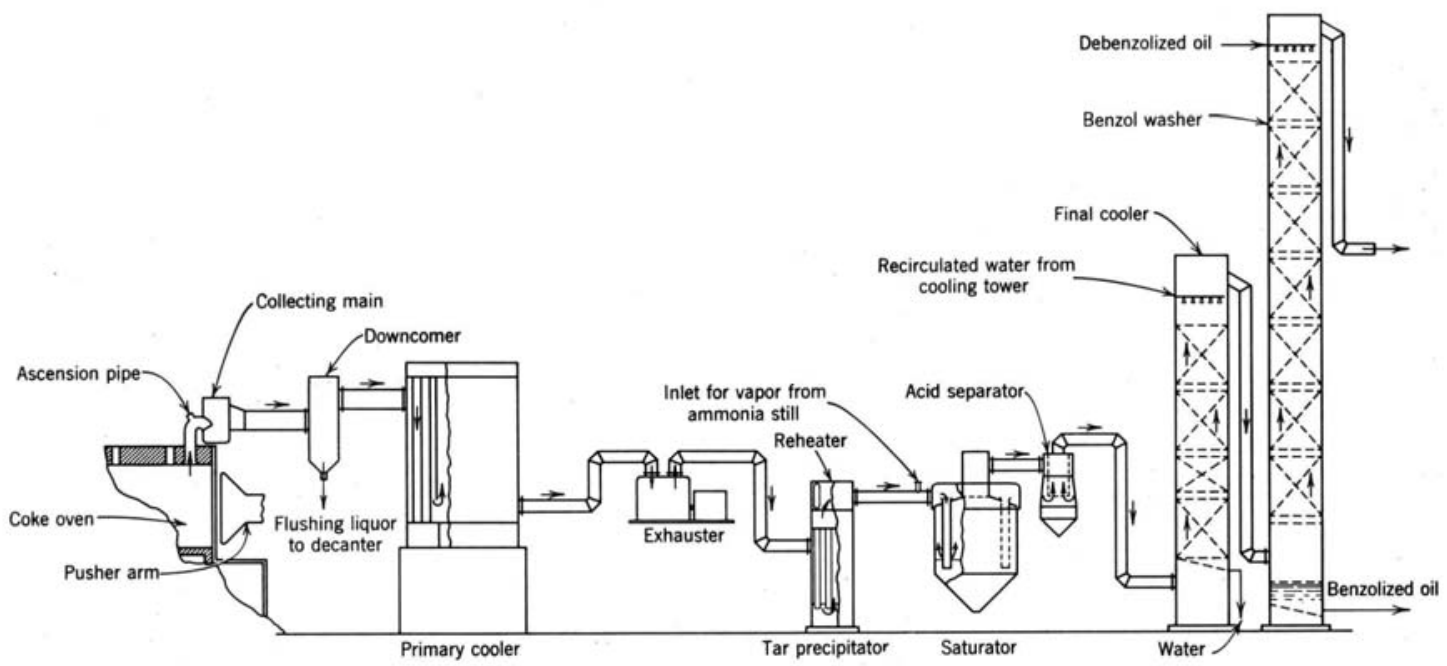

Figure 1.2: Tar and gas recovery in a byproduct coke facility ${ }^{[20]}$

The heavy tar is transferred from a heated storage tank to a dehydrating flash unit at atmospheric pressure whereby light oil and water are vaporized. Flash units are used to prevent fouling of the distillation columns by the tar. The light oil is sent back to the dehydrating unit as reflux. All subsequent operations are conducted under vacuum. The dehydrated tar is heated and then sent to a primary flash unit to drive off volatile compounds, which are sent to the first fractionating column. The liquid residue (top tar) is heated to a higher temperature before entering the secondary flash unit to strip all components except the pitch. As shown in Figure 1.3, the light compounds from the primary and secondary flash units are sent to a series of distillation columns, each column equipped with its own reheater, and each seceding column operating at higher 
temperature. Through this separation process the entire range of coal-tar distillates and pitch is made, as indicated in Table 1.3.

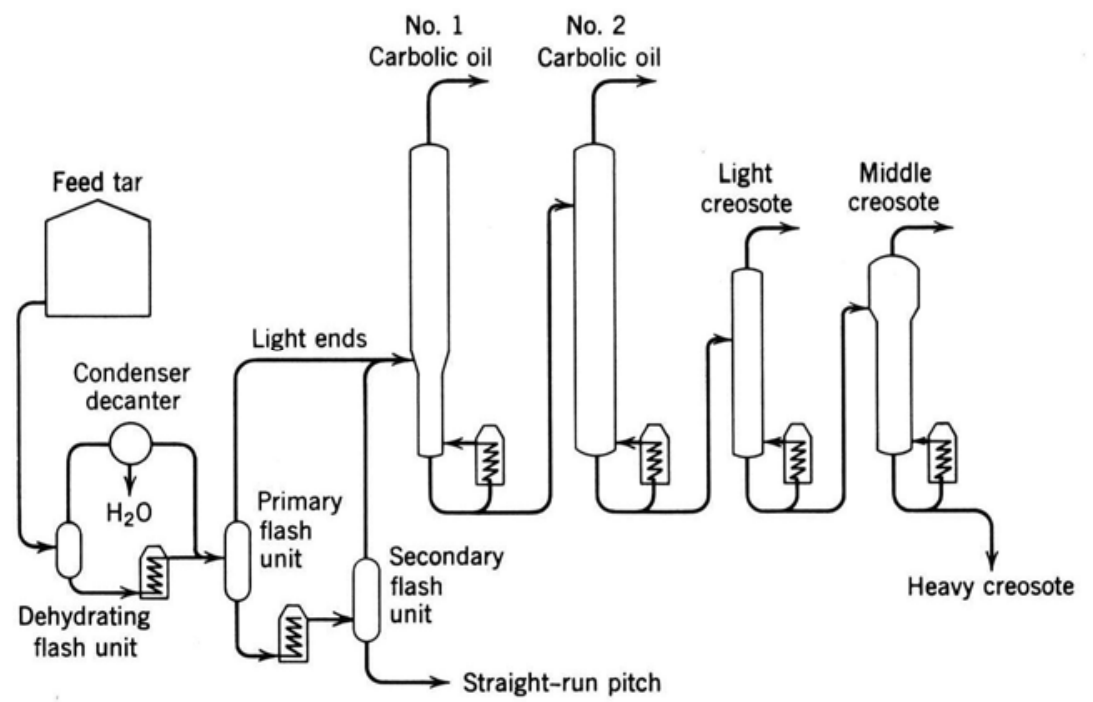

Figure 1.3: Process flow diagram for a coal-tar distillation plant ${ }^{\text {[20] }}$

Table 1.3: Coal-tar distillation fractions

\begin{tabular}{|c|c|c|}
\hline Tar fraction & Boiling range, ${ }^{\circ} \mathrm{C}$ & Major component \\
\hline Light oil & To 210 & $\begin{array}{l}\text { Benzene, Toluene, Xylene, Solvent } \\
\text { naphtha, Tar acids \& bases }\end{array}$ \\
\hline Middle oil & $210-230$ & Tar acids \& bases, Naphthalene \\
\hline Methylnaphthalene & $230-270$ & Mixed methylnaphthalenes \\
\hline Light creosote & $270-315$ & Acenaphthene, Fluorene \\
\hline Middle creosote & $315-355$ & Phenanthrene, Anthracene \\
\hline Heavy creosote & $355-450$ & Pyrene, Chrysene, Flouranthene \\
\hline Pitch & Above 450 & Complex condensed aromatics \\
\hline
\end{tabular}

\subsubsection{Coal-Extract Pitch}

Thermally decomposing coal in the presence of a suitable liquid has been variously labeled solvent extraction, solvent refining, digestion, or direct liquefaction [21]. In most cases, ground coal is mixed with an aromatic-type solvent and subjected to high temperatures, with or without added catalyst, and with or without hydrogen 
pressure. With very few exceptions, these processes usually involve hydrogenation in order to increase the hydrogen-to-carbon ratio of the feed coal such that a fluid product can be obtained. One of the major roles played by these solvents is that of a vehicle by which coal can be handled and conveyed as a slurry to a coal extraction reactor.

Another important role of the solvent relates directly to the chemistry of thermal coal dissolution, for it has been recognized for quite some time that the key to any successful commercial coal extraction operation is dependent primarily on the composition and characteristics of the solvent [22]. Indeed, the argument can be made that the solvent is more important in extraction than the coal. The preponderance that solvents exert on coal extraction is at least two fold: 1) the stabilization of reactive coal components and 2) the maintenance or suspension of the coal molecules in solution.

It is generally believed that at temperatures above $350^{\circ} \mathrm{C}$ coal molecules fragment into smaller molecular weight species by a homolytic bond scission mechanism to produce free-radical chemical identities [23]. Ideally, hydrogen is available to combine with the free radicals, a reaction which results in soluble and stable products [24]. If sources of hydrogen can not react with the free radicals, then it is possible for recombination reactions to occur. Recombination of reactive coal molecules results in products that are refractive, insoluble, and non-distillable [25].

One of the most important sources of hydrogen during coal extraction is found in certain chemical components of the solvent, the most effective of which are chemical species containing hydroaromatic structures [24]. Tetralin $(1,2,3,4$ tetrahydronaphthalene) is the most well-known example of such a structure. Four hydrogen atoms in tetralin are labile and are available to stabilize coal free radicals, 
preventing them from repolymerizing into higher molecular weight species [26]. This process can be seen in Figure 1.4, where tetralin donates its hydrogen to coal.

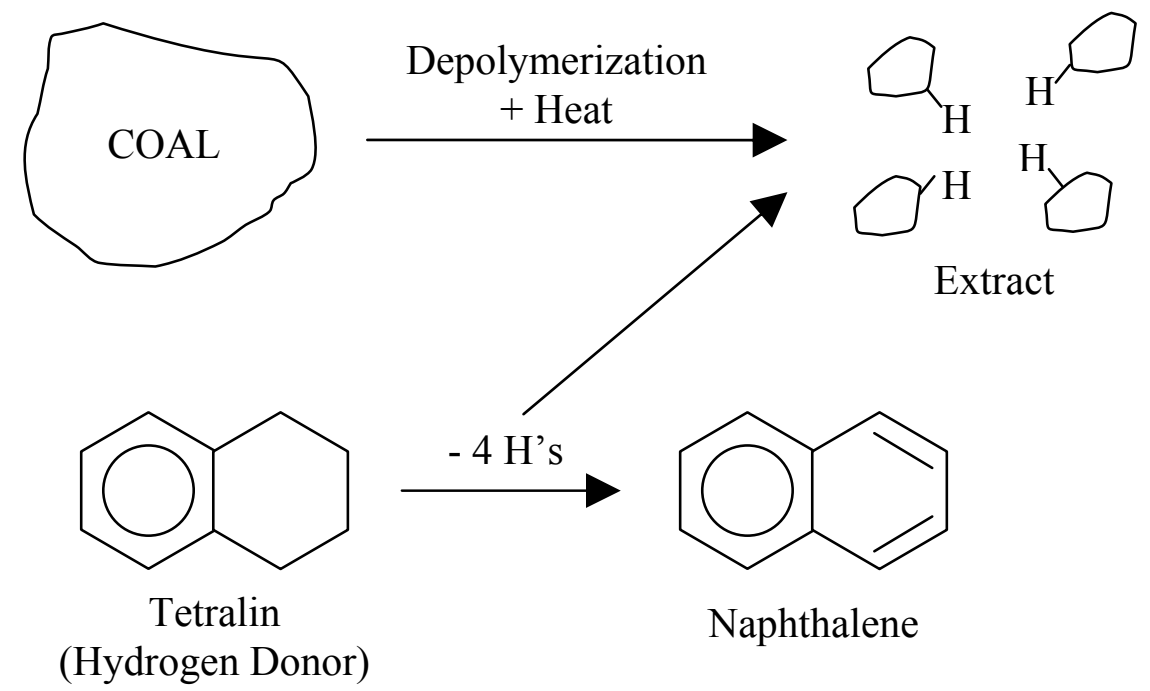

Figure 1.4: Mechanism of solvent hydrogenation of coal

The hydrogen donation provides hydrogen to the coal fragments without the use of gaseous hydrogen pressure. Solvents containing hydrogen bonded in naphthenic and paraffinic compounds are unfavorable in solvent extraction.

In Germany, around 1913, M. Pott and H. Broche developed the first commercial solvent extraction process, which shortly afterward became known as the Pott-Broche process. By the latter part of the $20^{\text {th }}$ century commercial-scale processes, such as the solvent refined coal (SRC I and SRC II) and Exxon Donor Solvent (EDS), were also based on the solvent extraction technology originally developed by Pott and Broche [27]. The approach used in this thesis to obtain a coal-derived pitch is a variant of the PottBroche coal extraction. The choice of this conversion process is based on its relative ease of operation, the capability of in-house equipment, and ability to control the degree of hydrogenation [28]. 
In the original Pott-Broche extraction, a bituminous coal was dried and ground to 95 percent $<100$ mesh and 65 percent $<250$ mesh in a large ball mill. The ground coal was then mixed with tetralin in a 2:1 solvent-to-coal ratio. The slurry of coal and tetralin was preheated and then pumped into a reactor operating at approximately $430^{\circ} \mathrm{C}$ and 2,200 psi. The original extraction process took place within one hour, which was adequate to dissolve approximately 75 percent of the coal mass. The Pott-Broche process was varied to run at pressures typically around 1,400 to $2,200 \mathrm{psi}$ and temperatures ranging from $415^{\circ} \mathrm{C}$ to $430^{\circ} \mathrm{C}$ for 60 to 90 minutes [5]. After solvent extraction, the slurry was hot filtered in batches through ceramic filters. The filtrate was then vacuum distilled to yield an extract with a melting point of about $200^{\circ} \mathrm{C}$, typically containing less than 0.05 weight percent ash.

The original intention was to produce an extract product suitable for further hydrogenation and upgrading into distillate fuels. Pott later discovered that the product was of such low ash that the coal extract was perfectly suitable as feeds for high quality cokes for use in carbon and graphite electrodes. Pott also found that tetralin could be replaced with tetralin/cresols blends as the hydrogen donating solvent system. Furthermore, Pott also determined that the tetralin/cresols mixture could be replaced with middle distillate cuts obtained from other hydrogenation processes, thus reducing the cost of the coal extraction drastically. These middle oils contain partially hydrogenated aromatics (hydroaromatics) that facilely donate their hydrogen to the coal. The basic flow diagram of the process operating in the "middle-oil mode" is shown in Figure 1.5 and typical product slate is presented in Table 1.4. 


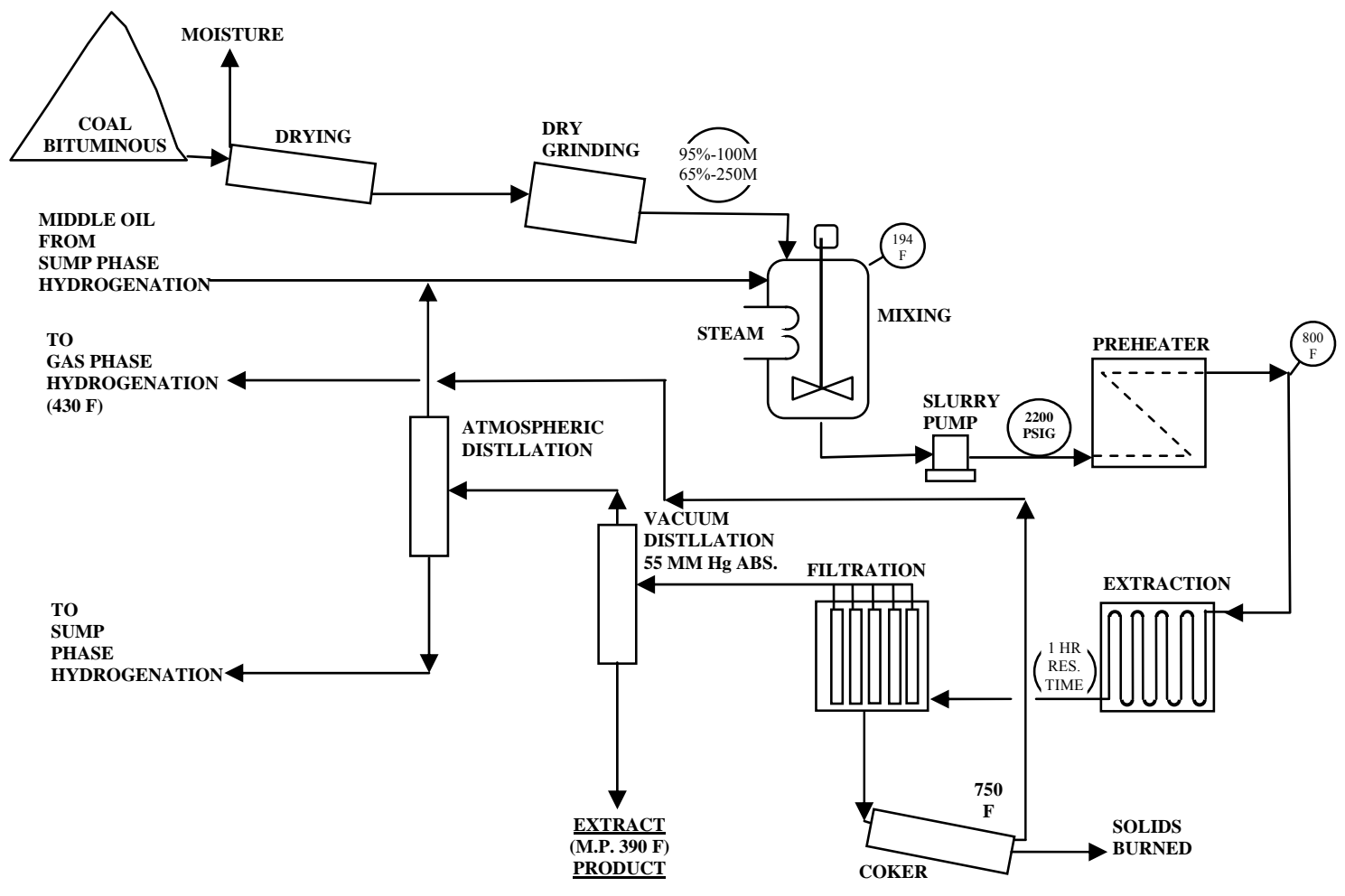

Figure 1.5: Pott-Broche Process used in Germany ${ }^{[26]}$

Table 1.4: Nominal product distribution from solvent extraction of coal with middle oil $^{[29]}$

\begin{tabular}{ll}
\hline Product & Mass wt \% of Feed Coal \\
\hline Fuel Gas $(\mathrm{C} 1-\mathrm{C} 4)$ & 6.9 \\
Naphtha $\left(\mathrm{C} 5-175^{\circ} \mathrm{C}\right)$ & 4.9 \\
Fuel Oil $\left(175-455^{\circ} \mathrm{C}\right)$ & 11.7 \\
Undistilled (coal-extract pitch) & 60.1 \\
Unconverted Coal & 7.2 \\
Non-Fuel Gases & 9.2 \\
\hline Total & 100.0
\end{tabular}

\subsection{Thesis Goals}

It must be appreciated from the previous discussion that the family of pitches is vast, although only three types were presented. Nonetheless, no matter what the source of tars, and the pitches produced from them, these liquid materials are usually unsuitable 
for immediate end use as is, and must be altered or processed to meet the specifications established by the consumer. Several techniques are used to modify pitch composition and, subsequently, their properties to meet these qualifications. Some of the more common methods of treating pitches to adjust their properties are listed below in Table 1.5 .

Table 1.5: Methods used for modification of pitch composition and properties

\begin{tabular}{ll}
\hline Physical Methods & Chemical Methods \\
\hline Solvent extraction or fractionation & $\begin{array}{l}\text { Thermochemical treatment using air- } \\
\text { blowing } \\
\text { Thermochemical treatment using inert gas } \\
\text { (nitrogen) }\end{array}$ \\
Distillation & $\begin{array}{l}\text { Chemical polymerization using sulfur } \\
\text { Catalytic polymerization using } \mathrm{FeCl}_{3} \text { or } \\
\mathrm{AlCl}_{3} \text { (Lewis Acids) }\end{array}$ \\
\hline
\end{tabular}

Air-blowing is the method selected in this thesis because of its effectiveness. From the range of pitches available for study, three were examined in detail. Two of the pitches are used widely by the carbon industry and are readily available: a petroleumderived A240 pitch manufactured by Marathon-Ashland Petroleum and a coal-tar binder pitch marketed by Koppers Industries. The third pitch is a coal-extract pitch developed at West Virginia University as part of this thesis effort. The motivation in the selection of the pitches is based on the disparate nature of the feedstocks so that comparisons among conventional petroleum and coke-oven pitches, and novel coal-derived pitches, can be made.

It is anticipated that feeds developed from coal-extract pitches may play a more significant role in the future, particularly in the United States, because the trend in 
petroleum pitch composition indicates an increase in sulfur and metals content [30]. Sulfur and metals are contaminants that adversely affect pitch quality and performance in practical applications. Furthermore, the future availability of pitches derived from metallurgical coke ovens is becoming increasingly uncertain because of environmental regulations, decreased demand for steel, and improved methods of steel production [31]. These business pressures result in lesser amounts of metallurgical coke being produced and, consequently, related byproducts.

Currently, little work has been published pertaining to the modification of coalextract pitches by air-blowing. Thus, the results of this research will contribute to our basic understanding of coal and pitch chemistry. In addition, the results will establish whether there are similarities or differences, dependent on feed source, in pitch modification processes, and whether air-blowing is applicable to coal-extract derivatives. 


\section{Chapter 2 - Literature Review}

\subsection{Modification of Pitch Properties by Air Blowing}

There are numerous methods available for modifying pitch properties, as was shown in Table 1.3. One of the methods, air-blowing, was chosen in this thesis research because of its effectiveness and general commercial practice. The process of air-blowing is used widely in industry for producing asphalts, for modification of pitch viscosity, and for adjusting other pitch properties for various carbon-based products [32]. In this chapter, the effects of air-blowing pitches are reviewed.

\subsubsection{Effects on Softening Point}

Maeda et al. [33] from Osaka Gas Ltd. in Japan studied the effects of air-blowing pitches for spinning general purpose carbon fibers. In their research, a QI-free coal-tar pitch was air-blown for various times at $330^{\circ} \mathrm{C}, 360^{\circ} \mathrm{C}$, and $380^{\circ} \mathrm{C}$. The objective was to obtain an isotropic pitch with a softening point of about $280^{\circ} \mathrm{C}$, which was considered optimal for carbon fiber spinning. The results showed that air-blowing indeed caused an increase in the softening point, with less time required to attain a softening point of $280^{\circ} \mathrm{C}$ at the higher treatment temperatures. Maeda et al. also compared the results of the air-blown coal-tar pitch with an air-blown hydrogenated coal-tar pitch, and an air-blown petroleum pitch. It was determined that the air-blowing process was effective with all of the pitches, as can be seen in Figure 2.1. Maeda et al. concluded that the pitches undergo a series of intermolecular linking of molecules resulting in increases in softening point. 


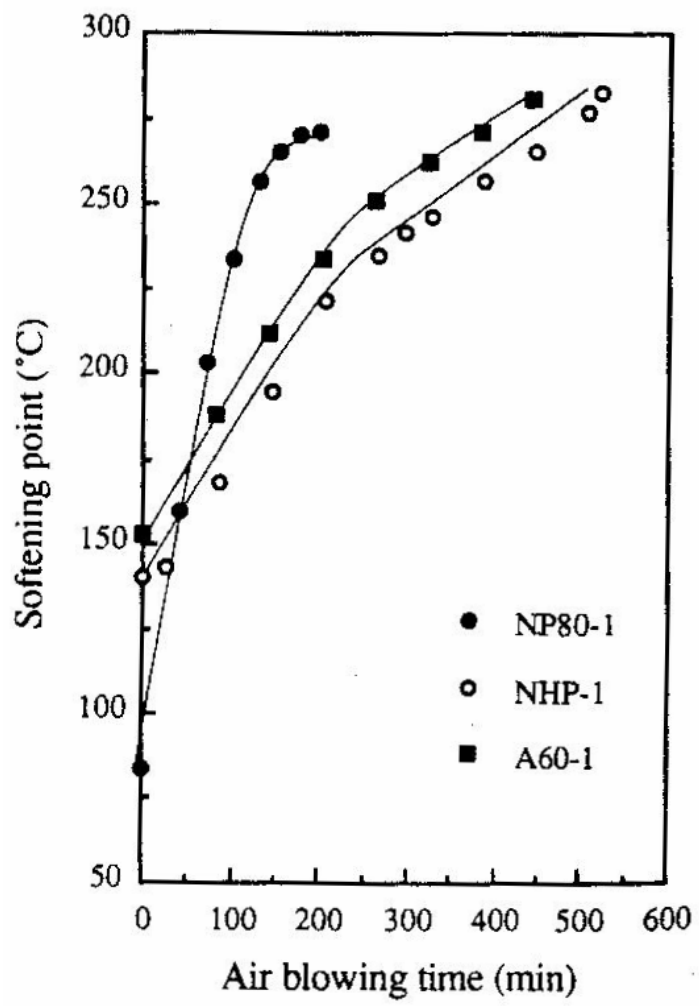

Figure 2.1: Softening point of coal-tar (NP80-1), hydrogenated coal-tar (NHP-1) and petroleum pitches $(\mathrm{A60}-1)$ during air-blowing at $330^{\circ} \mathrm{C}^{[34]}$

The softening point of pitch can be increased by either distillation of lighter fractions, structural change of component molecules (dehydrogenation, aromatization, and oxidation), and condensation of lighter molecules into heavier ones. For example, Zeng et al. [34] found that air-blowing increases the softening point through all of these mechanisms, although structural change and condensation of component molecules are more prevalent in air than in either inert atmosphere or by distillation.

Yamaguchi et al. [32] isolated specific compounds from coal-tar pitch and air blew them at $330^{\circ} \mathrm{C}$. They found that air-blowing had the greatest effect on alkylsubstituted compounds. Thus, they concluded that pitches containing these types of compounds are more sensitive in raising softening point than other classes of molecules. 
Similar studies were undertaken and reported by Machnikowski et al. [35] on coal-tar pitch compounds, Blanco et al. [36] on coal-tar pitch, and Menendez et al. [37] on impregnating coal-tar pitch. The results and conclusions drawn by these researchers on the effects of air-blowing pitches on softening point are in general accordance with other groups.

\subsubsection{Effects on Coke Yield}

Yamaguchi et al. [32] chose air-blowing as a method to modify pitch properties because they claim that the process more effectively increases coke yield than heat treatment, distillation, or any other methods.

Fernandez et al. [38] studied the effects of air-blowing two types of coal-tar pitches (CTPA binder pitch and CTPB impregnating pitch) on coking properties for use as matrix materials in $\mathrm{C} / \mathrm{C}$ composites. They found that the coke yield dramatically increased as the extent of air-blowing progressed. This can be seen in Table 2.1, where CTPA and CTPB are the parent pitches, and 0 through 3 designates air-blowing times in hours. They also showed that there is an increase in the density and strength, as well as a decrease in the porosity and reactivity, of the resultant cokes as air-blowing severity of the pitch increased.

Maeda et al. [33] demonstrated similar results to those of Fernandez et al., and showed that as time increased during the air-blowing of coal-tar pitch at $360^{\circ} \mathrm{C}$ the coke yield could be increased. In this instance, the coke yield increased from $67 \%$ for the parent pitch (softening point $82^{\circ} \mathrm{C}$ ) to over $90 \%$ for the most severely modified pitch (softening $312.5^{\circ} \mathrm{C}$ ). 


\section{Table 2.1: Coke yield (wt \%) for air-blown pitch A and pitch B}

\begin{tabular}{lc} 
Sample & Coke Yield (wt\%) \\
\hline CTPA & 48.4 \\
CTPA0 & 54.3 \\
CTPA1 & 70.8 \\
CTPA2 & 72.1 \\
CTPA3 & 79.4 \\
& \\
CTPB & 35.2 \\
CTPB0 & 37.8 \\
CTPB1 & 62.4 \\
CTPB2 & 64.4 \\
CTPB3 & 67.9 \\
\hline
\end{tabular}

\subsubsection{Effects on Viscosity}

A great deal of work has been published on various aspects of rheology related to isotropic and mesophase pitch, and during the transformation from isotropic to anisotropic pitch [37, 39]. Unfortunately, comparatively little work has been published on the effects of air-blowing pitches on rheology. However, Menendez et al. [37] investigated the rheological behavior of a coal-tar impregnating pitch after it was airblown for various times at $275^{\circ} \mathrm{C}$ using transient shear and controlled-strain oscillatory rheometry. The rheological experiments were performed at a shear viscosity of approximately $50 \mathrm{~Pa} \cdot \mathrm{sec}^{-1}$. The essential elements of this analytical technique are the ability to isolate two viscoelastic phenomena, i.e., one component associated with elastic behavior and the other component with viscous flow. As can be seen in Figure 2.2, the parent pitch showed a purely viscous behavior, where there is no "overshoot" (the appearance of a spike in the figure) while the air-blown pitches showed increasing stress "overshoot" as time of air-blowing increased. 


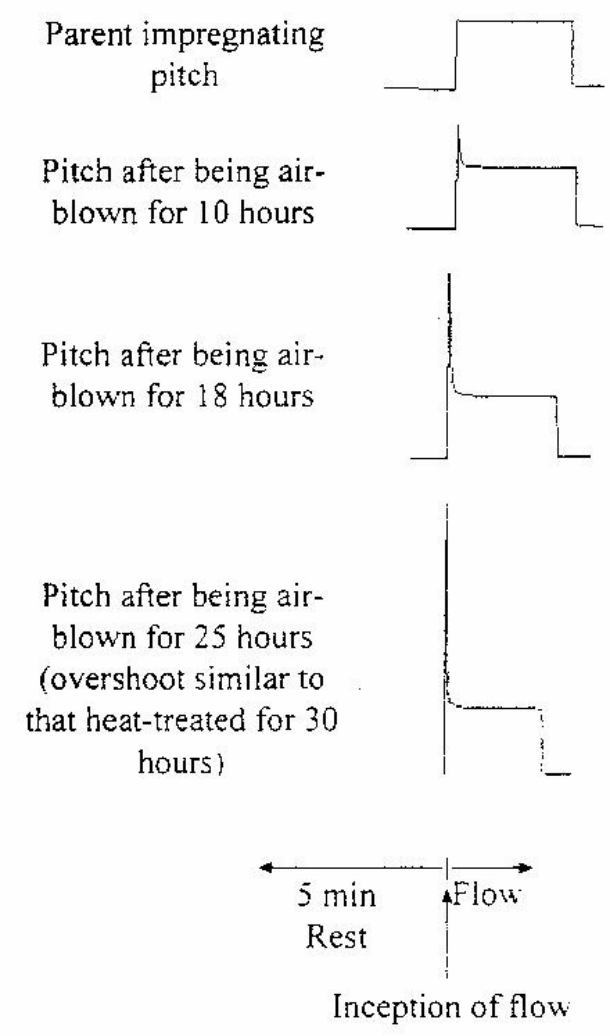

\section{Figure 2.2: Shear stress response upon start up of shear flow for the parent pitch and the air-blown pitches ${ }^{[37]}$}

The air-blown pitch became a more elastic material as can be seen by the increased "overshoots". The conclusion was made that the increased elasticity is attributed to the formation of large, cross-linked aromatic molecules, as a result of air blowing.

\subsection{Williams, Landel, and Ferry Viscosity Model}

The Williams-Landel-Ferry (WLF) equation evolved from an empirical relationship describing viscosity dependence on temperature. The WLF expression can be related to fundamental principles. Beginning with Eyring's rate theories, Doolittle [39] entailed thermodynamic principles to describe viscosity changes based on free volume concepts. Cohen and Turnball further developed Doolittle's free volume model into a useable equation [39]. Later, Williams, Landel, and Ferry developed and 
incorporated the Doolittle equation into their own free volume expression, which became known as the WLF equation [40]. This involved establishing a relationship with the activation energy of the material and the thermal energy introduced into the material. The activation energy can be related to the free volume in the sample. The WLF equation incorporates the use of an arbitrary reference temperature and viscosity. The WLF equation is shown below by:

$$
\log \mu=\log \mu_{r}-\frac{C_{1, r}\left(T-T_{r}\right)}{C_{2, r}+T-T_{r}}
$$

where $\mu_{r}$ is the viscosity at the reference temperature, $T_{r}$, and $C_{1, r}$ and $C_{2, r}$ are constants dependent upon the choice of reference temperature.

The WLF equation was employed by Nazem and Lewis for the rheological characterization of mesophase-containing pitches [41]. Their method established a shift factor, $A_{T}$, which is the ratio of relaxation times for the pitch at a measured temperature and the reference temperature. Because of its thermodynamic significance, the glass transition temperature $\left(\mathrm{T}_{\mathrm{g}}\right)$ is often used for the reference temperature in the WLF equation. This is because the free volume changes rapidly at the glass transition temperature in most pitch materials. When plotted against a temperature, the shift factor places the viscosities measured at different temperatures onto one line of a constant slope. They showed that the shift factor could be represented by the relationship:

$$
\log A_{T}=\log \left(\frac{\mu T_{r}}{\mu_{r} T}\right)
$$


The following equation is simply rearranged into a slope-intercept form. This was done by the logarithmic of the reference viscosity $\left(\log \mu_{\mathrm{r}}\right)$ being transferred to the left side of Equation 2.1 resulting in:

$$
\log \frac{\mu}{\mu_{r}}=-k\left(T-T_{r}\right)
$$

$$
\text { where } k=\frac{C_{1, r}}{C_{2, r}+T-T_{r}}
$$

The difference in the logarithmic of the temperature and reference temperature $(\log (\mathrm{T}-$ $\mathrm{T}_{\mathrm{r}}$ )) was added to both sides of Equation 2.3. After rearranging and collecting variables, the equation is now in slope-intercept form $(\mathrm{y}=\mathrm{mx}+\mathrm{b})$ as shown in Equation 2.4.

$$
\begin{array}{cc}
y & m \quad x+b \\
\log A_{T}=\log \left(\frac{\mu T_{r}}{\mu_{r} T}\right)= & -k\left(T-T_{r}\right)+\log \frac{T_{r}}{T}
\end{array}
$$

Aside from fundamental implications, Equations 2.1 and 2.4 are used widely in both industry and academe, in a practical sense, to predict the viscosity behavior of both isotropic and mesophasic pitches. Remarkably, as shown in Figure 2.3, the WLF relationship holds for pitches that range from nearly isotropic to essentially crystalline in nature. 


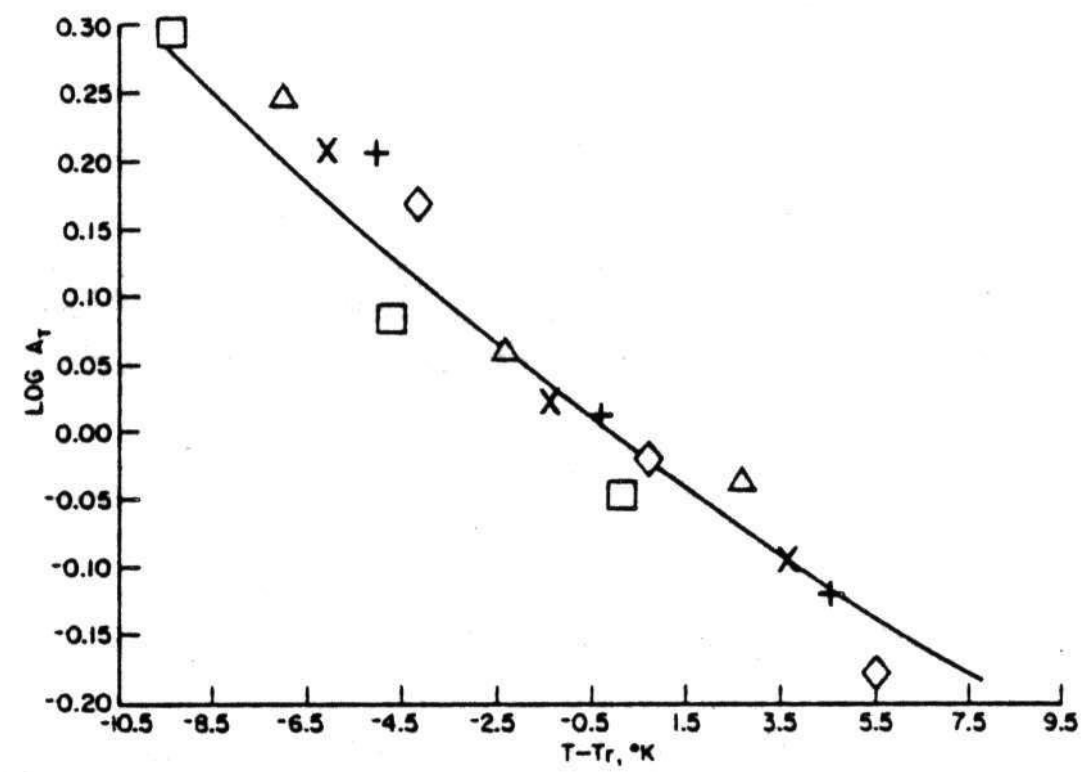

Figure 2.3: Plot of ( $\mathrm{T}-\mathrm{Tr}$ ) vs. Log AT for a range of mesophase-containing pitches

\subsection{Effects on Solubility}

Choi et al. [43] thermally treated a coal-tar pitch with air and nitrogen in glass tubes using a gas flow rate of $250 \mathrm{~cm}^{3} / \mathrm{min}$ and initial pitch load of 5.0 grams. Treatment resulted in the insolubility of coal-tar pitch in toluene to increase as reaction time is increased. The air-blowing reaction increased the toluene insolubility (TI) content rapidly in the first 30 minutes and then more slowly around $60 \mathrm{TI}$ wt \%. Blowing in nitrogen increased the TI content steadily, as time increased, but required a much longer treatment period to reach the same TI content as the air-blown pitch. The results of these reactions can be seen in Figure 2.4 at the four different temperatures used. The decrease in solubility is attributed to the increased molecular weight of the pitch. 


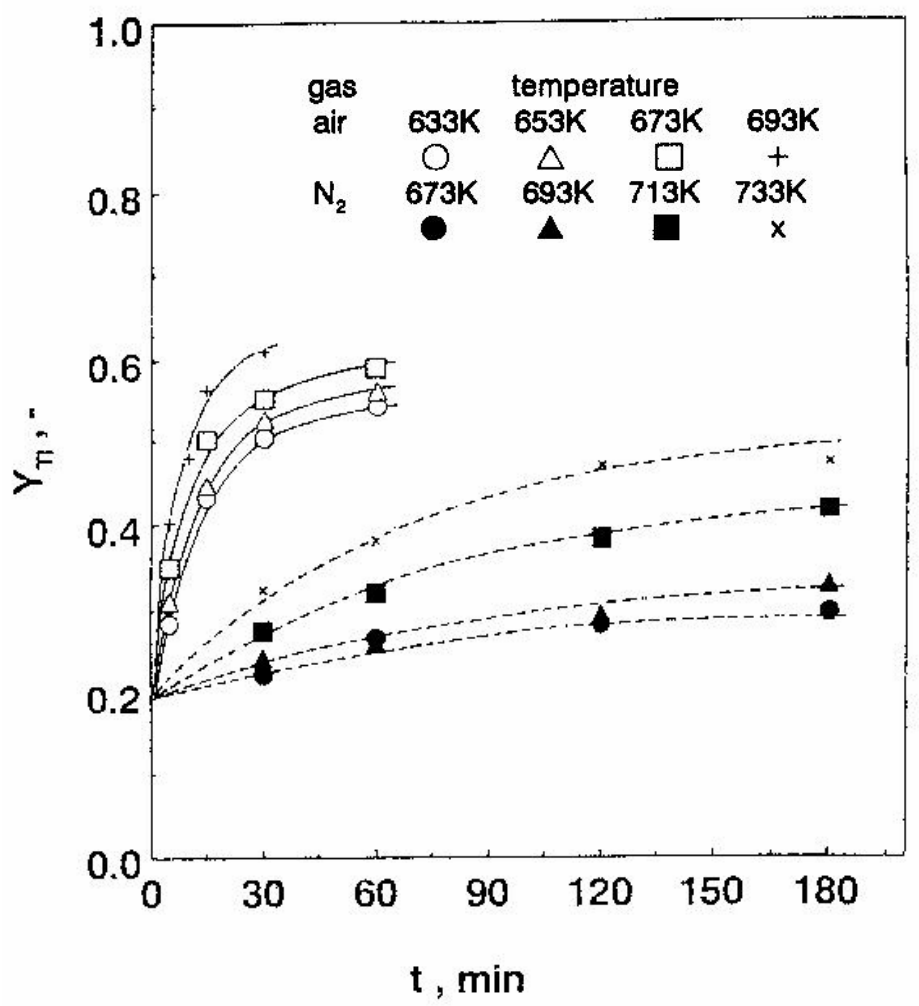

Figure 2.4: Variation of toluene insoluble content of coal-tar pitch with increased reaction time at four various temperatures

Machnikowski et al. [35], Blanco et al. [36], Fernandez et al. [38], and Menendez et al. [37] also showed that the insolubility of pitch increases as the air-blowing time and temperature is increased.

\subsection{Effects of Air-blowing on Chemical Changes and Mechanisms}

\subsubsection{Reaction Pathways}

It is established that air-blowing modifies coal-tar and petroleum pitches. Both pitches follow the same overall trends in reference to softening point, coke yield, and solubility. Nevertheless, there are mechanistic differences that are a function of the precursor. For example, petroleum pitches are less aromatic than coal-tar pitches and this key chemical feature affects the way the two pitches react in air-blowing reactions. 
Several studies have been done to elucidate these reaction mechanisms. A general mechanism proposed by Barr et al. [44] is shown by:

$$
\frac{1}{2} \mathrm{O}_{2}+2 \mathrm{Ar} \rightarrow \mathrm{Ar}-\mathrm{Ar}+\mathrm{H}_{2} \mathrm{O}
$$

where Ar is a pitch molecule. Note that this mechanism does not result in the addition of oxygen in the pitch product. Barr et al. suggested that the reaction consists of cross linked oligomers being formed, while Zeng et al. [34] suggested that the reaction consisted of creating large planar macromolecules through extensive ring condensation. Zeng et al. emphasize the importance of chemical composition of the coal pitch and the selection of the processing temperature. The results of Fernandez et al. [38] and Zeng et al. are in agreement with the mechanism proposed by Barr et al.

Maeda et al. [33] determined that the $\mathrm{C} / \mathrm{H}$ atomic ratio increases as the temperature and time of air-blowing are increased. This suggested to them that a dehydrogenative condensation of pitch molecules was taking place. In this study, the airprocessed coal-tar and hydrogenated coal-tar $\mathrm{C} / \mathrm{H}$ atomic ratios increased significantly, but the increase in $\mathrm{C} / \mathrm{H}$ atomic ratio for petroleum pitches was less. The mechanisms that Maeda et al. proposed can be seen below in Figure 2.5. 

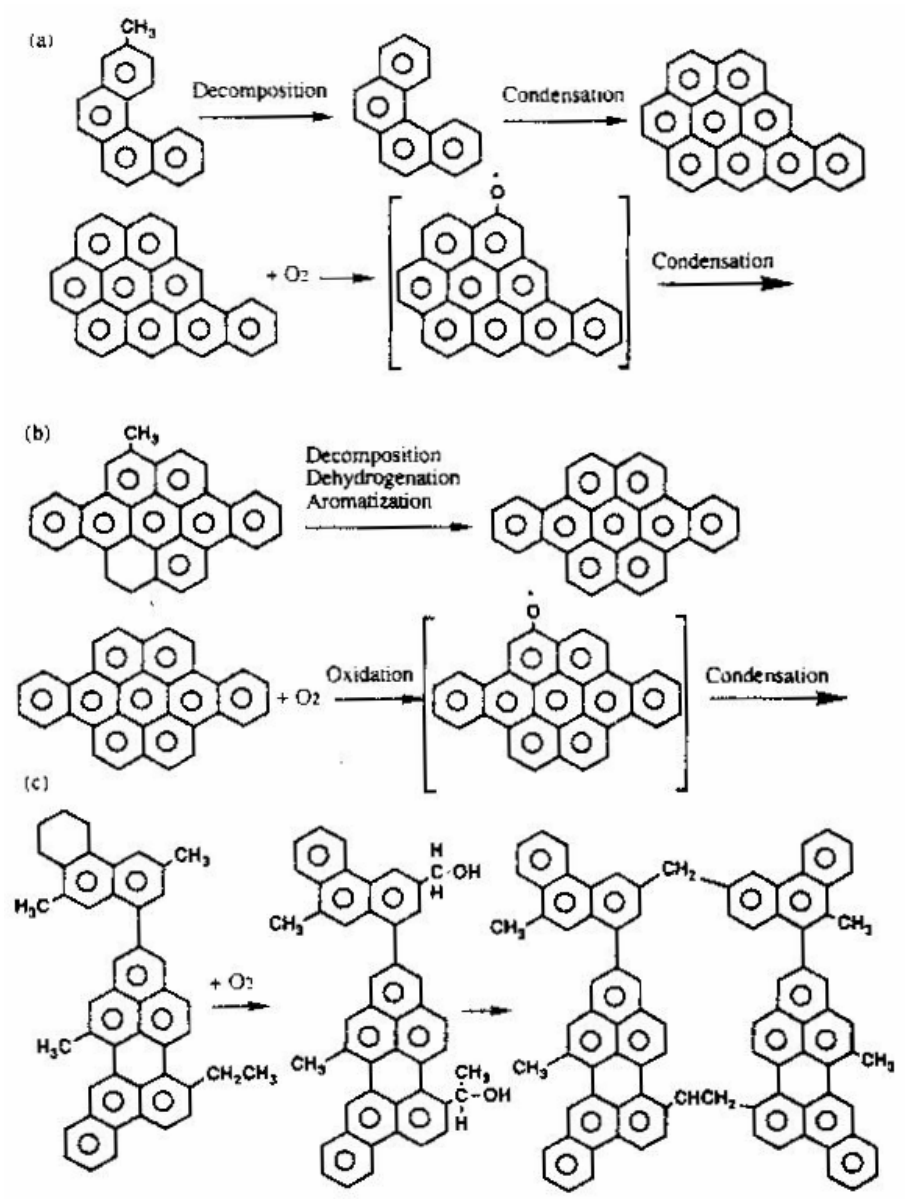

Figure 2.5: Oxidation schemes of coal-tar and petroleum pitches. (a) Coal-tar pitch (b) Hydrogenated coal-tar pitch (c) Petroleum pitch [34]

The coal-tar pitch represented in Figure 2.5a is subjected to a decomposition reaction where air-blowing first causes the side chains to be eliminated. At the same time, air-blowing also creates free radicals, promoting the condensation of constituents by dehydrogenation and aromatization [34]. Combination of these free radicals leads to more condensation reactions and significant increases in aromatic structures within the pitch. Air-blowing of the hydrogenated coal-tar pitch in Figure 2.5b starts out similarly by removing the side chains from the parent pitch. Additionally, the reaction proceeds through dehydrogenation and aromatization resulting in condensation and an increase in aromaticity. The petroleum pitch, however, goes through a different mechanism in which 
there is not an increase in polycondensed aromatic rings. Blanco et al. [36] also observed a decrease in hydrogen content as air-blowing time of a coal-tar pitch was increased. The parent pitch, with a softening point of $97^{\circ} \mathrm{C}$, had an initial $\mathrm{C} / \mathrm{H}$ atomic ratio of 1.64 . The $\mathrm{C} / \mathrm{H}$ atomic ratio increased to 1.87 while the softening point increased to $210^{\circ} \mathrm{C}$ after the parent pitch was air-blown for 30 hours. Similar trends in $\mathrm{C} / \mathrm{H}$ atomic ratio were also reported in studies by Fernandez et al. and Menedez et al [37].

In an attempt to understand the chemistry further, Zeng et al. analyzed a petroleum pitch, coal-tar pitch, and hydrogenated coal-tar pitch by field-desorption mass spectrometry (FD-MS). This technique determines the molecular weight of the constituent molecules in the pitches before and after air-blowing was conducted. It was found that air-blowing increased the average molecular weights of the petroleum pitch from approximately 670 to $700 \mathrm{amu}$. The coal-tar pitch and hydrogenated coal-tar pitch increased from roughly 250 to $340 \mathrm{amu}$ and 415 to $515 \mathrm{amu}$, respectively. Notice that the molecular weight of the petroleum pitch increased slightly while the coal-tar and hydrogenated coal-tar pitches had a dramatic increase of about 100amu. It was proposed that the coal-tar and hydrogenated coal-tar follow two similar mechanisms while the petroleum pitch mechanism differs slightly.

Yamaguchi [32] of Osaka Gas Co. isolated specific aromatic hydrocarbons found in coal-tar pitches which were then air-blown at $330^{\circ} \mathrm{C}$. By doing this a specific reaction mechanism could be proposed by knowing the starting product structure and determining the final product structure using FD-MS, gas chromatography-mass spectrometry (GCMS), nuclear magnetic resonance (NMR), and Fourier-transform infrared spectroscopy (FT-IR). It was found that alkyl-substituted aromatic compounds polymerized through 
methylene, biphenyl, and ether-type bonding, leading some of the methylene functionality to change into carbonyl groups during the air-blowing reaction [32].

Choi et al. [43] examined petroleum and coal-tar pitches that were thermally treated under both nitrogen and air. They determined that the gas flow rate and pitch loads did not change the kinetics of the reactions significantly. This can be seen in Figure 2.6 where the toluene insoluble yield remains relatively constant over the changing pitch load and gas flow rates.

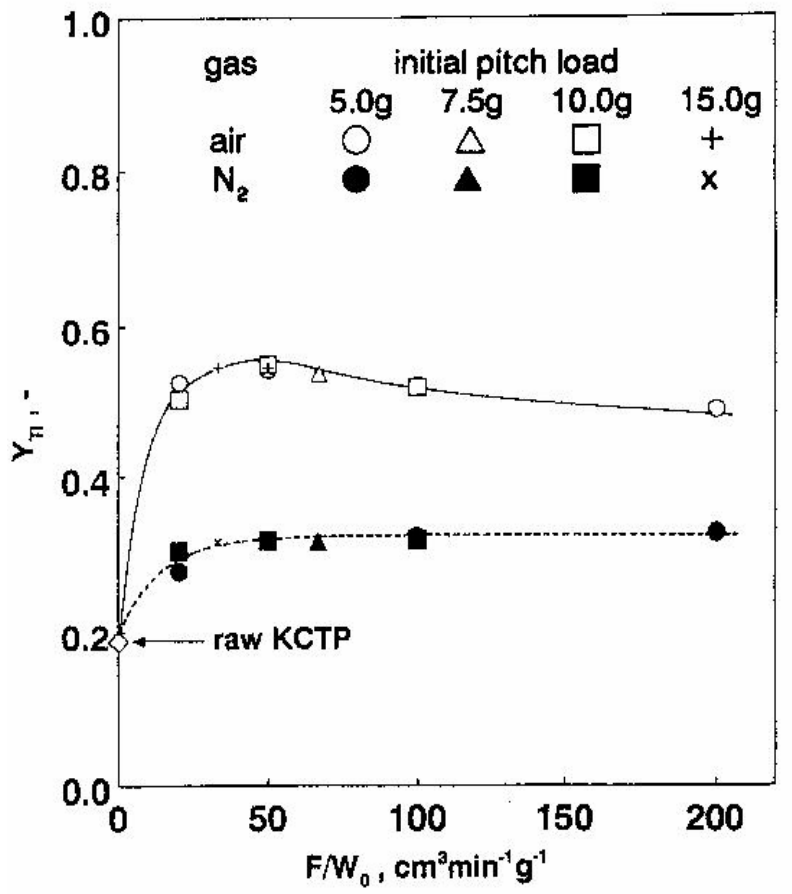

\section{Figure 2.6: Dependency of TI Yields from coal-tar pitch on gas flow rate in air and nitrogen with different initial pitch load ${ }^{[43]}$}

Kinetic analyses are commonly accomplished by determining the solubility of pitch after processing as a function of time and temperature [39]. As an example of this approach to kinetic modeling, the work of Eser et al. [45] is presented. Although Eser et al. were concerned with the kinetics of carbonization, and not air-blowing, the modeling methodology remains the same. These studies were undertaken to provide a better 
understanding of the mechanisms involved with the heating of petroleum feeds in coke formation. They determined the relative rates of carbonization by examining the amount of pyridine insolubles (PI) formed as a function of time and temperature as compared to A240 petroleum pitch, shown in Figure 2.7.

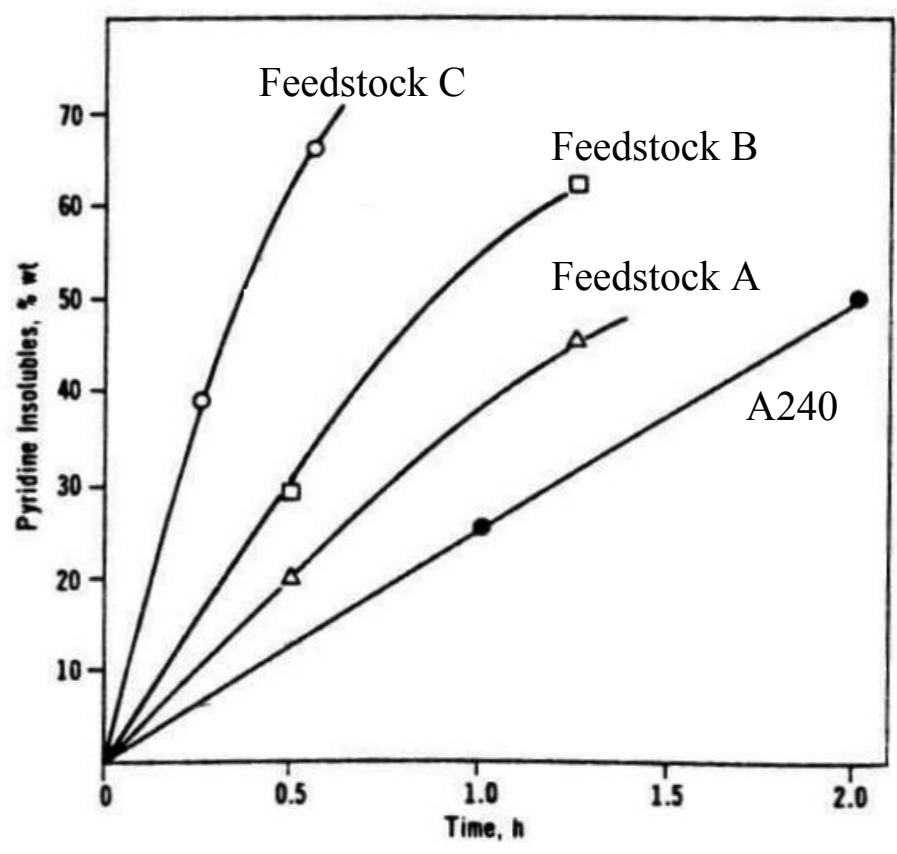

Figure 2.7: Relative carbonization of petroleum feedstocks at a heat treatment temperature of $723 \mathrm{~K}$

Esser et al. assumed that the carbonization followed first-order kinetics. The associated Arrhenius plots for the rates of PI formation are shown in Figures 2.8 and 2.9, for one of the petroleum materials. The slope and intercept of the line in Figure 2.9 are used to calculate activation energy and preexponential factor for carbonization, respectively. Based on the interpretation of the kinetic parameters, the authors were able to argue that petroleum fractions prone to high rates of carbonization produce isotropic cokes. 


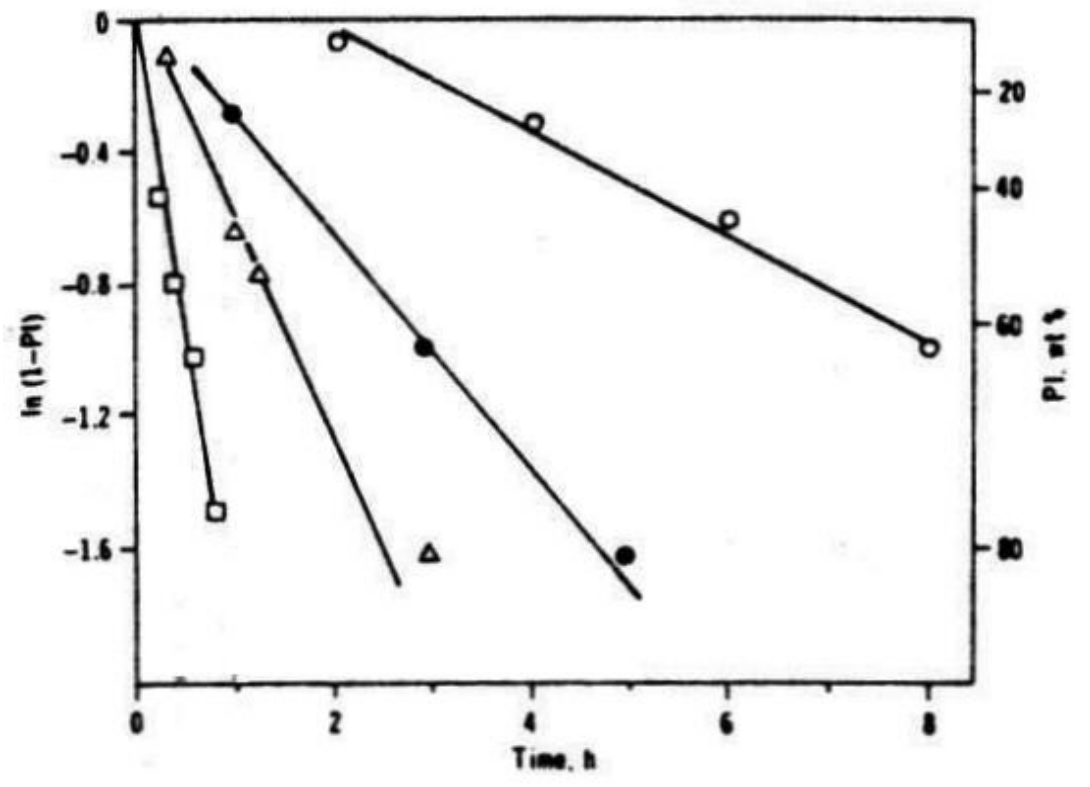

Figure 2.8: First-order plots for pyridine insolubles formation fromVR2 pentane insolubles

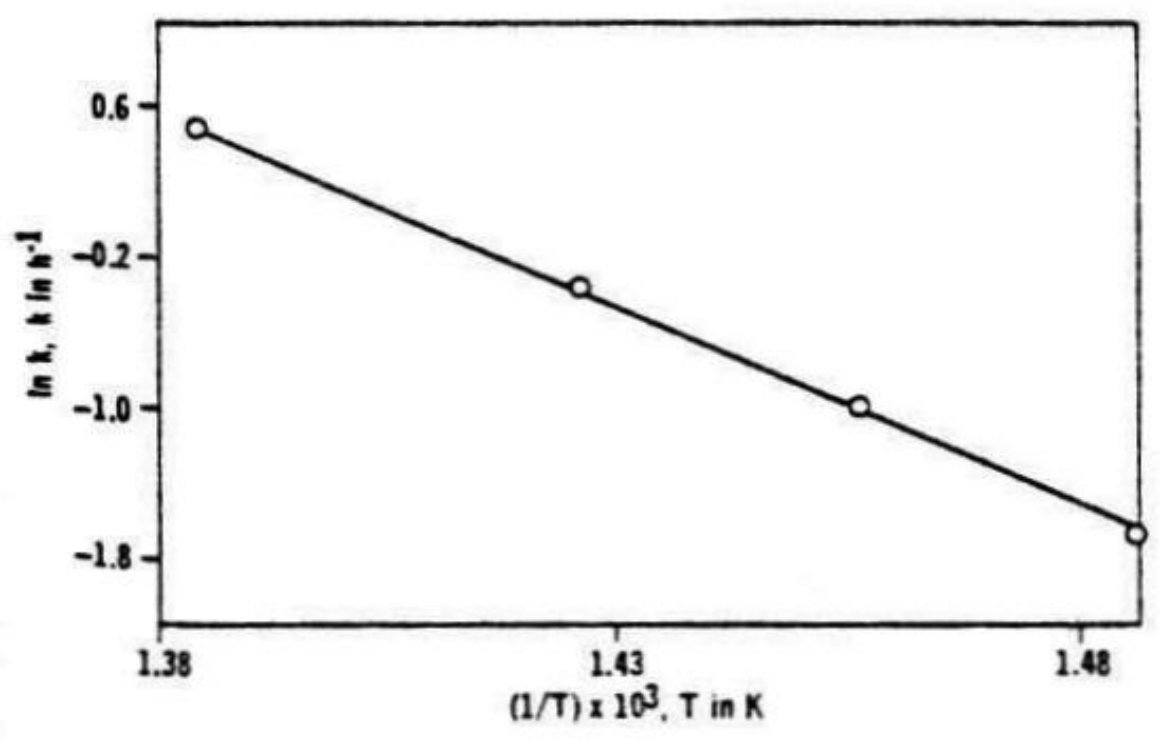

Figure 2.9: Arrhenius plot for VR2 pentane insolubles 


\subsubsection{Thermogravimetric Analysis (TGA)}

Rand [46] discussed techniques used in TGA analysis. In Figure 2.10a, the temperature vs. weight loss curves for pitch A240, and its thermally treated analogs are shown. Curve 1 is A240 feed, and as the extent of thermal treatment increased (curves 2 through 4) less weight loss occurs. This is expected since the thermal processing removed volatiles. Although weight loss curves provide valuable information in their own right, Rand pointed out that these types of plots obscure the fact that the total weight loss is dependent on any prior thermal history. Thus, Rand suggested that it is more informative to express the TGA data in terms of volatile content, as shown below:

$$
\gamma=\left(\mathrm{W}_{\mathrm{T}}-\mathrm{W}_{\mathrm{F}}\right) / \mathrm{W}_{\mathrm{T}}
$$

where $\mathrm{W}_{\mathrm{T}}$ is the sample weight at temperature $\mathrm{T}$ and $\mathrm{W}_{\mathrm{F}}$ is the sample weight at some final temperature. When the TGA data are expressed thus, the points are brought together at the higher temperatures, which indicate that the previous thermal processing of A240 has not changed pyrolysis behavior at the higher temperature significantly, as can be seen in Figure 2.10b. If the volatile fractions had not converged, then it can be assumed that some mechanistic change had occurred during the thermal treatment of A240 before the TGA experiment. 


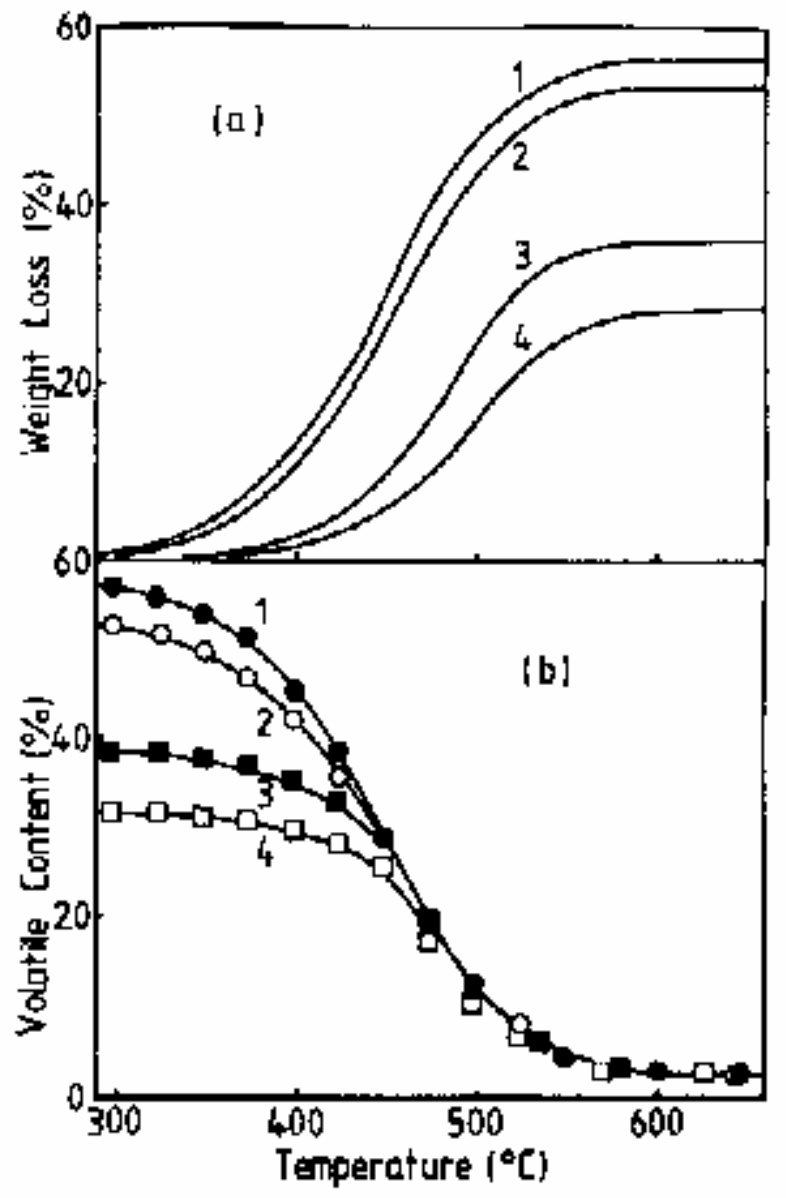

Figure 2.10: Thermogravimetric (TGA) data for pyrolysis products of A240 petroleum pitch, 1 - as recieved; $2-365^{\circ} \mathrm{C} ; 3-400^{\circ} \mathrm{C} ; 4-460^{\circ} \mathrm{C}$

\subsection{3 van Krevelen Plots}

A graphical method for studying the chemical changes that occur during the coalification process was developed in 1950 by D.W. van Krevelen [47]. This method, which became known as van Krevelen plots or diagrams, consists of graphing the atomic hydrogen-to-carbon ratio versus the atomic oxygen-to-carbon ratio of organic materials. As shown in Figure 2.11, the reactions associated with the alteration of organic materials follow certain trends. Depending on the slope and direction of these trends, the atomic 
ratios indicate that decarboxylation, dehydration, and dehydrogenation reactions could account for the variations in the properties of coal.

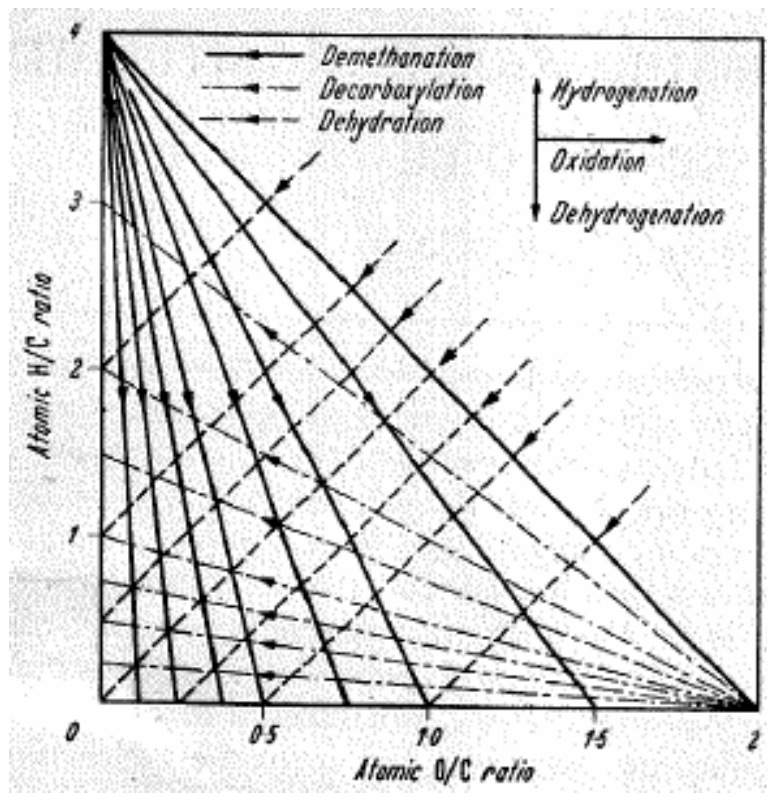

Figure 2.11: $\mathrm{H} / \mathrm{C}$ versus $\mathrm{O} / \mathrm{C}$ diagram $^{[48]}$

For example, van Krevelen analyzed the elemental composition of a wide range of coals that varied in rank. He examined lignites, bituminous coals, and anthracites. He also included coal antecedents in his analysis: wood, cellulose, and lignin. As shown in Figure 2.12, van Krevelen suggested that the process of coalification is associated first with little change in hydrogen content but with large decreases in oxygen content. Decreases in hydrogen content occur prevalently during the latter stages of coal maturation. 


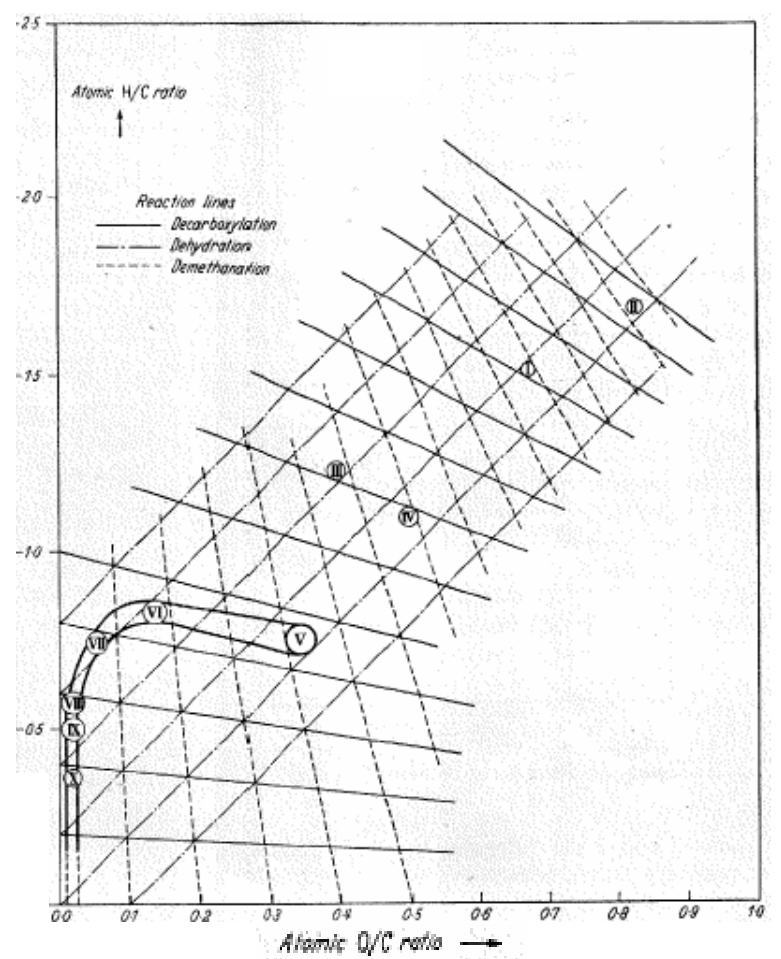

Figure 2.12: $\mathrm{H} / \mathrm{C}$ versus O/C for I) Wood, II) Cellulose, III) Lignin, IV) Peat, V) Lignite, VI) Low rank bituminous coal, VII) Medium rank bituminous coal, VIII) High rank bituminous coal, IX) Semi-anthracite, X) Anthracite ${ }^{[47]}$

To explain the chemical progression from low rank to high rank coal, van Krevelen proposed that decarboxylation reactions take place upon going from lignite (V) to low rank bituminous coal (VI). Dehydration occurs predominantly proceeding from low rank bituminous (VI) to high rank bituminous coal (VIII). The final stage of coalification, the transformation of high rank bituminous coal (VIII) into anthracite (X), entails demethanation.

The use of the van Krevelen plots can be extended to explain the mechanisms occurring during the thermal-chemical treatment of other bituminous materials. Joseph and Oberlin [48] studied the effects of air oxidizing various carbonaceous materials at different temperatures and time. They postulated that two parts are associated with oxidation. The first part involves a rapid release of hydrogen, after which oxygen content 
increases slowly, as shown in Figure 2.13. Joseph and Oberlin also noted that the slopes of the oxidation paths were distinctly different and depend upon the elemental composition of the starting material. They pointed out as well that all of the materials studied tend to reach the same plateau at an $\mathrm{O} / \mathrm{C}$ atomic ratio of about 0.5 .

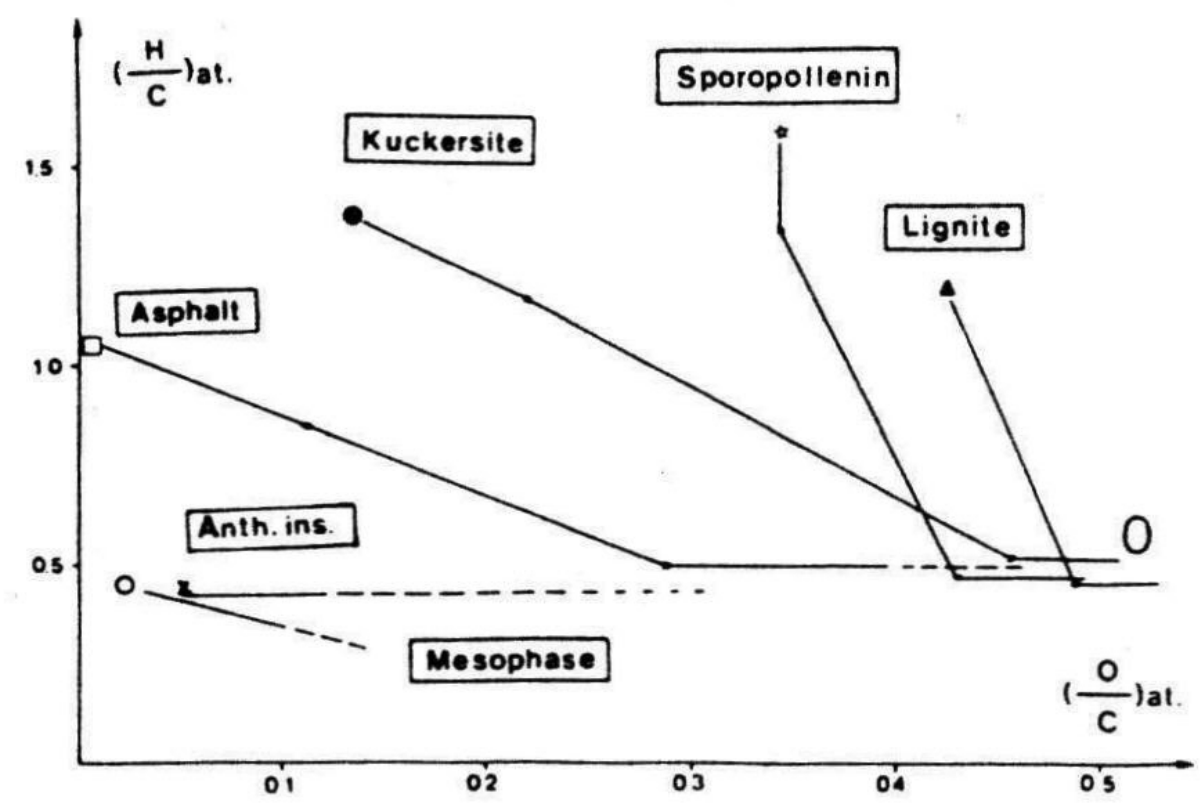

Figure 2.13: van Krevelen diagrams showing oxidation paths of various organic materials

It is important to realize that usually elemental analysis is performed to obtain the $\mathrm{C}, \mathrm{H}, \mathrm{N}$, and $\mathrm{S}$ weight percentages, and oxygen is determined by difference. It is best to determine oxygen directly, as was done by Joseph and Oberlin, since there are errors associated with the determination of each element. This means that finding the percent oxygen by difference does not necessarily measure the content of oxygen accurately in many instances. A separate or direct measure of oxygen content is preferred to ensure that the $\mathrm{C}, \mathrm{H}, \mathrm{S}, \mathrm{N}$, and $\mathrm{O}$ contents are indeed accurate and that all five elements add up to 100 percent, in order to make the van Krevelen plots reliable. 


\section{$2.5 \quad$ Effects of Air-blowing on Optical Activity}

Blanco et al. [36] and Maeda et al. [33] found by optical microscopy under polarized light that no anisotropy or mesophase was present in pitches after air-blowing. The absence of anisotropy is very important in the general purpose fiber industry. This is because the viscosity of mesophase is much greater than the surrounding isotropic phase, such that during the fiber spinning step, the anisotropic structures form imperfections along the filament axis. 


\section{Chapter 3 - Experimental Procedure}

In this chapter, the experimental procedures for pitch preparation, air-blowing conditions, and the subsequent analyses are discussed. Three pitches were chosen for airblowing: Marathon-Ashland A240 petroleum pitch, Koppers coal-tar binder pitch, and a coal-extract pitch. All pitches were air-blown in a 1-liter autoclave for various times and temperatures.

\subsection{Feed Pitch Preparation}

The A240 petroleum pitch was used as received from the Marathon-Ashland Petroleum plant in Findlay, Ohio, without any modification prior to air-blowing. Properties of the A240 petroleum pitch can be seen in Table 3.1.

Table 3.1: A240 Petroleum Pitch properties

\begin{tabular}{|l|c|}
\hline Ash (\%) & 0.04 \\
\hline Mettler Softening Pt. $\left({ }^{\circ} \mathrm{C}\right)$ & 116.9 \\
\hline Density (g/cc) & 1.236 \\
\hline WVU Coke Yield (\%) & 50.9 \\
\hline Conradson Coke Yield (\%) & 47.2 \\
\hline Toluene Insolubles (\%) & 5.7 \\
\hline Pyridine Insolubles (\%) & 0.8 \\
\hline
\end{tabular}

The coal-tar pitch was received from Koppers Industries Inc. Since this pitch is laden with solid materials, called quinoline insolubles (QI), steps were undertaken for their removal. This was accomplished by placing approximately $1 \mathrm{~kg}$ of coal-tar pitch in a 10-L flask. Three to four liters of N-methyl pyrolidone (NMP) were added to the pitch. The flask was then rotated in a hot oil bath at $100^{\circ} \mathrm{C}$ at atmospheric pressure for one hour 
using a Buchi R-152 rotary evaporator to dissolve the pitch, as can be seen below in Figure 3.1.

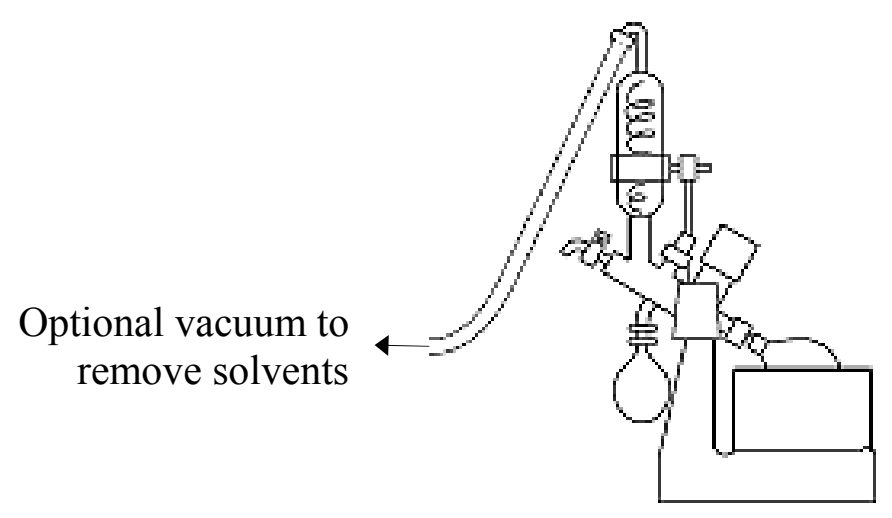

Figure 3.1: Rotary Evaporator

After dissolution, the flask was removed from the rotary evaporator and the mixture apportioned into $750 \mathrm{~mL}$ centrifuge containers. Care was taken to ensure that the amount of solution was counterweighted evenly in the IEC PR-7000 centrifuge. Centrifugation was conducted at $4000 \mathrm{rpm}$ (2000 times the force of gravity) for $1 \mathrm{hr}$ to remove most of the undissolved solids, including ash. The supernatant liquid was decanted into a container, and then pressure filtered using a Millipore pressure filter apparatus at 15-20 psig using Fisher Brand G6 glass fiber filters (1.6 $\mu \mathrm{m}$ retention). The filtrate was then returned to a clean 10-L flask to remove the NMP from the coal-tar pitch using the rotary evaporator under vacuum at about $80^{\circ} \mathrm{C}$. After most of the NMP was removed, the oil-bath temperature was increased to approximately $110^{\circ} \mathrm{C}$ to remove the remaining NMP. The flask was removed from the rotary evaporator and the pitch was cooled in a refrigerated room. Dry ice was added to make the pitch brittle. The pitch was then chipped out very carefully, making sure not to break the flask, and placed into metal containers. The containers were then placed in a vacuum oven at approximately $170^{\circ} \mathrm{C}$ 
overnight using a nitrogen purge to remove any residual NMP solvent. The properties of the coal-tar pitch before and after the filtration can be seen in Table 3.2.

Table 3.2: Koppers Coal-Tar Pitch Properties

\begin{tabular}{|l|c|c|}
\hline & As Received & Post-filtration \\
\hline Mettler Softening Pt. $\left({ }^{\circ} \mathrm{C}\right)$ & 109.9 & 108.1 \\
\hline Ash (\%) & 0.18 & 0.05 \\
\hline WVU Coke Yield (\%) & - & 53.95 \\
\hline Conradson Coke Yield (\%) & - & 48.0 \\
\hline Toluene Insolubles (\%) & 28.8 & 17.0 \\
\hline Quinoline/NMP Insolubles (\%) & 12.8 & Nil \\
\hline
\end{tabular}

\subsubsection{Coal-Extract Pitch Preparation}

The coal-extract pitch used in the experiments was developed using the West Virginia Marfolk Eagle Seam Coal. Characterization of this coal is shown in Table 3.3, 3.4 , and 3.5.

Table 3.3: Petrographic Analysis of Marfolk Eagle

\begin{tabular}{|l|c|}
\hline County & Boone County \\
\hline Mine & Massey’s Marfork Operation \\
\hline Vitrinite $(\%$ vol) & 70.0 \\
\hline Liptinite $(\%$ vol) & 7.6 \\
\hline Inertnites $(\%$ vol) & 20.4 \\
\hline Mineral Matter $(\%$ vol) & 2.0 \\
\hline
\end{tabular}


Table 3.4: Elemental Analysis (wt \%)

\begin{tabular}{|l|l|}
\hline $\mathrm{C}$ & 81.86 \\
\hline $\mathrm{H}$ & 5.08 \\
\hline $\mathrm{S}$ & 0.95 \\
\hline $\mathrm{O}$ & 4.89 \\
\hline $\mathrm{C} / \mathrm{H}$ atomic ratio & 1.35 \\
\hline
\end{tabular}

Table 3.5: Proximate Analysis (dry basis, wt \%)

\begin{tabular}{|l|l|}
\hline Fixed Carbon & 62.0 \\
\hline Volatile Matter & 32.0 \\
\hline Ash & 6.0 \\
\hline
\end{tabular}

The coal was set out in the laboratory overnight to remove surface moisture before grinding to approximately 20 Tyler mesh using a Holmes hammermill crusher. The coal was placed in metal pans and dried in vacuum ovens at a temperature of approximately $75^{\circ} \mathrm{C}$ under a nitrogen purge to remove any residual water.

Seven and a half liters of 1,2,3,4-tetrahydronaphthalene (tetralin) were added along with $3 \mathrm{~kg}$ of the 20 -mesh coal (solvent to coal of 2.5 to 1 , approximately) into a 5 gallon batch reactor. The reactor lid was then bolted to the body using a torque wrench to $150 \mathrm{lb}$-ft, according to specifications. The reactor was then purged of air with hydrogen for approximately 5 minutes and then pressurized to 500 psig hydrogen at room temperature. The reactor was then stirred while heating and brought to $450^{\circ} \mathrm{C}$ for $1.5 \mathrm{hr}$. About 3.5 hours were required to reach operating conditions. After reaction was complete, the reactor contents were cooled and about half of the mixture transferred to a 10-L flask. The flask was then placed on the rotary evaporator at $80^{\circ} \mathrm{C}$ to remove the tetralin and any other liquid reaction products. A heat gun was needed to assist in the 
removal of the solvent since tetralin was converted into naphthalene. The naphthalene condensed as a solid on the internal surfaces of the rotary evaporator causing plugging. To avoid blockage, heat was applied externally to the surface of the rotary evaporator where any noticeable naphthalene accumulated. After most of the liquid was removed, the bath temperature was increased to $110^{\circ} \mathrm{C}$ to remove most of the remaining tetralin/naphthalene. This was followed by pouring 3-4 liters of NMP into the flask and dissolving the coal-extract pitch for 1 hour at $100^{\circ} \mathrm{C}$. After dissolution, the flask was removed from the rotary evaporator and the mixture apportioned into $750 \mathrm{~mL}$ centrifuge containers. Centrifugation was conducted at $4000 \mathrm{rpm}$ for $1 \mathrm{hr}$ to remove most of the undissolved coal and ash. The supernatant liquid was then pressure filtered through Fisher G6 filters and the NMP was removed following the same method as for the coaltar pitch mentioned above in section 3.1.1. After cooling and removal, the pitch was then placed in a vacuum oven at approximately $170^{\circ} \mathrm{C}$ overnight using a nitrogen purge to remove any remaining solvent. This process was repeated for the remaining half of the reactor contents. After both batches of pitch were vacuum dried, they were ground and mixed together.

\subsection{Air-blowing Procedure}

Air-blowing of the pitches was conducted in a 1-liter autoclave. The pitch was subjected to air-blowing at temperatures of $250^{\circ} \mathrm{C}, 275^{\circ} \mathrm{C}$, and $300^{\circ} \mathrm{C}$ for various periods. A schematic of the reactor can be seen below in Figure 3.2. 


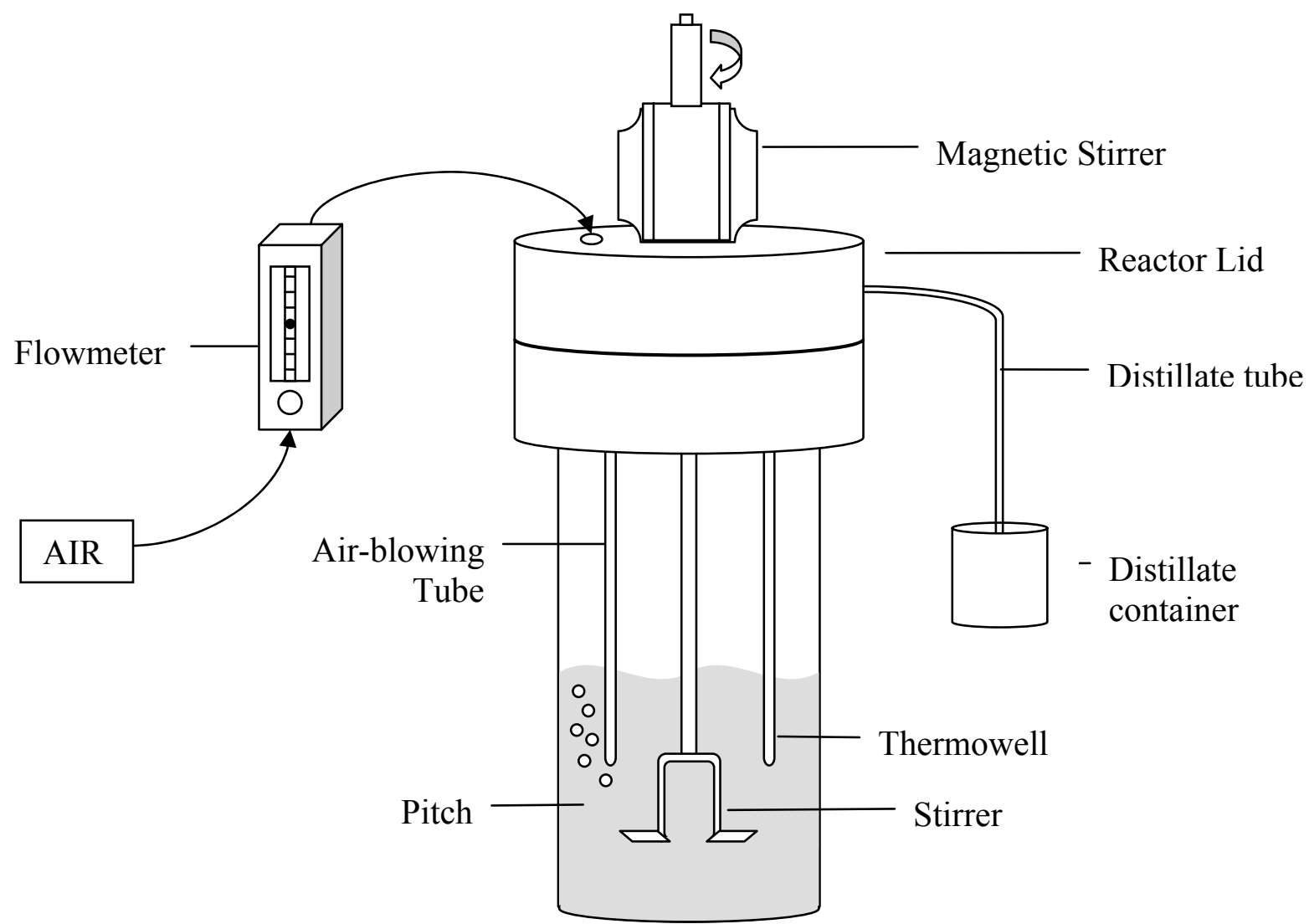

Figure 3.2: Diagram of the 1-liter autoclave used in air-blowing experiments

A Riteflow 150mm flowmeter controlled the rate of airflow into the pitch. The air-blowing tube was placed into the pitch next to the stirrer to ensure good mixing of air. A thermocouple monitored the temperature of the pitch during air-blowing. The distillate tube allowed any light fractions of the pitch to escape into a collection container for weighing.

About 300 grams of pitch were weighed and placed into the 1-liter autoclave while the distillate container was placed at the end of the distillate tube. The reactor was then set to the desired temperature and allowed to heat up until the pitch became molten. While this was occurring, the airflow rate was set at approximately $1,182 \mathrm{~mL} / \mathrm{min}(1.2$ $\mathrm{L} / \mathrm{min}$ ) on the airflow meter to assure the airflow in the air tube was unobstructed. The 
flow rate could be held constant from batch to batch by using the manufacturers table of flow rate settings for air. Once the pitch was molten, the autoclave lid was attached and care was taken to make sure the thermocouple, magnetic stirrer, and distillate line were all performing properly. The reactor was then allowed to heat up further to the desired air-blowing temperature while being stirred. The reaction temperature was reached as quickly as possible. The time it took the reactor to heat up to the desired operating temperature can be seen in Table 3.6.

Table 3.6: Time to reach air-blowing temperature after pitch became molten

\begin{tabular}{|c|c|}
\hline Temperature $\left({ }^{\circ} \mathrm{C}\right)$ & Nominal time (min.) \\
\hline 250 & 10 \\
\hline 275 & 20 \\
\hline 300 & 25 \\
\hline
\end{tabular}

When the reaction reached operating temperature, the stirrer was set to a speed of 750 rpm. During the reaction, the stirrer was stopped momentarily and turned by hand to ensure the material remained fluid and had not solidified. Table 3.7 shows the chosen reaction times at the three temperatures. 
Table 3.7: Air oxidation reaction times and temperatures of the three pitches

\begin{tabular}{|c|c|c|c|}
\cline { 2 - 4 } \multicolumn{1}{c|}{} & \multicolumn{3}{|c|}{ Time (hr) } \\
\cline { 2 - 4 } & Ashland A240 Pitch & Koppers Coal-tar Pitch & Coal-extract pitch \\
\hline \multirow{3}{*}{$250^{\circ} \mathrm{C}$} & 9 & 8 & 3 \\
\cline { 2 - 4 } & 24 & 16 & 5 \\
\cline { 2 - 4 } & 30 & 24 & - \\
\cline { 2 - 4 } & 45 & 30 & - \\
\hline \multirow{3}{*}{$275^{\circ} \mathrm{C}$} & 9 & 5 & 5 \\
\cline { 2 - 4 } & 17 & 10 & - \\
\cline { 2 - 4 } & 24 & 15 & - \\
\hline \multirow{3}{*}{$300^{\circ} \mathrm{C}$} & 28 & 21 & 2 \\
\cline { 2 - 4 } & 6 & 3 & 3 \\
\cline { 2 - 4 } & 8 & 5 & 4 \\
\cline { 2 - 4 } & 14 & 8 & 5 \\
\cline { 2 - 4 } & 18 & 10 & 2 \\
\hline
\end{tabular}

At the end of the reaction, the stirrer was stopped and the bolts on the reactor were loosened. The reactor lid was removed and set aside in a pan while the reactor was quenched to room temperature by immersion in cool water. After the reactor was cooled, the contents were chipped out and weighed along with any distillate that was recovered for mass balances. The reactor was cleaned out with a wire brush and solvent prior to each run to ensure no cross contamination occurred. Mass balances of each run are shown in Appendix I.

\subsection{Characterization of Pitches}

Conventional characterization tests were completed to determine the effects of air-blowing on the pitches. The tests used to characterize the pitch were softening point, density, ash, Conradson carbon, WVU coke, viscosity, pyridine extraction, thermogravimetric analysis (TGA), Fourier-transform infrared spectroscopy (FTIR), elemental analysis, and optical microscopy. 
The softening point, ash, Conradson carbon, WVU coke, and pyridine extraction tests were all done in duplicate. The equation used to determine the amount of error in the results is shown by:

$$
\begin{aligned}
& \% \text { Relative Error }=\frac{\left|V_{1}-V_{2}\right|}{A V G} * 100 \% \\
& \text { where } \begin{aligned}
\mathrm{V} 1 & =\text { Value } 1 \\
\mathrm{~V} 2 & =\text { Value } 2 \\
\mathrm{AVG} & =\text { Average of Value } 1 \text { and } 2
\end{aligned}
\end{aligned}
$$

The error bars on the data plots are calculated by

$$
\text { Error bar value }=\frac{\left|V_{1}-V_{2}\right|}{2}
$$

The error bar values are shown on the graphs as lines above and below each data point, and show the range in which the recorded values lie.

\subsubsection{Softening Point}

Softening point was determined using a Mettler FP80 HT apparatus according to ASTM D3104-99. The pitch was passed through an 8-mesh onto a 20-mesh sieve. The pitch remaining on the 20-mesh sieve was used to fill the sample cups on the hot plate. The pitch was then heated being very careful not to heat too much and cause it to smoke. After the pitch melted in the cup, more pitch was added until the sample cup was full. The samples were allowed to cool and a lead shot was placed on the top of the cup. The sample cup was then placed in the Mettler apparatus and the softening point temperature determined. The measured values are provided in Appendix II. 


\subsubsection{Density}

Density determinations were conducted using an AccuPyc 1330 pycnometer according to ASTM 2320-98. Five determinations were completed with the average

value and standard deviation recorded in Appendix II. Since the reactor was quenched quickly after the air-blowing reaction ended, the pitch solidified quickly and entrapped some of the air. Air entrapment in the pitch resulted in spuriously low-density values. To resolve this problem 5-10 grams of the air-blown pitch were added to a ceramic crucible. The pitch was annealed at $100^{\circ} \mathrm{C}$ above the softening point for 20 minutes if the softening point was less than $200^{\circ} \mathrm{C}$, or 30 minutes if the softening point was over $200^{\circ} \mathrm{C}$. This allowed for the air in the pitch to escape so that an accurate density could be taken. Results of determinations are found in Appendix II.

\subsubsection{Ash Test}

Ash test was done according to ASTM D2415-98. The ceramic crucibles were heated by flame to a red glow and immediately set in a desiccator to ensure there was no moisture on the crucibles before using. Approximately, 0.4 to 0.6 grams of the pitch were weighed out into the crucible. The crucible was then set into the oven with the lid tilted slightly to allow airflow into the sample. The oven then heated up the crucibles at $5^{\circ} \mathrm{C} / \mathrm{min}$ to $400^{\circ} \mathrm{C}$ and then $3^{\circ} \mathrm{C} / \mathrm{min}$ from $400^{\circ} \mathrm{C}$ to $750^{\circ} \mathrm{C}$. The samples were then held in the oven for 180 minutes to ensure complete combustion. After test completed the crucibles were allowed to cool and weighed. 


\subsubsection{Conradson Carbon Test}

The Conradson Carbon test was completed using ASTM D189 to determine the coke yield. First, ceramic crucibles were heated by flame to a red glow and immediately set in a desiccator. This process ensured that no moisture was present on the crucibles before weighing. The crucibles were then weighed and recorded. Between $0.4-0.6$ grams of pitch were added to the crucible and recorded. The crucible was then placed in a small iron crucible and covered with lid. The small iron crucible was then placed into a larger iron crucible with coke breeze lining the bottom half. The purpose of the coke breeze was to act as an oxygen scavenger to protect the pitch from combustion. A lid was then placed on the top of the large iron crucible and the crucible was set on top of a Meker-type burner. The crucible was heated on a medium flame for about $11.5 \mathrm{~min}$ and then held on a low flame for 13 min to complete the initial devolatilization. Finally, the flame was set to a high flame and held there for $7 \mathrm{~min}$ on very high heat. After completion of the test, the flame was extinguished allowing the iron crucible to cool slightly. The ceramic crucible, still warm, was removed and set in a dessicator to completely cool to room temperature. The crucible was then weighed and a Conradson carbon yield was determined as a percentage of mass remaining based on the mass of initial pitch. The determinations are shown in Appendix II.

\subsubsection{WVU Coke Test}

WVU Coke test is a different test for determining the coke yield. The WVU method test cokes the pitch slowly, as opposed to the rather severe conditions encountered with the Conradson Carbon test. Slow heating is preferred in order to allow 
sufficient time for optical texture formation in the resultant cokes in order to determine coke structure. First, ceramic crucibles were heated by flame to a red glow and immediately set in a desiccator to ensure there was no moisture on the crucibles before weighing. The crucibles were weighed and recorded. Between $0.4-0.6$ grams of pitch were added to the crucible and the weight recorded. Another larger crucible was filled halfway with coke breeze. A lid was put on the small crucible and set on top of the coke breeze followed by adding more coke breeze to the top of the small crucible until it was fully covered. As with the Conradson carbon test, the coke breeze acted as an oxygen barrier to prevent the pitch sample from burning. A lid was placed on the large crucible and set in a programmable furnace. The heating rate used was $5^{\circ} \mathrm{C} / \mathrm{min}$ up to $600^{\circ} \mathrm{C}$ and held for 120 minutes. Then the sample was allowed to cool to room temperature and weighed. The WVU Coke yield is calculated by Equation 3.3 and the results tabulated in Appendix II.

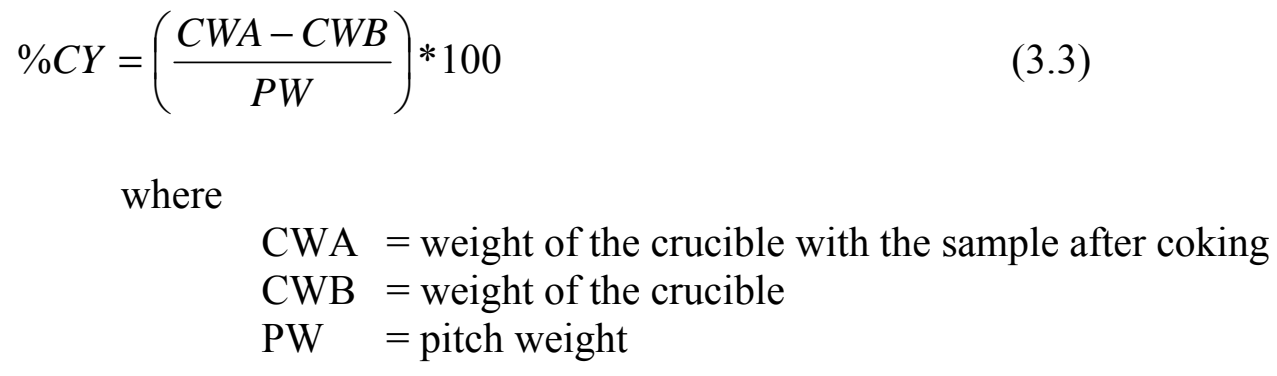

\subsubsection{Viscosity}

Viscosity was determined using a Brookfield DV-III Rheometer according to ASTM D5018-89. The instrument was checked for accuracy by determining the viscosity of fluids of known rheology. Approximately 12 grams of pitch were placed into the sample chamber. The sample chamber was then heated up to approximately $15-20^{\circ} \mathrm{C}$ 
above the softening point of the pitch. A Brookfield SC4-34 spindle was used to deliver defined shear rates in order to determine shear stress. From these data, it is possible for the dedicated computer system to calculate the viscosity of the pitch at that temperature. After the viscosity of the pitch at the first temperature was determined, the temperature was raised $10^{\circ} \mathrm{C}$ and the method repeated. The $10^{\circ} \mathrm{C}$ increments continued until the pitch viscosity was less than $1,000 \mathrm{cP}$. Summary data are found in Appendix IV.

\subsubsection{Pyridine Insoluble Content}

A pyridine extraction was done on the pitch to determine the amount of pyridine insoluble material present in the feed and air-blown pitches. One hundred milliliters of pyridine were added to a $500 \mathrm{~mL}$ beaker while a magnetic stirrer was used to stir the solvent on a hot plate. A known amount of pitch, approximately 3 grams, was weighed and added to the pyridine. The mixture was then heated to the point where pyridine started to condense on the sides of the beaker at about $115^{\circ} \mathrm{C}$ and held for approximately ten minutes. A watch glass placed on top of the beaker helped in condensing the pyridine and prohibiting it from boiling off. After the solution was finished heating, the hot plate was turned off while allowing it to continue to stir. The weights of a $250 \mathrm{~mL}$ round bottom flask, two boiling chips, and a thimble were recorded. The two boiling chips were added to the flask. The flask was clamped onto the bottom of a ring stand and a small funnel was placed into the top of the flask. The thimble was placed in this funnel and another funnel was placed on a ring support above the thimble. The bottom of the second funnel was barely inserted into the top of the thimble. This setup can be seen below in Figure 3.3. 


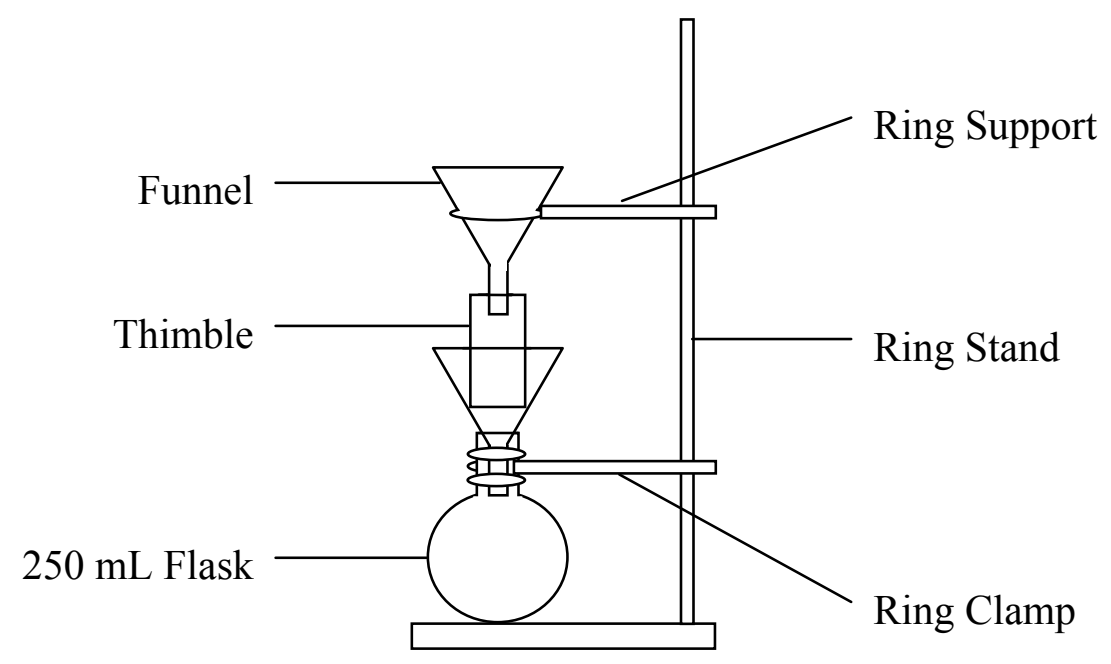

Figure 3.3: Diagram of ring stand setup

The mixture of pyridine was taken off the hotplate when cooled enough to the touch. A magnetic wand was used to remove the stirrer and residual material rinsed off with pyridine into the funnel. The solution was poured into the top funnel making sure that the thimble below did not overflow. The thimble was drained into the flask and more solution was added to the thimble to keep it full until the beaker was empty. The beaker was rinsed out with pyridine into the thimble and the thimble was allowed to drain completely. The funnel was rinsed off and removed from the ring stand being careful not to knock over the thimble. A Soxhlet apparatus was obtained and a ceramic spacer was placed in the bottom of the Soxhlet. The spacer keeps the thimble above the level of the drain tube and prevents the thimble from overflowing during extraction. Using forceps, the thimble was placed on top of the crucible in the Soxhlet. The bottom funnel was rinsed with pyridine making certain there was no remaining solution left on it. The flask was removed from the ring stand and placed onto the bottom of the Soxhlet. The flask was set onto a heating mantle and the Soxhlet was attached to a condenser. A variac was 
used to heat the mantle up to the point that pyridine was condensing on the inside of the Soxhlet. Figure 3.4 shows the setup of the Soxhlet apparatus.

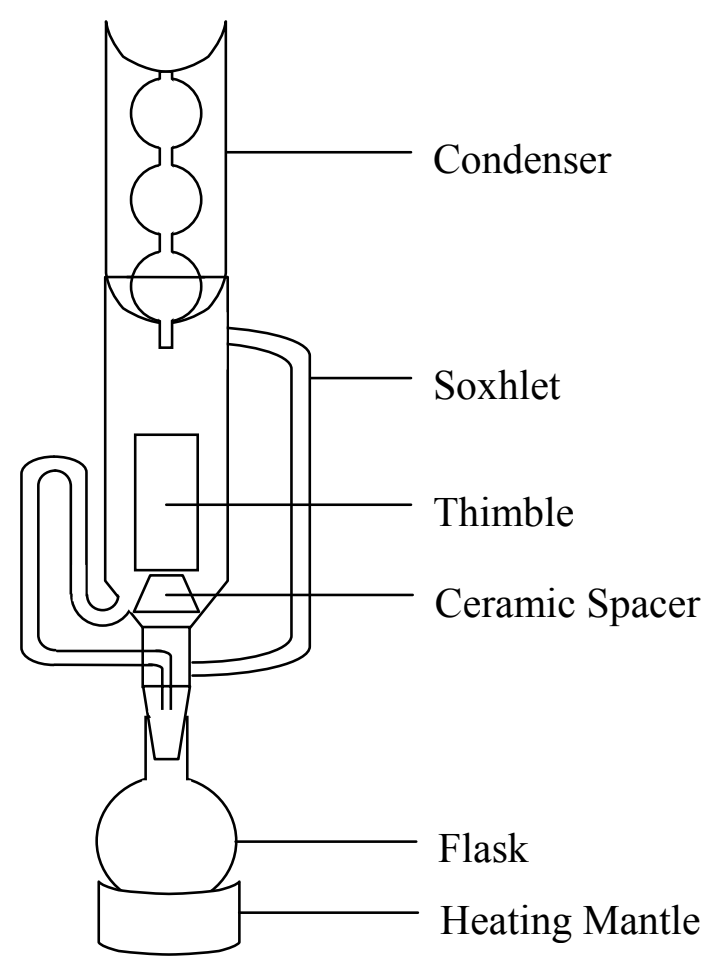

Figure 3.4: Soxhlet apparatus setup

The Soxhlet extraction continued overnight or until the solution was clear, which generally required 24 hours. The heating mantle was then switched off and the flask and Soxhlet were left to cool. When cooled, the Soxhlet was tilted slightly until the solution was siphoned into the flask, making sure that solution from inside the thimble was not spilt out. When the thimble was completely drained, it was removed and placed in a beaker to dry. The solution was rinsed out of the Soxhlet into the flask and the solvent was removed using a rotary evaporator at $160^{\circ} \mathrm{C}$. The flask and thimble were then dried 
in a vacuum oven at approximately $110^{\circ} \mathrm{C}$ overnight. Results are recorded in Appendix II.

The flask and thimble were weighed and the pyridine insoluble yield (\% PI) was calculated using Equation 3.2.

$$
\% P I=\left(\frac{A T W-T W}{P W}\right) * 100
$$

where

$$
\begin{array}{ll}
\text { ATW } & =\text { weight of thimble and insolubles after dried in vacuum oven } \\
\text { TW } & =\text { thimble weight } \\
\text { PW } & =\text { pitch weight }
\end{array}
$$

\subsubsection{Elemental Analysis}

Elemental analysis was completed on all of the pitch materials using a Thermoquest Flash EA 1112, using two separate methods. The first method measured the amount of $\mathrm{C}, \mathrm{H}, \mathrm{S}$, and $\mathrm{N}(\mathrm{CHSN})$ while the second method determined the amount of oxygen directly. Measurements were conducted in triplicate to provide statistical reliability. The CHSN test was done by weighing approximately 2 to 3 milligrams of pitch into a tin sample cup. After this was done, about 2-3 milligrams of vanadium pentoxide, an oxidizer, were added to aid in the combustion. The instrument dropped the sample into a furnace in an oxygen environment to combust the sample completely. The combustion products passed through catalysts to convert the gases into other gases that are separable by gas chromatography and detected.

The second method measured the amount of oxygen that was contained in the sample. Approximately 3 milligrams of sample were weighed in a silver sample cup. Then approximately $2-3 \mathrm{mg}$ of vanadium pentoxide was added on top of the sample to 
aid in the combustion. The sample undergoes nearly instant combustion while being transformed into the products $\mathrm{N}_{2}, \mathrm{CO}, \mathrm{SO}_{2}$, and $\mathrm{H}_{2} \mathrm{O}$ when dropped into the reactor at a temperature of $1060^{\circ} \mathrm{C}$. The amount of oxygen was determined by measuring the amount of $\mathrm{CO}$ and $\mathrm{SO}_{2}$ formed during the combustion of the material. Results of the both elemental analysis methods can be found in Appendix V.

\subsubsection{FTIR}

Fourier-transform infrared spectroscopy (FTIR) was done to examine at the aromaticity and functional group changes associated with air-blowing pitches. A Nicolet 510P FT-IR Spectrometer was used and the KBr-pellet method, as described by J. Yang, was followed [49]. First, about $300 \mathrm{mg}$ of potassium bromide (KBr) were weighed and added to a sample capsule. Next, approximately $3 \mathrm{mg}$ of pitch sample were added to the sample capsule with the $\mathrm{KBr}$. The capsule was then capped and a thin piece of parafilm was wrapped around the cap to ensure no sample escapes. The capsule was then placed in a Wig-L-Bug and shaken for 2 minutes at $3800 \mathrm{rpm}$. After this was done, the parafilm was removed and the capsule tapped on the counter firmly to make sure the sample did not remain in the cap when opened. The cap was then removed and the sample carefully poured into the pellet-press chamber manufactured by Spectra-Tech. The chamber was then tapped a few times to make certain the level of the sample was even. Next, the stainless steel rod was placed into the chamber on top of the sample. The assembled pellet press was held loosely in a hydraulic press for about 2 minutes while vacuum was applied. The vacuum assists in removing trapped air, which could interfere with making transparent $\mathrm{KBr}$ disks. The setup can be seen in Figure 3.5. 


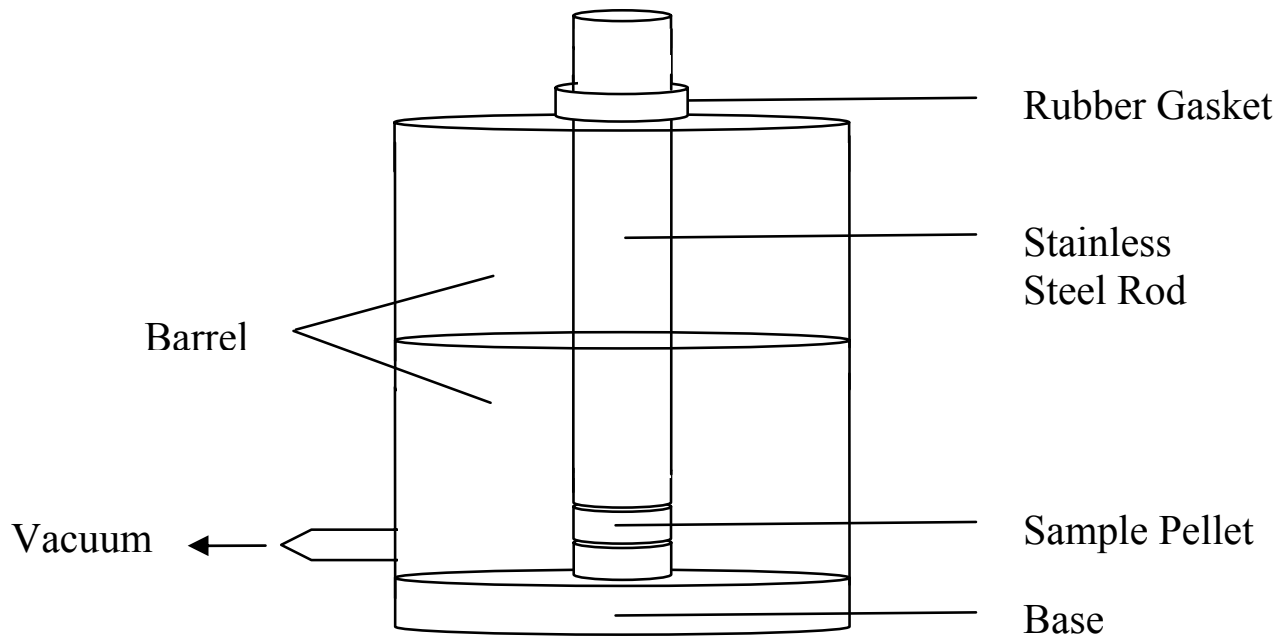

\section{Figure 3.5: Diagram of Spectra-tech pellet apparatus}

The pressure on the hydraulic press was then increased to approximately $2,000 \mathrm{psi}$

for two minutes with the chamber still under vacuum. After this was done, the vacuum was released and the pressure on the hydraulic press was released. The sample chamber and rod were then placed upside down with a spacer on the top of the press to allow the pellet to be pushed out. A razor blade was sometimes required to pry the sample pellet from the stainless steel rod. This was done very carefully to ensure that the pellet was not broken or had any defects since it is very delicate. The pellet was then weighed and then placed into the FTIR sample holder. The sample holder was placed into the instrument carefully ensuring that the laser was hitting the center of the pellet. The instrument was purged with dry air for approximately 15 minutes before the analysis was initiated. The analysis was run using an absorbance spectral resolution of 2 wave numbers with 254 spectral scans.

The procedure above explains sample preparation. Before any sample pellets were analyzed in the FT-IR, a background spectrum was needed. This was done by using 
the same procedure above without any sample added to the capsule. Since $\mathrm{KBr}$ readily absorbs atmospheric water, a background spectrum needs to be run every few hours. This ensured that the correct background was subtracted on each of the samples. The potassium bromide should be stored at approximately $90^{\circ} \mathrm{C}$ under vacuum when not in use to remove the moisture. After the background was collected, the analysis could be done using the sample pellet for the pitch as explained above. This procedure was done for each of the feed pitches and the air-blown pitches. The recorded data are tabulated in Appendix VI.

\subsubsection{Thermogravimetric Analysis}

Thermogravimetric data were obtained on all of the air-blown pitches and their feed materials using a TG-151 Thermo Gravimetric Analyzer (TGA) by Kahn Instruments. The TGA heated the sample up while measuring the weight change over a specified time period and temperature rate. The quartz sample container was removed from the TGA and zeroed on a Mettler-Toledo MX/UMX balance. Approximately 100 mg of material were then added to the container. The quartz sample container was then carefully placed back onto the TGA. The body of the TGA was then raised carefully ensuring the container was not touching the walls. The body was then hand tightened to the lid. The pitch was then heated at a rate of $3^{\circ} \mathrm{C} / \mathrm{min}$ up to $900^{\circ} \mathrm{C}$. The tests were all done in the presence of nitrogen at atmospheric pressure. The devolatization of each sample could then be compared to illustrate the effects of air-blowing on pitches. 


\section{Chapter 4 - Results and Discussion}

The purpose of this thesis project was to study the effects of air-blowing on the properties of three types of pitches: petroleum pitch, coal-tar pitch, and coal-extract pitch. This was done through a series of air-blowing experiments at three temperatures: $250^{\circ} \mathrm{C}$, $275^{\circ} \mathrm{C}$, and $300^{\circ} \mathrm{C}$. At each of these temperatures, the pitches were reacted for varying amounts of time. The resultant air-blown pitches showed an increase in the softening point, coke yield, viscosity, density, and aromaticity $(\mathrm{C} / \mathrm{H})$. There was also a dramatic difference between the three types of pitches in their reactivities. The results discussed in this chapter show that pitch treatment with air can result in an isotropic pitch with potentially desirable properties for use in many carbon applications.

\subsection{Characterization of Pitches}

The feed pitches were characterized to determine some of their properties prior to treatment, as shown in Table 4.1. All of the feeds were low in ash content, similar softening point, and coke yield. However, the coal-tar pitch was significantly more dense and contained more pyridine insolubles (PI) than the other two materials.

Table 4.1: Properties of the feed pitch

\begin{tabular}{|l|c|c|c|}
\hline & $\begin{array}{c}\text { A240 petroleum } \\
\text { pitch }\end{array}$ & $\begin{array}{c}\text { Koppers } \\
\text { coal-tar pitch } \\
\text { (filtered) }\end{array}$ & $\begin{array}{c}\text { WVU coal- } \\
\text { extract pitch }\end{array}$ \\
\hline Ash (wt \%) & 0.04 & 0.05 & 0.01 \\
\hline Mettler Softening Pt. $\left({ }^{\circ} \mathrm{C}\right)$ & 116.9 & 108.1 & 121.7 \\
\hline Density $\left(\mathrm{g} / \mathrm{cc}^{3}\right.$ ) & 1.236 & 1.304 & 1.246 \\
\hline WVU Coke Yield (wt \%) & 50.9 & 53.7 & 56.0 \\
\hline Conradson Coke Yield (wt \%) & 47.1 & 48.0 & 52.9 \\
\hline Pyridine Insolubles (wt \%) & 0.84 & 11.50 & 0.15 \\
\hline
\end{tabular}




\subsubsection{Softening Point}

Treatment of the feed pitches by air-blowing increases the softening point dramatically compared to using an inert gas such as nitrogen. The A240 petroleum pitch softening point increased from $116.9^{\circ} \mathrm{C}$ for the parent pitch to about $175^{\circ} \mathrm{C}$ after airblowing for 6 hours at $300^{\circ} \mathrm{C}$. When the same pitch was subjected to the same conditions replacing air with nitrogen the softening point only increased to about $134^{\circ} \mathrm{C}$. The effects on the pitch softening point using air and nitrogen blowing can be seen below in Figure 4.1.

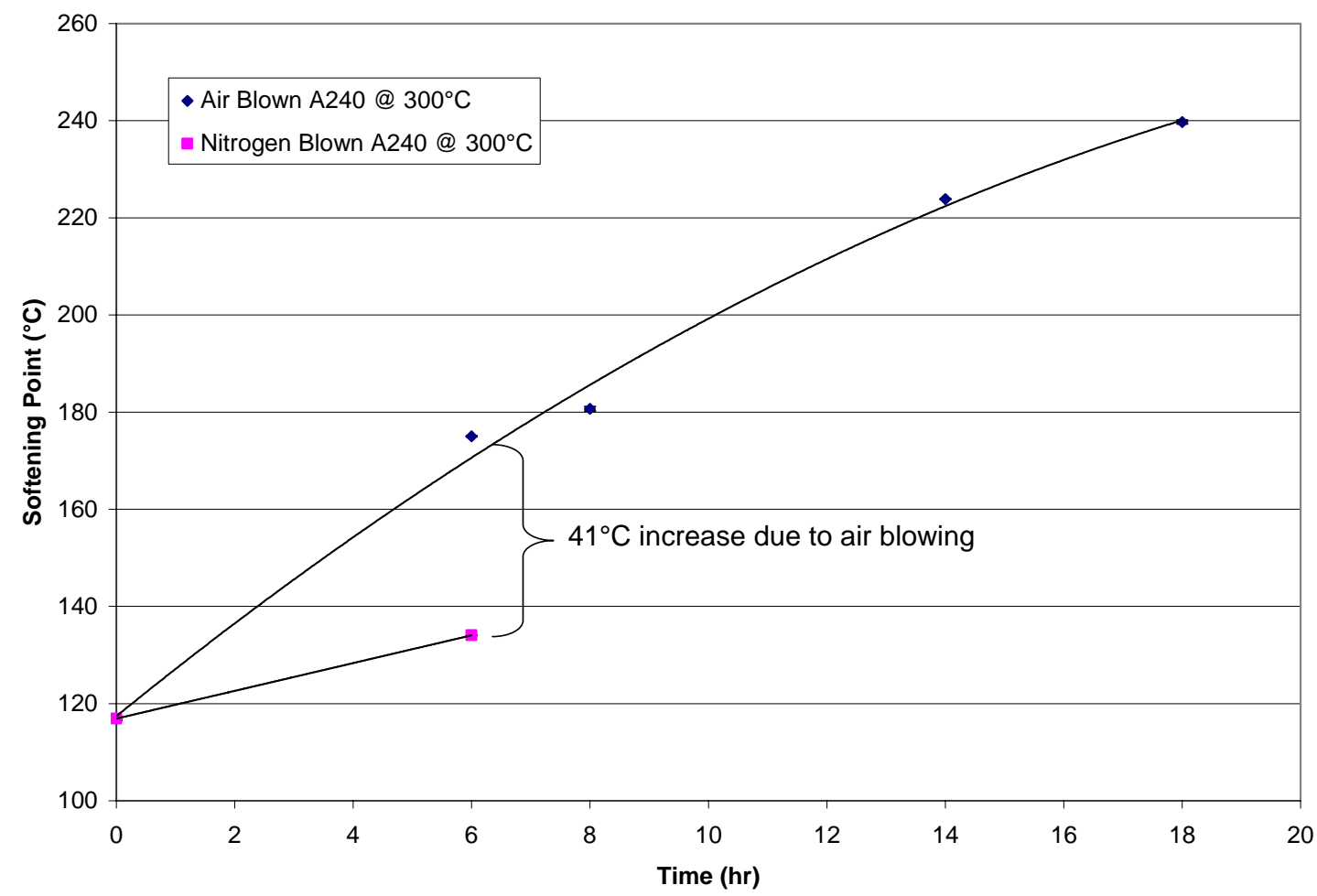

Figure 4.1: Softening point effects of nitrogen and air-blowing at $300^{\circ} \mathrm{C}$ on the petroleum pitch, A240

A similar effect was seen with the coal-tar pitch when subjected to air and nitrogen treatment. The softening point of the coal-tar pitch feed was increased from $108^{\circ} \mathrm{C}$ to $174^{\circ} \mathrm{C}$ after 5 hours of air-blowing at $300^{\circ} \mathrm{C}$. Nitrogen blowing the same 
amount of time and temperature resulted in the increase of the parent pitch from $108^{\circ} \mathrm{C}$ to $131^{\circ} \mathrm{C}$. The air treatment showed a $43^{\circ} \mathrm{C}$ increase over the nitrogen under the same reaction conditions. The effect on the pitch using both air and nitrogen can be seen in Figure 4.2.

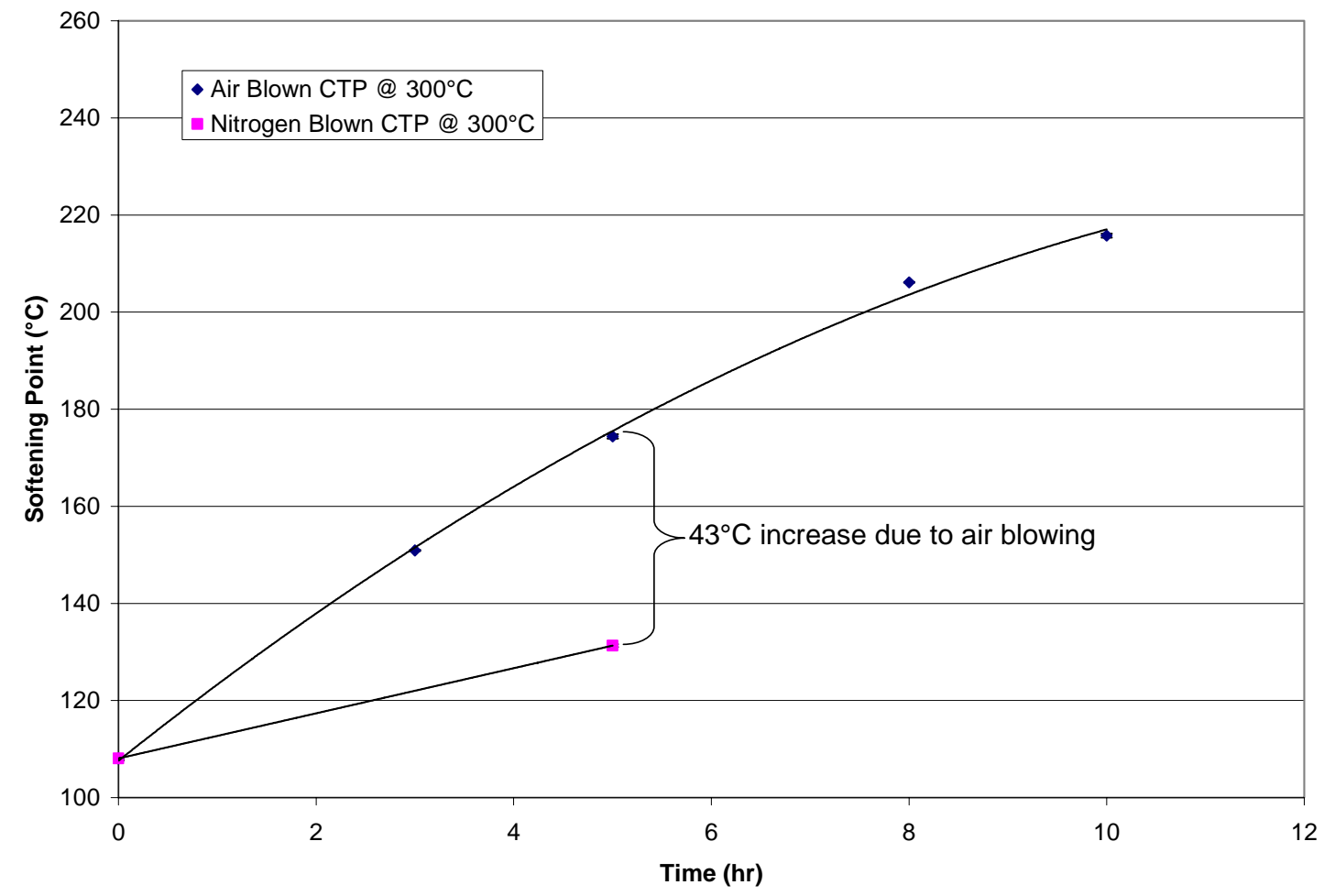

Figure 4.2: Softening point effects of nitrogen and air-blowing at $300^{\circ} \mathrm{C}$ on the Koppers coal-tar pitch

The results from Figures 4.1 and 4.2 show that air-blowing the pitch is more effective than using nitrogen to increase the softening point. The A240 petroleum pitch had a $41^{\circ} \mathrm{C}$ increase in softening point while the coal-tar pitch had a similar increase of $43^{\circ} \mathrm{C}$. Similar results were noted in the literature, as reviewed in Chapter 2 . It can be inferred that significantly longer treatment would be required in nitrogen to achieve the same softening point obtained in air. 
The results of air-blowing on the softening point can be seen in Figure 4.3. It is clear that softening point increases at shorter treatment times at the higher temperatures. These observations are similar to those reported by other researchers, as discussed in the literature review.

The effects of air-blowing on the WVU coal-extract pitch is shown below in Figure 4.3. Unlike the other two pitches, the WVU extract pitch requires much less time to increase softening point at any given temperature. This shows that the WVU coalextract pitch is more sensitive to air-blowing compared to the other two pitches. This can be more easily seen in Figure 4.4, in which softening points of all three materials airblown at $300^{\circ} \mathrm{C}$ are plotted together. Here, the coal-extract is evidently more susceptible to air-blowing. 

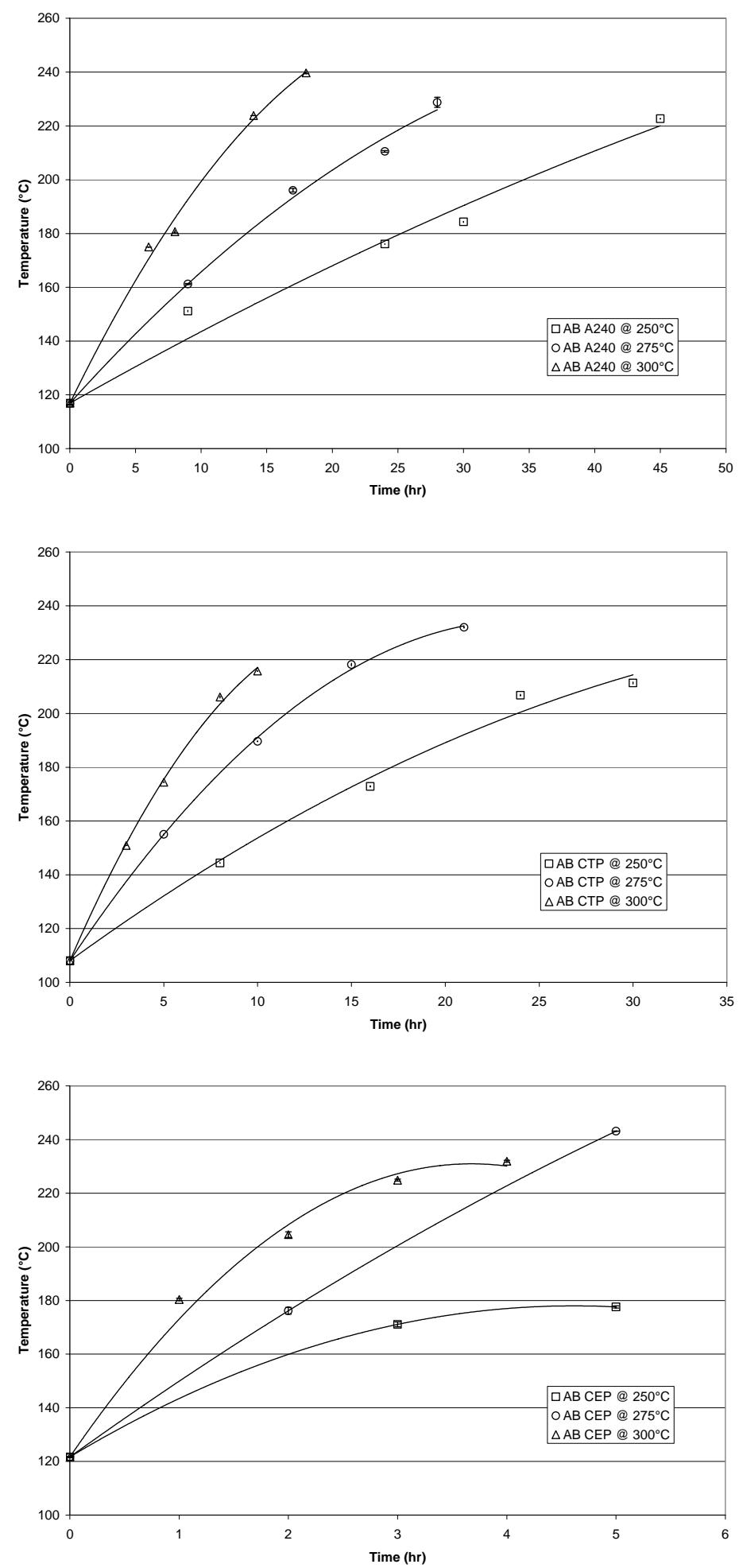

Figure 4.3: Softening point temperatures of petroleum, coal-tar, and coal-extract feed and air-blown pitches at reaction temperatures of $250^{\circ} \mathrm{C}, 275^{\circ} \mathrm{C}$, $300^{\circ} \mathrm{C}$ 


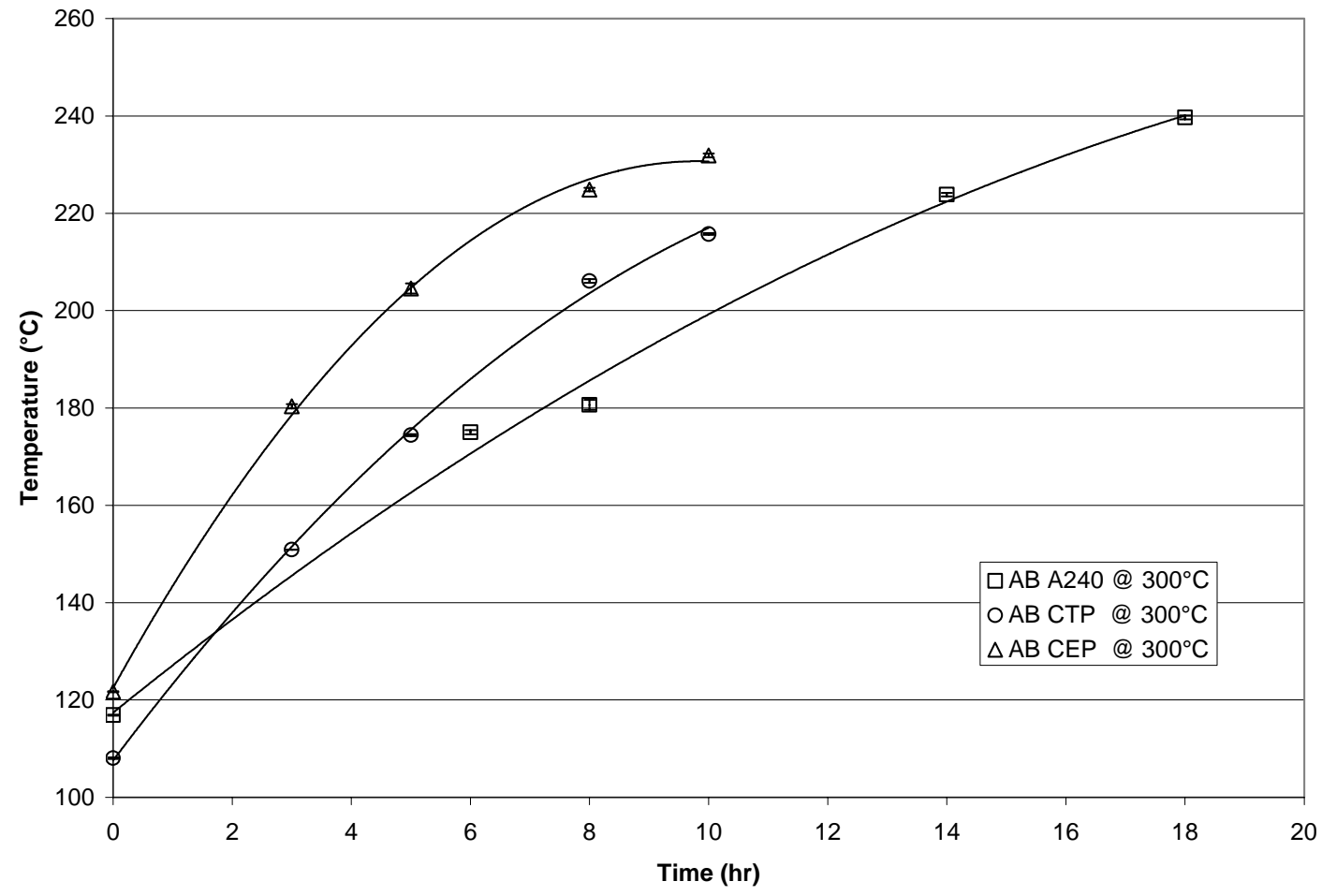

Figure 4.4: Softening points of air-blown reaction at $300^{\circ} \mathrm{C}$ for all three pitches

\subsubsection{Coke Content Determination}

The results of air-blowing on the Conradson Coke yield can be seen in Figure 4.5. It is clear that coke yield increases the most at the higher temperatures and longer treatment times, as with the softening point of the pitch. These observations are similar to those reported by other researchers, as discussed in the literature review. Unlike the other two pitches, the WVU extract pitch requires much less time to increase the coke yield at any given temperature. The WVU coke yield can be seen in Figure 4.6. This shows similar trends as the Conradson Coke test. 

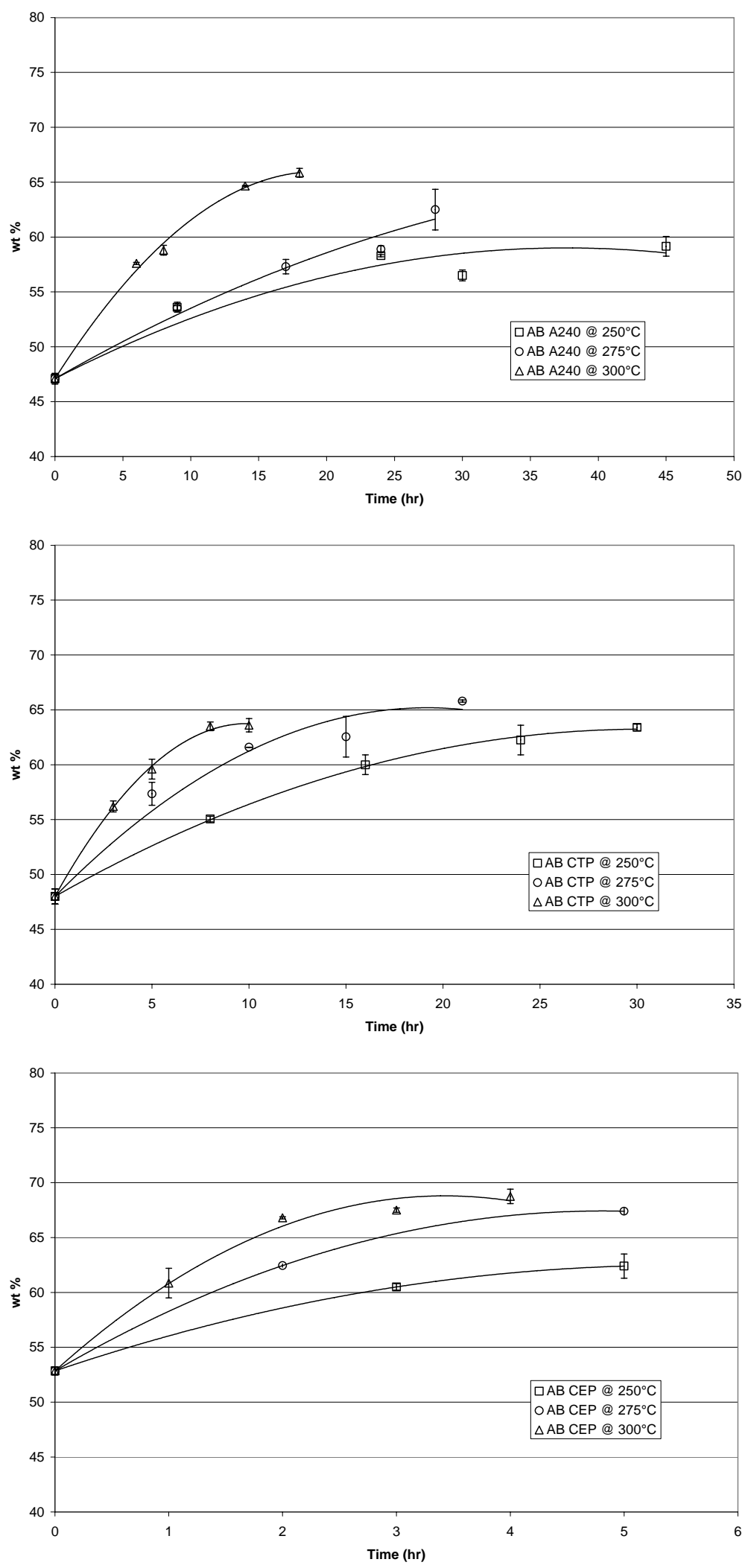

Figure 4.5: Conradson coke yield of petroleum, coal-tar, and coal-extract pitches air-blown for various periods at 250,275 , and $300^{\circ} \mathrm{C}$ 

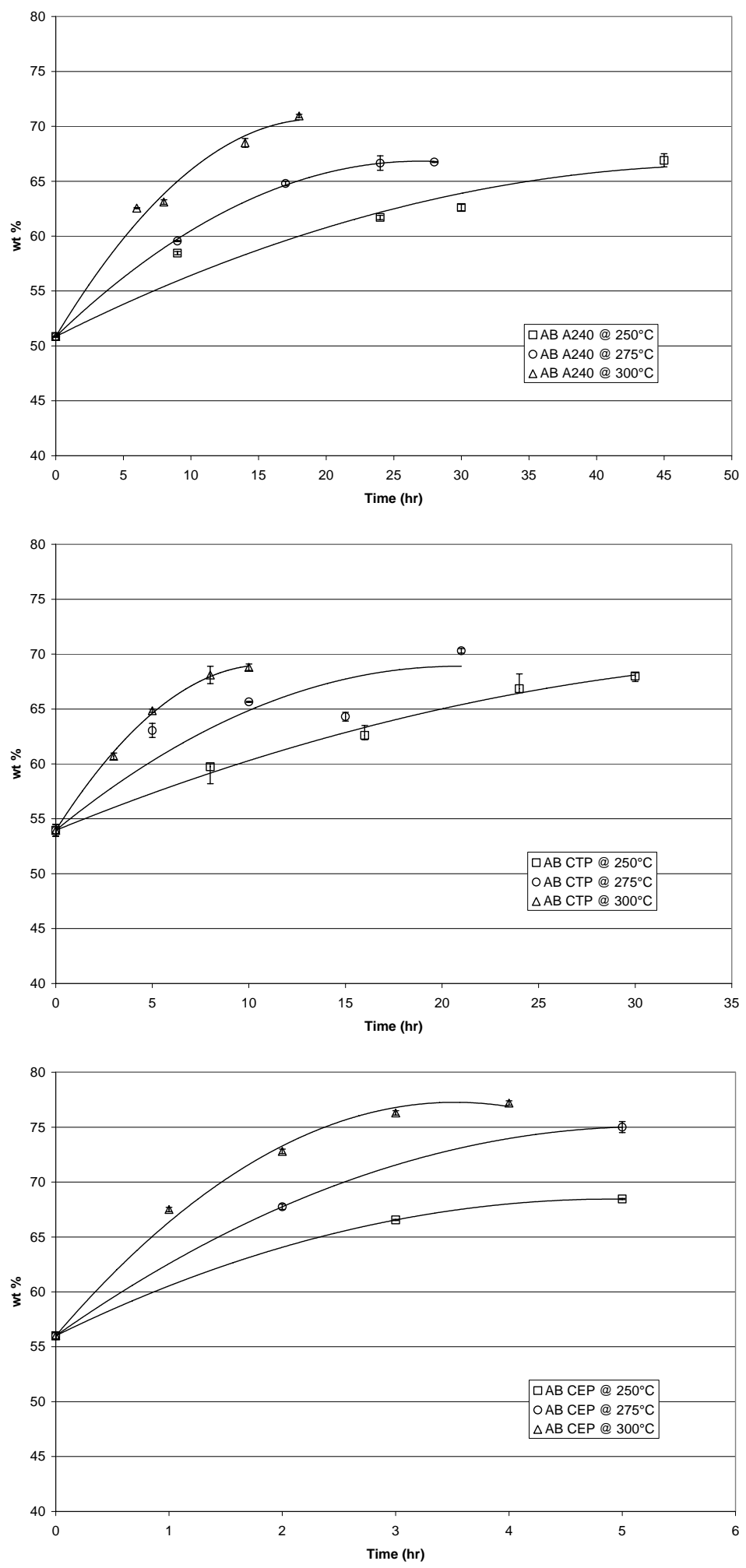

Figure 4.6: WVU coke yield of A240 petroleum pitch, Koppers coal-tar pitch, and WVU coal-extract pitch 


\subsubsection{Density}

The density of the three pitches was increased as the air-blowing temperature and time were increased. The results of air-blowing on the density can be seen in Figure 4.7. Following the same trends as observed with softening points and coke yields, densities are quite sensitive to air-blowing. The increase in density suggests that air-blowing results in a tighter or more compact ordering of molecules since there is more mass per unit volume. 

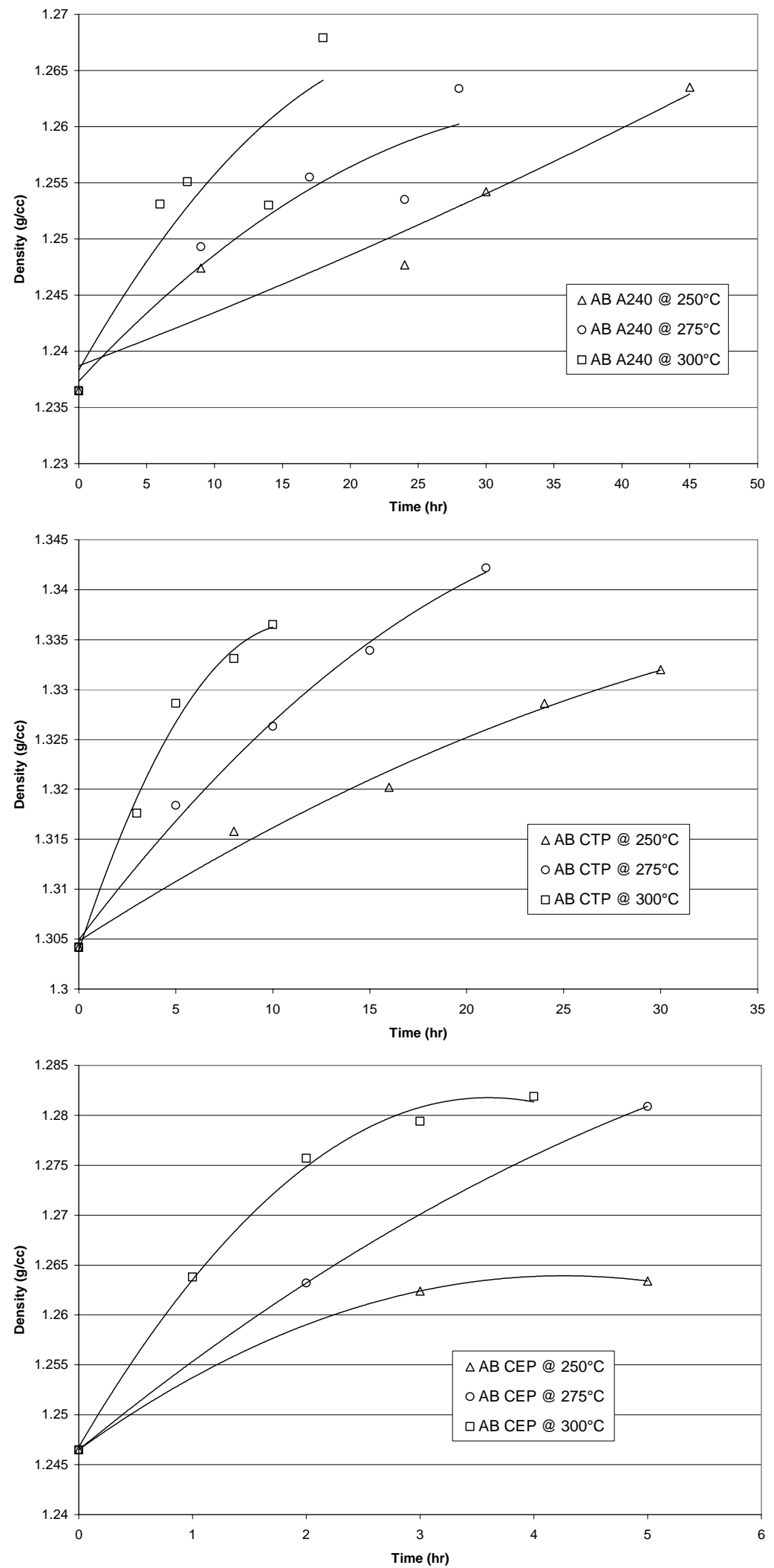

Figure 4.7: Density of petroleum, coal-tar, and coal-extract pitches air-blown at $250,275,300^{\circ} \mathrm{C}$ 


\subsubsection{Viscosity}

The WLF equation was chosen to model the viscosity of the air-blown pitches. Normally, the glass transition temperature, $\mathrm{T}_{\mathrm{g}}$, should be chosen as the reference temperature. Attempts were made to determine $\mathrm{T}_{\mathrm{g}}$ by differential scanning calorimeter (DSC) without success. Only feed pitches exhibited $T_{g}$ with the air-blown materials showing no transitions. Therefore, a glass transition temperature was estimated as $80 \%$ of the Mettler softening point, as suggested by Barr and Lewis [44]. Insertion of this calculated Tg into the WFL equation (and assuming $\mathrm{n}_{\mathrm{r}}=10^{6} \mathrm{cP}$ at $\mathrm{Tg}$ ) led to a great deal of scatter in the data. But since the reference temperature can be arbitrary, the corresponding viscosity can be determined graphically. As can be seen in Figure 4.8, all of the curves intersect at a viscosity of $10,000 \mathrm{cP}(\log 4)$ for the petroleum pitch. This could also be seen in the coal-tar and coal-extract viscosity measurements shown in Figures 4.9 and 4.10, respectively. Each curve was fitted to a logarithmic equation, in which the reference temperature was estimated by substituting log 4 . From these equations, the temperature for the reference viscosity could be determined. This temperature and viscosity were used as the reference temperature and reference viscosity, respectively. After the reference temperature and viscosity were determined, the data for all of the treated pitches were modeled using the WLF equation shown by:

$$
\log \left(\left(\frac{n}{T}\right)\left(\frac{T_{R}}{n_{r}}\right)\right)=T-T_{R}
$$

As can be seen from this information in Figure 4.11, the data fit on an approximate straight line. The relationship indicates that the rheological behavior of both the feed and air-blown pitches behaves similarly to other types of conventional pitches and the visco-rheological behavior can be modeled using established theories. The WLF 
plots for A240, coal-tar, and coal-extract pitches are shown in Figures 4.11, 4.12, and 4.13 , respectively. 

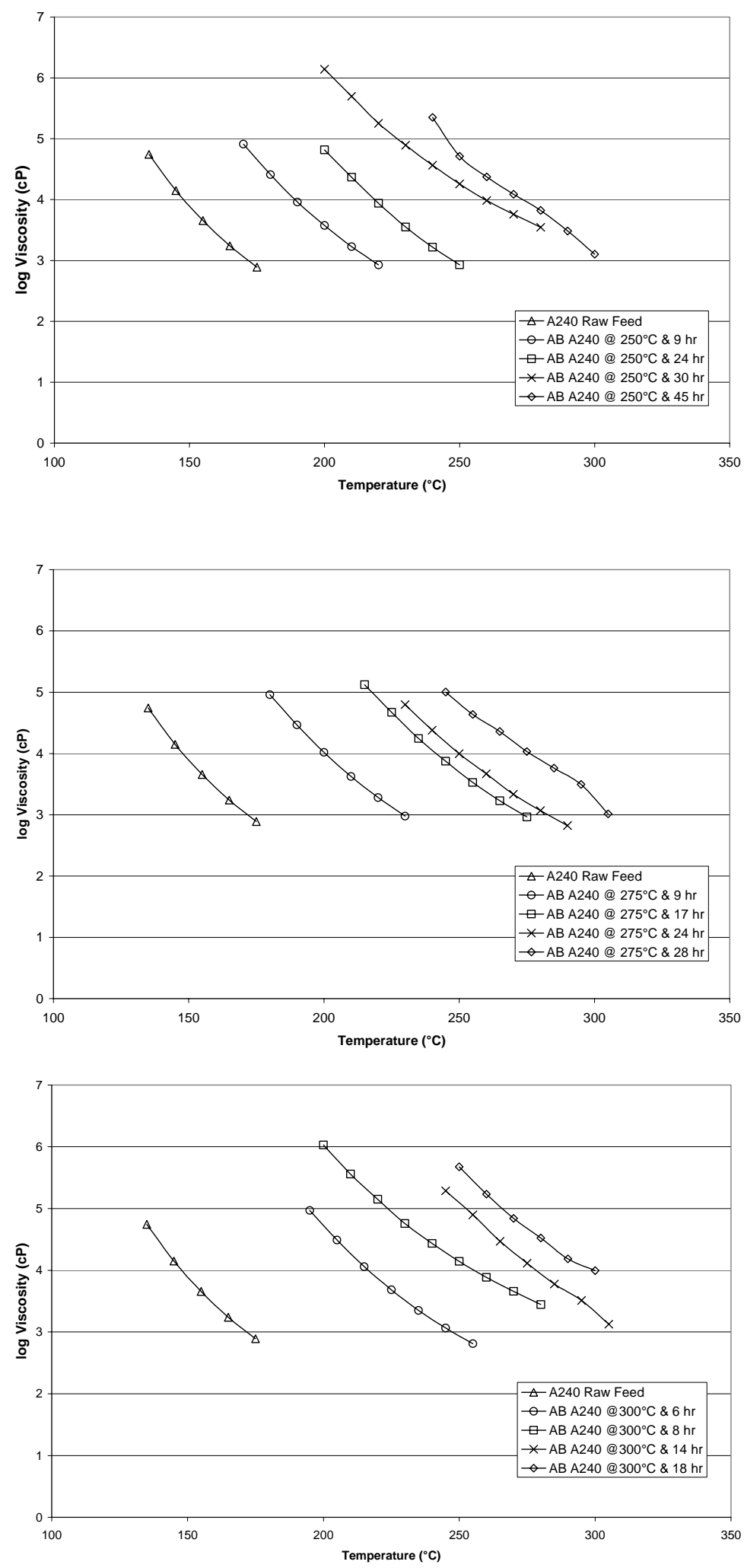

Figure 4.8: Temperature dependence of viscosity for $\mathrm{A} 240$ petroleum pitch at $250^{\circ} \mathrm{C}, 275^{\circ} \mathrm{C}$, and $300^{\circ} \mathrm{C}$ 

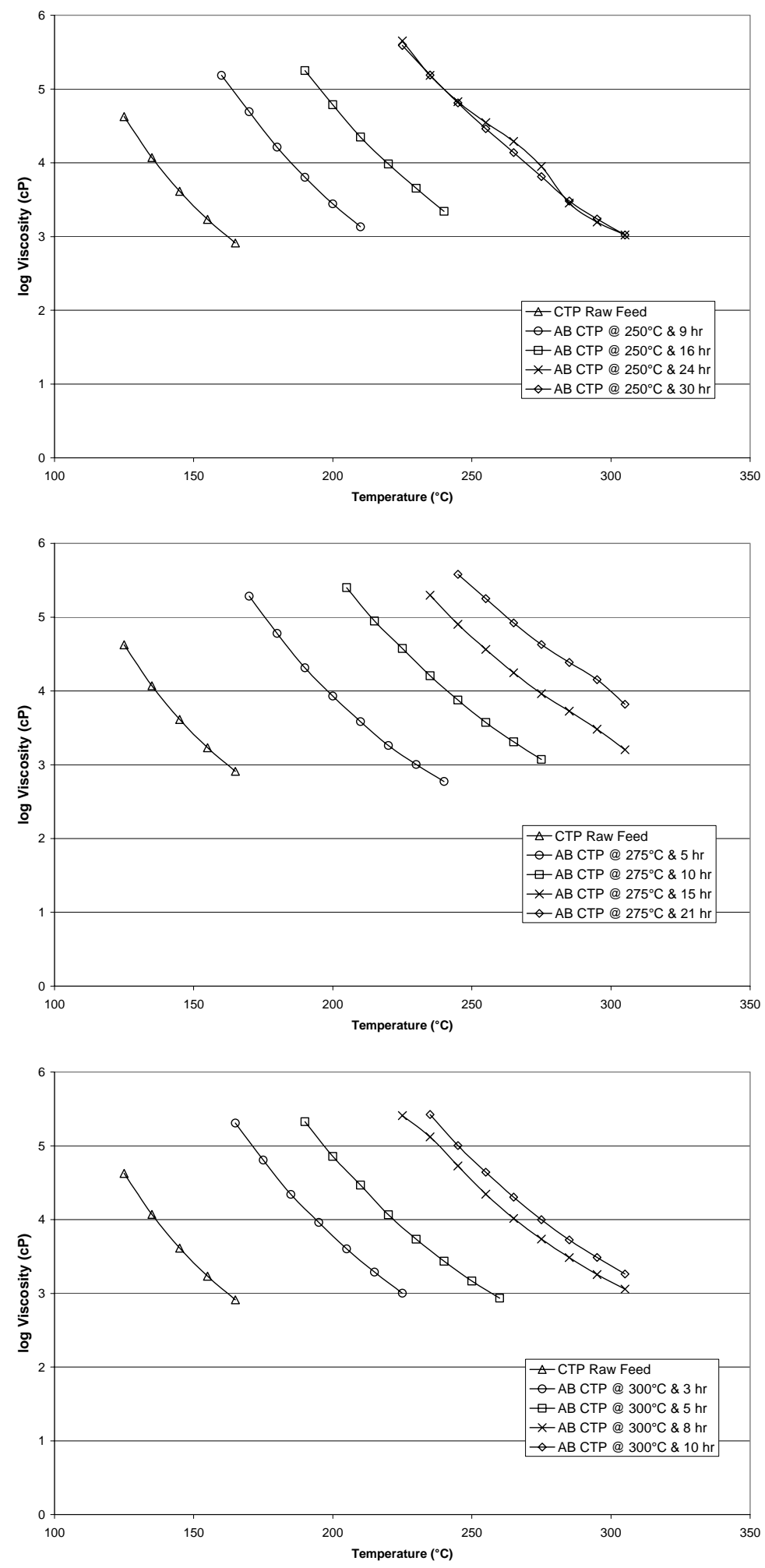

Figure 4.9: Temperature dependence of viscosity for Koppers coal-tar pitch at $250^{\circ} \mathrm{C}, 275^{\circ} \mathrm{C}$, and $300^{\circ} \mathrm{C}$ 

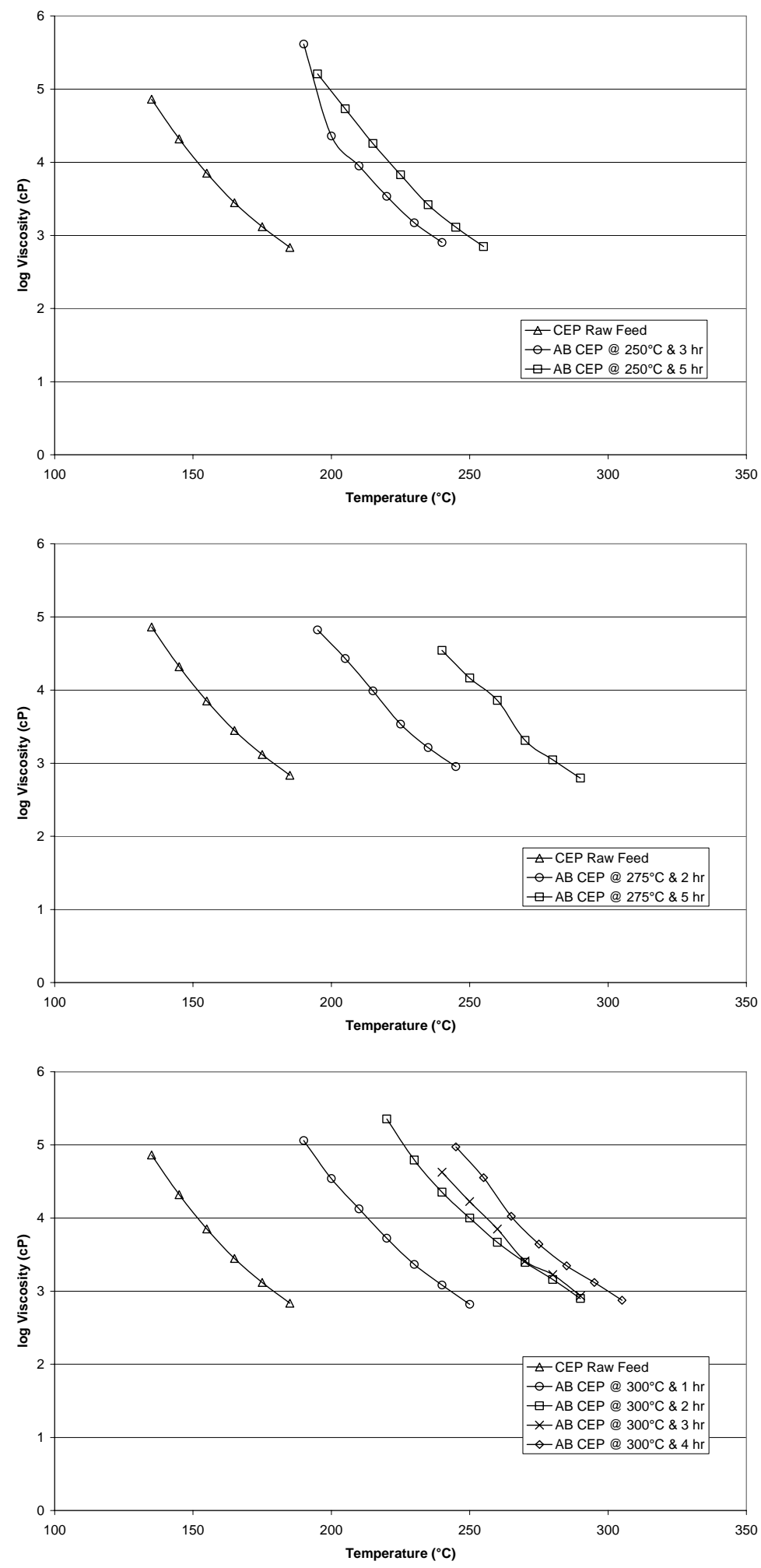

Figure 4.10: Temperature dependence of viscosity for WVU coal-extract pitch (CEP) at $250^{\circ} \mathrm{C}, 275^{\circ} \mathrm{C}$, and $300^{\circ} \mathrm{C}$ 

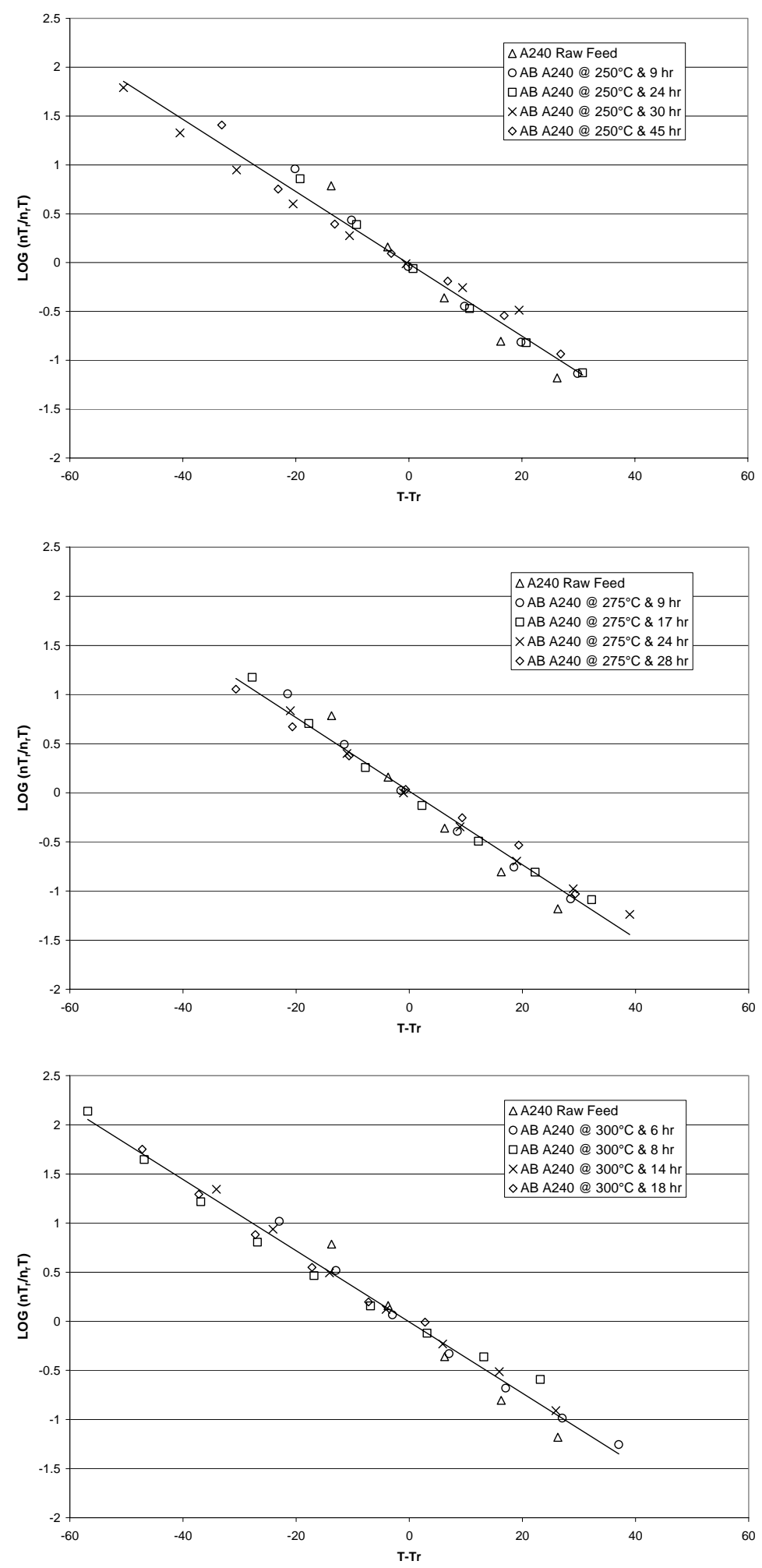

Figure 4.11: WFL model of $\mathrm{A} 240$ petroleum pitch at $250^{\circ} \mathrm{C}, 275^{\circ} \mathrm{C}$, and $300^{\circ} \mathrm{C}$ 

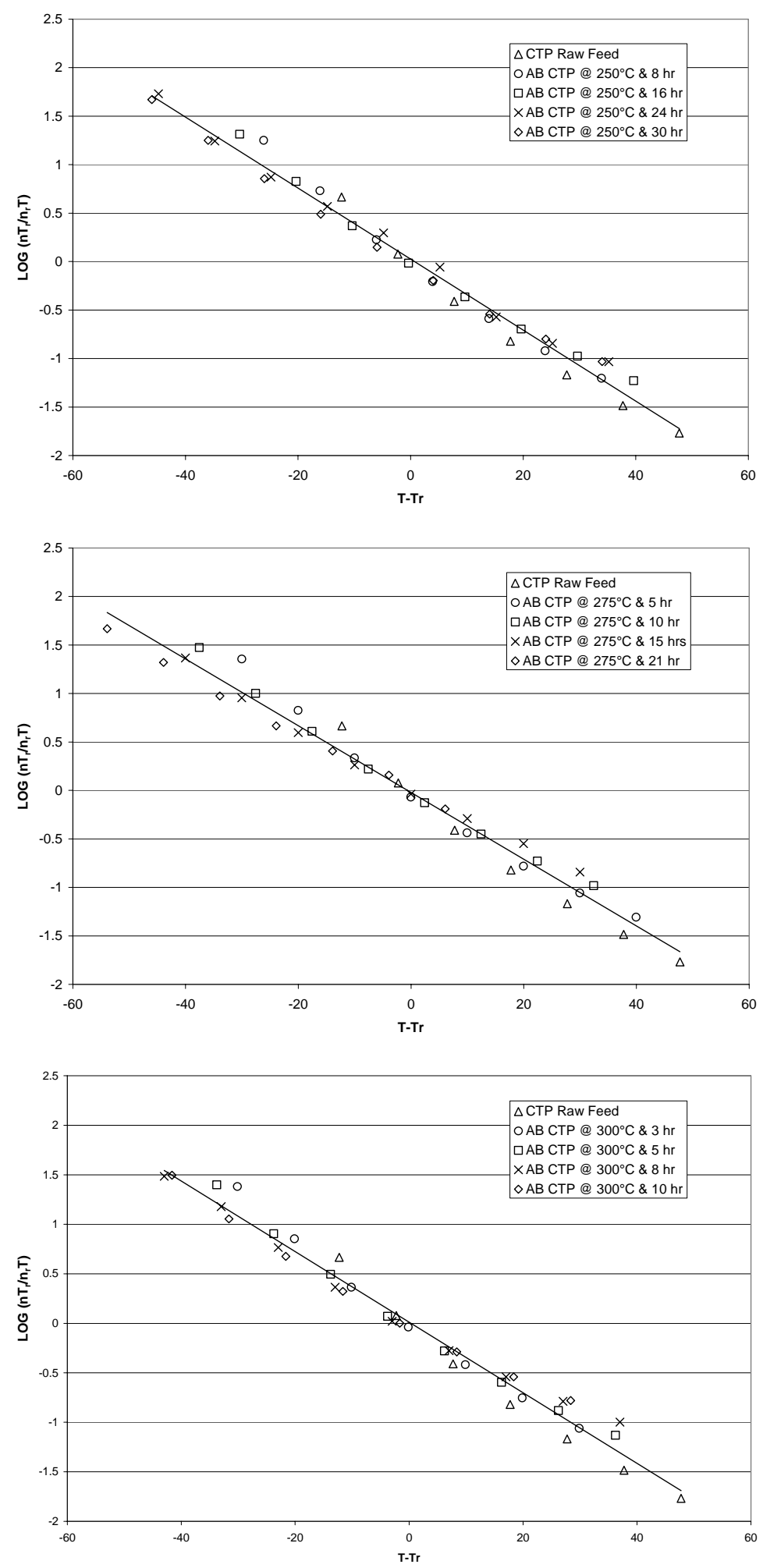

Figure 4.12: WFL model of Koppers coal-tar pitch (CTP) at $250^{\circ} \mathrm{C}, 275^{\circ} \mathrm{C}$, and $300^{\circ} \mathrm{C}$ 

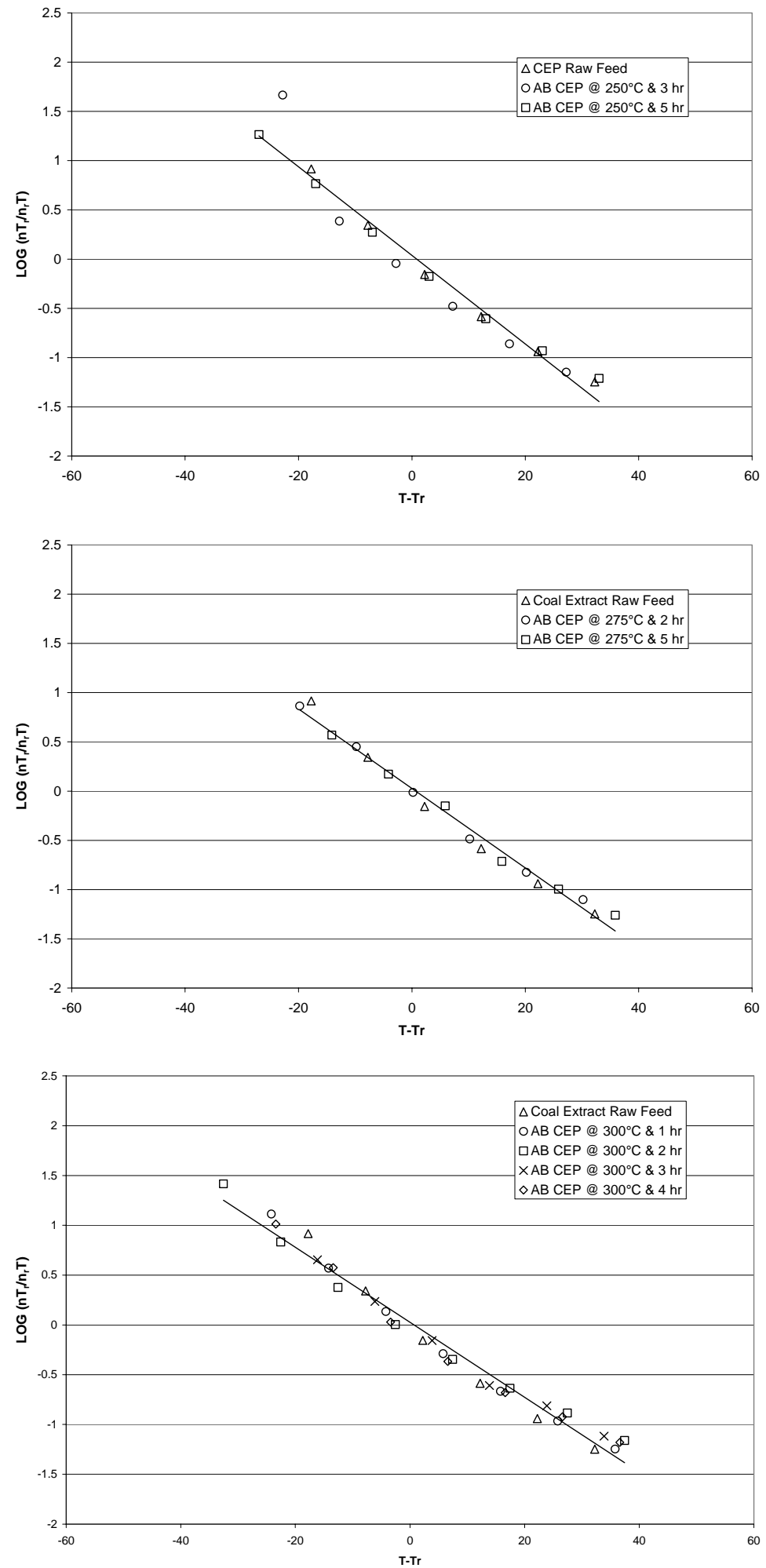

Figure 4.13: WFL model of WVU coal-extract pitch (CTP) at $250^{\circ} \mathrm{C}, 275^{\circ} \mathrm{C}$, and $300^{\circ} \mathrm{C}$ 


\subsubsection{Insolubility}

The insolubility of the feed pitches in pyridine was approximately nil except for the coal-tar pitch, with a pyridine insoluble content (PI) of about 11.5 percent, as can be seen in Table 4.1. After heat treatment with air, the PI content of all three pitches increased. As can be seen in Figures $4.14-4.16$, the higher treatment temperatures yield more PI content in less amount of time. In Figure 4.14, the PI content of the petroleum pitch continued to increase as treatment time increased for each temperature.

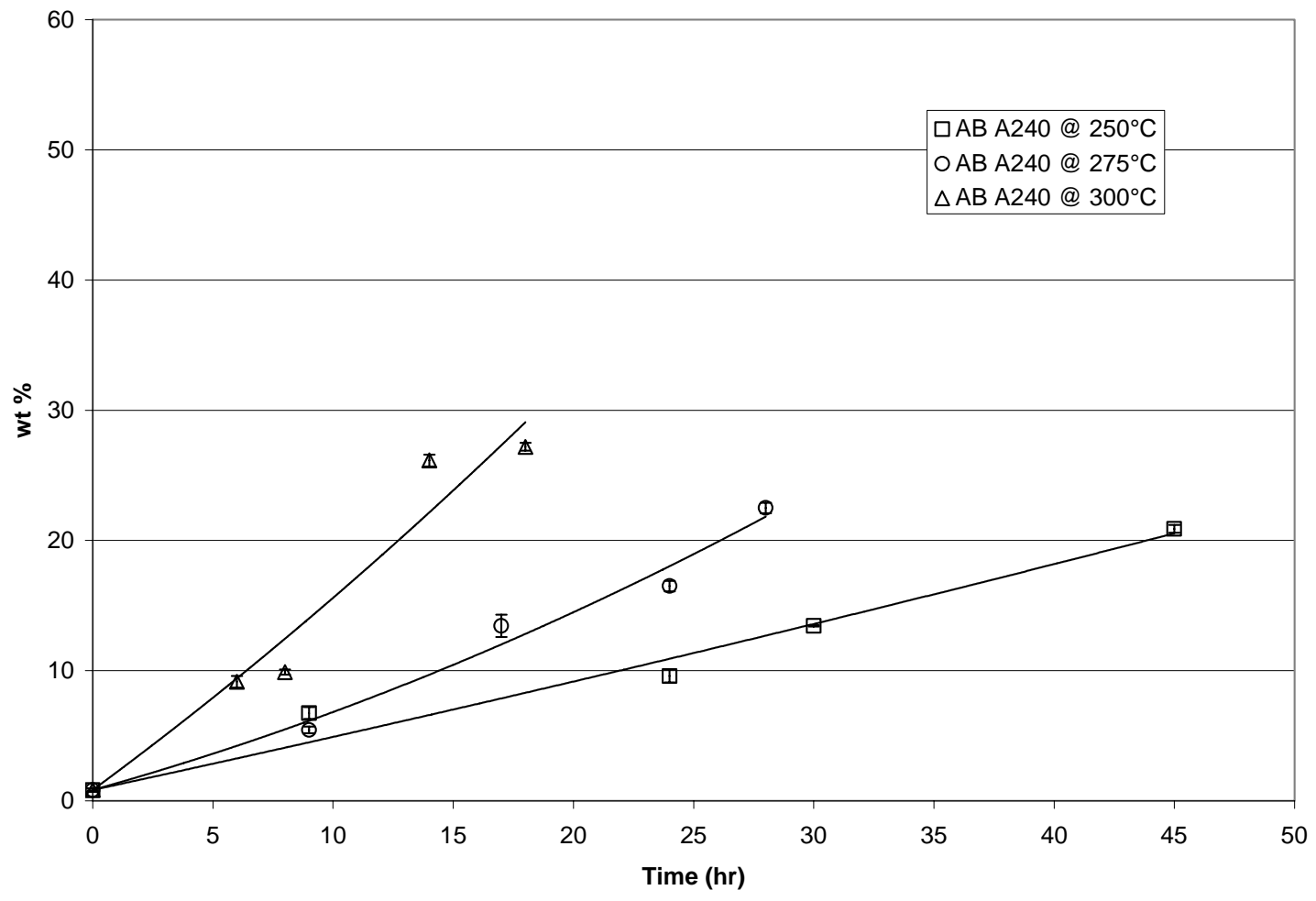

Figure 4.14: Pyridine insoluble content of A240 petroleum pitch

Figure 4.15 shows the effects of air-blowing the coal-tar pitch. These results are different from the A240 results in that the PI content first rapidly increases then appear to reach an asymptotical value. 


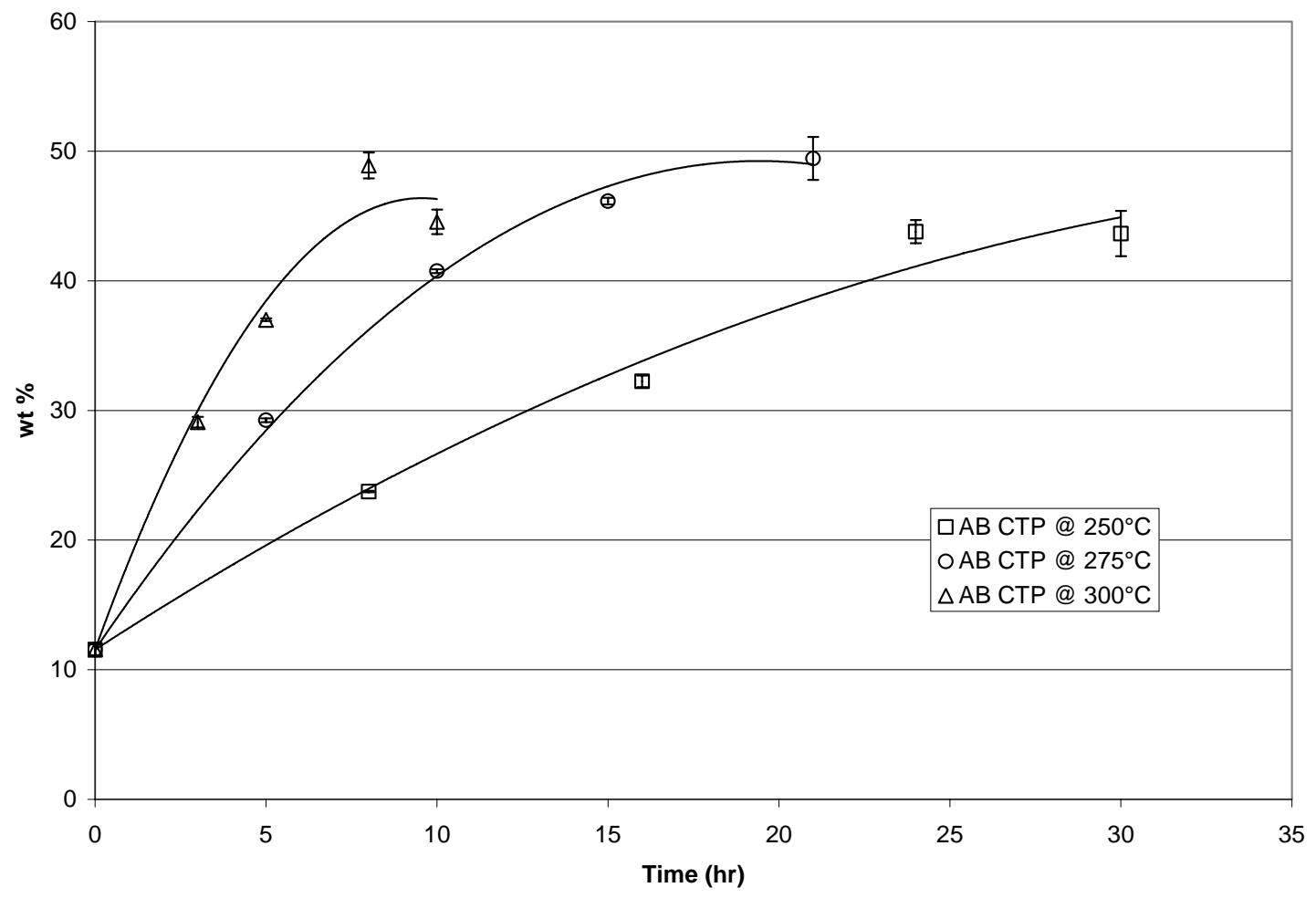

Figure 4.15: Pyridine insoluble content of Koppers coal-tar pitch

On the otherhand, the air-blown coal-extract pitches generated PI much more rapidly than the other two materials, as can be seen by comparing the time axis in Figure 4.16. 


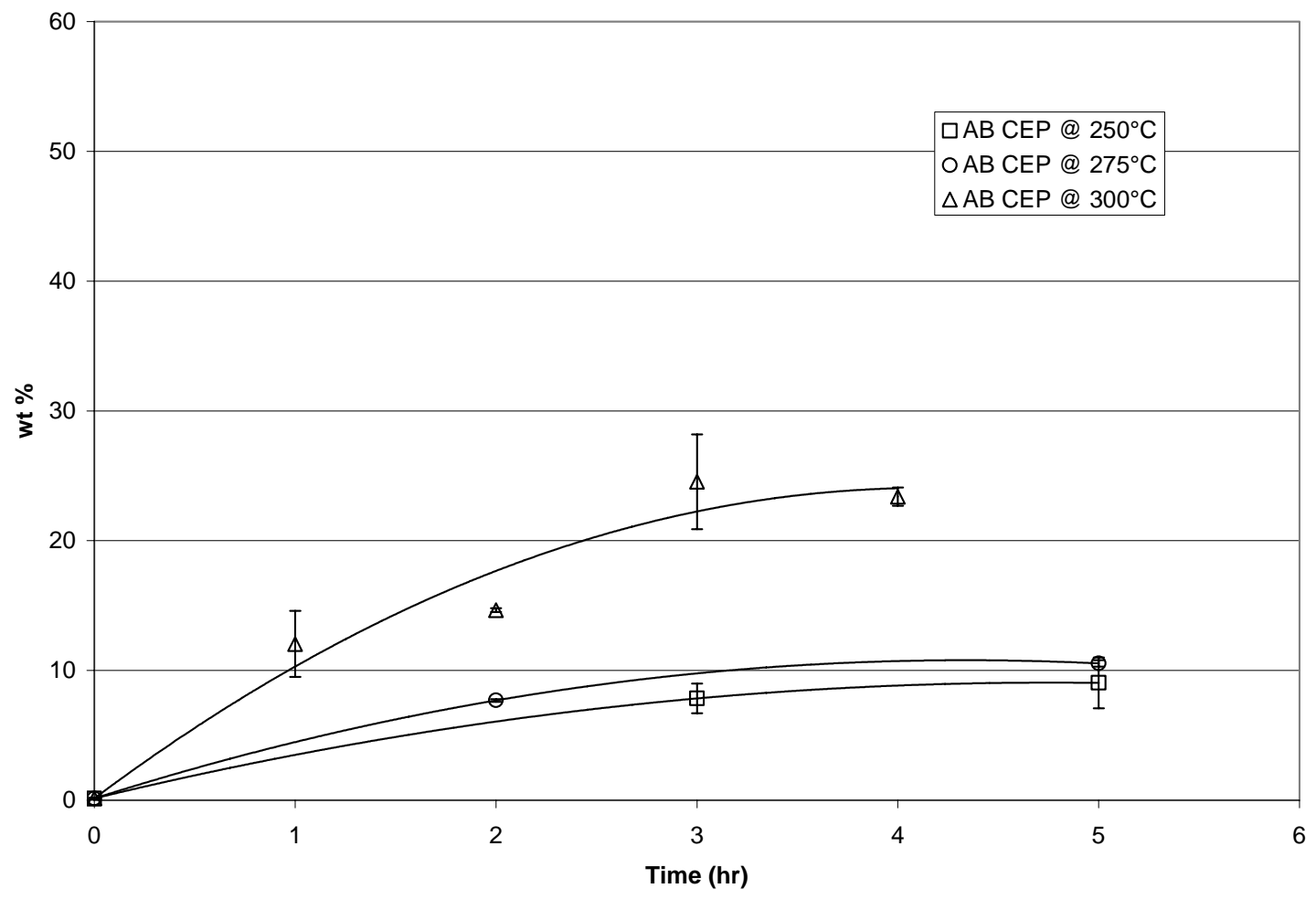

Figure 4.16: Pyridine insoluble content of WVU coal-extract pitch

\subsection{Chemical Changes/Mechanisms}

\subsubsection{Kinetic Modeling}

Kinetic modeling of the pitches being air-blown was done using a simplified chemical equation shown below.

$$
1 / 2 \mathrm{O}_{2}+2 \mathrm{~A}-\mathrm{H} \stackrel{k}{\longrightarrow} \mathrm{B}+\mathrm{H}_{2} \mathrm{O}
$$

This equation shows what possibly occurred during the heat treatment of the pitches when air was blown into the pitch. Notice in the equation that the oxygen from the air is not incorporated in the end product of the air-blown pitch, B. Instead the oxygen combines with the hydrogen from the aromatic pitch molecule, A-H, and forms water 
which exits the reactor in the form of steam. From equation 4.2, a kinetic equation can be determined assuming second order kinetics. This equation can be seen below as:

$$
-\frac{d[A-H]}{d t}=k[A-H]^{2}
$$

This equation was integrated from PI wt $\% \mathrm{~A}_{\mathrm{O}}$ to $\mathrm{A}$ and from time $0 \mathrm{hr}$ to each treatment time. Through integration and rearranging the equation becomes:

$$
\frac{1}{[A]}=k t+\frac{1}{\left[A_{0}\right]}
$$

The graphs of this equation for each of the three pitches can be seen in Figure 4.17. The slopes of these lines were calculated for the values of the rate constant, k, at each temperature. From the Arrhenius equation shown below, the activation energy for each pitch can be determined using the rate constants calculated above.

$$
\frac{d[\ln k]}{d T}=\frac{E a}{R T^{2}}
$$

This equation above was integrated and rearranged to produce

$$
\ln k=-\frac{E a}{R}\left(\frac{1}{T}\right)+\ln K
$$

The values for the natural $\log$ of the rate constants were plotted on a graph versus the inverse temperature in Kelvin to calculate the activation energies for each pitch. Plots for each pitch can be seen in Figure 4.18 while the values of the activation energies can be seen in Table 4.2.

Table 4.2: Activation energies for the air-blowing of three types of pitches

\begin{tabular}{|c|c|c|c|c|}
\cline { 2 - 5 } \multicolumn{1}{c|}{} & $\ln \mathrm{K}$ & $\mathrm{K}(1 / \mathrm{hr})$ & $-\mathrm{Ea} / \mathrm{R}$ & $\begin{array}{c}\mathrm{Ea} \\
(\mathrm{kcal} / \mathrm{mole})\end{array}$ \\
\hline A240 & 10.2 & 27694.8 & -8133.6 & 16.2 \\
\hline CTP & 10.4 & 32305.7 & -7559.8 & 15.0 \\
\hline CEP & 11.8 & 134995.9 & -8271.2 & 16.4 \\
\hline
\end{tabular}



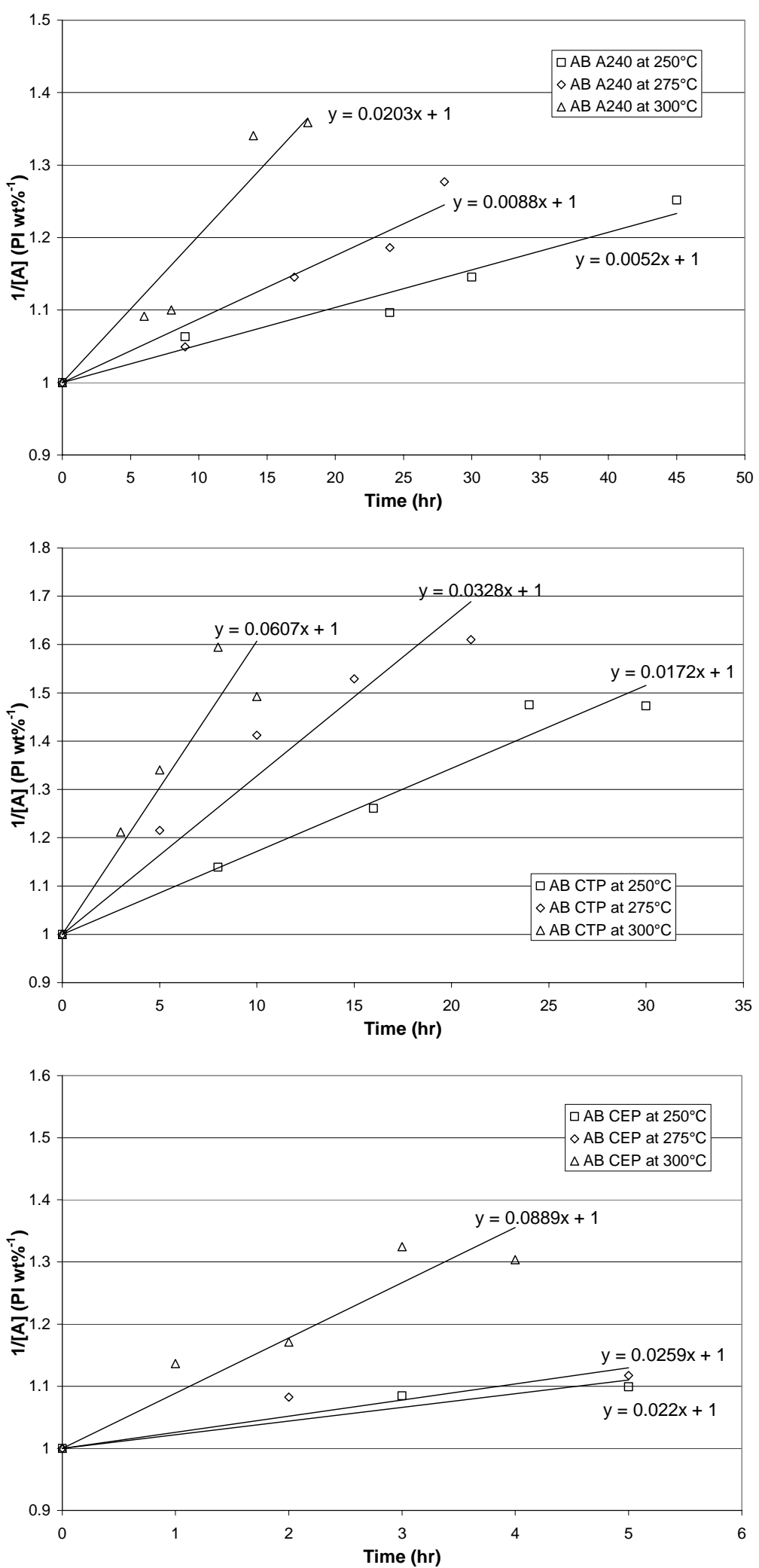

Figure 4.17: Rate constant data for the air-blowing kinetics of petroleum pitch A240, coal-tar pitch, and coal-extract pitch 


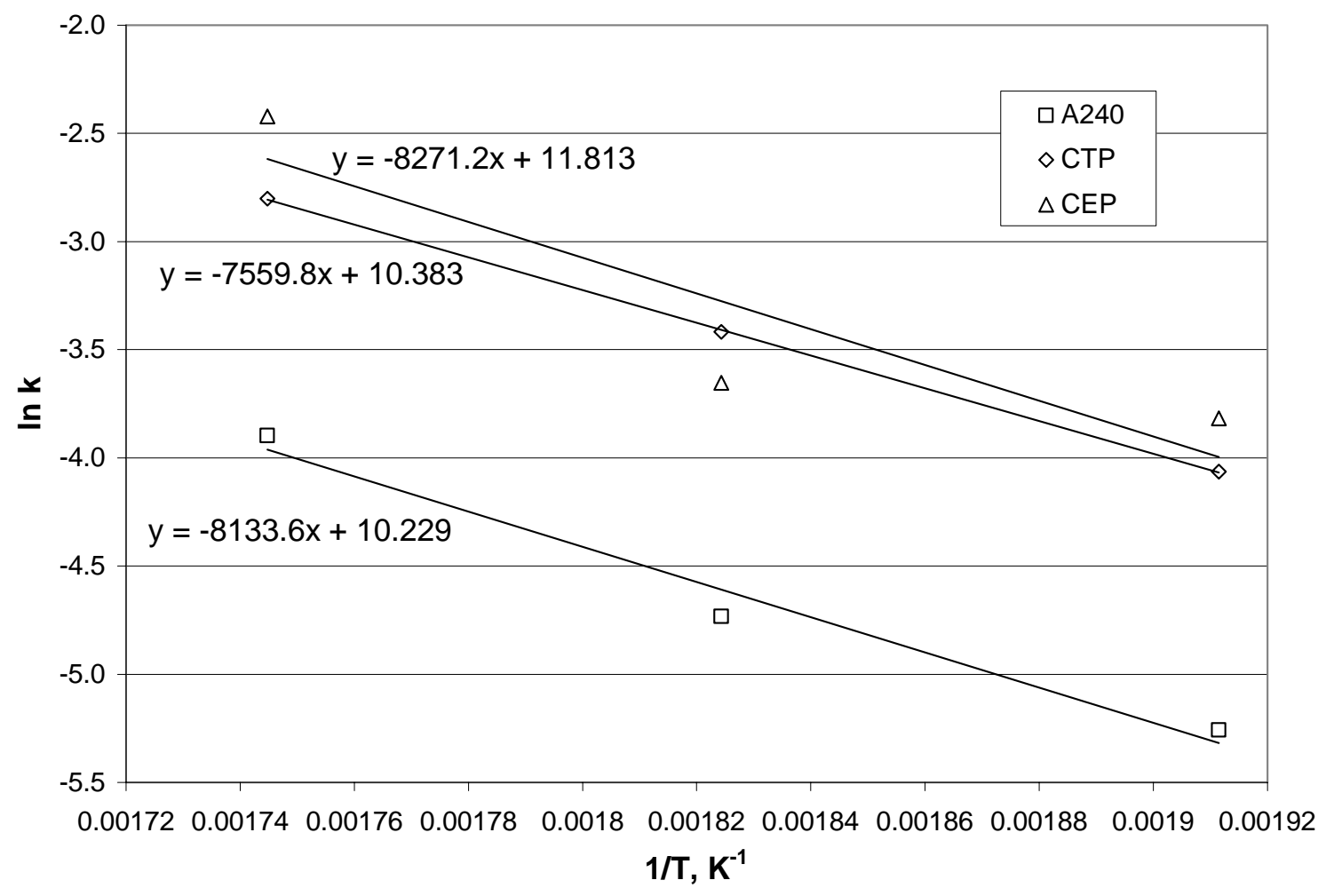

Figure 4.18: Activation Energies for the air-blowing of petroleum pitch A240, coaltar pitch, and coal-extract pitch

\subsubsection{Thermogravimetric Analysis}

The TGA analysis was conducted on all of the feed and air-blown pitches. Figure 4.19 shows the weight loss of the A240 feed and air-blown pitches at the various times for the temperatures of $250^{\circ} \mathrm{C}, 275^{\circ} \mathrm{C}$, and $300^{\circ} \mathrm{C}$. In this plot, it can be seen that the weight loss of the pitches significantly increases starting at about $250^{\circ} \mathrm{C}$ until about $550^{\circ} \mathrm{C}$. After $550^{\circ} \mathrm{C}$, the rate of weight loss begins to decrease until $900^{\circ} \mathrm{C}$ was reached. From this it can be concluded that majority of the volatile content was removed when the temperature reaches $550^{\circ} \mathrm{C}$. 
Figure 4.20 shows the weight loss of the coal-tar pitches air-blown at the various times for the temperatures of $250^{\circ} \mathrm{C}, 275^{\circ} \mathrm{C}$, and $300^{\circ} \mathrm{C}$. In this plot, it can be seen that the weight loss of the pitches significantly increases starting at about $300^{\circ} \mathrm{C}$ until about $575^{\circ} \mathrm{C}$. After $575^{\circ} \mathrm{C}$, the rate of weight loss begins to decrease until $900^{\circ} \mathrm{C}$. From this it can be concluded that majority of the volatile content was removed when the temperature reaches $575^{\circ} \mathrm{C}$.

Figure 4.21 shows the weight loss of the coal-extract pitches air-blown at the various times for the temperatures of $250^{\circ} \mathrm{C}, 275^{\circ} \mathrm{C}$, and $300^{\circ} \mathrm{C}$. In this plot, it can be seen that the weight loss of the pitches significantly increases starting at about $200^{\circ} \mathrm{C}$ until about $525^{\circ} \mathrm{C}$. After $525^{\circ} \mathrm{C}$, the rate of weight loss begins to decrease until $900^{\circ} \mathrm{C}$. From this it can be concluded that majority of the volatile content was removed when the temperature reaches $525^{\circ} \mathrm{C}$. 

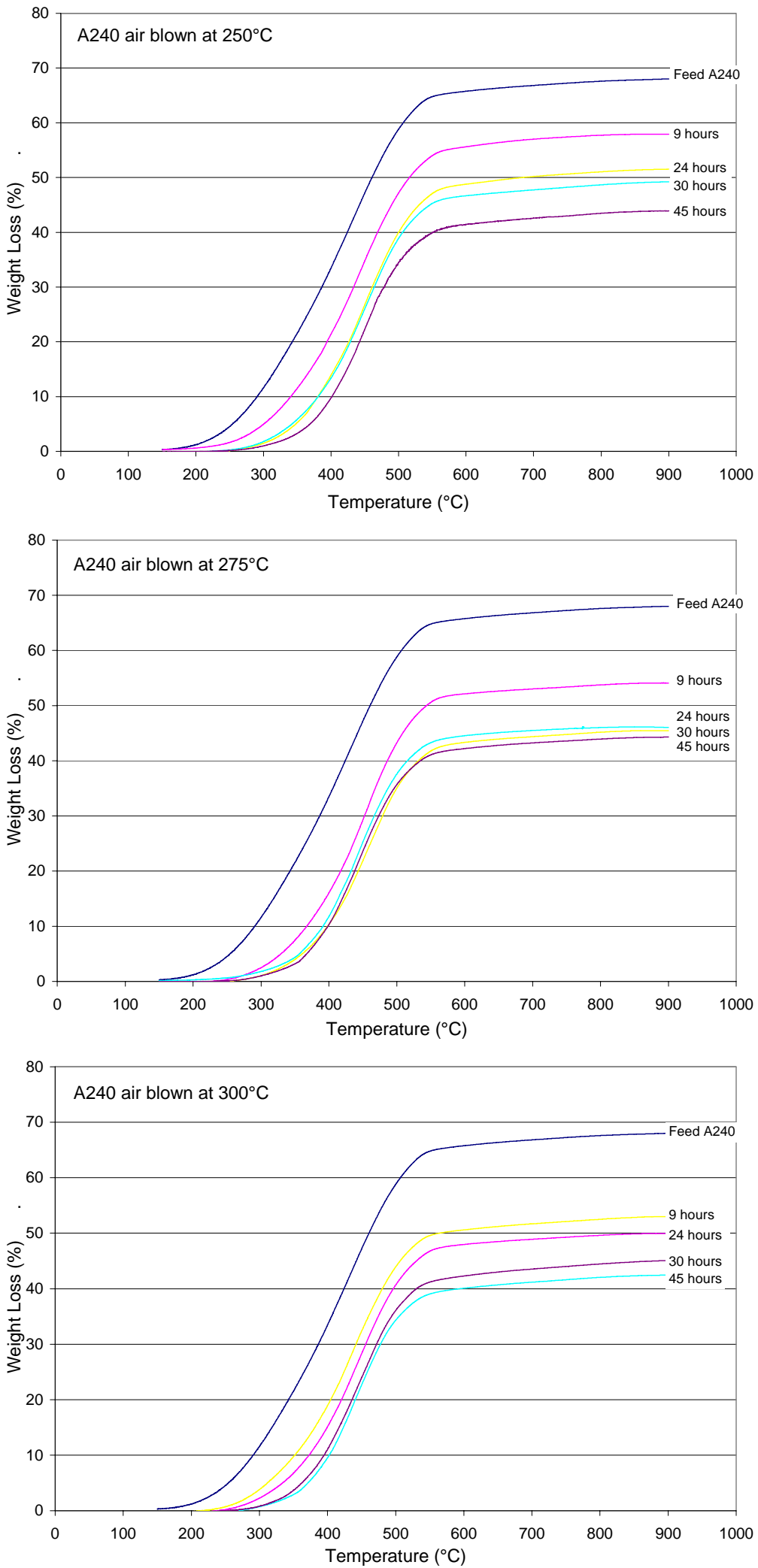

Figure 4.19: Petroleum pitch weight loss for air-blowing at $250^{\circ} \mathrm{C}, 275^{\circ} \mathrm{C}$, and $300^{\circ} \mathrm{C}$ 

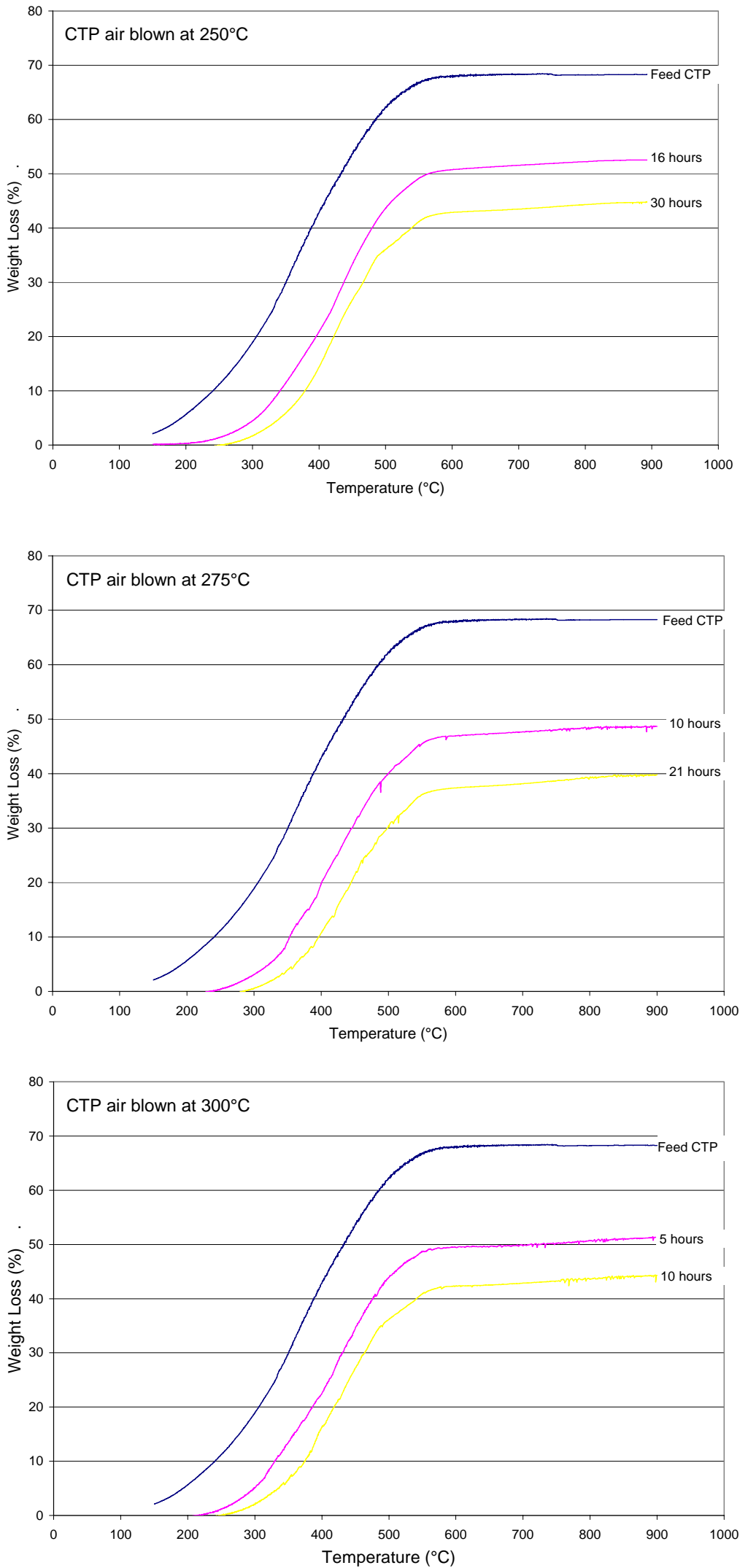

Figure 4.20: Coal-tar pitch weight loss for air-blowing at $250^{\circ} \mathrm{C}, 275^{\circ} \mathrm{C}$, and $300^{\circ} \mathrm{C}$ 

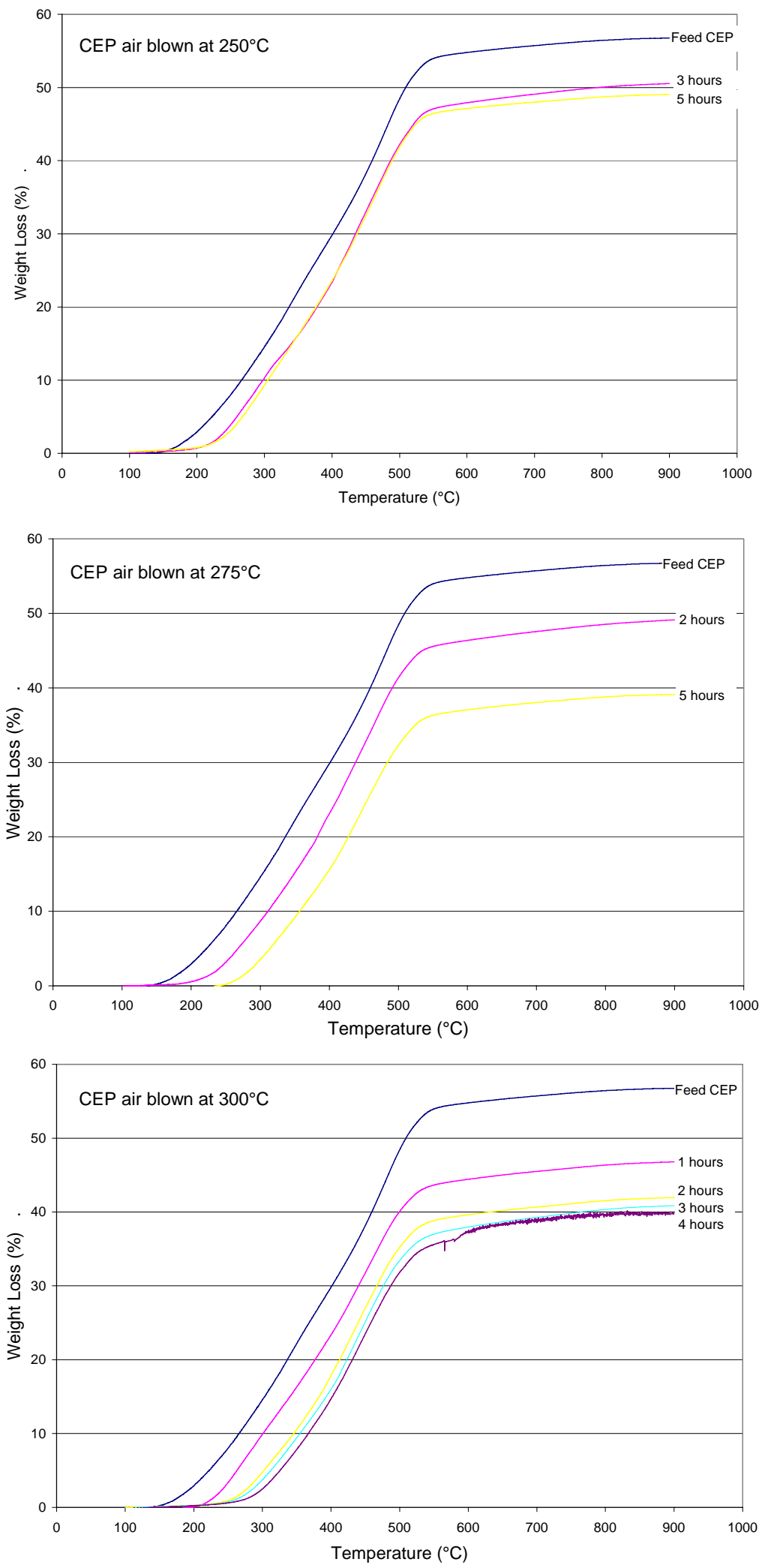

Figure 4.21: Coal-extract weight loss for air-blowing at $250^{\circ} \mathrm{C}, 275^{\circ} \mathrm{C}$, and $300^{\circ} \mathrm{C}$ 
Another way of looking at the TGA data is showing the volatile fraction remaining in the pitch. Figure 4.22 shows the volatile fraction of the pitch after being heated from room temperature to $900^{\circ} \mathrm{C}$. This shows a sharp decline in the amount of volatile matter from approximately $250^{\circ} \mathrm{C}$ of the heating process up to approximately $550^{\circ} \mathrm{C}$. After $550^{\circ} \mathrm{C}$, the volatile fraction of the pitches begins to decrease and approach zero. It is important to note that all of the runs for the A240 end at the same point, implying the reaction mechanism is similar for the A240 pitch at each temperature and time.

The volatile fraction remaining in the coal-tar pitch after being heated from room temperature to $900^{\circ} \mathrm{C}$ is shown in Figure 4.23. This shows a sharp decline in the amount of volatile matter from approximately $300^{\circ} \mathrm{C}$ of the heating process up to about $575^{\circ} \mathrm{C}$. After $575^{\circ} \mathrm{C}$, the volatile fraction of the pitches begins to decrease and approach zero. As well as with the A240 pitch, it is important to note that all of the runs for the coal-tar pitch end at the same point. This shows that the reactions occurring in the coal-tar pitch for all times and temperatures are similar. Although, this does not imply that petroleum pitch and coal-tar pitch are going through similar reaction mechanisms and could be very different from each other due to the structural differences making up the pitches.

The volatile fraction remaining in the coal-extract pitch after being heated from room temperature to $900^{\circ} \mathrm{C}$ is shown in Figure 4.24. This shows a sharp decline in the amount of volatile matter from approximately $200^{\circ} \mathrm{C}$ of the heating process up to approximately $525^{\circ} \mathrm{C}$. After $525^{\circ} \mathrm{C}$, the volatile fraction of the pitches begins to decrease and approach zero. It is important to note that at each temperature the runs converge upon one point. Like the petroleum and coal-tar pitch, this indicates that a related 
mechanism is occurring in each of the air-blown runs of coal-extract pitch. As mentioned before, this does not indicate a similar mechanism between this pitch and the other two since they contain many structural differences. This just simply implies that each pitch has one similar reaction mechanism occurring during the air-blowing of each run period. 

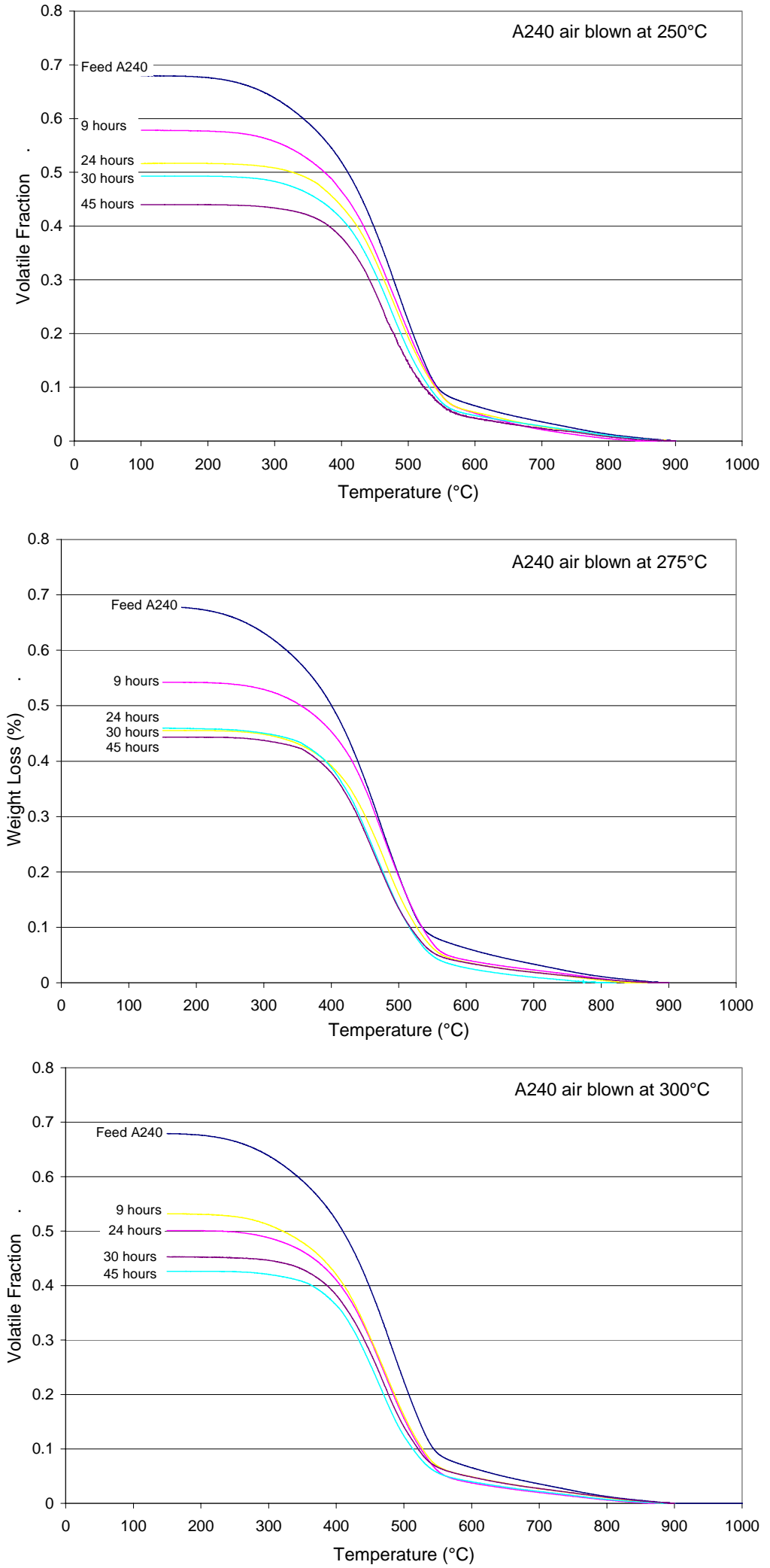

Figure 4.22: Volatile fraction remaining for $\mathrm{AB} A 240$ at $250^{\circ} \mathrm{C}, 275^{\circ} \mathrm{C}$, and $300^{\circ} \mathrm{C}$ 

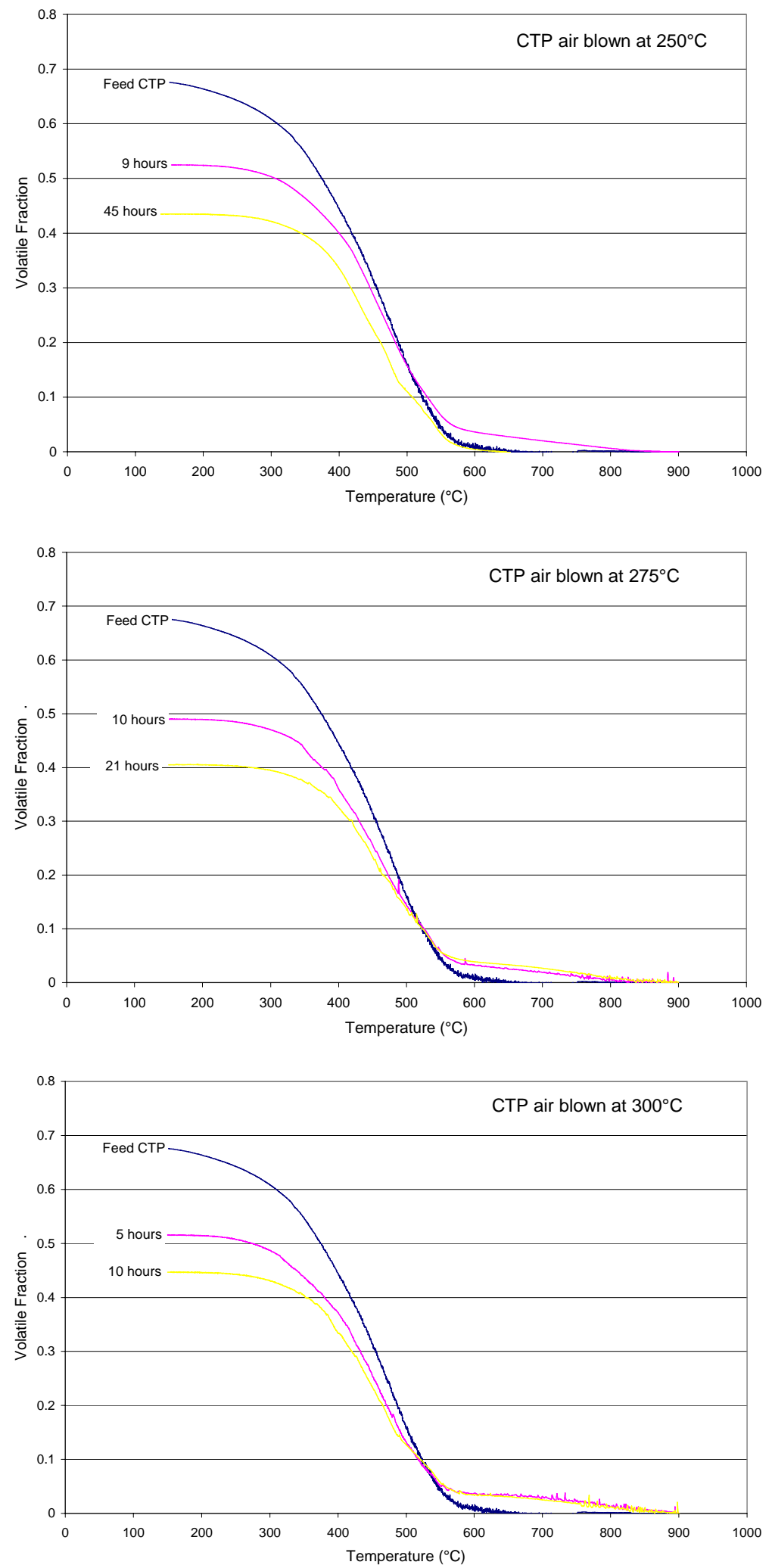

Figure 4.23: Volatile fraction remaining for $\mathrm{AB} C \mathrm{CTP}$ at $250^{\circ} \mathrm{C}, 275^{\circ} \mathrm{C}$, and $300^{\circ} \mathrm{C}$ 

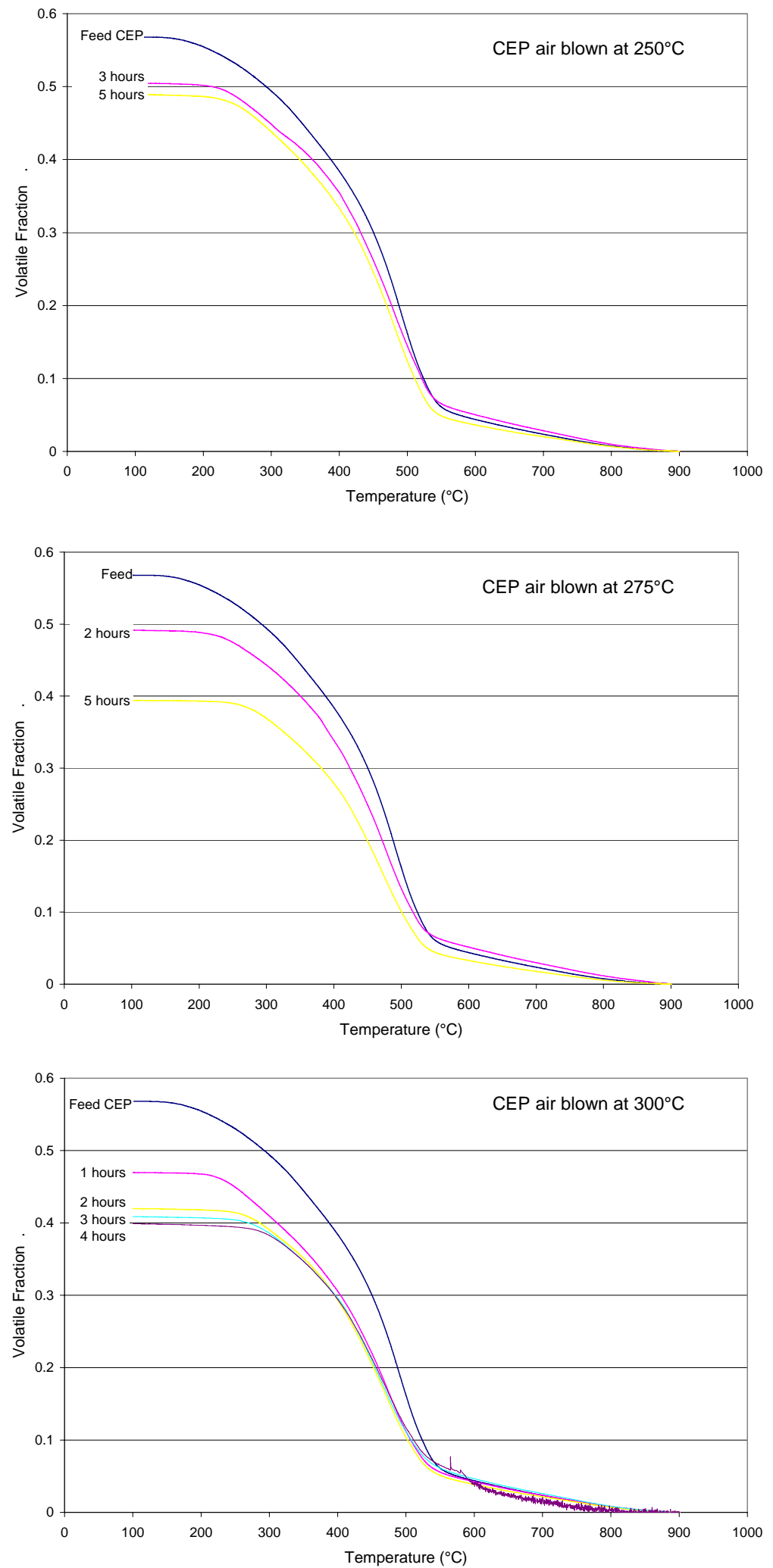

Figure 4.24: Volatile fraction for $\mathrm{AB}$ Coal-extract at $250^{\circ} \mathrm{C}, 275^{\circ} \mathrm{C}$, and $300^{\circ} \mathrm{C}$ 
It can be seen that as the feed pitches were air-blown, less material is removed when heated in the TGA. This concurs with the literature reviewed and shows that airblowing is indeed an effective way to polymerize the smaller molecular chains in the pitches. Increasing the overall molecular weight results in less volatility. Also, since the volatile fraction plots converge to a constant value, it can be inferred that a similar chemistry or mechanism is associated with the air-blowing process for each individual feed.

\subsubsection{Elemental Analysis and van Krevelen Plots}

An elemental analysis on the pitches can provide insight into the mechanisms of air-blowing. The carbon-to-hydrogen $(\mathrm{C} / \mathrm{H})$ atomic ratio increased for the petroleum pitch, as can be seen in Figure 4.25, while the higher treatment temperatures had a greater increase at a significantly less time. The trends suggest two possible mechanisms. First, an increase in carbon content is possible or, second, a decrease in hydrogen content occurred. Either result will lead to an increase in the $\mathrm{C} / \mathrm{H}$ atomic ratio. However, the literature suggests the latter effect is more probable. 


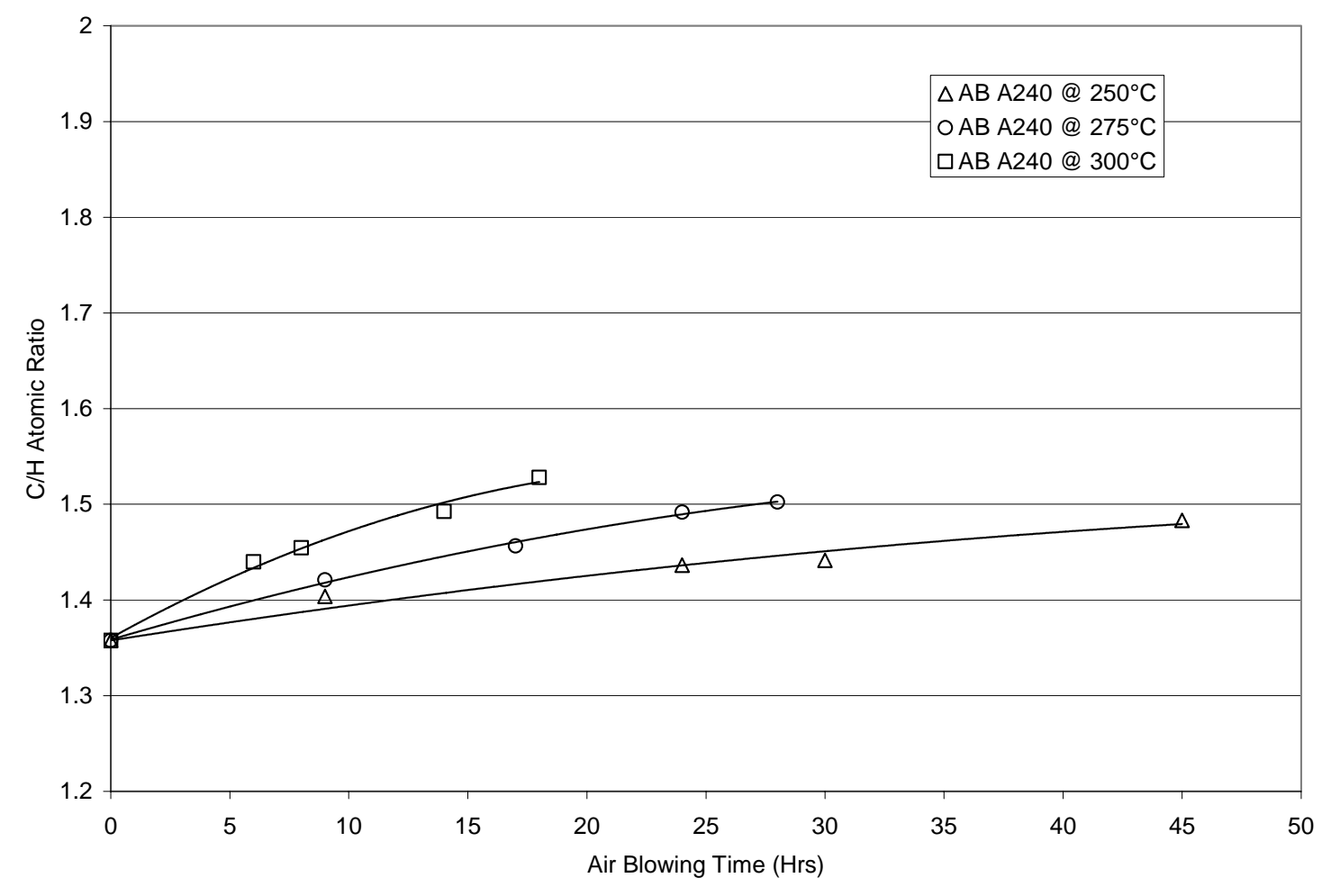

Figure 4.25: C-H Atomic Ratio vs AB Time A240

As with the petroleum pitch, the carbon-to-hydrogen $(\mathrm{C} / \mathrm{H})$ atomic ratio increased in the coal-tar pitch, as can be seen in Figure 4.26. The coal-tar pitch also showed that at the higher treatment temperatures, the $\mathrm{C} / \mathrm{H}$ increased at a significantly less time. Even though there was an increase in the $\mathrm{C} / \mathrm{H}$, the largest change was from about 1.6 to 1.9 from the feed pitch to the 10 hour air-blown pitch at $300^{\circ} \mathrm{C}$. 


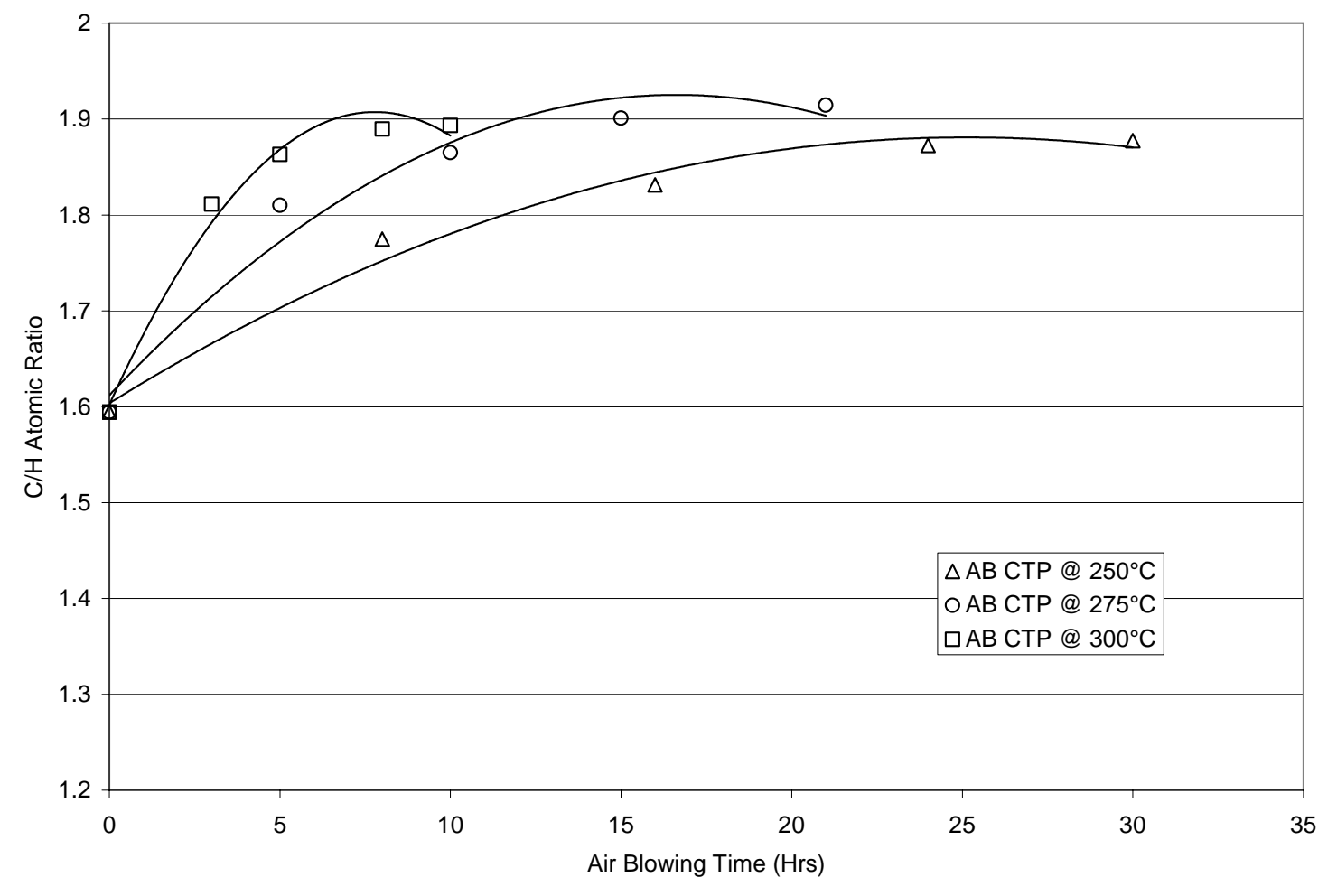

Figure 4.26: C-H Atomic Ratio vs AB Time CTP

The carbon-to-hydrogen $(\mathrm{C} / \mathrm{H})$ atomic ratio also increased in the coal-extract pitch, as can be seen in Figure 4.27, while the higher treatment temperatures had an increase at a significantly less time. Even though there was an increase in the $\mathrm{C} / \mathrm{H}$, the largest change was about $0.2 \%$ for the feed pitch to the 18 hour air-blown pitch at $300^{\circ} \mathrm{C}$, and never increased over $1.5 \%$. This signifies that a very small change is occurring in the $\mathrm{C} / \mathrm{H}$ atomic ratio when the pitch is air-blown. 


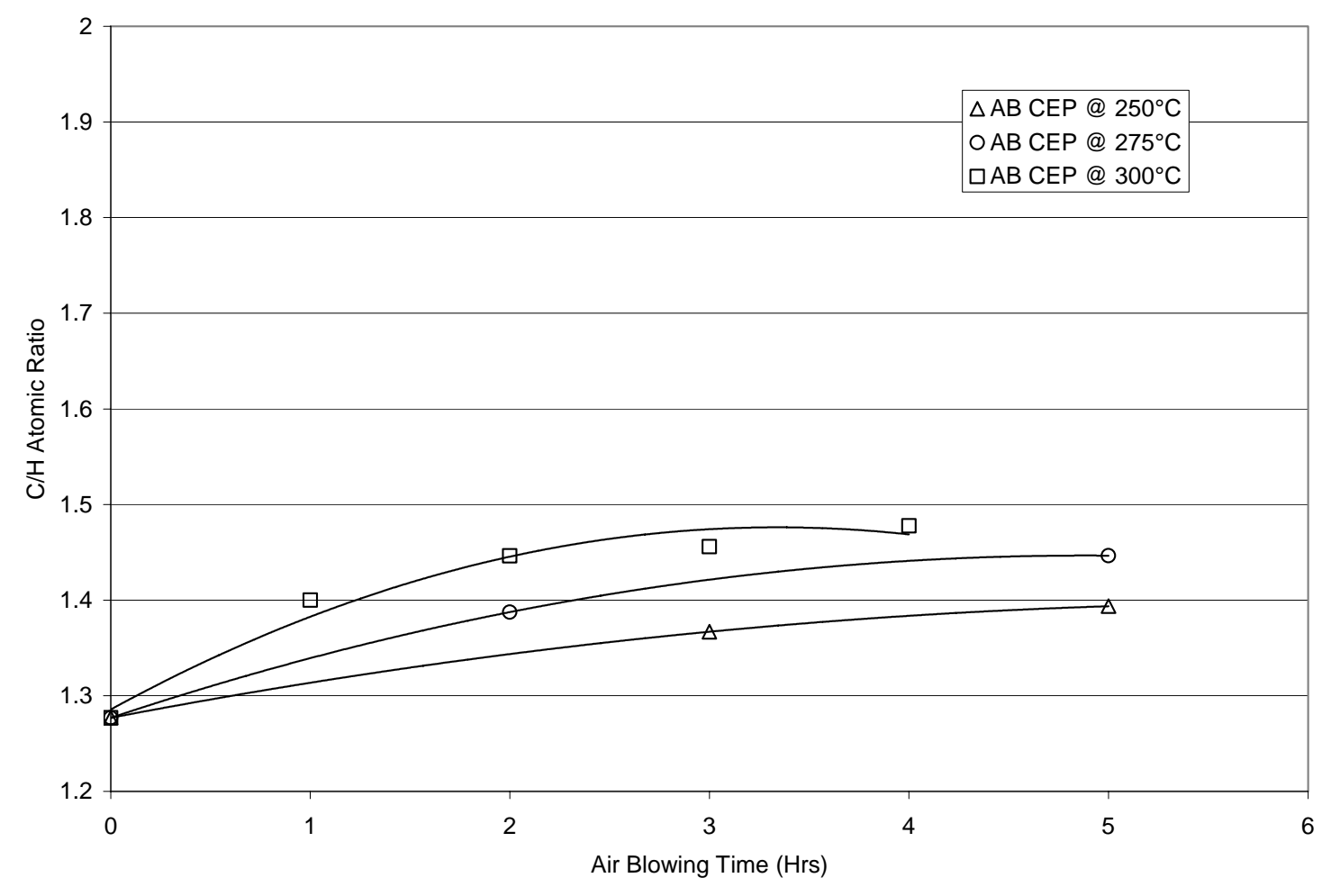

Figure 4.27: C-H Atomic Ratio versus air-blown time for coal-extract

Along with the $\mathrm{C} / \mathrm{H}$ ratio increasing in the petroleum pitches, the oxygen content of the pitches was increased slightly, as can be seen in Figure 4.28. The largest percentage change in oxygen was $0.5 \%$ while still remaining under $1 \%$ of total oxygen content. This small increase indicated that the pitch does not significantly pick up a great deal of oxygen during the air-blowing process. This shows that the oxygen is not significantly incorporated into the pitch products. 


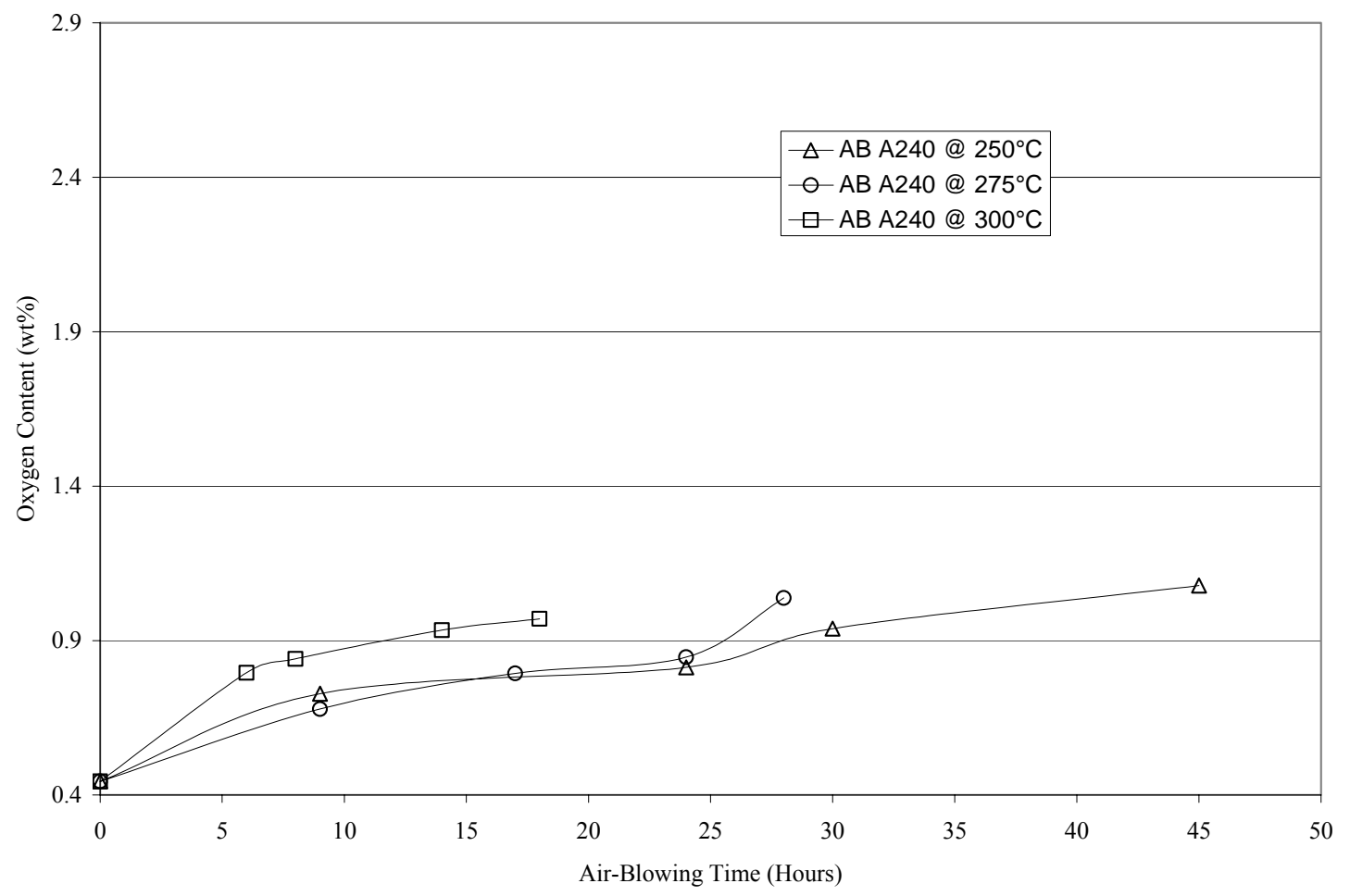

Figure 4.28: Oxygen content for air-blown petroleum pitch

Along with the petroleum pitch, the oxygen content in the coal-tar pitches was for the most part increased after an initial decrease. The initial decrease was more than likely associated with the removal of the small amount of volatile components through distillation. This can be seen in Figure 4.29, where the largest percentage change in oxygen was less than $0.25 \%$ while still remaining under $1 \%$ of total oxygen content. As for the petroleum pitch, this small increase indicates that the pitch did not significantly pick up a great deal of oxygen during the air-blowing process. 


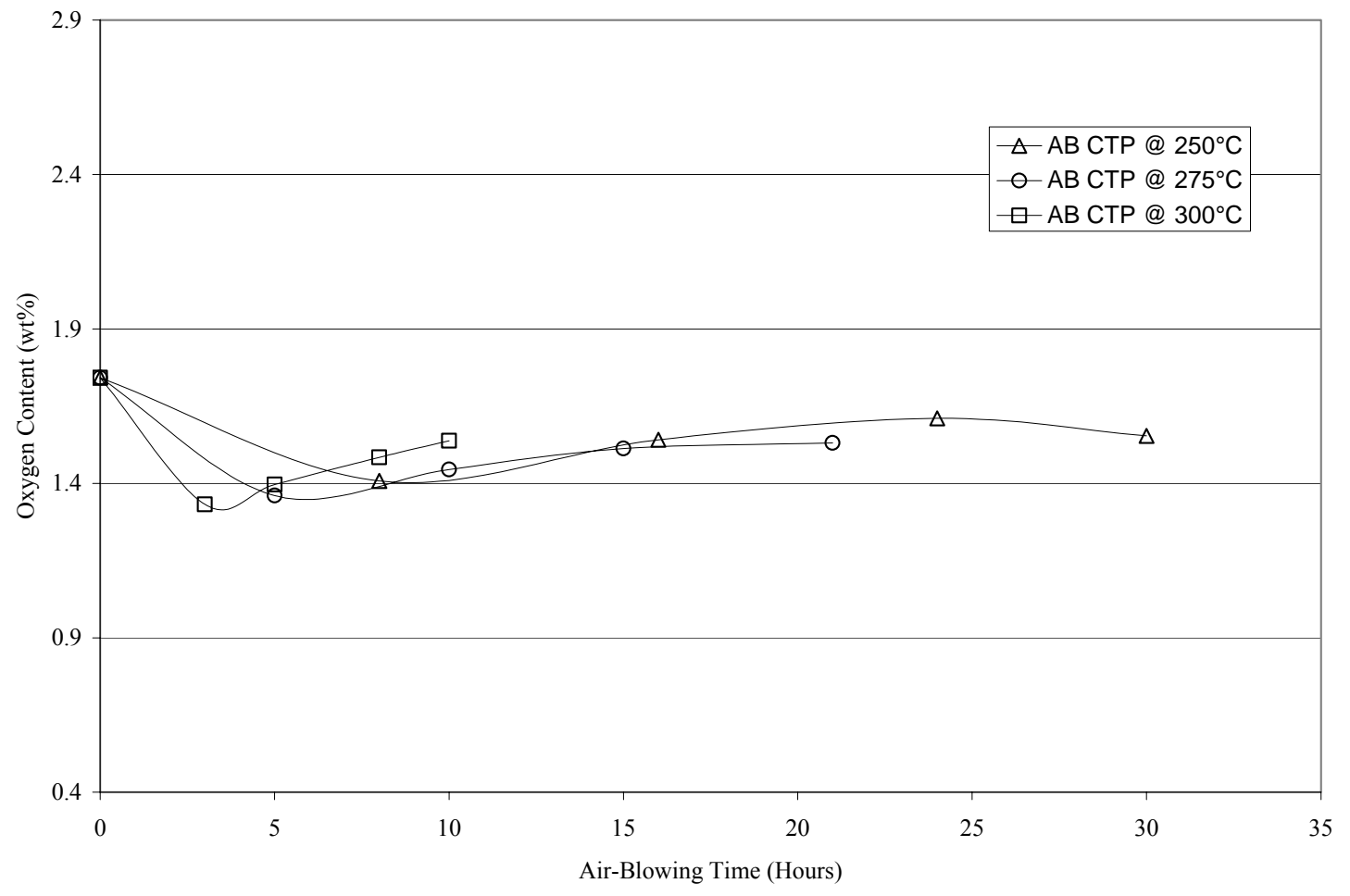

Figure 4.29: Oxygen content for air-blown coal-tar pitch

There was a decrease in the oxygen content of the coal-extract pitch initially, probably because of some distillation, as can be seen in Figure 4.30. The change was less than $0.25 \%$. This small decrease strongly emphasizes the point that the pitch does not significantly pick up a great deal of oxygen during the air-blowing process. Therefore, the assumption of the oxygen not being incorporated into the pitch is justified. 


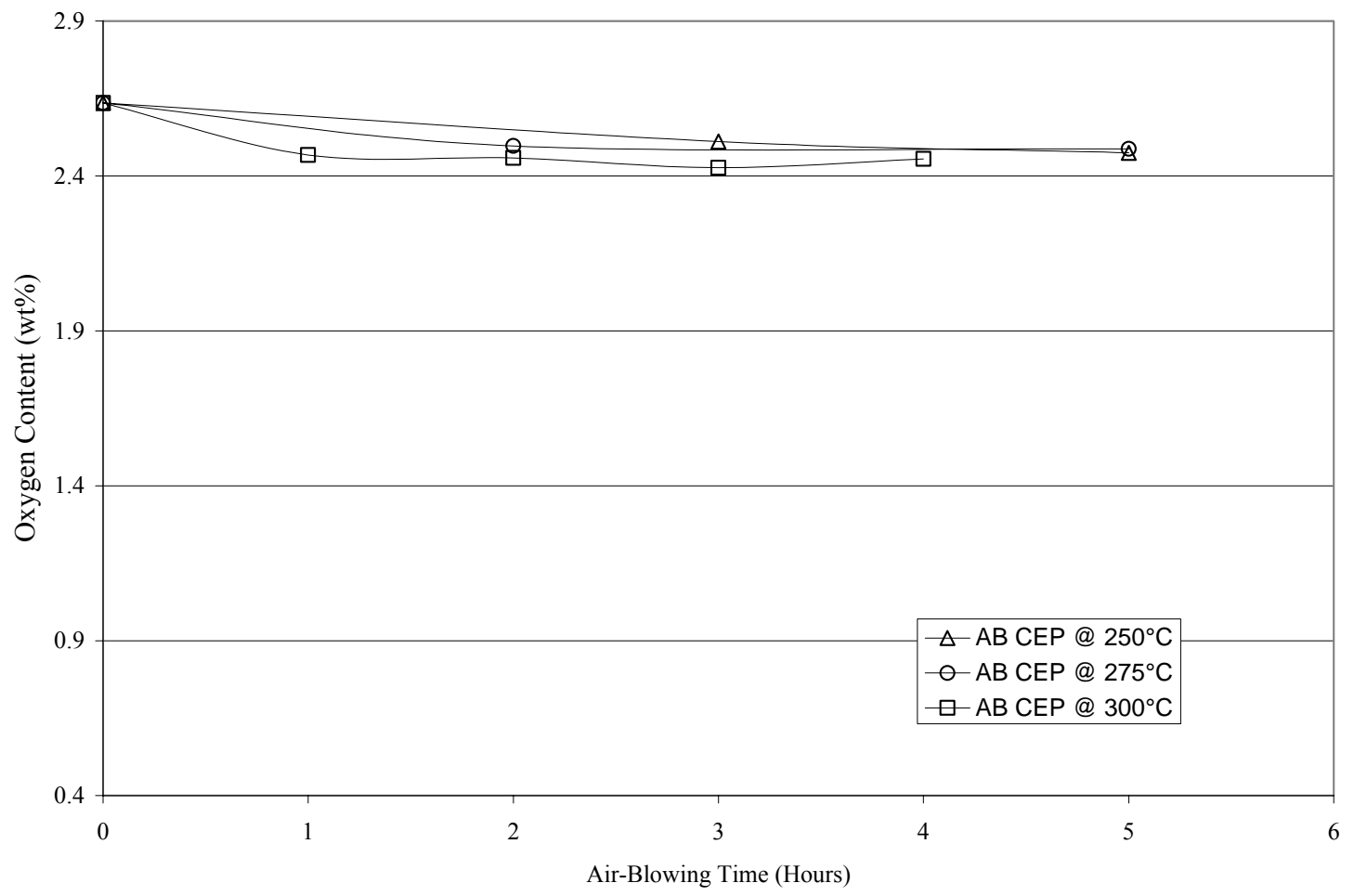

Figure 4.30: Oxygen content for air-blown coal-extract pitch

van Krevelen plots were constructed to provide insight into the types of mechanisms occurring in the pitch when air blown. The mechanisms that were possible during the air-blowing process could include dehydroxylation, dealkylation, as well as other possible pathways. With the data from the feed pitches and the subsequent airblown pitches plotted, a mechanism can be postulated for each pitch. A graph of possible mechanisms can be seen below in Figure 4.31. 


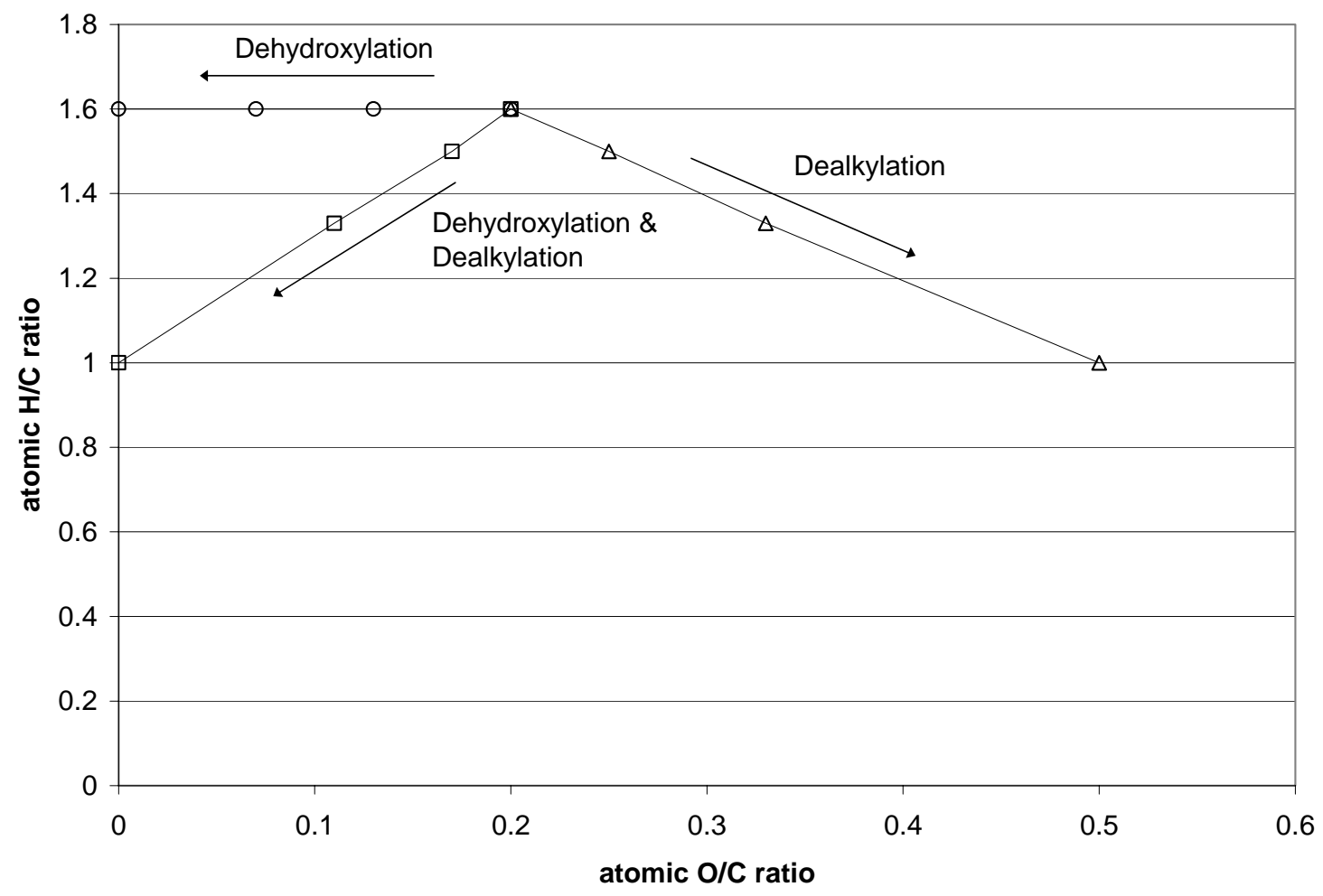

Figure 4.31: Typical van Krevelen plot

The van Krevelen plot for the petroleum pitch can be seen in Figure 4.32. From this plot, it is apparent that a dealkylation type of reaction took place during the airblowing of the petroleum pitch. 


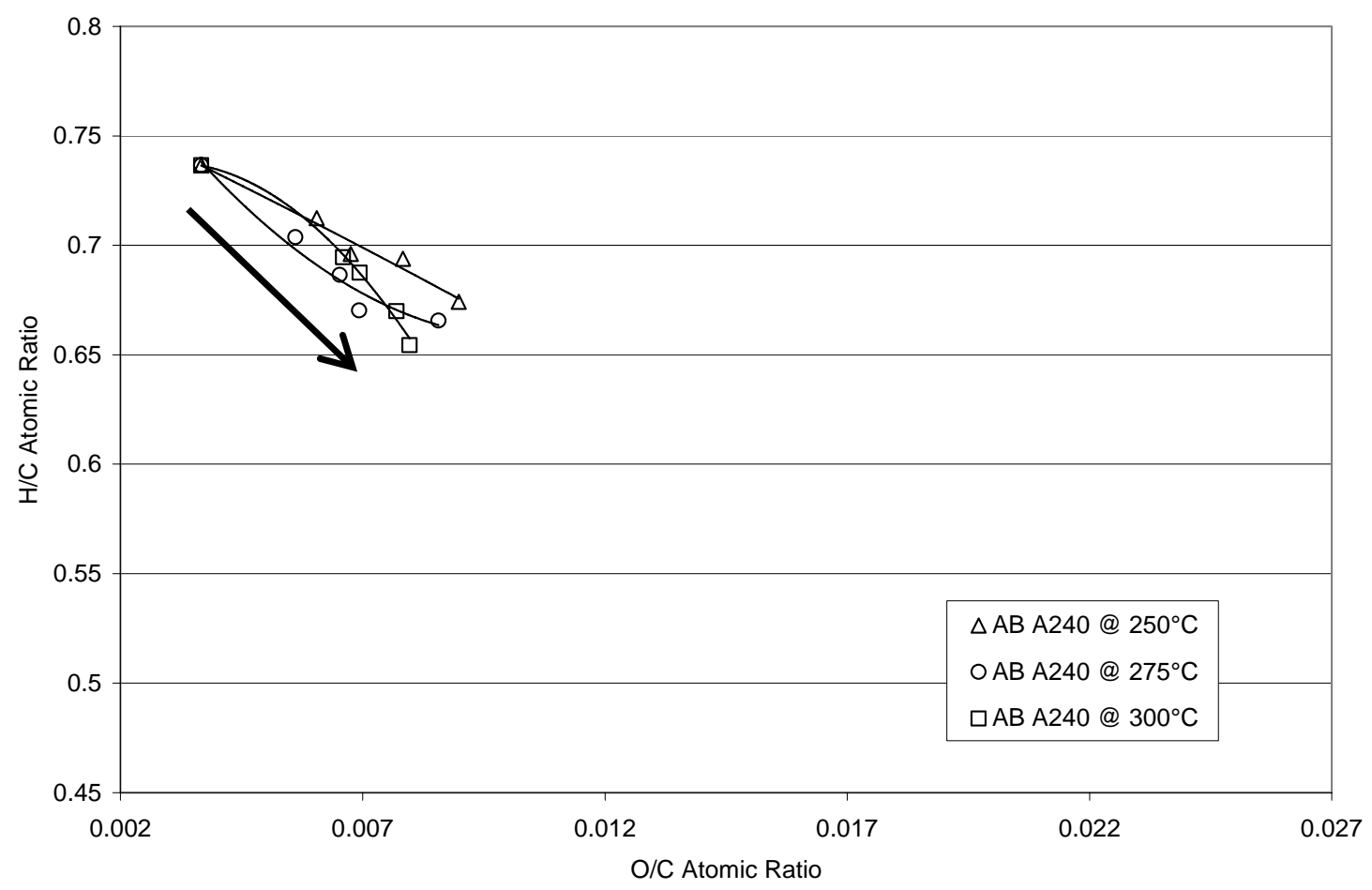

Figure 4.32: van Krevelen plot for A240 petroleum pitch

The van Krevelen plot was also completed on the coal-tar pitch to estimate the types of changes occurring when air-blown, as can be seen in Figure 4.33. The van Krevelen plot for the coal-tar pitch is different from the petroleum pitch. From these data, it shows a combination of dehydroxylation and dealkylation reactions might occur after air-blowing. 


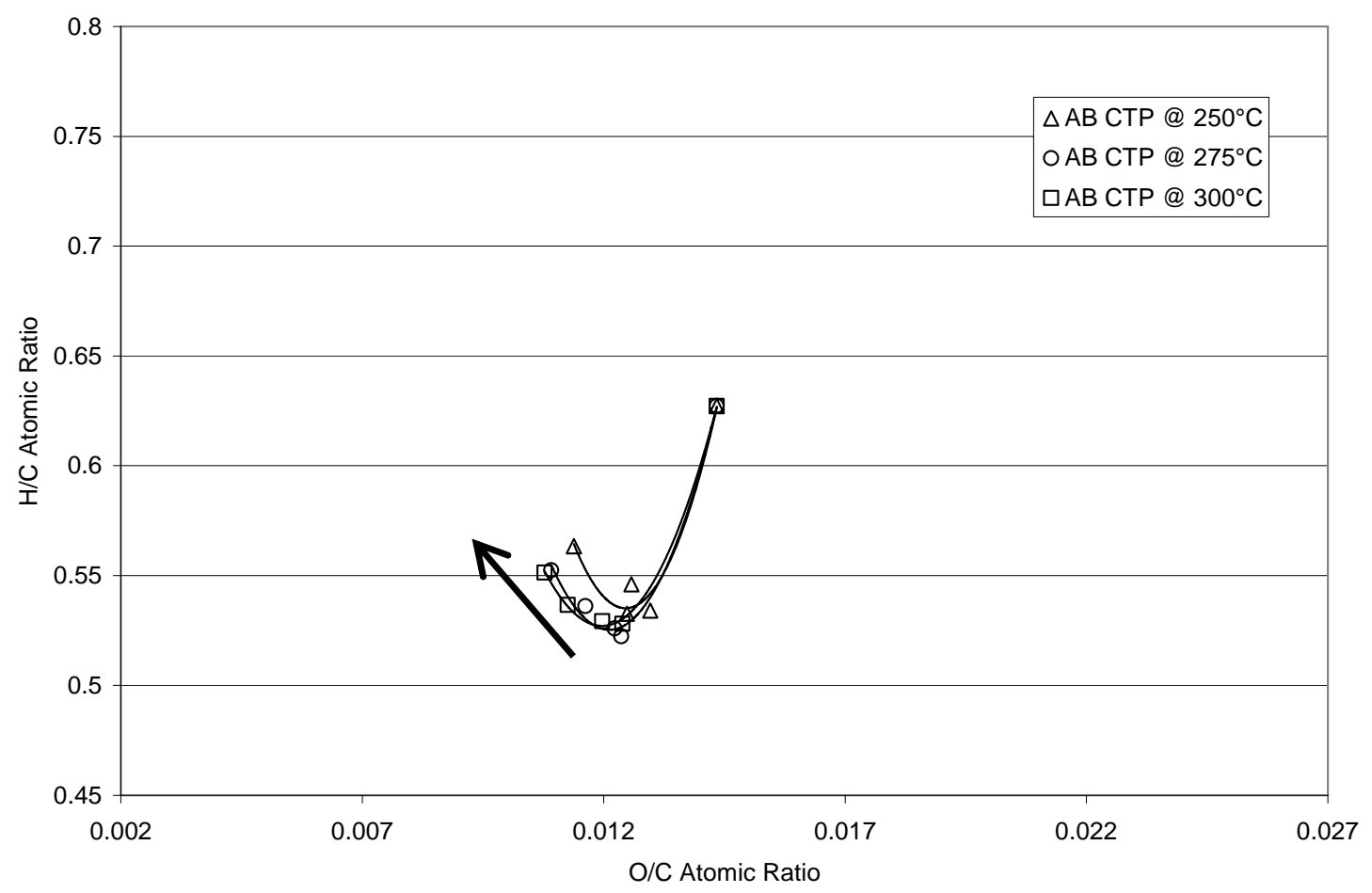

Figure 4.33: van Krevelen plot for coal-tar pitch

The Van Krevelen plot for the coal-extract pitch can be seen in Figure 4.34. The coal-extract pitch exhibits a dehydrogenation mechanism according to this plot. 


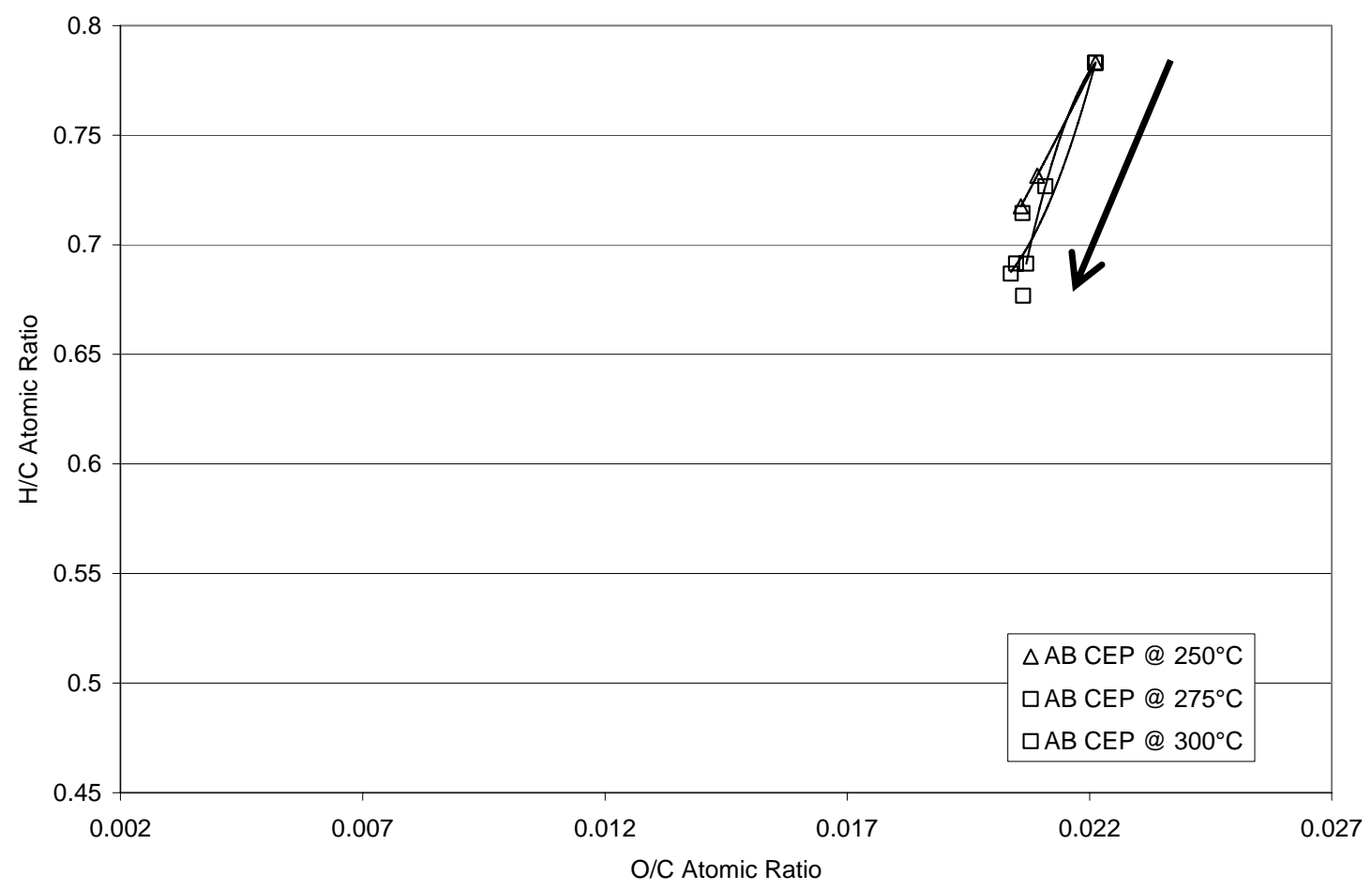

Figure 4.34: van Krevelen plot for coal-extract pitch

From these $\mathrm{C} / \mathrm{H}$ atomic ratio plots of data and the van Krevelen plots it can be seen that each type of pitch reacts by a different type of mechanism. The mechanism occurring in the petroleum pitch appears to be dealkylation, while the coal-tar pitch exhibits both mechanisms of dehydroxylation and dealkylation, and the coal-extract pitch shows evidence of dehydrogenation. Although the van Krevelen diagrams can provide insight in the global reactions occurring during air blowing of pitches, it is significant that the details of the chemistry are dependent on the feed material.

\subsubsection{FTIR}

Some quantitative observations can be made by comparing FTIR results to changes in oxygen content and carbon-to-hydrogen atomic ratio. It should be kept in 
mind that the chemical processes associated with air-blowing and high temperatures, in general, are exceeding complex.

Figures 4.35 through 4.37 make these respective comparisons. The FTIR analysis was developed by integrating the absorbance associated with the aliphatic carbon-hydrogen stretching mode $\left(2900 \mathrm{~cm}^{-1}\right)$ and comparing this to the integrated absorbance associated with the aromatic carbon-carbon "breathing" mode $\left(1600 \mathrm{~cm}^{-1}\right)$. Drbohlav and Stevenson [50] have shown that the breathing mode does not change significantly during the oxidation of pitch and, thus, can be exploited as an in-situ internal standard. It is clearly shown that changes in hydrogen content play an important role during air-blowing and that the $\mathrm{C} / \mathrm{H}$ atomic ratio increases for all of the pitches. The petroleum pitch contains more hydrogen than the other two pitches, and the coal-tar pitch is the most aromatic. It is also clear that the incorporation of oxygen into the product is minimal. The FTIR spectral interpretation indicates that aliphatic groups are more prevalent in the A240 pitch and that these types of functionality decrease dramatically with the progression of air-blowing, in accordance with changes in $\mathrm{C} / \mathrm{H}$ atomic. Also, since it is known that coal-tar pitch contains very few aliphatic side chains (primarily methyl), the changes in $\mathrm{C} / \mathrm{H}$ atomic ratio must be attributed to reactions not related to these groups, as indicated by the FTIR. These reactions probably take place at hydrogen directly attached to aromatic rings, as supported by the FTIR data. The changes associated with the coal-extract pitch are generally between those of the petroleum and coal-tar pitches. 

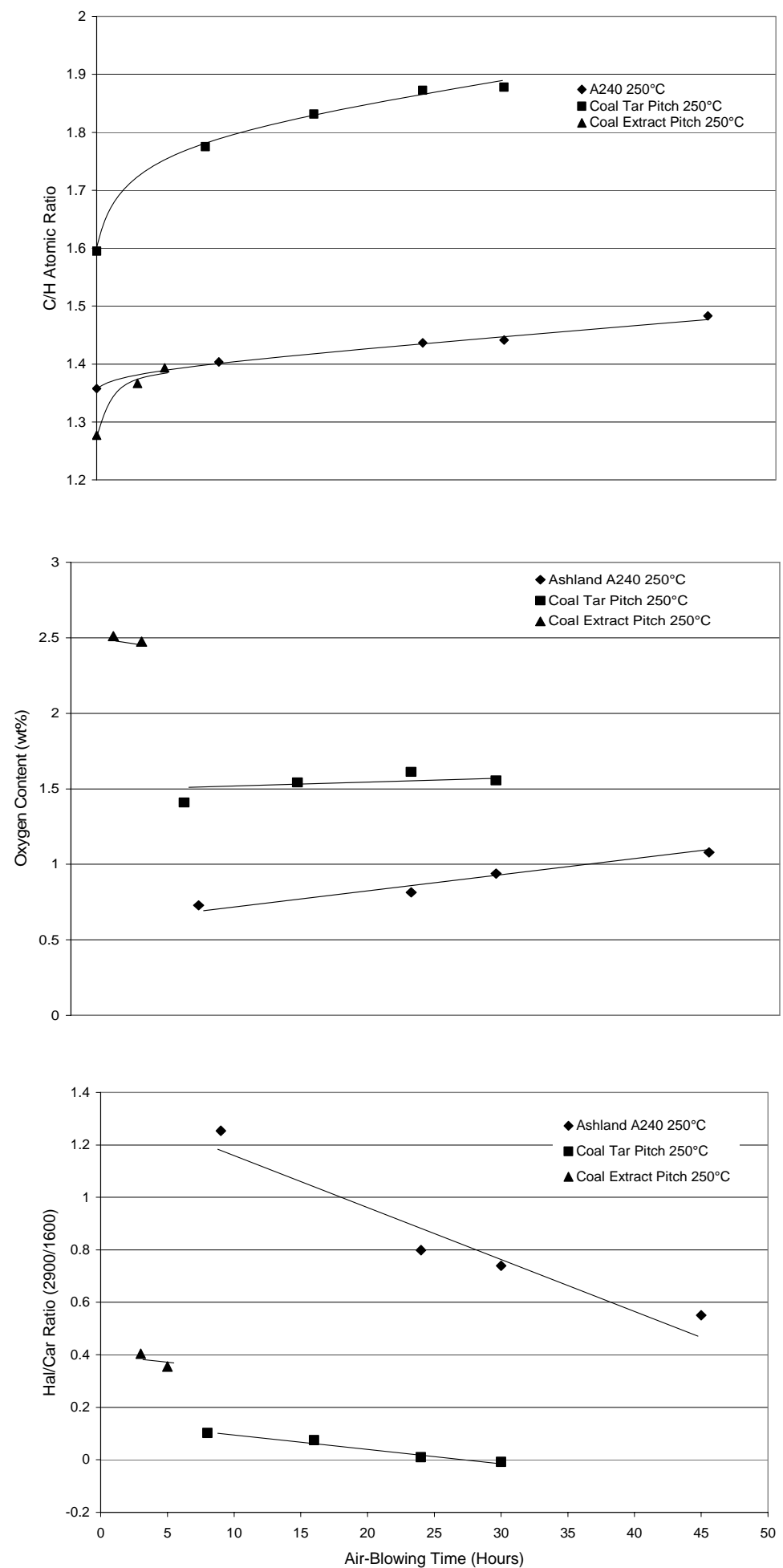

Figure 4.35: Elemental Analysis and FTIR comparison for the three air blown pitches at $250^{\circ} \mathrm{C}$ 

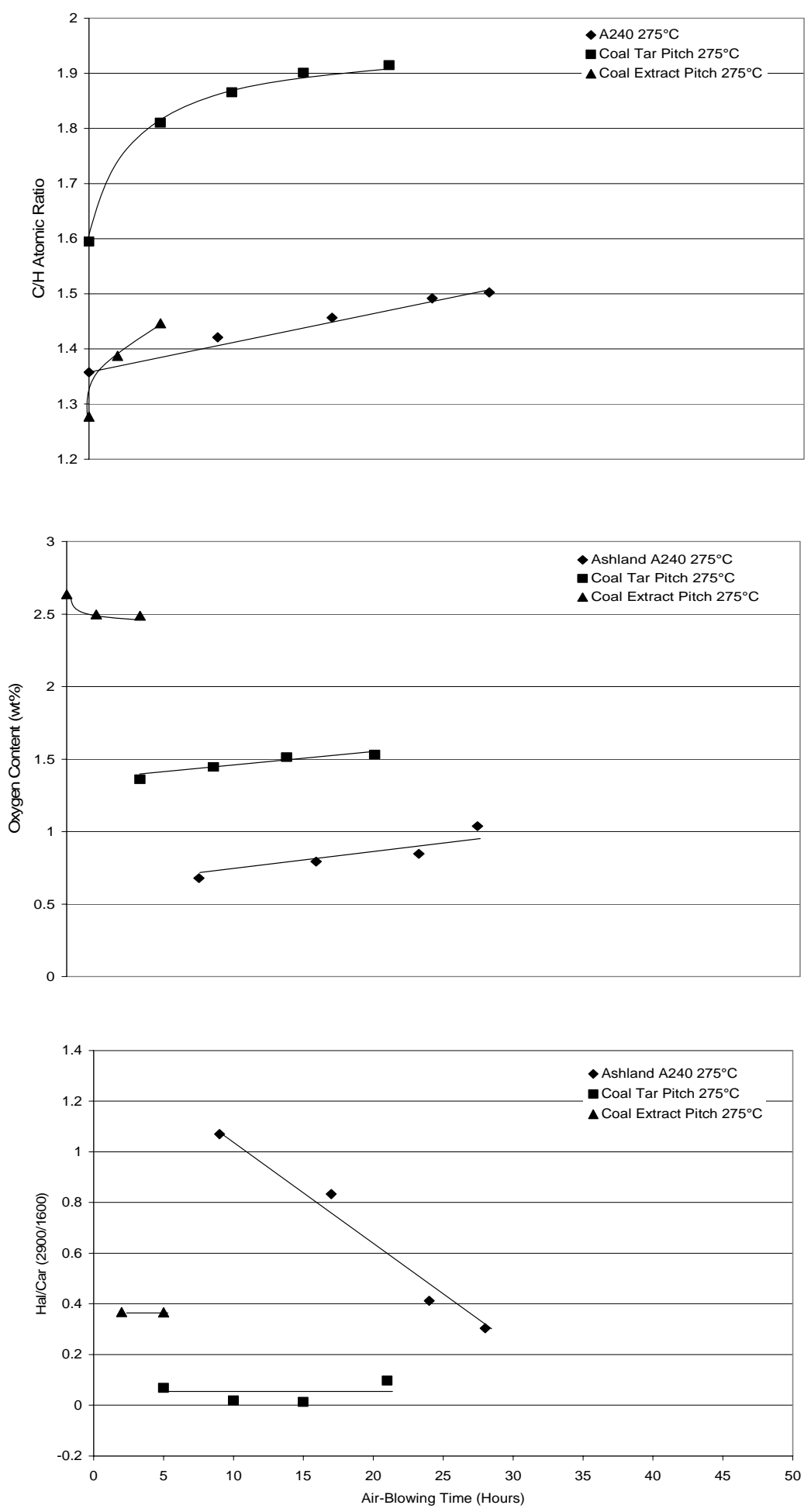

Figure 4.36: Elemental Analysis and FTIR comparison for the three air blown pitches at $275^{\circ} \mathrm{C}$ 

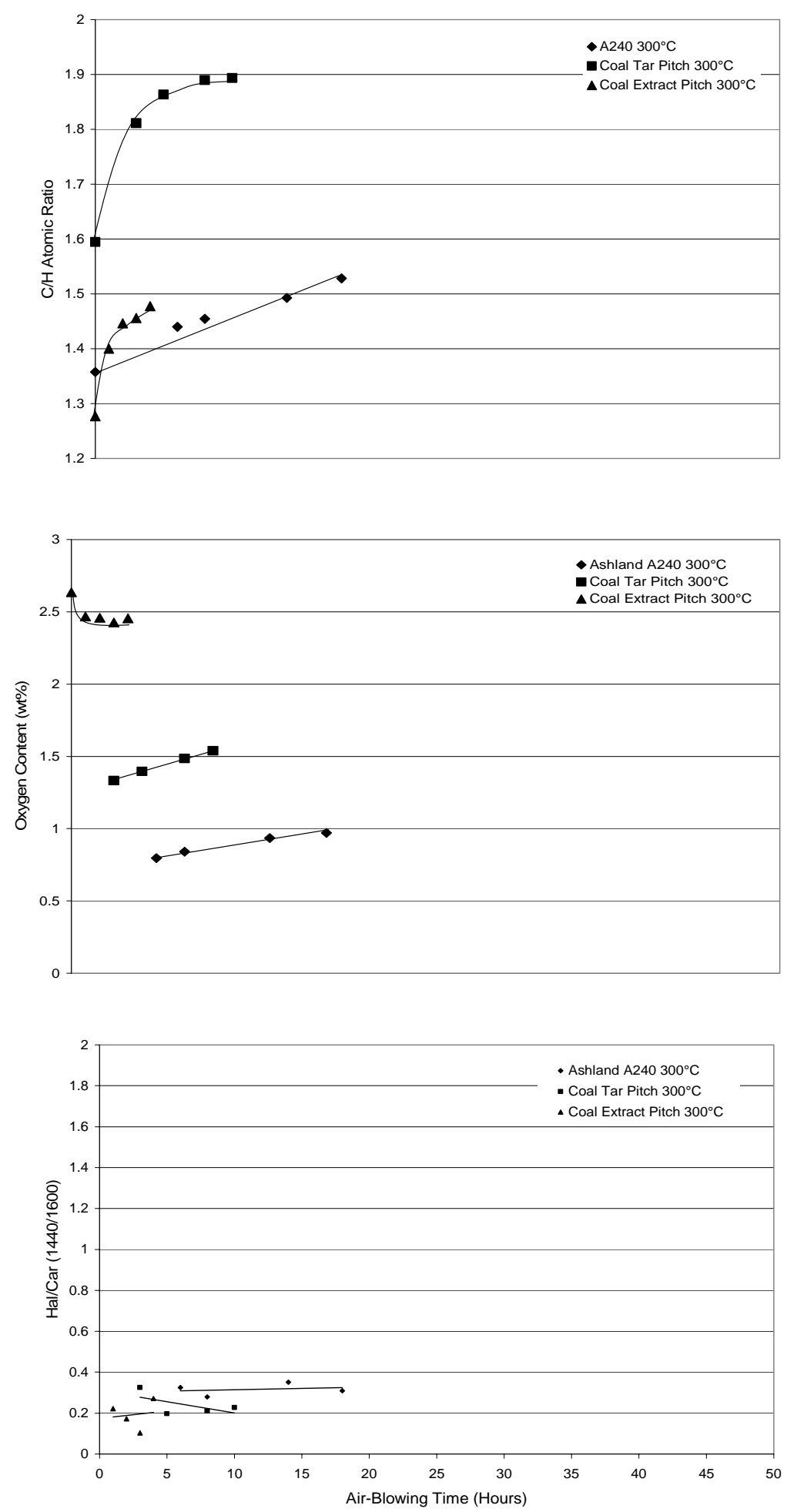

Figure 4.37: Elemental Analysis and FTIR comparison for the three air blown pitches at $300^{\circ} \mathrm{C}$ 


\subsection{Optical Activity}

All of the feed pitches were examined for optical activity under the microscope. It was determined that all three pitches had no optical activity and were therefore essentially isotropic. Each of the air-blown pitches was also examined to ensure that no anisotropy occurred during the air-blowing process. All feed and air-blown pitches had no optical activity. The green cokes from the WVU coking test method were examined optically. In all instances and for all pitch materials, the resultant cokes exhibited flowdomain anisotropy. Thus, it was demonstrated that air-blowing pitches does not diminish or interfere with the development of long-range order during carbonization. 


\section{Chapter 5 - Conclusions and Recommendations}

\subsection{Conclusions}

The results of this research have shown that air blowing is effective in modifying the properties of not only conventional petroleum and coal-tar pitches but also novel coal-extract pitches. Phenomenologically, air blowing increases softening point temperature, density, coke yield, and viscosity. The rheological behavior of the pitches can be described well using the established WLF model. This allows the possible tailoring of pitches for use in many applications that are viscosity sensitive.

Chemically, air blowing results in an increase in the carbon-to-hydrogen ratio with little incorporation of oxygen into the product. Examination of the modified pitches using van Krevelen diagrams suggest that, although similar trends in physical properties were common to all of the pitches, there are subtle differences in the mechanism of air blowing. The petroleum pitch appeared to undergo dealkylation and the coal-extract pitch dehydrogenation. However, it is uncertain by what means the coal-tar pitch is affected. Chemical changes observed by FTIR spectroscopic analysis are consistent with the results of elemental and van Krevelen plots in that air blowing is involved with the removal of hydrogen and alkyl groups. Kinetic modeling of the production of pyridine insolubles by air blowing indicates that the activation energy is similar for all pitch materials, about $14-18 \mathrm{kcal} / \mathrm{mol}$.

Optical microscopy of the air-blown pitches under polarized light revealed that no anisotropy was present. Thus all pitches remained isotropic following modification. However, carbonization of the air-blown materials resulted in green cokes that are highly anisotropic. Thus it is possible to improve the coke yield of isotropic pitches 
dramatically yet still maintain a high level of crystallinity necessary in some carbon products.

\subsection{Recommendations for Future Work}

The result of this thesis work leads to several recommendations for future work. This process needs to be scaled up to ensure the same results are obtained when the pitches are air-blown. It would be useful to coke enough of the air-blown pitch for testing in laboratory anodes to determine suitability in aluminum production. Other coals should be used to make the coal-extract pitch to see if the properties after air blowing are similar as with the coal-extract pitch presented in this thesis.

Additionally, more analyses needs to be performed on the air-blown pitches. Proton NMR and C-13 NMR would be very useful in looking at the mechanisms occurring during the air-blowing process. Proton NMR would show how the hydrogen chemistry changes during and after air blowing and C-13 NMR would also be very useful in looking at the carbon structures within the molecules of the pitches. Finally, provision should be made to collect and analyze all of the volatile products emanating from the airblowing reactor, especially water. 


\section{REFERENCES}

1. Brown, W. H., Introduction to Organic and Biochemistry, Willard Grant Press, Inc., Boston, Massachusetts, 1972.

2. Rhodes, E. O., "The History of Coal Tar and Light Oil” in Bituminous Materials: Asphalts, Tars, and Pitches, Vol. III, Arnold J. Hoiberg, ed., Interscience Publishers, New York, 1966.

3. Petroleum Derived Carbons, ACS Symposium Series 21, Deviney, M. L. and O’Grady, T. M. eds., Washington, D. C., 1976.

4. Hanson, W. E., "Nomenclature and Terms," in Bituminous Materials: Asphalts, Tars, and Pitches, Vol. I, Arnold J. Hoiberg, ed., Robert E. Krieger Publishing Company, Huntington, NY, 1979.

5. Lowry, H.H. Chemistry of Coal Utilization Vol I \& II, National Research Council, H. H. Lowry ed., 1945.

6. Mantell, C.L. The Carbon and Graphite Handbook. Huntington, N.Y.: R.E. Krieger Pub. Co., 1979.

7. Schobert, H. H. Coal: The Energy Source of the Past and Future. American Chemical Society, Washington, D. C., 1987.

8. Smith, E. B., "Destructive Distillation of Wood as Applied to the Naval Stores Industry" in Naval Stores: History, Production, Distribution, and Consumption Thomas Gamble, ed., Savannah: Weekly Naval Stores Review, 1921. 
9. Newman , J. W. and K. L., "A History of Pitch Technologies," in Introduction to Carbon Technologies, H. Marsh, Edward A. Heintz, and Francisco Rodriguez-Reinoso eds., University of Alicante, 329-423.

10. Gray, Ralph J. and Krupinski, Ken C., "Pitch Production: Supply, coking, optical microscopy and applications," in Introduction to Carbon Technologies, H. Marsh, Edward A. Heintz, and Francisco Rodriguez-Reinoso eds., University of Alicante, 329-423.

11. Gary, James H. and Handwerk, Glenn E. Petroleum Refining: Technology and Economics. New York: M. Dekker. 1975.

12. Berkovich, A.J., Lafferty, C.J., and Derbyshire, F.J. Low Severity Extraction of Pitch from Coal as a Precursor to Value added Products - Revisited. American Chemical Society: Division of Fuel Chemistry (2000), 45(2), 25356.

13. Song, Chunshan and Schobert, Harold H. Non-Fuel Uses of Coals and Synthesis of Chemicals and Materials. American Chemical Society: Division of Fuel Chemistry (1995), 40(2), 249-59.

14. Stansberry, Peter G., Zondlo, John W., Racunas, Bernard, and Wombles, Robert H., "Development of Binder Pitches from Coal-Extract and Coal-Tar Pitch Blends," Light Metals, 581-585.

15. Brooks, J.D. and Taylor, G. H., Chem. Phys. Carbon, 7, 237, (1971)

16. John W. Newman "What is Petroleum Pitch?” in Petroleum Derived Carbons, Marvin L. Deviney and Thomas M. O'Grady eds., ACS Symposium Series 21, Washington, D. C., 1976. 
17. Adams "Delayed Coking: Practice and Theory," In Introduction to Carbon Technologies, H. Marsh, Edward A. Heintz, and Francisco RodriguezReinoso eds., Universityof Alicante, 329-423.

18. Ellis, Paul J. and Paul, Christopher A., "Tutorial: Petroleum Coke Calcining and Uses of Calcined Petroleum Coke," $3^{\text {rd }}$ International Conference on Refining Processes, AIChE 2000 Spring National Meeting, March 5-9, 2000, Atlanta, GA

19. Denig, Fred "Industrial Coal Carbonization," in Chemistry of Coal Utilization, H. H. Lowry, ed., John Wiley \& Sons, Inc., NY, 1945.

20. Smith, F. A. et al. "Manufacture of Coal Tar and Pitches," in Bituminous materials: asphalts, tars, and pitches Vol III, New York, Interscience Publishers, 1966

21. Merrick, David. Coal Combustion and Conversion Technology. New York: Elsevier. 1984

22. H. H. Storch. "Hydrogenation of Coal and Tar," in Chemistry of Coal Utilization, H. H. Lowry, ed., John Wiley \& Sons, Inc., NY, 1945.

23. Curran, G.P., Struck, R.T., Gorin, E. Ind. Eng. Chem., Proc. Des. Dev. 1967, 6, 166 .

24. Bockrath, Bradley C. "Chemistry of Hydrogen Donor Solvents," in Coal Science, Vol 2, Martin L. Gorbaty ed., Academic Press Inc., NY. 1983.

25. Derbyshire, Frank J., Odoerfer, G.A., Varghese, P., and Whitehurst, Duayne D. Coal dissolution in high boiling process solvents. Fuel (1982), 61, 899906. 
26. Bearse, A et al. Liquefaction and Chemical Refining of Coal. A Battelle Energy Program Report. July 1974. http://www.fischertropsch.org/DOE/DOE_reports/pb289660/pb289660_toc.pdf

27. DOE Coal Liquefaction Research Needs Panel Assessment. Coal Liquefaction a Research Needs Assessment. Final Report. March 1989.

28. West Virginia University. Coal Based Nuclear Graphites for the New Production Gas Cooled Reactor: Task 1. Final Report for March 1, 1991 to February 28, 1994

29. Probstein, Ronald F. and Hicks, R. Edwin. Synthetic Fuels. New York : McGraw-Hill, 1982.

30. Great Lakes Carbon $7^{\text {th }}$ Carbon Conference. The Woodlands, TX. September 2003.

31. Wombles, Robert H. Experience with Petroleum Enhanced Coal Tar Pitch. Australian Smelter Conference, Queenstown, Australia. 2000.

32. Yamaguchi, Chiharu; Mondori, Juji; Matsumoto, Akira; Honma, Hidekazu; Kumagai, Haruo; Sanada, Yuzo. Air-blowing reactions of pitch: I. Oxidation of aromatic hydrocarbons. Carbon (1995), 33(2), 193-201.

33. Maeda, Toyohiro; Zeng, Shu Ming; Tokumitsu, Katsuhisa; Mondori, Juji; Mochida, Isao. Preparation of isotropic pitch precursors for general purpose carbon fibers (GPCF) by air blowing - I. Preparation of spinnable isotropic pitch precursor from coal tar by air blowing. Carbon (1993), 31(3), 407-12.

34. Zeng, Shu Ming; Maeda, Toyohiro; Tokumitsu, Katsuhisa; Mondori, Juji; Mochida, Isao. Preparation of isotropic pitch precursors for general purpose 
carbon fibers (GPCF) by air blowing - II. Air blowing of coal tar, hydrogenated coal tar, and petroleum pitches. Carbon (1993), 31(3), 41319.

35. Machnikowski, J.; Kaczmarska, H.; Gerus-Piasecka, I.; Diez, M. A.; Alvarez, R.; Garcia, R. Structural modification of coal-tar pitch fractions during mild oxidation - relevance to carbonization behavior. Carbon (2002), 40(11), 1937-1947.

36. Blanco, C.; Santamaria, R.; Bermejo, J.; Menendez, R. A comparative study of air-blown and thermally treated coal-tar pitches. Carbon (2000), 38(4), 517-523.

37. Menendez, R.; Fleurot, O.; Blanco, C.; Santamaria, R.; Bermejo, J.; Edie, D. Chemical and rheological characterization of air-blown coal-tar pitches. Carbon (1998), 36(7-8), 973-979.

38. Fernandez, J. J.; Figueiras, A.; Granda, M.; Bermejo, J.; Menendez, R. Modification of coal-tar pitch by air-blowing - I. Variation of pitch composition and properties. Carbon (1995), 33(3), 295-307.

39. Khandare, Pravin M.. Characterization of Mesophase Pitch Materials from Petroleum and Coal-Derived Precursors: Kinetics and Rheology at Elevated Temperatures. Dissertation. West Virginia University. November 1995.

40. William, M. L., Landel, R. E., and Ferry, J. D., J. Am. Chem. Soc., 77, pg. $3701(1955)$

41. Nazem, F. F.; Lewis, I. C. Viscosity and WLF-type behavior of mesophase pitches. Molecular Crystals and Liquid Crystals. (1986), 139(3-4), 195-207. 
42. Nazem, F. F. and Lewis, I. C., $17^{\text {th }}$ Biennial Conference on Carbon. (1985), 338-339.

43. Choi, J. H.; Kumagai, H.; Chiba, T.; Sanada, Y. Carbonization of pitches in air blowing batch reactor. Carbon (1995), 33(2), 109-14.

44. Barr, J. B.; Lewis, I. C. Chemical changes during the mild air oxidation of pitch. Carbon (1978), 16(6), 439-44.

45. S. Eser, R. G. Jenkins, and F. J. Derbyshire. Carbon (1986), 24, 77-82

46. Rand, B. The Pitch-Mesophase-Coke Transformation As Studied by Thermal Analytical and Rheological Techniques. in ed. Bacha John D. et al. Petroleum-Derived Carbons. American Chemical Society. 1986.

47. van Krevelen, D. W. Graphical-statistical method for the study of structure and reaction processes of coal. Staatmijnen, Limburg, Neth. Fuel (1950), 29 269-84.

48. Joseph, D. and Oberlin, A. Oxidation of Carbonaceous Matter-I. Elemental Analysis $(C, H, O)$ and IR Spectrometry. Carbon, 21(6), 559-64

49. Yang, J. A Study on the carbonization of coal-derived pitches. M.S. Thesis, WVU

50. Drbohlav and Stevenson Carbon, vol. 33, pp. 693-711 (1995) 
APPENDICES 
Appendix I

Mass Balance Data Tables 


\section{Ashland A240 Petroleum Pitch}

\begin{tabular}{|l|c|c|c|c|}
\hline & \multicolumn{4}{|c|}{$250^{\circ} \mathrm{C}$} \\
\hline & $9 \mathrm{hr}$ & $24 \mathrm{hr}$ & $30 \mathrm{hr}$ & $45 \mathrm{hr}$ \\
\hline A240 wt. (g) & 300.22 & 300.02 & 300.22 & 300.1 \\
\hline final wt. (g) & 247.54 & 263.85 & 267.17 & 257.1 \\
\hline final dist. wt. (g) & - & 16.94 & 15.33 & 3.15 \\
\hline \% pitch recovered & 82.45 & 87.94 & 88.99 & 85.67 \\
\hline \% dist. & - & 5.65 & 5.11 & 1.05 \\
\hline
\end{tabular}

\begin{tabular}{|l|c|c|c|c|}
\hline & \multicolumn{4}{|c|}{$275^{\circ} \mathrm{C}$} \\
\hline & $9 \mathrm{hr}$ & $17 \mathrm{hr}$ & $24 \mathrm{hr}$ & $28 \mathrm{hr}$ \\
\hline A240 wt. & 300.22 & 300.09 & 300.34 & 300.07 \\
\hline final wt. (g) & & 261.1 & 259.65 & 260.69 \\
\hline final dist. wt. (g) & 15.6 & 22.46 & 27.86 & - \\
\hline \% pitch recovered & - & 87.01 & 86.45 & 86.88 \\
\hline \% dist. & 5.20 & 7.48 & 9.28 & - \\
\hline
\end{tabular}

\begin{tabular}{|l|c|c|c|c|}
\hline & \multicolumn{4}{|c|}{$300^{\circ} \mathrm{C}$} \\
\hline & $6 \mathrm{hr}$ & $8 \mathrm{hr}$ & $14 \mathrm{hr}$ & $18 \mathrm{hr}$ \\
\hline A240 wt. (g) & 300.2 & 300.07 & 300.36 & 300.06 \\
\hline final wt. (g) & 265.2 & 269.21 & 257.2 & 256.64 \\
\hline final dist. wt. (g) & 23.06 & 21.59 & 30.19 & 31.36 \\
\hline \% pitch recovered & 88.34 & 89.72 & 85.63 & 85.53 \\
\hline$\%$ dist. & 7.68 & 7.19 & 10.05 & 10.45 \\
\hline
\end{tabular}




\section{Koppers Coal-Tar Pitch}

\begin{tabular}{|l|c|c|c|c|}
\hline & \multicolumn{4}{|c|}{$250^{\circ} \mathrm{C}$} \\
\hline & $8 \mathrm{hr}$ & $16 \mathrm{hr}$ & $24 \mathrm{hr}$ & $30 \mathrm{hr}$ \\
\hline CTP wt. (g) & 300.9 & 300.07 & 300.24 & 300.78 \\
\hline final wt. (g) & 274.6 & 263.61 & 262.03 & 264.4 \\
\hline final dist. wt. (g) & 1.45 & 8.03 & 6.76 & 2.9 \\
\hline \% pitch recovered & 91.26 & 87.85 & 87.27 & 87.90 \\
\hline \% dist. & 0.48 & 2.68 & 2.25 & 0.96 \\
\hline
\end{tabular}

\begin{tabular}{|l|c|c|c|c|}
\hline & \multicolumn{4}{|c|}{$275^{\circ} \mathrm{C}$} \\
\hline & $5 \mathrm{hr}$ & $10 \mathrm{hr}$ & $15 \mathrm{hr}$ & $21 \mathrm{hr}$ \\
\hline CTP wt. & 300.74 & 300.49 & 300.18 & 300.03 \\
\hline final wt. (g) & - & 277.98 & 268.55 & 270.19 \\
\hline final dist. wt. (g) & 1.7 & 2.79 & 6.84 & 5.17 \\
\hline \% pitch recovered & - & 92.51 & 89.46 & 90.05 \\
\hline \% dist. & 0.57 & 0.93 & 2.28 & 1.72 \\
\hline
\end{tabular}

\begin{tabular}{|l|c|c|c|c|}
\hline & \multicolumn{4}{|c|}{$300^{\circ} \mathrm{C}$} \\
\hline & $3 \mathrm{hr}$ & $5 \mathrm{hr}$ & $8 \mathrm{hr}$ & $10 \mathrm{hr}$ \\
\hline CTP wt. (g) & 300.35 & 300.66 & 300.87 & 300.52 \\
\hline final wt. (g) & 281.62 & 278.38 & 270.08 & 264 \\
\hline final dist. wt. (g) & 2.46 & 4.26 & 6.2 & 11.41 \\
\hline \% pitch recovered & 93.76 & 92.59 & 89.77 & 87.85 \\
\hline \% dist. & 0.82 & 1.42 & 2.06 & 3.80 \\
\hline
\end{tabular}




\section{WVU Coal-Extract Pitch}

\begin{tabular}{|l|c|c|}
\hline & \multicolumn{2}{|c|}{$250^{\circ} \mathrm{C}$} \\
\hline & $3 \mathrm{hr}$ & $5 \mathrm{hr}$ \\
\hline CEP wt. (g) & 300.06 & 300 \\
\hline final wt. (g) & 257.1 & 251.25 \\
\hline final dist. wt. (g) & 0.54 & 1.45 \\
\hline \% pitch recovered & 85.68 & 83.75 \\
\hline \% dist. & 0.18 & 0.48 \\
\hline
\end{tabular}

\begin{tabular}{|l|c|c|}
\hline & \multicolumn{2}{|c|}{$275^{\circ} \mathrm{C}$} \\
\hline & $2 \mathrm{hr}$ & $5 \mathrm{hr}$ \\
\hline CEP wt. & 300.48 & 300.12 \\
\hline final wt. (g) & 311.37 & 265.7 \\
\hline final dist. wt. (g) & 265.43 & 7.38 \\
\hline \% pitch recovered & 103.62 & 88.53 \\
\hline \% dist. & 88.34 & 2.46 \\
\hline
\end{tabular}

\begin{tabular}{|l|c|c|c|c|}
\hline & \multicolumn{4}{|c|}{$300^{\circ} \mathrm{C}$} \\
\hline & $1 \mathrm{hr}$ & $2 \mathrm{hr}$ & $3 \mathrm{hr}$ & $4 \mathrm{hr}$ \\
\hline CEP wt. (g) & 300.42 & 300.08 & 301.05 & 300.13 \\
\hline final wt. (g) & 280.74 & 272.01 & 266.67 & 258.94 \\
\hline final dist. wt. (g) & 1.4 & 1.19 & nil & 4.32 \\
\hline \% pitch recovered & 93.45 & 90.65 & 88.58 & 86.28 \\
\hline \% dist. & 0.47 & 0.40 & - & 1.44 \\
\hline
\end{tabular}

\section{Nitrogen Blown coal-tar pitch and petroleum pitch}

\begin{tabular}{|l|c|}
\hline & $300^{\circ} \mathrm{C}$ \\
\hline & $6 \mathrm{hr}$ \\
\hline A240 wt. & 300.28 \\
\hline final wt. (g) & 264.92 \\
\hline final dist. wt. (g) & 10.78 \\
\hline \% pitch recovered & 88.22 \\
\hline \% dist. & 3.59 \\
\hline
\end{tabular}

\begin{tabular}{|l|c|}
\hline & $300^{\circ} \mathrm{C}$ \\
\hline & $5 \mathrm{hr}$ \\
\hline CTP wt. & 300.44 \\
\hline final wt. (g) & 235.02 \\
\hline final dist. wt. (g) & nil \\
\hline$\%$ pitch recovered & 78.23 \\
\hline$\%$ dist. & nil \\
\hline
\end{tabular}




\section{Appendix II}

Relative Error Data Tables 


\section{Ashland A240 Petroleum Pitch}

\begin{tabular}{|c|r|r|r|r|r|}
\hline Temp ${ }^{\circ} \mathrm{C}$ & $\begin{array}{c}\text { Time, } \\
\text { hrs }\end{array}$ & \multicolumn{1}{|c|}{ S.P., ${ }^{\circ} \mathrm{C}$} & $\begin{array}{c}\text { C.C., } \\
\text { wt\% }\end{array}$ & $\begin{array}{c}\text { WVU, } \\
\text { wt\% }\end{array}$ & PI, wt\% \\
\hline- & 0 & 116.5 & 47.6 & 50.9 & 0.72 \\
\hline- & 0 & 117.3 & 46.6 & 50.8 & 0.96 \\
\hline Average & 0 & 116.9 & 47.1 & 50.85 & 0.84 \\
\hline \% Rel. Error & - & 0.684346 & 2.123142 & 0.1966568 & 28.57143 \\
\hline Rel. Error & - & 0.4 & 0.5 & 0.05 & 0.12 \\
\hline
\end{tabular}

\begin{tabular}{|c|r|r|r|r|r|}
\hline Temp ${ }^{\circ} \mathrm{C}$ & $\begin{array}{c}\text { Time, } \\
\text { hrs }\end{array}$ & \multicolumn{1}{|c|}{ S.P., ${ }^{\circ} \mathrm{C}$} & $\begin{array}{c}\text { C.C., } \\
\text { wt\% }\end{array}$ & \multicolumn{1}{c|}{$\begin{array}{c}\text { WVU, } \\
\text { wt\% }\end{array}$} & \multicolumn{1}{c|}{ PI, wt\% } \\
\hline $250^{\circ} \mathrm{C}$ & 9 & 150.9 & 53.1 & 58.6 & 7.2 \\
\hline $250^{\circ} \mathrm{C}$ & 9 & 151.4 & 54 & 58.3 & 6.3 \\
\hline Average & 9 & 151.15 & 53.55 & 58.45 & 6.75 \\
\hline \% Rel. Error & - & 0.330797 & 1.680672 & 0.5132592 & 13.33333 \\
\hline Rel. Error & - & 0.25 & 0.45 & 0.15 & 0.45 \\
\hline
\end{tabular}

\begin{tabular}{|c|r|r|r|r|r|}
\hline Temp ${ }^{\circ} \mathrm{C}$ & $\begin{array}{c}\text { Time, } \\
\text { hrs }\end{array}$ & \multicolumn{1}{c|}{ S.P., ${ }^{\circ} \mathrm{C}$} & $\begin{array}{c}\text { C.C., } \\
\text { wt\% }\end{array}$ & \multicolumn{1}{c|}{$\begin{array}{c}\text { WVU, } \\
\text { wt\% }\end{array}$} & \multicolumn{1}{c|}{ PI, wt $\%$} \\
\hline $250^{\circ} \mathrm{C}$ & 24 & 176.1 & 57.4 & 61.9 & 9.1 \\
\hline $250^{\circ} \mathrm{C}$ & 24 & 176 & 57.2 & 61.5 & 10.1 \\
\hline Average & 24 & 176.05 & 57.3 & 61.7 & 9.6 \\
\hline \% Rel. Error & - & 0.056802 & 0.34904 & 0.6482982 & 10.41667 \\
\hline Rel. Error & - & 0.05 & 0.1 & 0.2 & 0.5 \\
\hline
\end{tabular}

\begin{tabular}{|c|r|r|r|r|r|}
\hline Temp ${ }^{\circ} \mathrm{C}$ & $\begin{array}{c}\text { Time, } \\
\text { hrs }\end{array}$ & S.P., ${ }^{\circ} \mathrm{C}$ & $\begin{array}{c}\text { C.C., } \\
\text { wt\% }\end{array}$ & \multicolumn{1}{c|}{$\begin{array}{c}\text { WVU, } \\
\text { wt\% }\end{array}$} & PI, wt\% \\
\hline $250^{\circ} \mathrm{C}$ & 30 & 184.5 & 58.4 & 62.3 & 13.4 \\
\hline $250^{\circ} \mathrm{C}$ & 30 & 184.1 & 59.4 & 62.9 & 13.5 \\
\hline Average & 30 & 184.3 & 58.9 & 62.6 & 13.45 \\
\hline \% Rel. Error & - & 0.217037 & 1.697793 & 0.9584665 & 0.743494 \\
\hline Rel. Error & - & 0.2 & 0.5 & 0.3 & 0.05 \\
\hline
\end{tabular}

\begin{tabular}{|c|r|r|r|r|r|}
\hline Temp ${ }^{\circ} \mathrm{C}$ & $\begin{array}{c}\text { Time, } \\
\text { hrs }\end{array}$ & \multicolumn{1}{c|}{ S.P., ${ }^{\circ} \mathrm{C}$} & $\begin{array}{c}\text { C.C., } \\
\text { wt\% }\end{array}$ & \multicolumn{1}{c|}{$\begin{array}{c}\text { WVU, } \\
\text { wt\% }\end{array}$} & \multicolumn{1}{c|}{ PI, wt\% } \\
\hline $250^{\circ} \mathrm{C}$ & 45 & 222.5 & 63.4 & 67.5 & 21.2 \\
\hline $250^{\circ} \mathrm{C}$ & 45 & 222.8 & 61.6 & 66.3 & 20.6 \\
\hline Average & 45 & 222.65 & 62.5 & 66.9 & 20.9 \\
\hline \% Rel. Error & - & 0.134741 & 2.88 & 1.793722 & 2.870813 \\
\hline Rel. Error & - & 0.15 & 0.9 & 0.6 & 0.3 \\
\hline
\end{tabular}




\begin{tabular}{|c|r|r|r|r|r|}
\hline Temp ${ }^{\circ} \mathrm{C}$ & $\begin{array}{c}\text { Time, } \\
\text { hrs }\end{array}$ & S.P., ${ }^{\circ} \mathrm{C}$ & $\begin{array}{c}\text { C.C., } \\
\text { wt\% }\end{array}$ & \multicolumn{1}{c|}{$\begin{array}{c}\text { WVU, } \\
\text { wt } \%\end{array}$} & PI, wt $\%$ \\
\hline $275^{\circ} \mathrm{C}$ & 9 & 161 & 58.5 & 59.6 & 5.7 \\
\hline $275^{\circ} \mathrm{C}$ & 9 & 161.4 & 54.8 & 59.5 & 5.2 \\
\hline Average & 9 & 161.2 & 56.65 & 59.55 & 5.45 \\
\hline \% Rel. Error & - & 0.248139 & 6.531333 & 0.1679261 & 9.174312 \\
\hline Rel. Error & - & 0.2 & 1.85 & 0.05 & 0.25 \\
\hline
\end{tabular}

\begin{tabular}{|c|c|r|r|r|r|}
\hline Temp ${ }^{\circ} \mathrm{C}$ & $\begin{array}{c}\text { Time, } \\
\text { hrs }\end{array}$ & \multicolumn{1}{|c|}{ S.P., ${ }^{\circ} \mathrm{C}$} & $\begin{array}{c}\text { C.C., } \\
\text { wt\% }\end{array}$ & \multicolumn{1}{c|}{$\begin{array}{c}\text { WVU, } \\
\text { wt\% }\end{array}$} & PI, wt\% \\
\hline $275^{\circ} \mathrm{C}$ & 17 & 195.4 & 60.9 & 64.6 & 14.3 \\
\hline $275^{\circ} \mathrm{C}$ & 17 & 196.7 & 60.5 & 65 & 12.6 \\
\hline Average & 17 & 196.05 & 60.7 & 64.8 & 13.45 \\
\hline \% Rel. Error & - & 0.663096 & 0.658979 & 0.617284 & 12.63941 \\
\hline Rel. Error & - & 0.65 & 0.2 & 0.2 & 0.85 \\
\hline
\end{tabular}

\begin{tabular}{|c|r|r|r|r|r|}
\hline Temp ${ }^{\circ} \mathrm{C}$ & $\begin{array}{c}\text { Time, } \\
\text { hrs }\end{array}$ & \multicolumn{1}{c|}{ S.P., ${ }^{\circ} \mathrm{C}$} & $\begin{array}{c}\text { C.C., } \\
\text { wt\% }\end{array}$ & \multicolumn{1}{c|}{$\begin{array}{c}\text { WVU, } \\
\text { wt\% }\end{array}$} & PI, wt\% \\
\hline $275^{\circ} \mathrm{C}$ & 24 & 210.2 & 62.9 & 66 & 16.9 \\
\hline $275^{\circ} \mathrm{C}$ & 24 & 210.8 & 61.9 & 67.3 & 16.1 \\
\hline Average & 24 & 210.5 & 62.4 & 66.65 & 16.5 \\
\hline \% Rel. Error & - & 0.285036 & 1.602564 & 1.9504876 & 4.848485 \\
\hline Rel. Error & - & 0.3 & 0.5 & 0.65 & 0.4 \\
\hline
\end{tabular}

\begin{tabular}{|c|r|r|r|r|r|}
\hline Temp ${ }^{\circ} \mathrm{C}$ & $\begin{array}{c}\text { Time, } \\
\text { hrs }\end{array}$ & \multicolumn{1}{c|}{ S.P., ${ }^{\circ} \mathrm{C}$} & $\begin{array}{c}\text { C.C., } \\
\text { wt } \%\end{array}$ & \multicolumn{1}{c|}{$\begin{array}{c}\text { WVU, } \\
\text { wt } \%\end{array}$} & Pl, wt\% \\
\hline $275^{\circ} \mathrm{C}$ & 28 & 230.6 & 64.8 & 66.8 & 22.9 \\
\hline $275^{\circ} \mathrm{C}$ & 28 & 226.9 & 64.3 & 66.7 & 22.1 \\
\hline Average & 28 & 228.75 & 64.55 & 66.75 & 22.5 \\
\hline \% Rel. Error & - & 1.617486 & 0.774593 & 0.1498127 & 3.555556 \\
\hline Rel. Error & - & 1.85 & 0.25 & 0.05 & 0.4 \\
\hline
\end{tabular}

\begin{tabular}{|c|r|r|r|r|r|}
\hline Temp ${ }^{\circ} \mathrm{C}$ & $\begin{array}{c}\text { Time, } \\
\text { hrs }\end{array}$ & S.P., ${ }^{\circ} \mathrm{C}$ & $\begin{array}{c}\text { C.C., } \\
\text { wt\% }\end{array}$ & \multicolumn{1}{c|}{$\begin{array}{c}\text { WVU, } \\
\text { wt\% }\end{array}$} & PI, wt\% \\
\hline $300^{\circ} \mathrm{C}$ & 6 & 175.1 & 58.1 & 62.6 & 8.7 \\
\hline $300^{\circ} \mathrm{C}$ & 6 & 174.9 & 57.1 & 62.5 & 9.6 \\
\hline Average & 6 & 175 & 57.6 & 62.55 & 9.15 \\
\hline \% Rel. Error & - & 0.114286 & 1.736111 & 0.1598721 & 9.836066 \\
\hline Rel. Error & - & 0.1 & 0.5 & 0.05 & 0.45 \\
\hline
\end{tabular}

\begin{tabular}{|c|r|r|r|r|r|}
\hline Temp ${ }^{\circ} \mathrm{C}$ & $\begin{array}{c}\text { Time, } \\
\text { hrs }\end{array}$ & \multicolumn{1}{c|}{ S.P., ${ }^{\circ} \mathrm{C}$} & $\begin{array}{c}\text { C.C., } \\
\text { wt\% }\end{array}$ & \multicolumn{1}{c|}{$\begin{array}{c}\text { WVU, } \\
\text { wt } \%\end{array}$} & \multicolumn{1}{c|}{ PI, wt $\%$} \\
\hline $300^{\circ} \mathrm{C}$ & 8 & 181.1 & 58.9 & 62.9 & 10.1 \\
\hline $300^{\circ} \mathrm{C}$ & 8 & 180.2 & 58.7 & 63.3 & 9.7 \\
\hline Average & 8 & 180.65 & 58.8 & 63.1 & 9.9 \\
\hline \% Rel. Error & - & 0.498201 & 0.340136 & 0.6339144 & 4.040404 \\
\hline Rel. Error & - & 0.45 & 0.1 & 0.2 & 0.2 \\
\hline
\end{tabular}




\begin{tabular}{|c|r|r|r|r|r|}
\hline Temp ${ }^{\circ} \mathrm{C}$ & $\begin{array}{c}\text { Time, } \\
\text { hrs }\end{array}$ & \multicolumn{1}{c|}{ S.P., ${ }^{\circ} \mathrm{C}$} & $\begin{array}{c}\text { C.C., } \\
\text { wt\% }\end{array}$ & \multicolumn{1}{c|}{$\begin{array}{c}\text { WVU, } \\
\text { wt } \%\end{array}$} & PI, wt $\%$ \\
\hline $300^{\circ} \mathrm{C}$ & 14 & 223.9 & 64.6 & 68.1 & 25.7 \\
\hline $300^{\circ} \mathrm{C}$ & 14 & 223.8 & 64.7 & 68.9 & 26.6 \\
\hline Average & 14 & 223.85 & 64.65 & 68.5 & 26.15 \\
\hline \% Rel. Error & - & 0.044673 & 0.154679 & 1.1678832 & 3.441683 \\
\hline Rel. Error & - & 0.05 & 0.05 & 0.4 & 0.45 \\
\hline
\end{tabular}

\begin{tabular}{|c|r|r|r|r|r|}
\hline Temp ${ }^{\circ} \mathrm{C}$ & $\begin{array}{c}\text { Time, } \\
\text { hrs }\end{array}$ & \multicolumn{1}{c|}{ S.P., ${ }^{\circ} \mathrm{C}$} & $\begin{array}{c}\text { C.C., } \\
\text { wt } \%\end{array}$ & \multicolumn{1}{c|}{$\begin{array}{c}\text { WVU, } \\
\text { wt\% }\end{array}$} & PI, wt $\%$ \\
\hline $300^{\circ} \mathrm{C}$ & 18 & 239.3 & 67.2 & 70.8 & 26.9 \\
\hline $300^{\circ} \mathrm{C}$ & 18 & 240.1 & 64.5 & 71.1 & 27.5 \\
\hline Average & 18 & 239.7 & 65.85 & 70.95 & 27.2 \\
\hline \% Rel. Error & - & 0.333751 & 4.100228 & 0.422833 & 2.205882 \\
\hline Rel. Error & - & 0.4 & 1.35 & 0.15 & 0.3 \\
\hline
\end{tabular}

\section{Koppers Coal-Tar Pitch}

\begin{tabular}{|c|r|r|r|r|r|}
\hline Temp ${ }^{\circ} \mathrm{C}$ & $\begin{array}{c}\text { Time, } \\
\text { hrs }\end{array}$ & \multicolumn{1}{c|}{ S.P., ${ }^{\circ} \mathrm{C}$} & $\begin{array}{c}\text { C.C., } \\
\text { wt\% }\end{array}$ & $\begin{array}{c}\text { WVU, } \\
\text { wt\% }\end{array}$ & PI, wt\% \\
\hline- & 0 & 108.2 & 47.3 & 54.5 & 11.1 \\
\hline- & 0 & 107.9 & 48.7 & 53.4 & 12 \\
\hline Average & 0 & 108.05 & 48 & 53.95 & 11.55 \\
\hline \% Rel. Error & - & 0.277649 & 2.916667 & 2.0389249 & 7.792208 \\
\hline Rel. Error & - & 0.15 & 0.7 & 0.55 & 0.45 \\
\hline
\end{tabular}

\begin{tabular}{|c|r|r|r|r|r|}
\hline Temp ${ }^{\circ} \mathrm{C}$ & $\begin{array}{c}\text { Time, } \\
\text { hrs }\end{array}$ & \multicolumn{1}{c|}{ S.P., ${ }^{\circ} \mathrm{C}$} & $\begin{array}{c}\text { C.C., } \\
\text { wt\% }\end{array}$ & \multicolumn{1}{c|}{$\begin{array}{c}\text { WVU, } \\
\text { wt\% }\end{array}$} & \multicolumn{1}{c|}{ PI, wt $\%$} \\
\hline $250^{\circ} \mathrm{C}$ & 8 & 144.3 & 54.8 & 61.3 & 23.8 \\
\hline $250^{\circ} \mathrm{C}$ & 8 & 144.5 & 55.3 & 58.2 & 23.7 \\
\hline Average & 8 & 144.4 & 55.05 & 59.75 & 23.75 \\
\hline \% Rel. Error & - & 0.138504 & 0.908265 & 5.1882845 & 0.421053 \\
\hline Rel. Error & - & 0.1 & 0.25 & 1.55 & 0.05 \\
\hline
\end{tabular}

\begin{tabular}{|c|r|r|r|r|r|}
\hline Temp ${ }^{\circ} \mathrm{C}$ & $\begin{array}{c}\text { Time, } \\
\text { hrs }\end{array}$ & \multicolumn{1}{c|}{ S.P., ${ }^{\circ} \mathrm{C}$} & $\begin{array}{c}\text { C.C., } \\
\text { wt\% }\end{array}$ & \multicolumn{1}{c|}{$\begin{array}{c}\text { WVU, } \\
\text { wt\% }\end{array}$} & Pl, wt\% \\
\hline $250^{\circ} \mathrm{C}$ & 16 & 172.6 & 59.1 & 63 & 31.8 \\
\hline $250^{\circ} \mathrm{C}$ & 16 & 173.1 & 60.9 & 62.2 & 32.7 \\
\hline Average & 16 & 172.85 & 60 & 62.6 & 32.25 \\
\hline \% Rel. Error & - & 0.289268 & 3 & 1.2779553 & 2.790698 \\
\hline Rel. Error & - & 0.25 & 0.9 & 0.4 & 0.45 \\
\hline
\end{tabular}




\begin{tabular}{|c|r|r|r|r|r|}
\hline Temp ${ }^{\circ} \mathrm{C}$ & $\begin{array}{c}\text { Time, } \\
\text { hrs }\end{array}$ & \multicolumn{1}{c|}{ S.P., ${ }^{\circ} \mathrm{C}$} & $\begin{array}{c}\text { C.C., } \\
\text { wt\% }\end{array}$ & \multicolumn{1}{c|}{$\begin{array}{c}\text { WVU, } \\
\text { wt } \%\end{array}$} & PI, wt $\%$ \\
\hline $250^{\circ} \mathrm{C}$ & 24 & 206.4 & 60.9 & 66.5 & 42.9 \\
\hline $250^{\circ} \mathrm{C}$ & 24 & 207.1 & 63.6 & 67.2 & 44.7 \\
\hline Average & 24 & 206.75 & 62.25 & 66.85 & 43.8 \\
\hline \% Rel. Error & - & 0.338573 & 4.337349 & 1.0471204 & 4.109589 \\
\hline Rel. Error & - & 0.35 & 1.35 & 0.35 & 0.9 \\
\hline
\end{tabular}

\begin{tabular}{|c|r|r|r|r|r|}
\hline Temp ${ }^{\circ} \mathrm{C}$ & $\begin{array}{c}\text { Time, } \\
\text { hrs }\end{array}$ & S.P., ${ }^{\circ} \mathrm{C}$ & $\begin{array}{c}\text { C.C., } \\
\text { wt\% }\end{array}$ & \multicolumn{1}{c|}{$\begin{array}{c}\text { WVU, } \\
\text { wt } \%\end{array}$} & PI, wt\% \\
\hline $250^{\circ} \mathrm{C}$ & 30 & 210.9 & 63.1 & 67.5 & 41.9 \\
\hline $250^{\circ} \mathrm{C}$ & 30 & 211.7 & 63.7 & 68.5 & 45.4 \\
\hline Average & 30 & 211.3 & 63.4 & 68 & 43.65 \\
\hline \% Rel. Error & - & 0.378609 & 0.946372 & 1.4705882 & 8.018328 \\
\hline Rel. Error & - & 0.4 & 0.3 & 0.5 & 1.75 \\
\hline
\end{tabular}

\begin{tabular}{|c|r|r|r|r|r|}
\hline Temp ${ }^{\circ} \mathrm{C}$ & $\begin{array}{c}\text { Time, } \\
\text { hrs }\end{array}$ & \multicolumn{1}{c|}{ S.P., ${ }^{\circ} \mathrm{C}$} & $\begin{array}{c}\text { C.C., } \\
\text { wt } \%\end{array}$ & \multicolumn{1}{c|}{$\begin{array}{c}\text { WVU, } \\
\text { wt\% }\end{array}$} & \multicolumn{1}{c|}{ PI, wt\% } \\
\hline $275^{\circ} \mathrm{C}$ & 5 & 154.8 & 58.4 & 63.7 & 29.1 \\
\hline $275^{\circ} \mathrm{C}$ & 5 & 155.3 & 56.3 & 62.4 & 29.4 \\
\hline Average & 5 & 155.05 & 57.35 & 63.05 & 29.25 \\
\hline \% Rel. Error & - & 0.322477 & 3.661726 & 2.0618557 & 1.025641 \\
\hline Rel. Error & - & 0.25 & 1.05 & 0.65 & 0.15 \\
\hline
\end{tabular}

\begin{tabular}{|c|r|r|r|r|r|}
\hline Temp ${ }^{\circ} \mathrm{C}$ & $\begin{array}{c}\text { Time, } \\
\text { hrs }\end{array}$ & \multicolumn{1}{c|}{ S.P., ${ }^{\circ} \mathrm{C}$} & $\begin{array}{c}\text { C.C., } \\
\text { wt } \%\end{array}$ & \multicolumn{1}{c|}{$\begin{array}{c}\text { WVU, } \\
\text { wt\% }\end{array}$} & Pl, wt\% \\
\hline $275^{\circ} \mathrm{C}$ & 10 & 189.4 & 61.6 & 65.6 & 40.9 \\
\hline $275^{\circ} \mathrm{C}$ & 10 & 189.8 & 61.6 & 65.7 & 40.6 \\
\hline Average & 10 & 189.6 & 61.6 & 65.65 & 40.75 \\
\hline \% Rel. Error & - & 0.21097 & 0 & 0.1523229 & 0.736196 \\
\hline Rel. Error & - & 0.2 & 0 & 0.05 & 0.15 \\
\hline
\end{tabular}

\begin{tabular}{|c|r|r|r|r|r|}
\hline Temp ${ }^{\circ} \mathrm{C}$ & $\begin{array}{c}\text { Time, } \\
\text { hrs }\end{array}$ & S.P., ${ }^{\circ} \mathrm{C}$ & $\begin{array}{c}\text { C.C., } \\
\text { wt\% }\end{array}$ & $\begin{array}{c}\text { WVU, } \\
\text { wt } \%\end{array}$ & PI, wt $\%$ \\
\hline $275^{\circ} \mathrm{C}$ & 15 & 217.6 & 64.4 & 64.7 & 45.9 \\
\hline $275^{\circ} \mathrm{C}$ & 15 & 218.7 & 60.7 & 63.9 & 46.4 \\
\hline Average & 15 & 218.15 & 62.55 & 64.3 & 46.15 \\
\hline \% Rel. Error & - & 0.50424 & 5.915268 & 1.244168 & 1.083424 \\
\hline Rel. Error & - & 0.55 & 1.85 & 0.4 & 0.25 \\
\hline
\end{tabular}

\begin{tabular}{|c|r|r|r|r|r|}
\hline Temp ${ }^{\circ} \mathrm{C}$ & $\begin{array}{c}\text { Time, } \\
\text { hrs }\end{array}$ & S.P., ${ }^{\circ} \mathrm{C}$ & $\begin{array}{c}\text { C.C., } \\
\text { wt\% }\end{array}$ & $\begin{array}{c}\text { WVU, } \\
\text { wt } \%\end{array}$ & PI, wt $\%$ \\
\hline $275^{\circ} \mathrm{C}$ & 21 & 231.7 & 65.7 & 70.1 & 47.8 \\
\hline $275^{\circ} \mathrm{C}$ & 21 & 232.3 & 65.9 & 70.5 & 51.1 \\
\hline Average & 21 & 232 & 65.8 & 70.3 & 49.45 \\
\hline \% Rel. Error & - & 0.258621 & 0.303951 & 0.56899 & 6.673407 \\
\hline Rel. Error & - & 0.3 & 0.1 & 0.2 & 1.65 \\
\hline
\end{tabular}




\begin{tabular}{|c|r|r|r|r|r|}
\hline Temp ${ }^{\circ} \mathrm{C}$ & $\begin{array}{c}\text { Time, } \\
\text { hrs }\end{array}$ & \multicolumn{1}{|c|}{ S.P., ${ }^{\circ} \mathrm{C}$} & $\begin{array}{c}\text { C.C., } \\
\text { wt\% }\end{array}$ & \multicolumn{1}{c|}{$\begin{array}{c}\text { WVU, } \\
\text { wt } \%\end{array}$} & \multicolumn{1}{c|}{ PI, wt $\%$} \\
\hline $300^{\circ} \mathrm{C}$ & 3 & 150.9 & 55.7 & 61 & 29.5 \\
\hline $300^{\circ} \mathrm{C}$ & 3 & 150.9 & 56.7 & 60.4 & 28.7 \\
\hline Average & 3 & 150.9 & 56.2 & 60.7 & 29.1 \\
\hline \% Rel. Error & - & 0 & 1.779359 & 0.9884679 & 2.749141 \\
\hline Rel. Error & - & 0 & 0.5 & 0.3 & 0.4 \\
\hline
\end{tabular}

\begin{tabular}{|c|r|r|r|r|r|}
\hline Temp ${ }^{\circ} \mathrm{C}$ & $\begin{array}{c}\text { Time, } \\
\text { hrs }\end{array}$ & \multicolumn{1}{|c|}{ S.P., ${ }^{\circ} \mathrm{C}$} & $\begin{array}{c}\text { C.C., } \\
\text { wt\% }\end{array}$ & $\begin{array}{c}\text { WVU, } \\
\text { wt\% }\end{array}$ & PI, wt $\%$ \\
\hline $300^{\circ} \mathrm{C}$ & 5 & 174.6 & 60.5 & 64.7 & 37.1 \\
\hline $300^{\circ} \mathrm{C}$ & 5 & 174.2 & 58.7 & 65 & 36.9 \\
\hline Average & 5 & 174.4 & 59.6 & 64.85 & 37 \\
\hline \% Rel. Error & - & 0.229358 & 3.020134 & 0.462606 & 0.540541 \\
\hline Rel. Error & - & 0.2 & 0.9 & 0.15 & 0.1 \\
\hline
\end{tabular}

\begin{tabular}{|c|r|r|r|r|r|}
\hline Temp ${ }^{\circ} \mathrm{C}$ & $\begin{array}{c}\text { Time, } \\
\text { hrs }\end{array}$ & \multicolumn{1}{c|}{ S.P., ${ }^{\circ} \mathrm{C}$} & $\begin{array}{c}\text { C.C., } \\
\text { Wt\% }\end{array}$ & \multicolumn{1}{c|}{$\begin{array}{c}\text { WVU, } \\
\text { Wt\% }\end{array}$} & PI, wt\% \\
\hline $300^{\circ} \mathrm{C}$ & 8 & 205.7 & 63.1 & 67.3 & 49.9 \\
\hline $300^{\circ} \mathrm{C}$ & 8 & 206.5 & 63.9 & 68.9 & 47.9 \\
\hline Average & 8 & 206.1 & 63.5 & 68.1 & 48.9 \\
\hline \% Rel. Error & - & 0.388161 & 1.259843 & 2.349486 & 4.08998 \\
\hline Rel. Error & - & 0.4 & 0.4 & 0.8 & 1 \\
\hline
\end{tabular}

\begin{tabular}{|c|r|r|r|r|r|}
\hline Temp ${ }^{\circ} \mathrm{C}$ & $\begin{array}{c}\text { Time, } \\
\text { hrs }\end{array}$ & \multicolumn{1}{c|}{ S.P., ${ }^{\circ} \mathrm{C}$} & $\begin{array}{c}\text { C.C., } \\
\text { Wt } \%\end{array}$ & \multicolumn{1}{c|}{$\begin{array}{c}\text { WVU, } \\
\text { Wt } \%\end{array}$} & \multicolumn{1}{c|}{ PI, wt $\%$} \\
\hline $300^{\circ} \mathrm{C}$ & 10 & 215.9 & 63 & 69.1 & 45.5 \\
\hline $300^{\circ} \mathrm{C}$ & 10 & 215.6 & 64.2 & 68.5 & 43.6 \\
\hline Average & 10 & 215.75 & 63.6 & 68.8 & 44.55 \\
\hline \% Rel. Error & - & 0.13905 & 1.886792 & 0.872093 & 4.264871 \\
\hline Rel. Error & - & 0.15 & 0.6 & 0.3 & 0.95 \\
\hline
\end{tabular}

\section{WVU Coal-Extract Pitch}

\begin{tabular}{|c|r|r|r|r|r|}
\hline Temp ${ }^{\circ} \mathrm{C}$ & $\begin{array}{c}\text { Time, } \\
\text { hrs }\end{array}$ & S.P., ${ }^{\circ} \mathrm{C}$ & $\begin{array}{c}\text { C.C., } \\
\text { wt\% }\end{array}$ & \multicolumn{1}{c|}{$\begin{array}{c}\text { WVU, } \\
\text { wt\% }\end{array}$} & PI, wt\% \\
\hline- & 0 & 121.6 & 53.2 & 55.7 & 0.17 \\
\hline- & 0 & 121.8 & 52.5 & 56.3 & 0.12 \\
\hline Average & 0 & 121.7 & 52.85 & 56 & 0.145 \\
\hline \% Rel. Error & - & 0.164339 & 1.324503 & 1.0714286 & 34.48276 \\
\hline Rel. Error & - & 0.1 & 0.35 & 0.3 & 0.025 \\
\hline
\end{tabular}




\begin{tabular}{|c|r|r|r|r|r|}
\hline Temp ${ }^{\circ} \mathrm{C}$ & $\begin{array}{c}\text { Time, } \\
\text { hrs }\end{array}$ & \multicolumn{1}{c|}{ S.P., ${ }^{\circ} \mathrm{C}$} & $\begin{array}{c}\text { C.C., } \\
\text { wt\% }\end{array}$ & $\begin{array}{c}\text { WVU, } \\
\text { wt } \%\end{array}$ & PI, wt $\%$ \\
\hline $250^{\circ} \mathrm{C}$ & 3 & 170.2 & 60.8 & 66.5 & 6.7 \\
\hline $250^{\circ} \mathrm{C}$ & 3 & 172 & 60.2 & 66.6 & 9 \\
\hline Average & 3 & 171.1 & 60.5 & 66.55 & 7.85 \\
\hline \% Rel. Error & - & 1.052016 & 0.991736 & 0.150263 & 29.29936 \\
\hline Rel. Error & - & 0.9 & 0.3 & 0.05 & 1.15 \\
\hline
\end{tabular}

\begin{tabular}{|c|r|r|r|r|r|}
\hline Temp ${ }^{\circ} \mathrm{C}$ & $\begin{array}{c}\text { Time, } \\
\text { hrs }\end{array}$ & \multicolumn{1}{c|}{ S.P., ${ }^{\circ} \mathrm{C}$} & $\begin{array}{c}\text { C.C., } \\
\text { wt\% }\end{array}$ & $\begin{array}{c}\text { WVU, } \\
\text { wt } \%\end{array}$ & PI, wt $\%$ \\
\hline $250^{\circ} \mathrm{C}$ & 5 & 178 & 61.3 & 68.4 & 7.1 \\
\hline $250^{\circ} \mathrm{C}$ & 5 & 177.2 & 63.5 & 68.5 & 11 \\
\hline Average & 5 & 177.6 & 62.4 & 68.45 & 9.05 \\
\hline \% Rel. Error & - & 0.45045 & 3.525641 & 0.146092 & 43.09392 \\
\hline Rel. Error & - & 0.4 & 1.1 & 0.05 & 1.95 \\
\hline
\end{tabular}

\begin{tabular}{|c|r|r|r|r|r|}
\hline Temp ${ }^{\circ} \mathrm{C}$ & $\begin{array}{c}\text { Time, } \\
\text { hrs }\end{array}$ & \multicolumn{1}{c|}{ S.P., ${ }^{\circ} \mathrm{C}$} & $\begin{array}{c}\text { C.C., } \\
\text { wt\% }\end{array}$ & \multicolumn{1}{c|}{$\begin{array}{c}\text { WVU, } \\
\text { wt\% }\end{array}$} & Pl, wt\% \\
\hline $275^{\circ} \mathrm{C}$ & 2 & 177.4 & 62.6 & 67.5 & 7.8 \\
\hline $275^{\circ} \mathrm{C}$ & 2 & 174.9 & 62.3 & 68 & 7.6 \\
\hline Average & 2 & 176.15 & 62.45 & 67.75 & 7.7 \\
\hline \% Rel. Error & - & 1.419245 & 0.480384 & 0.7380074 & 2.597403 \\
\hline Rel. Error & - & 1.25 & 0.15 & 0.25 & 0.1 \\
\hline
\end{tabular}

\begin{tabular}{|c|r|r|r|r|r|}
\hline Temp ${ }^{\circ} \mathrm{C}$ & $\begin{array}{c}\text { Time, } \\
\text { hrs }\end{array}$ & S.P., ${ }^{\circ} \mathrm{C}$ & $\begin{array}{c}\text { C.C., } \\
\text { wt\% }\end{array}$ & $\begin{array}{c}\text { WVU, } \\
\text { wt\% }\end{array}$ & PI, wt $\%$ \\
\hline $275^{\circ} \mathrm{C}$ & 5 & 243.1 & 67.1 & 74.5 & 10.3 \\
\hline $275^{\circ} \mathrm{C}$ & 5 & 243.1 & 67.7 & 75.5 & 10.8 \\
\hline Average & 5 & 243.1 & 67.4 & 75 & 10.55 \\
\hline \% Rel. Error & - & 0 & 0.890208 & 1.3333333 & 4.739336 \\
\hline Rel. Error & - & 0 & 0.3 & 0.5 & 0.25 \\
\hline
\end{tabular}




\begin{tabular}{|c|r|r|r|r|r|}
\hline Temp ${ }^{\circ} \mathrm{C}$ & $\begin{array}{c}\text { Time, } \\
\text { hrs }\end{array}$ & \multicolumn{1}{|c|}{ S.P., ${ }^{\circ} \mathrm{C}$} & $\begin{array}{c}\text { C.C., } \\
\text { wt\% }\end{array}$ & \multicolumn{1}{c|}{$\begin{array}{c}\text { WVU, } \\
\text { wt\% }\end{array}$} & PI, wt\% \\
\hline $300^{\circ} \mathrm{C}$ & 1 & 179.9 & 59.5 & 67.3 & 9.5 \\
\hline $300^{\circ} \mathrm{C}$ & 1 & 180.8 & 62.2 & 67.7 & 14.6 \\
\hline Average & 1 & 180.35 & 60.85 & 67.5 & 12.05 \\
\hline \% Rel. Error & - & 0.49903 & 4.437141 & 0.5925926 & 42.32365 \\
\hline Rel. Error & - & 0.45 & 1.35 & 0.2 & 2.55 \\
\hline
\end{tabular}

\begin{tabular}{|c|r|r|r|r|r|}
\hline Temp ${ }^{\circ} \mathrm{C}$ & $\begin{array}{c}\text { Time, } \\
\text { hrs }\end{array}$ & S.P., ${ }^{\circ} \mathrm{C}$ & $\begin{array}{c}\text { C.C., } \\
\text { wt\% }\end{array}$ & \multicolumn{1}{c|}{$\begin{array}{c}\text { WVU, } \\
\text { wt\% }\end{array}$} & PI, wt $\%$ \\
\hline $300^{\circ} \mathrm{C}$ & 2 & 205.6 & 66.7 & 72.6 & 14.8 \\
\hline $300^{\circ} \mathrm{C}$ & 2 & 203.5 & 66.9 & 73 & 14.5 \\
\hline Average & 2 & 204.55 & 66.8 & 72.8 & 14.65 \\
\hline \% Rel. Error & - & 1.026644 & 0.299401 & 0.5494505 & 2.047782 \\
\hline Rel. Error & - & 1.05 & 0.1 & 0.2 & 0.15 \\
\hline
\end{tabular}

\begin{tabular}{|c|r|r|r|r|r|}
\hline Temp ${ }^{\circ} \mathrm{C}$ & $\begin{array}{c}\text { Time, } \\
\text { hrs }\end{array}$ & \multicolumn{1}{c|}{ S.P., ${ }^{\circ} \mathrm{C}$} & $\begin{array}{c}\text { C.C., } \\
\text { wt\% }\end{array}$ & \multicolumn{1}{c|}{$\begin{array}{c}\text { WVU, } \\
\text { wt\% }\end{array}$} & \multicolumn{1}{c|}{ Pl, wt $\%$} \\
\hline $300^{\circ} \mathrm{C}$ & 3 & 224.5 & 67.7 & 76.5 & 20.9 \\
\hline $300^{\circ} \mathrm{C}$ & 3 & 225.2 & 67.3 & 76.1 & 28.2 \\
\hline Average & 3 & 224.85 & 67.5 & 76.3 & 24.55 \\
\hline \% Rel. Error & - & 0.311319 & 0.592593 & 0.5242464 & 29.73523 \\
\hline Rel. Error & - & 0.35 & 0.2 & 0.2 & 3.65 \\
\hline
\end{tabular}

\begin{tabular}{|c|r|r|r|r|r|}
\hline Temp ${ }^{\circ} \mathrm{C}$ & $\begin{array}{c}\text { Time, } \\
\text { hrs }\end{array}$ & \multicolumn{1}{c|}{ S.P., ${ }^{\circ} \mathrm{C}$} & $\begin{array}{c}\text { C.C., } \\
\text { wt\% }\end{array}$ & \multicolumn{1}{c|}{$\begin{array}{c}\text { WVU, } \\
\text { wt } \%\end{array}$} & PI, wt\% \\
\hline $300^{\circ} \mathrm{C}$ & 4 & 231.5 & 69.4 & 77.4 & 24.1 \\
\hline $300^{\circ} \mathrm{C}$ & 4 & 232.3 & 68.1 & 77 & 22.7 \\
\hline Average & 4 & 231.9 & 68.75 & 77.2 & 23.4 \\
\hline \% Rel. Error & - & 0.344976 & 1.890909 & 0.5181347 & 5.982906 \\
\hline Rel. Error & - & 0.4 & 0.65 & 0.2 & 0.7 \\
\hline
\end{tabular}

\section{Nitrogen blown experiments}

\begin{tabular}{|l|r|r|}
\hline & Time (hr) & Softening Point $\left({ }^{\circ} \mathrm{C}\right)$ \\
\hline Nitrogen blown A240 & 6 & 134.1 \\
\hline Nitrogen blown CTP & 5 & 131.3 \\
\hline
\end{tabular}




\section{Appendix III. Density Data Tables}




\begin{tabular}{|c|c|c|}
\hline \multicolumn{3}{|c|}{ Petroleum Pitch A240 } \\
\hline & Time (hr) & Density $\left(\mathrm{g} / \mathrm{cc}^{3}\right)$ \\
\hline & 0 & 1.2365 \\
\hline \multirow{4}{*}{$\begin{array}{l}\cup \\
0 \\
0 \\
\\
\end{array}$} & 9 & 1.2474 \\
\hline & 24 & 1.2477 \\
\hline & 30 & 1.2542 \\
\hline & 45 & 1.2635 \\
\hline \multirow{4}{*}{$\begin{array}{l}\mathcal{U} \\
\stackrel{0}{N} \\
\end{array}$} & 9 & 1.2493 \\
\hline & 17 & 1.2555 \\
\hline & 24 & 1.2535 \\
\hline & 28 & 1.2634 \\
\hline \multirow{4}{*}{ 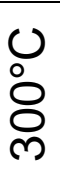 } & 6 & 1.2531 \\
\hline & 8 & 1.2551 \\
\hline & 14 & 1.2530 \\
\hline & 18 & 1.2679 \\
\hline
\end{tabular}

\begin{tabular}{|c|c|c|}
\hline \multicolumn{3}{|c|}{ Koppers Coal-tar Pitch } \\
\hline & Time (hr) & Density $\left(g / c^{3} c^{3}\right)$ \\
\hline & 0 & 1.3042 \\
\hline \multirow{4}{*}{$\begin{array}{l}0 \\
0 \\
0 \\
\sim \\
N\end{array}$} & 8 & 1.3158 \\
\hline & 16 & 1.3202 \\
\hline & 24 & 1.3286 \\
\hline & 30 & 1.3320 \\
\hline \multirow{4}{*}{$\begin{array}{l}\mathcal{U} \\
\stackrel{0}{N} \\
\end{array}$} & 5 & 1.3184 \\
\hline & 10 & 1.3263 \\
\hline & 15 & 1.3339 \\
\hline & 21 & 1.3422 \\
\hline \multirow{4}{*}{$\begin{array}{l}\text { U } \\
\text { ○ } \\
\text { ○े }\end{array}$} & 3 & 1.3176 \\
\hline & 5 & 1.3286 \\
\hline & 8 & 1.3331 \\
\hline & 10 & 1.3365 \\
\hline
\end{tabular}

\begin{tabular}{|c|c|c|}
\hline \multicolumn{3}{|c|}{ WVU Coal-extract Pitch } \\
\hline & Time (hr) & Density $\left(\mathrm{g} / \mathrm{cc}^{3}\right)$ \\
\hline & 0 & 1.2465 \\
\hline \multirow{2}{*}{$\begin{array}{l}0 \\
\stackrel{\circ}{\circ} \\
\stackrel{\circ}{N}\end{array}$} & 3 & 1.2624 \\
\hline & 5 & 1.2634 \\
\hline \multirow{2}{*}{$\begin{array}{l}\cup \\
\stackrel{0}{N} \\
\stackrel{N}{N}\end{array}$} & 2 & 1.2632 \\
\hline & 5 & 1.2809 \\
\hline \multirow{4}{*}{$\begin{array}{l}\mathcal{U} \\
\circ \\
\stackrel{\circ}{\circ} \\
\text { m }\end{array}$} & 1 & 1.2638 \\
\hline & 2 & 1.2757 \\
\hline & 3 & 1.2794 \\
\hline & 4 & 1.2819 \\
\hline
\end{tabular}




\section{Appendix IV}

\section{Viscosity Data Tables}




\section{Ashland A240 Petroleum Pitch}

\begin{tabular}{|c|c|c|c|c|c|c|}
\hline \multirow{2}{*}{\multicolumn{4}{|c|}{$\begin{array}{c}\text { Raw A-240 Feed } \\
0 \mathrm{hr} \text { A-240 }\end{array}$}} & \multirow{3}{*}{$\begin{array}{c}\text { Tr } \\
148.74 \\
\text { T-Ts }\end{array}$} & \multirow{3}{*}{$\begin{array}{c}\text { ur } \\
10000 \\
(n / T)^{\star}(T r / n r)\end{array}$} & \multirow[b]{3}{*}{$\begin{array}{l}\text { LOG } \\
\text { (stuff) }\end{array}$} \\
\hline & & & & & & \\
\hline $\begin{array}{l}\text { Temperature } \\
\left({ }^{\circ} \mathrm{C}\right)\end{array}$ & RPM & $\begin{array}{l}\text { Viscosity } \\
(\mathrm{cP})\end{array}$ & log Visc. & & & \\
\hline 135 & 0.8 & 55413 & 4.743612 & -13.74 & 6.1052812 & 0.785706 \\
\hline 145 & 3.3 & 14088 & 4.148849 & -3.74 & 1.445137324 & 0.159909 \\
\hline 155 & 11.5 & 4543 & 3.657343 & 6.26 & 0.435952142 & -0.36056 \\
\hline 165 & 29 & 1738 & 3.24005 & 16.26 & 0.1566728 & -0.80501 \\
\hline 175 & 58 & 777 & 2.890421 & 26.26 & 0.06604056 & -1.18019 \\
\hline
\end{tabular}

\begin{tabular}{|c|c|c|c|c|c|c|}
\hline \multirow{2}{*}{\multicolumn{4}{|c|}{$\begin{array}{c}\text { Temperature } 250^{\circ} \mathrm{C} \\
9 \mathrm{hr} A-240\end{array}$}} & \multirow{2}{*}{$\begin{array}{c}\mathrm{Tr} \\
190.14 \\
\end{array}$} & \multirow{2}{*}{$\begin{array}{c}\text { ur } \\
10000\end{array}$} & \\
\hline & & & & & & \\
\hline $\begin{array}{l}\text { Temperature } \\
\left({ }^{\circ} \mathrm{C}\right)\end{array}$ & RPM & $\begin{array}{l}\text { Viscosity } \\
\text { (cP) }\end{array}$ & log Visc. & T-Ts & $(\mathrm{n} / \mathrm{T})^{\star}(\mathrm{Tr} / \mathrm{nr})$ & LOG (stuff) \\
\hline 170 & 0.6 & 81383 & 4.910534 & -20.14 & 9.102449188 & 0.959158263 \\
\hline 180 & 2 & 25765 & 4.41103 & -10.14 & 2.721642833 & 0.434831131 \\
\hline 190 & 5.8 & 9112 & 3.959614 & -0.14 & 0.911871411 & -0.0400664 \\
\hline 200 & 14 & 3766 & 3.57588 & 9.86 & 0.35803362 & -0.44607619 \\
\hline 210 & 31 & 1689 & 3.22763 & 19.86 & 0.152926886 & -0.81551616 \\
\hline 220 & 62 & 845 & 2.926857 & 29.86 & 0.073031045 & -1.13649248 \\
\hline
\end{tabular}

\begin{tabular}{|c|c|c|c|c|c|c|}
\hline & \multirow{3}{*}{$\begin{array}{c}\text { Tr } \\
219.24\end{array}$} & \multirow{2}{*}{ ur } & \\
\hline & & & & & & \\
\hline \multicolumn{4}{|c|}{$24 \mathrm{hr}$ A-240 } & & 10000 & \\
\hline $\begin{array}{l}\text { Temperature } \\
\left({ }^{\circ} \mathrm{C}\right)\end{array}$ & RPM & $\begin{array}{l}\text { Viscosity } \\
\text { (cP) }\end{array}$ & log Visc. & T-Ts & $(\mathrm{n} / \mathrm{T})^{\star}(\mathrm{Tr} / \mathrm{nr})$ & LOG (stuff) \\
\hline 200 & 0.8 & 65761 & 4.817968 & -19.24 & 7.20872082 & 0.857858206 \\
\hline 210 & 1.8 & 23395 & 4.369123 & -9.24 & 2.442438 & 0.387823548 \\
\hline 220 & 5.3 & 8692 & 3.93912 & 0.76 & 0.866197309 & -0.06238317 \\
\hline 230 & 14.5 & 3550 & 3.550228 & 10.76 & 0.338392174 & -0.47057969 \\
\hline 240 & 16.53 & 1653 & 3.218273 & 20.76 & 0.15100155 & -0.82101859 \\
\hline 250 & 8.48 & 848 & 2.928396 & 30.76 & 0.074366208 & -1.12862436 \\
\hline
\end{tabular}




\begin{tabular}{|c|c|c|c|c|c|c|}
\hline & \multirow{2}{*}{$\begin{array}{c}\mathrm{Tr} \\
260.49\end{array}$} & ur & \\
\hline & $30 \mathrm{hr}$ & $A-240$ & & & 10000 & \\
\hline $\begin{array}{l}\text { Temperature } \\
\left({ }^{\circ} \mathrm{C}\right)\end{array}$ & RPM & $\begin{array}{l}\text { Viscosity } \\
(\mathrm{cP})\end{array}$ & log Visc. & T-Ts & $(\mathrm{n} / \mathrm{T})^{\star}(\mathrm{Tr} / \mathrm{nr})$ & LOG (stuff) \\
\hline 200 & 0.4 & 1384000 & 6.141136 & -60.49 & 180.25908 & 2.25589715 \\
\hline 210 & 1.1 & 497280 & 5.696601 & -50.49 & 61.684032 & 1.790172754 \\
\hline 220 & 2.8 & 179429 & 5.253893 & -40.49 & 21.24520919 & 1.327261012 \\
\hline 230 & 7 & 78446 & 4.894571 & -30.49 & 8.884521104 & 0.948634023 \\
\hline 240 & 14 & 36754 & 4.565305 & -20.49 & 3.989187275 & 0.600884425 \\
\hline 250 & 29 & 18097 & 4.257607 & -10.49 & 1.885635012 & 0.275457633 \\
\hline 260 & 52 & 9698 & 3.986682 & -0.49 & 0.9716277 & -0.01250011 \\
\hline 270 & 95 & 5747 & 3.759441 & 9.51 & 0.554457789 & -0.25613151 \\
\hline 280 & 155 & 3506 & 3.544812 & 19.51 & 0.326170693 & -0.48655506 \\
\hline
\end{tabular}

\begin{tabular}{|c|c|c|c|c|c|c|}
\hline & \multirow{2}{*}{$\begin{array}{c}\mathrm{Tr} \\
273.12\end{array}$} & ur & \\
\hline \multicolumn{4}{|c|}{45 hr A-240 } & & 10000 & \\
\hline $\begin{array}{l}\text { Temperature } \\
\left({ }^{\circ} \mathrm{C}\right)\end{array}$ & RPM & $\begin{array}{l}\text { Viscosity } \\
(\mathrm{cP})\end{array}$ & log Visc. & T-Ts & $(\mathrm{n} / \mathrm{T})^{\star}(\mathrm{Tr} / \mathrm{nr})$ & LOG (stuff) \\
\hline 240 & 0.2 & 224652 & 5.35151 & -33.12 & 25.5653976 & 1.407652551 \\
\hline 250 & 1 & 51709 & 4.713566 & -23.12 & 5.649104832 & 0.751979634 \\
\hline 260 & 2.2 & 23586 & 4.372654 & -13.12 & 2.477618585 & 0.39403445 \\
\hline 270 & 4.2 & 12255 & 4.088313 & -3.12 & 1.239661333 & 0.093303055 \\
\hline 280 & 8 & 6629 & 3.821448 & 6.88 & 0.6466116 & -0.18935651 \\
\hline 290 & 16 & 3048 & 3.484015 & 16.88 & 0.287058538 & -0.54202953 \\
\hline 300 & 38 & 1272 & 3.104487 & 26.88 & 0.11580288 & -0.93628064 \\
\hline
\end{tabular}

\begin{tabular}{|c|c|c|c|c|c|c|}
\hline \multirow{2}{*}{\multicolumn{4}{|c|}{$\begin{array}{c}\text { Temperature } 275^{\circ} \mathrm{C} \\
9 \mathrm{hr} \text { A-240 }\end{array}$}} & \multirow{3}{*}{$\begin{array}{c}\text { Tr } \\
201.48 \\
\text { T-Ts } \\
\end{array}$} & \multirow{3}{*}{$\begin{array}{c}\text { ur } \\
10000 \\
(n / T)^{\star}(\mathrm{Tr} / \mathrm{nr}) \\
\end{array}$} & \multirow[b]{3}{*}{ LOG (stuff) } \\
\hline & & & & & & \\
\hline $\begin{array}{l}\text { Temperature } \\
\left({ }^{\circ} \mathrm{C}\right)\end{array}$ & RPM & $\begin{array}{l}\text { Viscosity } \\
(\mathrm{cP})\end{array}$ & log Visc. & & & \\
\hline 180 & 0.5 & 91061 & 4.959332 & -21.48 & 10.19276127 & 1.008291852 \\
\hline 190 & 1.8 & 29327 & 4.467268 & -11.48 & 3.109896821 & 0.49274598 \\
\hline 200 & 5 & 10462 & 4.019615 & -1.48 & 1.05394188 & 0.022816662 \\
\hline 210 & 11.5 & 4215 & 3.624798 & 8.52 & 0.404399143 & -0.39318977 \\
\hline 220 & 24 & 1910 & 3.281033 & 18.52 & 0.174921273 & -0.75715737 \\
\hline 230 & 53 & 950 & 2.977724 & 28.52 & 0.08322 & -1.07977229 \\
\hline
\end{tabular}




\begin{tabular}{|r|r|r|r|r|r|r|}
\cline { 5 - 7 } & \multicolumn{1}{c|}{ Tr } & \multicolumn{1}{c|}{ ur } & \\
\hline $\begin{array}{l}\text { Temperature } \\
\left({ }^{\circ} \mathrm{C}\right)\end{array}$ & $\mathbf{1 7}$ hr A-240 & \multicolumn{1}{c|}{$\begin{array}{l}\text { Viscosity } \\
(\mathrm{CP})\end{array}$} & log Visc. & \multicolumn{1}{c|}{ T-Ts } & $(\mathrm{n} / \mathrm{T}) \star(\mathrm{Tr} / \mathrm{nr})$ & LOG (stuff) \\
\hline 215 & 0.4 & 132422 & 5.12196 & -27.75 & 14.95136767 & 1.174680922 \\
\hline 225 & 1.1 & 47063 & 4.67268 & -17.75 & 5.077574778 & 0.705656328 \\
\hline 235 & 2.5 & 17540 & 4.24403 & -7.75 & 1.811844681 & 0.258120965 \\
\hline 245 & 6.6 & 7489 & 3.874424 & 2.25 & 0.742022347 & -0.12958302 \\
\hline 255 & 14.5 & 3380 & 3.528917 & 12.25 & 0.321762745 & -0.49246424 \\
\hline 265 & 30 & 1698 & 3.229938 & 22.25 & 0.155543208 & -0.80814895 \\
\hline 275 & 50 & 924 & 2.965672 & 32.25 & 0.081564 & -1.08850148 \\
\hline
\end{tabular}

\begin{tabular}{|c|c|c|c|c|c|c|}
\hline & & & & Tr & ur & \\
\hline \multicolumn{4}{|c|}{$24 \mathrm{hr}$ A-240 } & 251.02 & 10000 & \\
\hline $\begin{array}{l}\text { Temperature } \\
\left({ }^{\circ} \mathrm{C}\right)\end{array}$ & RPM & $\begin{array}{l}\text { Viscosity } \\
\text { (cP) }\end{array}$ & log Visc. & T-Ts & $(\mathrm{n} / \mathrm{T})^{\star}(\mathrm{Tr} / \mathrm{nr})$ & LOG (stuff) \\
\hline 230 & 0.8 & 62687 & 4.797177 & -21.02 & 6.84160467 & 0.835157976 \\
\hline 240 & 2.1 & 24023 & 4.380627 & -11.02 & 2.512605608 & 0.400124325 \\
\hline 250 & 4.4 & 9952 & 3.99791 & -1.02 & 0.999260416 & -0.00032132 \\
\hline 260 & 10.5 & 4673 & 3.669596 & 8.98 & 0.451160177 & -0.34566924 \\
\hline 270 & 24 & 2170 & 3.33646 & 18.98 & 0.201745704 & -0.69519571 \\
\hline 280 & 42 & 1173 & 3.069298 & 28.98 & 0.10515945 & -0.97815169 \\
\hline 290 & 70 & 668 & 2.824776 & 38.98 & 0.057821159 & -1.23791321 \\
\hline
\end{tabular}

\begin{tabular}{|c|c|c|c|c|c|c|}
\hline & & & & Tr & ur & \\
\hline \multicolumn{4}{|c|}{28 hr A-240 } & 275.64 & 10000 & \\
\hline $\begin{array}{l}\text { Temperature } \\
\left({ }^{\circ} \mathrm{C}\right)\end{array}$ & RPM & $\begin{array}{l}\text { Viscosity } \\
\text { (cP) }\end{array}$ & log Visc. & T-Ts & $(\mathrm{n} / \mathrm{T})^{\star}(\mathrm{Tr} / \mathrm{nr})$ & LOG (stuff) \\
\hline 245 & 0.5 & 100778 & 5.003366 & -30.64 & 11.33814201 & 1.054541892 \\
\hline 255 & 1.2 & 43491 & 4.638399 & -20.64 & 4.701121271 & 0.672201454 \\
\hline 265 & 2.3 & 22821 & 4.358335 & -10.64 & 2.373728468 & 0.375431038 \\
\hline 275 & 4.8 & 10785 & 4.03282 & -0.64 & 1.081009964 & 0.033829697 \\
\hline 285 & 9 & 5772 & 3.761326 & 9.36 & 0.558243537 & -0.2531763 \\
\hline 295 & 15.6 & 3138 & 3.496653 & 19.36 & 0.29320621 & -0.53282684 \\
\hline 305 & 46 & 1035 & 3.01494 & 29.36 & 0.093536852 & -1.02901725 \\
\hline
\end{tabular}




\begin{tabular}{|c|c|c|c|c|c|c|}
\hline \multirow{2}{*}{\multicolumn{4}{|c|}{$\begin{array}{c}\text { Temperature } 300^{\circ} \mathrm{C} \\
6 \mathrm{hr} \text { A-240 }\end{array}$}} & \multirow{3}{*}{$\begin{array}{c}\text { Tr } \\
217.96 \\
\text { T-Ts } \\
\end{array}$} & \multirow{3}{*}{$\begin{array}{c}\mathbf{u r} \\
10000 \\
(\mathrm{n} / \mathrm{T})^{\star}(\mathrm{Tr} / \mathrm{nr}) \\
\end{array}$} & \multirow[b]{3}{*}{$\begin{array}{l}\text { LOG } \\
\text { (stuff) }\end{array}$} \\
\hline & & & & & & \\
\hline $\begin{array}{l}\text { Temperature } \\
\left({ }^{\circ} \mathrm{C}\right)\end{array}$ & RPM & $\begin{array}{l}\text { Viscosity } \\
\text { (cP) }\end{array}$ & log Visc. & & & \\
\hline 195 & 0.5 & 93220 & 4.969509 & -22.96 & 10.41960574 & 1.017851 \\
\hline 205 & 1.4 & 30979 & 4.491067 & -12.96 & 3.293747727 & 0.51769 \\
\hline 215 & 4.2 & 11469 & 4.059526 & -2.96 & 1.162689879 & 0.065464 \\
\hline 225 & 11.2 & 4831 & 3.684037 & 7.04 & 0.467984338 & -0.32977 \\
\hline 235 & 22 & 2247 & 3.351603 & 17.04 & 0.20840686 & -0.68109 \\
\hline 245 & 42 & 1161 & 3.064832 & 27.04 & 0.103286351 & -0.98596 \\
\hline 255 & 75 & 649 & 2.812245 & 37.04 & 0.055472957 & -1.25592 \\
\hline
\end{tabular}

\begin{tabular}{|c|c|c|c|c|c|c|}
\hline & \\
\hline & & & & \multirow{2}{*}{$\begin{array}{c}\mathrm{Tr} \\
256.83\end{array}$} & \multirow{2}{*}{$\frac{\text { ur }}{10000}$} & \multirow[b]{3}{*}{$\begin{array}{l}\text { LOG } \\
\text { (stuff) }\end{array}$} \\
\hline \multicolumn{4}{|c|}{8 hr A-240 } & & & \\
\hline $\begin{array}{l}\text { Temperature } \\
\left({ }^{\circ} \mathrm{C}\right)\end{array}$ & RPM & $\begin{array}{l}\text { Viscosity } \\
(\mathrm{cP})\end{array}$ & log Visc. & T-Ts & $(\mathrm{n} / \mathrm{T})^{\star}(\mathrm{Tr} / \mathrm{nr})$ & \\
\hline 200 & 0.5 & 1071360 & 6.029935 & -56.83 & 137.5786944 & 2.138551 \\
\hline 210 & 1.5 & 361813 & 5.558484 & -46.83 & 44.2497299 & 1.645911 \\
\hline 220 & 3 & 140800 & 5.148603 & -36.83 & 16.43712 & 1.215826 \\
\hline 230 & 9.8 & 57208 & 4.757457 & -26.83 & 6.388143757 & 0.805375 \\
\hline 240 & 20 & 27232 & 4.43508 & -16.83 & 2.9141644 & 0.464514 \\
\hline 250 & 38 & 13979 & 4.145476 & -6.83 & 1.436090628 & 0.157182 \\
\hline 260 & 70 & 7662 & 3.884342 & 3.17 & 0.756858254 & -0.12099 \\
\hline 270 & 120 & 4560 & 3.658965 & 13.17 & 0.433757333 & -0.36275 \\
\hline 280 & 190 & 2789 & 3.445449 & 23.17 & 0.255821025 & -0.59206 \\
\hline
\end{tabular}

\begin{tabular}{|c|c|c|c|c|c|c|}
\hline & \\
\hline & & & & \multirow{2}{*}{$\begin{array}{c}\mathrm{Tr} \\
279.09\end{array}$} & \multirow{2}{*}{$\frac{\text { ur }}{10000}$} & \multirow[b]{3}{*}{$\begin{array}{l}\text { LOG } \\
\text { (stuff) }\end{array}$} \\
\hline \multicolumn{4}{|c|}{$14 \mathrm{hr}$ A-240 } & & & \\
\hline $\begin{array}{l}\text { Temperature } \\
\left({ }^{\circ} \mathrm{C}\right)\end{array}$ & RPM & $\begin{array}{l}\text { Viscosity } \\
(\mathrm{cP})\end{array}$ & log Visc. & T-Ts & $(\mathrm{n} / \mathrm{T})^{\star}(\mathrm{Tr} / \mathrm{nr})$ & \\
\hline 245 & 0.3 & 193759 & 5.287262 & -34.09 & 22.07191809 & 1.34384 \\
\hline 255 & 0.7 & 79097 & 4.89816 & -24.09 & 8.656934012 & 0.937364 \\
\hline 265 & 1.8 & 29494 & 4.469734 & -14.09 & 3.106219042 & 0.492232 \\
\hline 275 & 4 & 13017 & 4.114511 & -4.09 & 1.321059829 & 0.120922 \\
\hline 285 & 8.5 & 5985 & 3.777064 & 5.91 & 0.586089 & -0.23204 \\
\hline 295 & 15 & 3243 & 3.510947 & 15.91 & 0.306809786 & -0.51313 \\
\hline 305 & 38 & 1343 & 3.128076 & 25.91 & 0.122891105 & -0.91048 \\
\hline
\end{tabular}




\begin{tabular}{|c|c|c|c|c|c|c|}
\hline \\
\hline & & & & Tr & ur & \\
\hline \multicolumn{4}{|c|}{$18 \mathrm{hr}$ A-240 } & 297.2 & 10000 & \\
\hline $\begin{array}{l}\text { Temperature } \\
\left({ }^{\circ} \mathrm{C}\right)\end{array}$ & RPM & $\begin{array}{l}\text { Viscosity } \\
(\mathrm{cP})\end{array}$ & log Visc. & T-Ts & $(\mathrm{n} / \mathrm{T})^{\star}(\mathrm{Tr} / \mathrm{nr})$ & $\begin{array}{l}\text { LOG } \\
\text { (stuff) }\end{array}$ \\
\hline 250 & 0.1 & 473899 & 5.675686 & -47.2 & 56.33711312 & 1.750795 \\
\hline 260 & 0.3 & 171363 & 5.233917 & -37.2 & 19.58810908 & 1.291993 \\
\hline 270 & 0.7 & 69242 & 4.84037 & -27.2 & 7.621749037 & 0.882055 \\
\hline 280 & 1.5 & 33393 & 4.523655 & -17.2 & 3.544428429 & 0.549546 \\
\hline 290 & 3 & 15357 & 4.186306 & -7.2 & 1.573827724 & 0.196957 \\
\hline 300 & 5.6 & 9876 & 3.994581 & 2.8 & 0.9783824 & -0.00949 \\
\hline
\end{tabular}

\section{Koppers Coal-Tar Pitch}

\begin{tabular}{|c|c|c|c|c|c|c|}
\hline \multirow{2}{*}{\multicolumn{4}{|c|}{$\begin{array}{c}\text { Raw CTP Feed } \\
0 \text { hr CTP }\end{array}$}} & \multirow{3}{*}{$\begin{array}{c}\text { Tr } \\
137.26 \\
\text { T-Ts } \\
\end{array}$} & \multirow{3}{*}{$\begin{array}{c}\text { ur } \\
10000 \\
(n / T)^{\star}(T r / n r) \\
\end{array}$} & \multirow[b]{3}{*}{ LOG (stuff) } \\
\hline & & & & & & \\
\hline $\begin{array}{l}\text { Temperature } \\
\left({ }^{\circ} \mathrm{C}\right)\end{array}$ & RPM & $\begin{array}{l}\text { Viscosity } \\
\text { (cP) }\end{array}$ & log Visc. & & & \\
\hline 125 & 1.2 & 42191 & 4.62522 & -12.26 & 4.632909328 & 0.6658538 \\
\hline 135 & 4.2 & 11769 & 4.07074 & -2.26 & 1.196602178 & 0.07794979 \\
\hline 145 & 11.5 & 4116 & 3.614475 & 7.74 & 0.389629076 & -0.40 \\
\hline 155 & 30 & 1708 & 3.232488 & 17.74 & 0.151251665 & -0.8202998 \\
\hline 165 & 50 & 817 & 2.912222 & 27.74 & 0.067964497 & -1.1677179 \\
\hline 175 & 125 & 418 & 2.621176 & 37.74 & 0.032785531 & -1.4843178 \\
\hline 185 & 190 & 230 & 2.361728 & 47.74 & 0.017064757 & -1.7678999 \\
\hline
\end{tabular}

\begin{tabular}{|c|c|c|c|c|c|c|}
\hline \multirow{2}{*}{\multicolumn{4}{|c|}{$\begin{array}{c}\text { Temperature } 250^{\circ} \mathrm{C} \\
8 \mathrm{hr} \text { CTP }\end{array}$}} & \multirow{3}{*}{$\begin{array}{c}\text { Tr } \\
186.09 \\
\text { T-Ts } \\
\end{array}$} & \multirow{3}{*}{$\begin{array}{c}\text { ur } \\
10000 \\
(n / T)^{\star}(T r / n r)\end{array}$} & \multirow[b]{3}{*}{ LOG (stuff) } \\
\hline & & & & & & \\
\hline $\begin{array}{l}\text { Temperature } \\
\left({ }^{\circ} \mathrm{C}\right)\end{array}$ & RPM & $\begin{array}{l}\text { Viscosity } \\
(\mathrm{cP})\end{array}$ & log Visc. & & & \\
\hline 160 & 0.3 & 152967 & 5.184598 & -26.09 & 17.79101814 & 1.250200803 \\
\hline 170 & 1.1 & 49190 & 4.691877 & -16.09 & 5.384568882 & 0.731150937 \\
\hline 180 & 2.9 & 16300 & 4.212188 & -6.09 & 1.685148333 & 0.226638135 \\
\hline 190 & 8 & 6359 & 3.803389 & 3.91 & 0.622813847 & -0.20564174 \\
\hline 200 & 19 & 2775 & 3.443263 & 13.91 & 0.258199875 & -0.58804397 \\
\hline 210 & 38 & 1356 & 3.13226 & 23.91 & 0.120160971 & -0.92023657 \\
\hline 220 & 65 & 741 & 2.869818 & 33.91 & 0.062678495 & -1.20288144 \\
\hline
\end{tabular}




\begin{tabular}{|c|c|c|c|c|c|c|}
\hline & & & & $\mathrm{Tr}$ & ur & \\
\hline \multicolumn{4}{|c|}{16 hr CTP } & 220.35 & 10000 & \\
\hline $\begin{array}{l}\text { Temperature } \\
\left({ }^{\circ} \mathrm{C}\right)\end{array}$ & RPM & $\begin{array}{l}\text { Viscosity } \\
(\mathrm{cP})\end{array}$ & log Visc. & T-Ts & $(\mathrm{n} / \mathrm{T})^{\star}(\mathrm{Tr} / \mathrm{nr})$ & LOG (stuff) \\
\hline 190 & 0.2 & 177562 & 5.24935 & -30.35 & 20.59251932 & 1.313709482 \\
\hline 200 & 0.9 & 60920 & 4.78476 & -20.35 & 6.711861 & 0.826842954 \\
\hline 210 & 2.2 & 22304 & 4.348383 & -10.35 & 2.340326857 & 0.369276517 \\
\hline 220 & 5 & 9610 & 3.982723 & -0.35 & 0.962528864 & -0.01658624 \\
\hline 230 & 11.5 & 4512 & 3.654369 & 9.65 & 0.432269217 & -0.36424569 \\
\hline 240 & 24 & 2192 & 3.340841 & 19.65 & 0.201253 & -0.69625764 \\
\hline 250 & 44 & 1202 & 3.079904 & 29.65 & 0.10594428 & -0.97492249 \\
\hline 260 & 75 & 699 & 2.844477 & 39.65 & 0.05924025 & -1.22738312 \\
\hline
\end{tabular}

\begin{tabular}{|c|c|c|c|c|c|c|}
\hline & & & & Tr & ur & \\
\hline \multicolumn{4}{|c|}{$24 \mathrm{hr}$ CTP } & 269.79 & 10000 & \\
\hline $\begin{array}{l}\text { Temperature } \\
\left({ }^{\circ} \mathrm{C}\right)\end{array}$ & RPM & $\begin{array}{l}\text { Viscosity } \\
(\mathrm{cP})\end{array}$ & log Visc. & T-Ts & $(\mathrm{n} / \mathrm{T})^{\star}(\mathrm{Tr} / \mathrm{nr})$ & LOG (stuff) \\
\hline 225 & 0.1 & 448704 & 5.65196 & -44.79 & 53.80260096 & 1.730803271 \\
\hline 235 & 0.3 & 152767 & 5.18403 & -34.79 & 17.53830167 & 1.243987536 \\
\hline 245 & 0.8 & 67336 & 4.828247 & -24.79 & 7.414930384 & 0.870107078 \\
\hline 255 & 1.5 & 35113 & 4.545468 & -14.79 & 3.7149554 & 0.569953604 \\
\hline 265 & 2.8 & 19453 & 4.288987 & -4.79 & 1.980462215 & 0.296766561 \\
\hline 275 & 6 & 8938 & 3.95124 & 5.21 & 0.876866553 & -0.0570665 \\
\hline 285 & 18 & 2836 & 3.452706 & 15.21 & 0.268464716 & -0.57111279 \\
\hline 295 & 32 & 1569 & 3.195623 & 25.21 & 0.143491698 & -0.84317322 \\
\hline 305 & 52 & 1050 & 3.021189 & 35.21 & 0.092878525 & -1.03208469 \\
\hline
\end{tabular}

\begin{tabular}{|c|c|c|c|c|c|c|}
\hline & \multirow{2}{*}{$\begin{array}{c}\text { Tr } \\
270.97\end{array}$} & \multirow{2}{*}{$\begin{array}{c}\text { ur } \\
10000\end{array}$} & \multirow[b]{3}{*}{ LOG (stuff) } \\
\hline & $30 \mathrm{hr}$ & CTP & & & & \\
\hline $\begin{array}{l}\text { Temperature } \\
\left({ }^{\circ} \mathrm{C}\right)\end{array}$ & RPM & $\begin{array}{l}\text { Viscosity } \\
\text { (cP) }\end{array}$ & log Visc. & T-Ts & $(\mathrm{n} / \mathrm{T})^{\star}(\mathrm{Tr} / \mathrm{nr})$ & \\
\hline 225 & 0.1 & 389317 & 5.590303 & -45.97 & 46.88587888 & 1.671042061 \\
\hline 235 & 0.3 & 154167 & 5.187991 & -35.97 & 17.77643914 & 1.24984477 \\
\hline 245 & 0.8 & 64786 & 4.811481 & -25.97 & 7.1653316 & 0.855236294 \\
\hline 255 & 1.9 & 28920 & 4.461198 & -15.97 & 3.073118588 & 0.48757932 \\
\hline 265 & 3.8 & 13750 & 4.138303 & -5.97 & 1.405976415 & 0.147978036 \\
\hline 275 & 8 & 6486 & 3.811977 & 4.03 & 0.639095062 & -0.19443454 \\
\hline 285 & 16 & 3022 & 3.480294 & 14.03 & 0.287323277 & -0.54162919 \\
\hline 295 & 28 & 1733 & 3.238799 & 24.03 & 0.159183393 & -0.79810224 \\
\hline 305 & & 1050 & 3.021189 & 34.03 & 0.093284754 & -1.03018933 \\
\hline
\end{tabular}




\begin{tabular}{|c|c|c|c|c|c|c|}
\hline \multirow{2}{*}{\multicolumn{4}{|c|}{$\begin{array}{c}\text { Temperature } 275^{\circ} \mathrm{C} \\
5 \mathrm{hr} \text { CTP }\end{array}$}} & \multirow{2}{*}{$\frac{\operatorname{Tr}}{200.04}$} & \multirow{2}{*}{$\frac{\text { ur }}{10000}$} & \multirow[b]{3}{*}{ LOG (stuff) } \\
\hline & & & & & & \\
\hline $\begin{array}{l}\text { Temperature } \\
\left({ }^{\circ} \mathrm{C}\right)\end{array}$ & RPM & $\begin{array}{l}\text { Viscosity } \\
\text { (cP) }\end{array}$ & log Visc. & T-Ts & $(\mathrm{n} / \mathrm{T})^{\star}(\mathrm{Tr} / \mathrm{nr})$ & \\
\hline 170 & 0.2 & 192859 & 5.28524 & -30.04 & 22.69383198 & 1.355907835 \\
\hline 180 & 0.7 & 60244 & 4.779914 & -20.04 & 6.695116533 & 0.825758141 \\
\hline 190 & 2.3 & 20578 & 4.313403 & -10.04 & 2.166538484 & 0.335766408 \\
\hline 200 & 5.8 & 8543 & 3.93161 & -0.04 & 0.85447086 & -0.06830274 \\
\hline 210 & 13.5 & 3848 & 3.585235 & 9.96 & 0.366549486 & -0.43586739 \\
\hline 220 & 26 & 1826 & 3.261501 & 19.96 & 0.1660332 & -0.77980506 \\
\hline 230 & 52 & 1009 & 3.003891 & 29.96 & 0.087756678 & -1.05671982 \\
\hline 240 & 85 & 593 & 2.773055 & 39.96 & 0.04942655 & -1.3060397 \\
\hline
\end{tabular}

\begin{tabular}{|c|c|c|c|c|c|c|}
\hline \\
\hline & & & & $\mathrm{Tr}$ & ur & \\
\hline \multicolumn{4}{|c|}{$10 \mathrm{hr}$ CTP } & 242.57 & 10000 & \\
\hline $\begin{array}{l}\text { Temperature } \\
\left({ }^{\circ} \mathrm{C}\right)\end{array}$ & RPM & $\begin{array}{l}\text { Viscosity } \\
\text { (cP) }\end{array}$ & log Visc. & T-Ts & $(\mathrm{n} / \mathrm{T})^{\star}(\mathrm{Tr} / \mathrm{nr})$ & LOG (stuff) \\
\hline 205 & 0.2 & 251346 & 5.400272 & -37.57 & 29.74097523 & 1.473355205 \\
\hline 215 & 0.6 & 88781 & 4.94832 & -27.57 & 10.01656147 & 1.000718661 \\
\hline 225 & 1.4 & 37749 & 4.576905 & -17.57 & 4.069677747 & 0.609560021 \\
\hline 235 & 3.2 & 16084 & 4.206394 & -7.57 & 1.660211013 & 0.22016329 \\
\hline 245 & 6.7 & 7530 & 3.876795 & 2.43 & 0.745531469 & -0.12753402 \\
\hline 255 & 14 & 3741 & 3.572988 & 12.43 & 0.355864459 & -0.44871538 \\
\hline 265 & 24 & 2045 & 3.310693 & 22.43 & 0.187190811 & -0.72771547 \\
\hline 275 & 44 & 1182 & 3.072617 & 32.43 & 0.104260996 & -0.98187813 \\
\hline
\end{tabular}

\begin{tabular}{|c|c|c|c|c|c|c|}
\hline \\
\hline & & & & \multirow{2}{*}{$\begin{array}{c}\text { Tr } \\
275.02\end{array}$} & \multirow{2}{*}{$\begin{array}{c}\text { ur } \\
10000\end{array}$} & \\
\hline \multicolumn{4}{|c|}{15 hr CTP } & & & \\
\hline $\begin{array}{l}\text { Temperature } \\
\left({ }^{\circ} \mathrm{C}\right)\end{array}$ & RPM & $\begin{array}{l}\text { Viscosity } \\
\text { (cP) }\end{array}$ & log Visc. & T-Ts & $(\mathrm{n} / \mathrm{T})^{\star}(\mathrm{Tr} / \mathrm{nr})$ & LOG (stuff) \\
\hline 235 & 0.2 & 198558 & 5.297887 & -40.02 & 23.23720049 & 1.366183805 \\
\hline 245 & 0.6 & 80283 & 4.904624 & -30.02 & 9.012012514 & 0.954821786 \\
\hline 255 & 1.4 & 36592 & 4.563386 & -20.02 & 3.946483075 & 0.596210245 \\
\hline 265 & 2.6 & 17650 & 4.246745 & -10.02 & 1.831736981 & 0.262863114 \\
\hline 275 & 5.5 & 9183 & 3.962985 & -0.02 & 0.918366785 & -0.03698383 \\
\hline 285 & 10 & 5327 & 3.726483 & 9.98 & 0.514046154 & -0.28899789 \\
\hline 295 & 16 & 3033 & 3.481872 & 19.98 & 0.282757851 & -0.54858533 \\
\hline 305 & 32 & 1597 & 3.203305 & 29.98 & 0.144002275 & -0.84163065 \\
\hline
\end{tabular}




\begin{tabular}{|c|c|c|c|c|c|c|}
\hline & & & & Tr & ur & \\
\hline \multicolumn{4}{|c|}{21 hr CTP } & 298.92 & 10000 & \\
\hline $\begin{array}{l}\text { Temperature } \\
\left({ }^{\circ} \mathrm{C}\right)\end{array}$ & RPM & $\begin{array}{l}\text { Viscosity } \\
(\mathrm{cP})\end{array}$ & log Visc. & T-Ts & $(\mathrm{n} / \mathrm{T})^{\star}(\mathrm{Tr} / \mathrm{nr})$ & LOG (stuff) \\
\hline 245 & 0.1 & 381519 & 5.581516 & -53.92 & 46.54843244 & 1.66790506 \\
\hline 255 & 0.3 & 178162 & 5.250815 & -43.92 & 20.88477845 & 1.319829872 \\
\hline 265 & 0.6 & 83482 & 4.921593 & -33.92 & 9.4167696 & 0.973901945 \\
\hline 275 & 1.1 & 42591 & 4.629318 & -23.92 & 4.629564262 & 0.665540117 \\
\hline 285 & 2.2 & 24322 & 4.385999 & -13.92 & 2.550993768 & 0.406709398 \\
\hline 295 & 3.5 & 14208 & 4.152533 & -3.92 & 1.439679783 & 0.158265906 \\
\hline 305 & 8 & 6599 & 3.819478 & 6.08 & 0.646745272 & -0.18926674 \\
\hline
\end{tabular}

\begin{tabular}{|c|c|c|c|c|c|c|}
\hline \multirow{2}{*}{\multicolumn{4}{|c|}{$\begin{array}{c}\text { Temperature } 300^{\circ} \mathrm{C} \\
3 \text { hr CTP }\end{array}$}} & \multirow{2}{*}{$\begin{array}{c}\mathrm{Tr} \\
195.13 \\
\end{array}$} & \multirow{2}{*}{$\frac{\text { ur }}{10000}$} & \multirow[b]{3}{*}{ LOG (stuff) } \\
\hline & & & & & & \\
\hline $\begin{array}{l}\text { Temperature } \\
\left({ }^{\circ} \mathrm{C}\right)\end{array}$ & RPM & $\begin{array}{l}\text { Viscosity } \\
\text { (cP) }\end{array}$ & log Visc. & T-Ts & $(\mathrm{n} / \mathrm{T})^{\star}(\mathrm{Tr} / \mathrm{nr})$ & \\
\hline 165 & 0.2 & 203357 & 5.308259 & -30.13 & 24.04912207 & 1.381099227 \\
\hline 175 & 0.8 & 64036 & 4.806424 & -20.13 & 7.14019696 & 0.853710192 \\
\hline 185 & 2.2 & 21923 & 4.3409 & -10.13 & 2.312343238 & 0.3640523 \\
\hline 195 & 5.8 & 9153 & 3.961563 & -0.13 & 0.9159102 & 0.038147104 \\
\hline 205 & 13 & 4010 & 3.603144 & 9.87 & 0.381693317 & 0.418285444 \\
\hline 215 & 27 & 1942 & 3.288249 & 19.87 & 0.176252307 & -0.75386519 \\
\hline 225 & 50 & 1004 & 3.001734 & 29.87 & 0.087071342 & 1.060124761 \\
\hline
\end{tabular}

\begin{tabular}{|c|c|c|c|c|c|c|}
\hline & & & & Tr & ur & \\
\hline \multicolumn{4}{|c|}{$5 \mathrm{hr}$ CTP } & 223.77 & 10000 & \\
\hline $\begin{array}{l}\text { Temperature } \\
\left({ }^{\circ} \mathrm{C}\right)\end{array}$ & RPM & $\begin{array}{l}\text { Viscosity } \\
\text { (cP) }\end{array}$ & log Visc. & T-Ts & $(\mathrm{n} / \mathrm{T})^{\star}(\mathrm{Tr} / \mathrm{nr})$ & LOG (stuff) \\
\hline 190 & 0.2 & 212055 & 5.326449 & -33.77 & 24.97449861 & 1.397496778 \\
\hline 200 & 0.7 & 71642 & 4.855168 & -23.77 & 8.01566517 & 0.903939568 \\
\hline 210 & 1.8 & 29294 & 4.466779 & -13.77 & 3.121484943 & 0.494361244 \\
\hline 220 & 4.2 & 11583 & 4.063821 & -3.77 & 1.17814905 & 0.071200237 \\
\hline 230 & 9 & 5412 & 3.733358 & 6.23 & 0.526540539 & 0.278568186 \\
\hline 240 & 18 & 2719 & 3.434409 & 16.23 & 0.253512763 & 0.596000172 \\
\hline 250 & 36 & 1468 & 3.166726 & 26.23 & 0.131397744 & 0.881412091 \\
\hline 260 & 60 & 860 & 2.934498 & 36.23 & 0.074016231 & 1.130673035 \\
\hline
\end{tabular}




\begin{tabular}{|c|c|c|c|c|c|c|}
\hline & & & & Tr & ur & \\
\hline \multicolumn{4}{|c|}{8 hr CTP } & 267.98 & 10000 & \\
\hline $\begin{array}{l}\text { Temperature } \\
\left({ }^{\circ} \mathrm{C}\right)\end{array}$ & RPM & $\begin{array}{l}\text { Viscosity } \\
\text { (cP) }\end{array}$ & log Visc. & T-Ts & $(\mathrm{n} / \mathrm{T})^{\star}(\mathrm{Tr} / \mathrm{nr})$ & LOG (stuff) \\
\hline 225 & 0.2 & 256445 & 5.408994 & -42.98 & 30.54316938 & 1.484914101 \\
\hline 235 & 0.4 & 132122 & 5.120975 & -32.98 & 15.06640577 & 1.17800966 \\
\hline 245 & 1 & 53269 & 4.726475 & -22.98 & 5.826541478 & 0.765410842 \\
\hline 255 & 2.2 & 22059 & 4.343586 & -12.98 & 2.318184635 & 0.365148023 \\
\hline 265 & 4.8 & 10360 & 4.01536 & -2.98 & 1.047650113 & 0.020216264 \\
\hline 275 & 10 & 5435 & 3.7352 & 7.02 & 0.529625927 & $0.276030763^{-}$ \\
\hline 285 & 17 & 3056 & 3.485153 & 17.02 & 0.287349782 & 0.541589127 \\
\hline 295 & 28 & 1795 & 3.254064 & 27.02 & 0.163059017 & -0.78765518 \\
\hline 305 & 47 & 1144 & 3.058426 & 37.02 & 0.100514466 & 0.997771432 \\
\hline
\end{tabular}

\begin{tabular}{|c|c|c|c|c|c|c|}
\hline & & & & Tr & ur & \\
\hline \multicolumn{4}{|c|}{10 hr CTP } & 276.63 & 10000 & \\
\hline $\begin{array}{l}\text { Temperature } \\
\left({ }^{\circ} \mathrm{C}\right)\end{array}$ & RPM & $\begin{array}{l}\text { Viscosity } \\
(\mathrm{cP})\end{array}$ & log Visc. & T-Ts & $(\mathrm{n} / \mathrm{T})^{\star}(\mathrm{Tr} / \mathrm{nr})$ & LOG (stuff) \\
\hline 235 & 0.2 & 266043 & 5.424952 & -41.63 & 31.31722344 & 1.495783251 \\
\hline 245 & 0.5 & 100539 & 5.002335 & -31.63 & 11.35187901 & 1.055067754 \\
\hline 255 & 1.2 & 43791 & 4.641385 & -21.63 & 4.750550718 & 0.676743959 \\
\hline 265 & 2.5 & 20132 & 4.303887 & -11.63 & 2.101552891 & 0.322540325 \\
\hline 275 & 5.2 & 9967 & 3.998564 & -1.63 & 1.002607713 & 0.001131041 \\
\hline 285 & 10 & 5303 & 3.724522 & 8.37 & 0.514725926 & 0.288423956 \\
\hline 295 & 17 & 3063 & 3.486147 & 18.37 & 0.287226336 & 0.541775742 \\
\hline 305 & 28 & 1832 & 3.262925 & 28.37 & 0.166159397 & 0.779475093 \\
\hline
\end{tabular}

\section{WVU Coal-Extract Pitch}

\begin{tabular}{|c|c|c|c|c|c|c|}
\hline \multirow{2}{*}{\multicolumn{4}{|c|}{$\begin{array}{c}\text { Raw Coal Extract Feed } \\
0 \mathrm{hr} \text { Coal Extract }\end{array}$}} & \multirow{3}{*}{$\begin{array}{c}\text { Tr } \\
152.76 \\
\text { T-Ts }\end{array}$} & \multirow{3}{*}{$\begin{array}{c}\text { ur } \\
10000 \\
(n / T)^{*}(T r / n r)\end{array}$} & \multirow[b]{3}{*}{ LOG (stuff) } \\
\hline & & & & & & \\
\hline $\begin{array}{l}\text { Temperature } \\
\left({ }^{\circ} \mathrm{C}\right)\end{array}$ & RPM & $\begin{array}{l}\text { Viscosity } \\
\text { (cP) }\end{array}$ & log Visc. & & & \\
\hline 135 & 0.7 & 72842 & \begin{tabular}{|l|}
4.862382 \\
\end{tabular} & -17.76 & 8.242476978 & 0.91605774 \\
\hline 145 & 2.2 & 20859 & \begin{tabular}{|l|}
4.319293 \\
\end{tabular} & -7.76 & 2.197531614 & 0.34193513 \\
\hline 155 & 5.6 & 7091 & 3.850707 & 2.24 & 0.698852361 & -0.1556146 \\
\hline 165 & 18 & 2803 & 3.447623 & 12.24 & 0.259506836 & -0.5858512 \\
\hline 175 & 36 & 1315 & \begin{tabular}{|l|}
3.118926 \\
\end{tabular} & 22.24 & 0.114788229 & -0.9401026 \\
\hline 185 & 66 & 684 & \begin{tabular}{|l|}
2.835056 \\
\end{tabular} & 32.24 & 0.056479914 & -1.248106 \\
\hline
\end{tabular}




\begin{tabular}{|c|c|c|c|c|c|c|}
\hline \multirow{2}{*}{\multicolumn{4}{|c|}{$\begin{array}{c}\text { Temperature } 250^{\circ} \mathrm{C} \\
3 \mathrm{hr} \text { Coal Extract }\end{array}$}} & \multirow{2}{*}{$\frac{\mathrm{Tr}}{212.78}$} & \multirow{2}{*}{$\frac{\text { ur }}{10000}$} & \multirow[b]{3}{*}{ LOG (stuff) } \\
\hline & & & & & & \\
\hline $\begin{array}{l}\text { Temperature } \\
\left({ }^{\circ} \mathrm{C}\right)\end{array}$ & RPM & $\begin{array}{l}\text { Viscosity } \\
\text { (cP) }\end{array}$ & log Visc. & T-Ts & $(\mathrm{n} / \mathrm{T})^{\star}(\mathrm{Tr} / \mathrm{nr})$ & \\
\hline 190 & 0.1 & 413312 & 5.616278 & -22.78 & 46.28659335 & 1.665455218 \\
\hline 200 & 2.1 & 22824 & 4.358392 & -12.78 & 2.42824536 & 0.385292568 \\
\hline 210 & 4.8 & 8911 & 3.949926 & -2.78 & 0.902896467 & -0.04436205 \\
\hline 220 & 12 & 3424 & 3.534534 & 7.22 & 0.331163055 & -0.47995812 \\
\hline 230 & 32 & 1488 & 3.172603 & 17.22 & 0.137659409 & -0.8611941 \\
\hline 240 & 62 & 801 & 2.903633 & 27.22 & 0.071015325 & -1.14864792 \\
\hline
\end{tabular}

\begin{tabular}{|c|c|c|c|c|c|c|}
\hline & & & & Tr & ur & \\
\hline \multicolumn{4}{|c|}{$5 \mathrm{hr}$ Coal Extract } & 221.97 & 10000 & \\
\hline $\begin{array}{l}\text { Temperature } \\
\left({ }^{\circ} \mathrm{C}\right)\end{array}$ & RPM & $\begin{array}{l}\text { Viscosity } \\
\text { (cP) }\end{array}$ & log Visc. & T-Ts & $(\mathrm{n} / \mathrm{T})^{\star}(\mathrm{Tr} / \mathrm{nr})$ & LOG (stuff) \\
\hline 195 & 0.3 & 161366 & 5.207812 & -26.97 & 18.36841591 & 1.264071704 \\
\hline 205 & 0.9 & 53855 & 4.731226 & -16.97 & 5.831314317 & 0.765766451 \\
\hline 215 & 2.4 & 18071 & 4.256982 & -6.97 & 1.86568366 & 0.270838008 \\
\hline 225 & 6.8 & 6749 & 3.829239 & 3.03 & 0.665811347 & -0.17664881 \\
\hline 235 & 19 & 2627 & 3.41946 & 13.03 & 0.248134123 & -0.60531351 \\
\hline 245 & 36 & 1290 & 3.11059 & 23.03 & 0.116874 & -0.93228209 \\
\hline 255 & 48 & 704 & 2.847573 & 33.03 & 0.061281129 & -1.21267324 \\
\hline
\end{tabular}

\begin{tabular}{|c|c|c|c|c|c|c|}
\hline \multirow{2}{*}{\multicolumn{4}{|c|}{$\begin{array}{c}\text { Temperature } 275^{\circ} \mathrm{C} \\
2 \mathrm{hr} \text { Coal Extract }\end{array}$}} & \multirow{2}{*}{$\begin{array}{c}\text { Tr } \\
214.79 \\
\end{array}$} & \multirow{2}{*}{$\frac{\text { ur }}{10000}$} & \multirow[b]{3}{*}{ LOG (stuff) } \\
\hline & & & & & & \\
\hline $\begin{array}{l}\text { Temperature } \\
\left({ }^{\circ} \mathrm{C}\right)\end{array}$ & RPM & $\begin{array}{l}\text { Viscosity } \\
\text { (cP) }\end{array}$ & log Visc. & T-Ts & $(\mathrm{n} / \mathrm{T})^{\star}(\mathrm{Tr} / \mathrm{nr})$ & \\
\hline 195 & 0.8 & 66361 & 4.821913 & -19.79 & 7.309579072 & 0.863892368 \\
\hline 205 & 2 & 26964 & 4.430784 & -9.79 & 2.825169541 & 0.451044515 \\
\hline 215 & 5.2 & 9725 & 3.98789 & 0.21 & 0.971550116 & -0.01253479 \\
\hline 225 & 14 & 3419 & 3.533899 & 10.21 & 0.326385338 & -0.48626936 \\
\hline 235 & 30 & 1634 & 3.213252 & 20.21 & 0.1493476 & -0.82580175 \\
\hline 245 & 58 & 899 & 2.95376 & 30.21 & 0.07881478 & -1.10339233 \\
\hline
\end{tabular}

\begin{tabular}{|c|c|c|c|c|c|c|}
\hline & \multirow{3}{*}{$\begin{array}{c}\mathrm{Tr} \\
254.12\end{array}$} & \multirow{2}{*}{ ur } & \\
\hline & & & & & & \\
\hline \multicolumn{4}{|c|}{$5 \mathrm{hr}$ Coal Extract } & & 10000 & \\
\hline $\begin{array}{l}\text { Temperature } \\
\left({ }^{\circ} \mathrm{C}\right)\end{array}$ & RPM & $\begin{array}{l}\text { Viscosity } \\
(\mathrm{cP})\end{array}$ & log Visc. & T-Ts & $(\mathrm{n} / \mathrm{T})^{\star}(\mathrm{Tr} / \mathrm{nr})$ & LOG (stuff) \\
\hline 240 & 1.6 & 34943 & 4.54336 & -14.12 & 3.699881317 & 0.568187793 \\
\hline 250 & 3.4 & 14609 & 4.16462 & -4.12 & 1.484975632 & 0.171719327 \\
\hline 260 & 7.5 & 7230 & 3.859138 & 5.88 & 0.706649077 & -0.1507962 \\
\hline 270 & 19 & 2052 & 3.312177 & 15.88 & 0.1931312 & -0.71414756 \\
\hline 280 & 41 & 1112 & 3.046105 & 25.88 & 0.100921943 & -0.9960144 \\
\hline 290 & 72 & 626 & 2.796574 & 35.88 & 0.054854869 & -1.26078482 \\
\hline
\end{tabular}




\begin{tabular}{|c|c|c|c|c|c|c|}
\hline \multirow{2}{*}{\multicolumn{4}{|c|}{$\begin{array}{c}\text { Temperature } 300^{\circ} \mathrm{C} \\
1 \mathrm{hr} \text { Coal Extract }\end{array}$}} & \multirow{2}{*}{\begin{tabular}{|c|}
$\operatorname{Tr}$ \\
214.2
\end{tabular}} & \multirow{2}{*}{$\frac{\text { ur }}{10000}$} & \multirow[b]{3}{*}{ LOG (stuff) } \\
\hline & & & & & & \\
\hline $\begin{array}{l}\text { Temperature } \\
\left({ }^{\circ} \mathrm{C}\right)\end{array}$ & RPM & $\begin{array}{l}\text { Viscosity } \\
(\mathrm{cP})\end{array}$ & log Visc. & T-Ts & $(\mathrm{n} / \mathrm{T})^{\star}(\mathrm{Tr} / \mathrm{nr})$ & \\
\hline 190 & 0.4 & 114875 & 5.060226 & -24.2 & 12.95064474 & 1.11229139 \\
\hline 200 & 1.5 & 34633 & 4.53949 & -14.2 & 3.7091943 & 0.569279584 \\
\hline 210 & 3.6 & 13330 & 4.12483 & -4.2 & 1.35966 & 0.133430321 \\
\hline 220 & 9 & 5286 & 3.723127 & 5.8 & 0.514664182 & 0.288476056 \\
\hline 230 & 22 & 2320 & 3.365488 & 15.8 & 0.216062609 & 0.665420385 \\
\hline 240 & 44 & 1213 & 3.083861 & 25.8 & 0.10826025 & 0.965530974 \\
\hline 250 & 80 & 661 & 2.820201 & 35.8 & 0.05663448 & 1.246919083 \\
\hline
\end{tabular}

\begin{tabular}{|c|c|c|c|c|c|c|}
\hline & \\
\hline & & & & \multirow{2}{*}{$\begin{array}{c}\text { Tr } \\
252.55\end{array}$} & ur & \\
\hline \multicolumn{4}{|c|}{$2 \mathrm{hr}$ Coal Extract } & & 10000 & \\
\hline $\begin{array}{l}\text { Temperature } \\
\left({ }^{\circ} \mathrm{C}\right)\end{array}$ & RPM & $\begin{array}{l}\text { Viscosity } \\
(\mathrm{cP})\end{array}$ & log Visc. & T-Ts & $(n / T)^{\star}(T r / n r)$ & LOG (stuff) \\
\hline 220 & 0.2 & 226752 & 5.355551 & -32.55 & 26.03009891 & 1.415475818 \\
\hline 230 & 0.8 & 62012 & 4.792476 & -22.55 & 6.809187217 & 0.833095275 \\
\hline 240 & 2 & 22555 & 4.353243 & -12.55 & 2.373443854 & 0.375378963 \\
\hline 250 & 5.2 & 9979 & 3.999087 & -2.55 & 1.00807858 & 0.003494387 \\
\hline 260 & 11 & 4641 & 3.666612 & 7.45 & 0.45080175 & 0.346014407 \\
\hline 270 & 18 & 2473 & 3.393224 & 17.45 & 0.231317093 & 0.635792275 \\
\hline 280 & 35 & 1445 & 3.159868 & 27.45 & 0.130333839 & 0.884942811 \\
\hline 290 & 62 & 795 & 2.900367 & 37.45 & 0.069233534 & 1.159683496 \\
\hline
\end{tabular}

\begin{tabular}{|c|c|c|c|c|c|c|}
\hline & & & & $\mathrm{Tr}$ & ur & \\
\hline \multicolumn{4}{|c|}{$3 \mathrm{hr}$ Coal Extract } & 256.13 & 10000 & \\
\hline $\begin{array}{l}\text { Temperature } \\
\left({ }^{\circ} \mathrm{C}\right)\end{array}$ & RPM & $\begin{array}{l}\text { Viscosity } \\
\text { (cP) }\end{array}$ & log Visc. & T-Ts & $(\mathrm{n} / \mathrm{T})^{\star}(\mathrm{Tr} / \mathrm{nr})$ & LOG (stuff) \\
\hline 240 & 1.2 & 42241 & 4.625734 & -16.13 & 4.507994721 & 0.653983399 \\
\hline 250 & 3 & 16776 & 4.224688 & -6.13 & 1.718734752 & 0.235208858 \\
\hline 260 & 7 & 7070 & 3.849419 & 3.87 & 0.696476577 & 0.157093485 \\
\hline 270 & 15 & 2595 & 3.414137 & 13.87 & 0.246169389 & 0.608765952 \\
\hline 280 & 34 & 1685 & 3.2266 & 23.87 & 0.154135375 & 0.812097677 \\
\hline 290 & 55 & 863 & 2.936011 & 33.87 & 0.076220755 & 1.117926753 \\
\hline
\end{tabular}




\begin{tabular}{|c|c|c|c|c|c|c|}
\hline \\
\hline & & & & \multirow{2}{*}{$\begin{array}{c}\mathrm{Tr} \\
268.39\end{array}$} & \multirow{2}{*}{$\frac{\text { ur }}{10000}$} & \\
\hline \multicolumn{4}{|c|}{4 hr Coal Extract } & & & \\
\hline $\begin{array}{l}\text { Temperature } \\
\left({ }^{\circ} \mathrm{C}\right)\end{array}$ & RPM & $\begin{array}{l}\text { Viscosity } \\
\text { (cP) }\end{array}$ & log Visc. & T-Ts & $(\mathrm{n} / \mathrm{T})^{\star}(\mathrm{Tr} / \mathrm{nr})$ & LOG (stuff) \\
\hline 245 & 0.5 & 93940 & 4.972851 & -23.39 & 10.29083943 & 1.012450802 \\
\hline 255 & 1.4 & 35692 & 4.552571 & -13.39 & 3.756617992 & 0.574797034 \\
\hline 265 & 4.6 & 10550 & 4.023252 & -3.39 & 1.068496038 & 0.028772916 \\
\hline 275 & 8.5 & 4404 & 3.643847 & 6.61 & 0.429814385 & 0.366719053 \\
\hline 285 & 22 & 2220 & 3.346353 & 16.61 & 0.209061684 & 0.679725555 \\
\hline 295 & 38 & 1313 & 3.118265 & 26.61 & 0.119456295 & -0.92279096 \\
\hline 305 & 70 & 752 & 2.876218 & 36.61 & 0.066173534 & 1.179315668 \\
\hline
\end{tabular}




\section{Appendix V \\ Elemental Analysis Data Tables}




\section{Ashland A240 Petroleum Pitch Elemental Analysis}

\begin{tabular}{|c|c|c|c|c|c|}
\hline \multicolumn{7}{|c|}{ Feed A240 } \\
\hline & $\% \mathrm{C}$ & $\% \mathrm{H}$ & $\% \mathrm{~N}$ & $\% \mathrm{~S}$ & $\% \mathrm{O}$ \\
\hline & 91.12 & 5.57 & 0 & 2.75 & 0.440924 \\
\hline & 91.04 & 5.58 & 0 & 2.66 & 0.445159 \\
\hline & 90.92 & 5.59 & 0 & 2.71 & 0.445991 \\
\hline & 90.66 & 5.57 & 0 & 2.79 & \\
\hline & 90.52 & 5.57 & 0 & 2.76 & \\
\hline Average & 90.75 & 5.57 & 0 & 2.73 & \\
\hline & 90.835 & 5.575 & 0 & 2.733333 & 0.444025 \\
\hline & & & & & \\
\hline & H/C Atomic & O/C Atomic & $1 / \mathrm{C}$ & $\mathrm{C} / \mathrm{H}$ Atomic & \\
\hline & 0.7365 & 0.003666 & 0.132108 & 1.357773 & \\
\hline
\end{tabular}

\begin{tabular}{|c|c|c|c|c|c|}
\hline \multicolumn{7}{|c|}{ A240 AB 250 ${ }^{\circ} \mathrm{C}$ For 9 Hours } \\
\hline & $\% \mathrm{C}$ & $\% \mathrm{H}$ & $\% \mathrm{~N}$ & $\% \mathrm{~S}$ & $\% \mathrm{O}$ \\
\hline & 90.37 & 5.35 & 0 & 2.46 & 0.724575 \\
\hline & 90.2 & 5.36 & 0 & 2.57 & 0.733055 \\
\hline & & & & & 0.726206 \\
\hline Average & 90.29 & 5.36 & 0 & 2.52 & 0.727946 \\
\hline & & & & & \\
\hline & H/C Atomic & O/C Atomic & $1 / \mathrm{C}$ & C/H Atomic & \\
\hline & 0.712371 & 0.006047 & 0.132905 & 1.4038 & \\
\hline
\end{tabular}

\begin{tabular}{|c|c|c|c|c|c|}
\hline \multicolumn{7}{|c|}{ A240 AB 250 ${ }^{\circ} \mathrm{C}$ For 24 Hours } \\
\hline & $\% \mathrm{C}$ & $\% \mathrm{H}$ & $\% \mathrm{~N}$ & $\% \mathrm{~S}$ & $\% \mathrm{O}$ \\
\hline & 90.22 & 5.2 & 0 & 2.46 & 0.844013 \\
\hline & 90.43 & 5.27 & 0 & 2.57 & 0.802049 \\
\hline & & & & & 0.793282 \\
\hline Average & 90.33 & 5.24 & 0 & 2.52 & 0.813115 \\
\hline & & & & & \\
\hline & $\mathrm{H} / \mathrm{C}$ Atomic & O/C Atomic & $1 / \mathrm{C}$ & $\mathrm{C} / \mathrm{H}$ Atomic & \\
\hline & 0.696114 & 0.006751 & 0.132846 & 1.4365 & \\
\hline
\end{tabular}

\begin{tabular}{|l|r|r|r|r|l|}
\hline \multicolumn{7}{|c|}{ A240 AB 250 ${ }^{\circ} \mathrm{C}$ For 30 Hours } \\
\hline & $\% \mathrm{C}$ & \multicolumn{1}{|c|}{$\% \mathrm{H}$} & $\% \mathrm{~N}$ & \multicolumn{1}{l|}{$\% \mathrm{~S}$} & $\% \mathrm{O}$ \\
\hline & 89.92 & 5.18 & 0 & 2.62 & 0.951372 \\
\hline & 89.96 & 5.21 & 0 & 2.65 & 0.967652 \\
\hline & & & & & 0.897381 \\
\hline Average & 89.94 & 5.2 & 0 & 2.64 & 0.938802 \\
\hline & & & & & \\
\hline & H/C Atomic & O/C Atomic & $1 / \mathrm{C}$ & C/H Atomic & \\
\hline & 0.693796 & 0.007829 & 0.133422 & 1.441346 & \\
\hline
\end{tabular}




\begin{tabular}{|c|c|c|c|c|c|}
\hline \multicolumn{7}{|c|}{ A240 AB 250 ${ }^{\circ} \mathrm{C}$ For 45 Hours } \\
\hline & $\% \mathrm{C}$ & $\% \mathrm{H}$ & $\% \mathrm{~N}$ & $\% \mathrm{~S}$ & $\% \mathrm{O}$ \\
\hline & 90.83 & 5.09 & 0 & 2.57 & 1.046996 \\
\hline & 90.68 & 5.08 & 0 & 2.53 & 1.062854 \\
\hline & 90.26 & 5.1 & 0 & 2.57 & 1.125383 \\
\hline Average & 90.59 & 5.09 & 0 & 2.56 & 1.078411 \\
\hline & & & & & \\
\hline & H/C Atomic & O/C Atomic & $1 / \mathrm{C}$ & $\mathrm{C} / \mathrm{H}$ Atomic & \\
\hline & 0.674247 & 0.008928 & 0.132465 & 1.483136 & \\
\hline
\end{tabular}

\begin{tabular}{|l|r|r|r|r|l|}
\hline \multicolumn{7}{|c|}{ A240 AB 275 ${ }^{\circ} \mathrm{C}$ For 9 Hours } \\
\hline & $\% \mathrm{C}$ & \multicolumn{1}{|c|}{$\% \mathrm{H}$} & \multicolumn{1}{l}{ \% } & \multicolumn{1}{l|}{$\% \mathrm{~S}$} & $\% \mathrm{O}$ \\
\hline & 90.51 & 5.31 & 0 & 2.57 & 0.666604 \\
\hline & 90.79 & 5.29 & 0 & 2.49 & 0.684084 \\
\hline & 90.87 & 5.36 & 0 & 2.59 & 0.685161 \\
\hline Average & 90.72 & 5.32 & 0 & 2.55 & 0.678616 \\
\hline & & & & & \\
\hline & H/C Atomic & O/C Atomic & $1 / \mathrm{C}$ & C/H Atomic & \\
\hline & 0.703704 & 0.00561 & 0.132275 & 1.421052 & \\
\hline
\end{tabular}

\begin{tabular}{|l|r|r|r|r|l|}
\hline \multicolumn{7}{|c|}{ A240 AB 275 ${ }^{\circ}$ For 17 Hours } \\
\hline & \% C & \% & \% & \multicolumn{1}{l|}{$\% \mathrm{~S}$} & $\% \mathrm{O}$ \\
\hline & 90.98 & 5.23 & 0 & 2.49 & 0.812993 \\
\hline & 91.29 & 5.21 & 0 & 2.34 & 0.767796 \\
\hline & 91.44 & 5.22 & 0 & 2.5 & 0.800016 \\
\hline Average & 91.24 & 5.22 & 0 & 2.44 & 0.793602 \\
\hline & & & & & \\
\hline & H/C Atomic & O/C Atomic & $1 / \mathrm{C}$ & C/H Atomic & \\
\hline & 0.686541 & 0.006523 & 0.131521 & 1.456577 & \\
\hline
\end{tabular}

\begin{tabular}{|c|c|c|c|c|c|}
\hline \multicolumn{6}{|c|}{ A240 AB $275^{\circ} \mathrm{C}$ For 24 Hours } \\
\hline & $\% \mathrm{C}$ & $\% \mathrm{H}$ & $\% \mathrm{~N}$ & $\% \mathrm{~S}$ & $\% O$ \\
\hline & & 5.07 & 0 & 2.28 & 0.80347 \\
\hline & 91.66 & 5.17 & 0 & 2.14 & 0.881325 \\
\hline & & & & & 0.854044 \\
\hline Average & 91.66 & 5.12 & $\underline{0}$ & 2.21 & 0.84628 \\
\hline & $\mathrm{H} / \mathrm{C}$ Atomic & O/C Atomic & $1 / C$ & $\mathrm{C} / \mathrm{H}$ Atomic & \\
\hline & 0.670303 & 0.006925 & 0.130919 & 1.491862 & \\
\hline
\end{tabular}




\begin{tabular}{|c|c|c|c|c|c|}
\hline \multicolumn{6}{|c|}{ A240 AB $275^{\circ} \mathrm{C}$ For 28 Hours } \\
\hline & $\% \mathrm{C}$ & $\% \mathrm{H}$ & $\% \mathrm{~N}$ & $\% \mathrm{~S}$ & $\% \mathrm{O}$ \\
\hline & 90.86 & 5.06 & 0 & 2.28 & 1.11178 \\
\hline & & 5.01 & 0 & 2.14 & 1.09633 \\
\hline & & & & & 0.905251 \\
\hline Average & 90.86 & 5.04 & 0 & 2.21 & 1.037787 \\
\hline & $\mathrm{H} / \mathrm{C}$ Atomic & O/C Atomic & $1 / C$ & $\mathrm{C} / \mathrm{H}$ Atomic & \\
\hline & 0.665639 & 0.008566 & 0.132071 & 1.502315 & \\
\hline
\end{tabular}

\begin{tabular}{|c|c|c|c|c|c|}
\hline \multicolumn{6}{|c|}{ A240 AB $300^{\circ} \mathrm{C}$ For 6 Hours } \\
\hline & $\% \mathrm{C}$ & $\% \mathrm{H}$ & $\% \mathrm{~N}$ & $\% \mathrm{~S}$ & $\% \mathrm{O}$ \\
\hline & 90.54 & 5.24 & 0 & 2.79 & 0.740902 \\
\hline & & & & & 0.797896 \\
\hline & & & & & 0.849621 \\
\hline Average & 90.54 & 5.24 & 0 & 2.79 & 0.79614 \\
\hline & $\mathrm{H} / \mathrm{C}$ Atomic & $\mathrm{O} / \mathrm{C}$ Atomic & $1 / C$ & $\mathrm{C} / \mathrm{H}$ Atomic & \\
\hline & 0.6945 & 0.006595 & 0.132538 & 1.439885 & \\
\hline
\end{tabular}

\begin{tabular}{|c|c|c|c|c|c|}
\hline \multicolumn{6}{|c|}{ A240 AB $300^{\circ} \mathrm{C}$ For 8 Hours } \\
\hline & $\% \mathrm{C}$ & $\% \mathrm{H}$ & $\% \mathrm{~N}$ & $\% \mathrm{~S}$ & $\% O$ \\
\hline & 90.58 & 5.26 & 0 & 2.73 & 0.831282 \\
\hline & 91.43 & 5.18 & 0 & 2.74 & 0.814459 \\
\hline & 90.8 & 5.2 & 0 & 2.58 & 0.877906 \\
\hline Average & 90.94 & 5.21 & 0 & 2.68 & 0.841216 \\
\hline & $\mathrm{H} / \mathrm{C}$ Atomic & O/C Atomic & $1 / C$ & $\mathrm{C} / \mathrm{H}$ Atomic & \\
\hline & 0.687486 & 0.006938 & 0.131955 & 1.454575 & \\
\hline
\end{tabular}

\begin{tabular}{|c|c|c|c|c|c|}
\hline \multicolumn{6}{|c|}{ A240 AB $300^{\circ} \mathrm{C}$ For 14 Hours } \\
\hline & $\% \mathrm{C}$ & $\% \mathrm{H}$ & $\% \mathrm{~N}$ & $\% \mathrm{~S}$ & $\% \mathrm{O}$ \\
\hline & 91.88 & 5.12 & 0 & 2.82 & 0.947338 \\
\hline & 91.17 & 5.14 & 0 & 2.74 & 0.953102 \\
\hline & 89.96 & 4.97 & 0 & 2.86 & 0.90169 \\
\hline Average & 91 & 5.08 & 0 & 2.81 & 0.934044 \\
\hline & $\mathrm{H} / \mathrm{C}$ Atomic & O/C Atomic & $1 / C$ & $\mathrm{C} / \mathrm{H}$ Atomic & \\
\hline & 0.66989 & 0.007698 & 0.131868 & 1.492782 & \\
\hline
\end{tabular}




\begin{tabular}{|c|c|c|c|c|c|}
\hline \multicolumn{6}{|c|}{ A240 AB $300^{\circ} \mathrm{C}$ For 18 Hours } \\
\hline & $\% \mathrm{C}$ & $\% \mathrm{H}$ & $\% \mathrm{~N}$ & $\% \mathrm{~S}$ & $\% \mathrm{O}$ \\
\hline & 90.45 & 4.95 & 0 & 2.4 & 0.966728 \\
\hline & 92.18 & 5 & 0 & 2.72 & 0.993438 \\
\hline & & & & & 0.950036 \\
\hline Average & 91.32 & 4.98 & 0 & 2.56 & 0.970067 \\
\hline & $\mathrm{H} / \mathrm{C}$ Atomic & $\mathrm{O} / \mathrm{C}$ Atomic & $1 / C$ & $\mathrm{C} / \mathrm{H}$ Atomic & \\
\hline & 0.654402 & 0.007967 & 0.131406 & 1.528112 & \\
\hline
\end{tabular}

\section{Koppers Coal-Tar Pitch Elemental Analysis}

\begin{tabular}{|l|l|r|l|l|l|}
\hline \multicolumn{7}{|c|}{ Feed QI-Free CTP } \\
\hline & $\% \mathrm{C}$ & \multicolumn{1}{|c|}{$\% \mathrm{H}$} & $\% \mathrm{~N}$ & $\% \mathrm{~S}$ & $\% \mathrm{O}$ \\
\hline & 91.01996 & 4.751735 & 1.613563 & 0.507936 & 1.612287 \\
\hline & 91.00024 & 4.77921 & 1.668421 & 0.463185 & 1.812512 \\
\hline & 91.36973 & 4.757663 & 1.753564 & 0.462952 & 1.803107 \\
\hline Average & 91.12998 & 4.76287 & 1.678516 & 0.478024 & 1.742636 \\
\hline & & & & & \\
\hline & H/C Atomic & O/C Atomic & $1 / \mathrm{C}$ & $\mathrm{C} / \mathrm{H}$ Atomic & \\
\hline & 0.627175 & 0.014342 & 0.13168 & 1.594452 & \\
\hline
\end{tabular}

\begin{tabular}{|l|l|l|l|l|l|}
\hline \multicolumn{7}{|c|}{ QI-Free CTP AB $250^{\circ} \mathrm{C}$ For 8 Hours } \\
\hline & $\% \mathrm{C}$ & $\% \mathrm{H}$ & $\% \mathrm{~N}$ & $\% \mathrm{~S}$ & $\% \mathrm{O}$ \\
\hline & 92.65916 & 4.357177 & 1.201271 & 0.481619 & 1.395564 \\
\hline & 92.84637 & 4.369372 & 1.259416 & 0.468107 & 1.414921 \\
\hline & 92.81541 & 4.340986 & 0.982595 & 0.4754 & 1.413002 \\
\hline Average & 92.77365 & 4.355826 & 1.14776 & 0.475042 & 1.407829 \\
\hline & & & & & \\
\hline & H/C Atomic & O/C Atomic & $1 / \mathrm{C}$ & C/H Atomic & \\
\hline & 0.563413 & 0.011381 & 0.129347 & 1.774896 & \\
\hline
\end{tabular}

\begin{tabular}{|l|l|l|l|l|l|}
\hline \multicolumn{7}{|c|}{ QI-Free CTP AB 250 ${ }^{\circ}$ For 16 Hours } \\
\hline & $\% \mathrm{C}$ & $\% \mathrm{H}$ & $\% \mathrm{~N}$ & $\% \mathrm{~S}$ & $\% \mathrm{O}$ \\
\hline & 91.67643 & 4.172395 & 0.808382 & 0.446882 & 1.572293 \\
\hline & 92.40559 & 4.208545 & 0.817773 & 0.45749 & 1.510206 \\
\hline & 91.74322 & 4.169261 & 0.787756 & 0.44933 & 1.542125 \\
\hline Average & 91.94174 & 4.1834 & 0.804637 & 0.451234 & 1.541542 \\
\hline & & & & & \\
\hline & H/C Atomic & O/C Atomic & $1 / \mathrm{C}$ & C/H Atomic & \\
\hline & 0.546007 & 0.012575 & 0.130517 & 1.83148 & \\
\hline
\end{tabular}




\begin{tabular}{|l|l|r|l|l|l|}
\hline \multicolumn{7}{|c|}{ QI-Free CTP AB $250^{\circ} \mathrm{C}$ For 24 Hours } \\
\hline & $\% \mathrm{C}$ & \multicolumn{1}{l}{$\% \mathrm{H}$} & $\% \mathrm{~N}$ & $\% \mathrm{~S}$ & $\% \mathrm{O}$ \\
\hline & 93.17706 & 4.124336 & 0.771888 & 0.456694 & 1.669852 \\
\hline & 93.22583 & 4.14598 & 0.826524 & 0.456752 & 1.576621 \\
\hline & 93.15246 & 4.171174 & 0.854902 & 0.465036 & 1.584814 \\
\hline Average & 93.18512 & 4.147163 & 0.817771 & 0.459494 & 1.610429 \\
\hline & & & & & \\
\hline & H/C Atomic & O/C Atomic & $1 / \mathrm{C}$ & C/H Atomic & \\
\hline & 0.534055 & 0.012962 & 0.128776 & 1.872467 & \\
\hline
\end{tabular}

\begin{tabular}{|l|c|l|l|l|l|}
\hline \multicolumn{7}{|c|}{ QI-Free CTP AB $250^{\circ} \mathrm{C}$ For 30 Hours } \\
\hline & $\% \mathrm{C}$ & $\% \mathrm{H}$ & $\% \mathrm{~N}$ & $\% \mathrm{~S}$ & $\% \mathrm{O}$ \\
\hline & 93.2603 & 4.16313 & 0.844691 & 0.487812 & 1.552691 \\
\hline & 93.41776 & 4.128587 & 0.796013 & 0.454817 & 1.564975 \\
\hline & 93.33428 & 4.135834 & 0.804245 & 0.423076 & 1.542821 \\
\hline Average & 93.33745 & 4.142517 & 0.814983 & 0.455235 & 1.553496 \\
\hline & & & & & \\
\hline & H/C Atomic & O/C Atomic & $1 / \mathrm{C}$ & C/H Atomic & \\
\hline & 0.532586 & 0.012483 & 0.128566 & 1.877632 & \\
\hline
\end{tabular}

\begin{tabular}{|l|l|l|l|l|l|}
\hline \multicolumn{7}{|c|}{ QI-Free CTP AB 275 ${ }^{\circ} \mathrm{C}$ For 5 Hours } \\
\hline & $\% \mathrm{C}$ & $\% \mathrm{H}$ & $\% \mathrm{~N}$ & $\% \mathrm{~S}$ & $\% \mathrm{O}$ \\
\hline & 93.53122 & 4.285515 & 0.790101 & 0.441382 & 1.361261 \\
\hline & 93.49592 & 4.308653 & 0.811481 & 0.450382 & 1.359222 \\
\hline & 93.50031 & 4.320952 & 0.857458 & 0.436146 & 1.361834 \\
\hline Average & 93.50915 & 4.30504 & 0.81968 & 0.442637 & 1.360772 \\
\hline & & & & & \\
\hline & H/C Atomic & O/C Atomic & $1 / \mathrm{C}$ & C/H Atomic & \\
\hline & 0.552464 & 0.010914 & 0.12833 & 1.810071 & \\
\hline
\end{tabular}

\begin{tabular}{|l|l|l|l|l|l|}
\hline \multicolumn{7}{|c|}{ QI-Free CTP AB 275 ${ }^{\circ}$ For 10 Hours } \\
\hline & $\% \mathrm{C}$ & $\% \mathrm{H}$ & $\% \mathrm{~N}$ & $\% \mathrm{~S}$ & $\% \mathrm{O}$ \\
\hline & 93.21045 & 4.165638 & 0.855119 & 0.45463 & 1.453016 \\
\hline & 93.34361 & 4.186713 & 0.821127 & 0.456663 & 1.426667 \\
\hline & 93.26183 & 4.149627 & 0.833573 & 0.436776 & 1.454795 \\
\hline & & & & & \\
\hline Average & 93.27196 & 4.167326 & 0.836606 & 0.449357 & 1.444826 \\
\hline & & & & & \\
\hline & H/C Atomic & O/C Atomic & $1 / \mathrm{C}$ & C/H Atomic & \\
\hline & 0.536152 & 0.011618 & 0.128656 & 1.865144 & \\
\hline
\end{tabular}




\begin{tabular}{|l|l|l|l|l|l|}
\hline \multicolumn{7}{|c|}{ QI-Free CTP AB $275^{\circ} \mathrm{C}$ For 15 Hours } \\
\hline & $\% \mathrm{C}$ & $\% \mathrm{H}$ & $\% \mathrm{~N}$ & $\% \mathrm{~S}$ & $\% \mathrm{O}$ \\
\hline & 92.94444 & 4.061543 & 0.914227 & 0.530581 & 1.482574 \\
\hline & 92.50633 & 4.062951 & 0.919787 & 0.424915 & 1.505741 \\
\hline & 92.98198 & 4.080009 & 1.025938 & 0.447781 & 1.55041 \\
\hline Average & 92.81092 & 4.068168 & 0.953317 & 0.467759 & 1.512908 \\
\hline & & & & & \\
\hline & H/C Atomic & O/C Atomic & $1 / \mathrm{C}$ & C/H Atomic & \\
\hline & 0.525994 & 0.012226 & 0.129295 & 1.901161 & \\
\hline
\end{tabular}

\begin{tabular}{|l|l|l|l|l|l|}
\hline \multicolumn{7}{|c|}{ QI-Free CTP AB 275C For 21 Hours } \\
\hline & $\% \mathrm{C}$ & $\% \mathrm{H}$ & $\% \mathrm{~N}$ & $\% \mathrm{~S}$ & $\% \mathrm{O}$ \\
\hline & 92.82796 & 4.043859 & 1.030268 & 0.448121 & 1.532696 \\
\hline & 92.86988 & 4.044569 & 1.043134 & 0.423473 & 1.531565 \\
\hline & 92.87373 & 4.037241 & 1.163639 & 0.446582 & 1.528481 \\
\hline Average & 92.85719 & 4.04189 & 1.079014 & 0.439392 & 1.530914 \\
\hline & & & & & \\
\hline & H/C Atomic & O/C Atomic & $1 / \mathrm{C}$ & $\mathrm{C} / \mathrm{H}$ Atomic & \\
\hline & 0.522336 & 0.012365 & 0.129231 & 1.914476 & \\
\hline
\end{tabular}

\begin{tabular}{|l|l|l|l|l|l|}
\hline \multicolumn{7}{|c|}{ QI-Free CTP AB $300^{\circ} \mathrm{C}$ For 3 Hours } \\
\hline & $\% \mathrm{C}$ & $\% \mathrm{H}$ & $\% \mathrm{~N}$ & $\% \mathrm{~S}$ & $\% \mathrm{O}$ \\
\hline & 92.64419 & 4.244493 & 1.131764 & 0.430905 & 1.391759 \\
\hline & 92.80296 & 4.272773 & 0.971312 & 0.462551 & 1.345259 \\
\hline & 92.68787 & 4.260565 & 0.883326 & 0.446775 & 1.259171 \\
\hline Average & 92.71167 & 4.259277 & 0.995467 & 0.446743 & 1.332033 \\
\hline & & & & & \\
\hline & H/C Atomic & O/C Atomic & $1 / \mathrm{C}$ & C/H Atomic & \\
\hline & 0.551293 & 0.010776 & 0.129434 & 1.813916 & \\
\hline
\end{tabular}

\begin{tabular}{|l|l|l|l|l|l|}
\hline \multicolumn{7}{|c|}{ QI-Free CTP AB $300^{\circ} \mathbf{C}$ For 5 Hours } \\
\hline & $\% \mathrm{C}$ & $\% \mathrm{H}$ & $\% \mathrm{~N}$ & $\% \mathrm{~S}$ & $\% \mathrm{O}$ \\
\hline & 93.09677 & 4.111135 & 0.809211 & 0.307992 & 1.382241 \\
\hline & 92.69948 & 4.172738 & 0.761682 & 0.457111 & 1.394702 \\
\hline & 93.36037 & 4.201414 & 0.809193 & 0.475167 & 1.411336 \\
\hline Average & 93.05221 & 4.161762 & 0.793362 & 0.413423 & 1.396093 \\
\hline & & & & & \\
\hline & H/C Atomic & O/C Atomic & $1 / \mathrm{C}$ & C/H Atomic & \\
\hline & 0.5367 & 0.011253 & 0.12896 & 1.863237 & \\
\hline
\end{tabular}




\begin{tabular}{|l|l|l|l|l|l|}
\hline \multicolumn{7}{|c|}{ QI-Free CTP AB $300^{\circ} \mathrm{C}$ For 8 Hours } \\
\hline & $\% \mathrm{C}$ & $\% \mathrm{H}$ & $\% \mathrm{~N}$ & $\% \mathrm{~S}$ & $\% \mathrm{O}$ \\
\hline & 93.22013 & 4.09496 & 0.745481 & 0.448594 & 1.450753 \\
\hline & 92.75369 & 4.102091 & 0.771363 & 0.446518 & 1.497172 \\
\hline & 93.01638 & 4.106703 & 0.823583 & 0.440363 & 1.504551 \\
\hline Average & 92.99673 & 4.101251 & 0.780142 & 0.445158 & 1.484158 \\
\hline & & & & & \\
\hline & H/C Atomic & O/C Atomic & $1 / \mathrm{C}$ & C/H Atomic & \\
\hline & 0.529212 & 0.011969 & 0.129037 & 1.889601 & \\
\hline
\end{tabular}

\begin{tabular}{|l|l|l|l|l|c|}
\hline \multicolumn{7}{|c|}{ QI-Free CTP AB $300^{\circ} \mathrm{C}$ For 10 Hours } \\
\hline & $\% \mathrm{C}$ & $\% \mathrm{H}$ & $\% \mathrm{~N}$ & $\% \mathrm{~S}$ & $\% \mathrm{O}$ \\
\hline & 93.69782 & 4.132432 & 0.817459 & 0.463781 & 1.52205 \\
\hline & 92.75738 & 4.078528 & 0.772548 & 0.438467 & 1.511883 \\
\hline & 92.79948 & 4.079633 & 0.787846 & 0.427387 & 1.579657 \\
\hline Average & 93.08489 & 4.096864 & 0.792617 & 0.443212 & 1.537864 \\
\hline & & & & & \\
\hline & H/C Atomic & O/C Atomic & $1 / \mathrm{C}$ & C/H Atomic & \\
\hline & 0.528146 & 0.012391 & 0.128915 & 1.893417 & \\
\hline
\end{tabular}

\section{WVU Coal-Extract Pitch Elemental Analysis}

\begin{tabular}{|c|c|c|c|c|c|}
\hline \multicolumn{7}{|c|}{ Feed Coal-Extract pitch H093 } \\
\hline & $\% \mathrm{C}$ & $\% \mathrm{H}$ & $\% \mathrm{~N}$ & $\% \mathrm{~S}$ & $\% \mathrm{O}$ \\
\hline & 88.93551 & 5.801709 & 1.774479 & 0.386957 & 2.636031 \\
\hline & 89.148 & 5.859317 & 1.795597 & 0.327164 & 2.600861 \\
\hline & 89.3736 & 5.792777 & 1.812606 & 0.320771 & 2.670465 \\
\hline Average & 89.15237 & 5.817934 & 1.794227 & 0.344964 & 2.635786 \\
\hline & & & & & \\
\hline & H/C Atomic & O/C Atomic & $1 / \mathrm{C}$ & C/H Atomic & \\
\hline & 0.7831 & 0.022174 & 0.134601 & 1.276976 & \\
\hline
\end{tabular}

\begin{tabular}{|c|c|c|c|c|c|}
\hline \multicolumn{6}{|c|}{ Coal-Extract pitch AB $250^{\circ} \mathrm{C}$ For 3 Hours } \\
\hline & $\% \mathrm{C}$ & $\% \mathrm{H}$ & $\% \mathrm{~N}$ & $\% \mathrm{~S}$ & $\% \mathrm{O}$ \\
\hline & 89.97158 & 5.484581 & 1.747659 & 0.31558 & 2.506908 \\
\hline & 90.03343 & 5.490194 & 1.658241 & 0.305784 & 2.519899 \\
\hline & 90.08024 & 5.490195 & 1.618606 & 0.304914 & 2.506846 \\
\hline Average & 90.02842 & 5.488323 & 1.674835 & 0.308759 & 2.511218 \\
\hline & & & & & \\
\hline & H/C Atomic & O/C Atomic & $1 / \mathrm{C}$ & C/H Atomic & \\
\hline & 0.731545 & 0.02092 & 0.133291 & 1.366969 & \\
\hline
\end{tabular}




\begin{tabular}{|c|c|c|c|c|c|}
\hline \multicolumn{7}{|c|}{ Coal-Extract pitch $\mathrm{AB} 250^{\circ} \mathrm{C}$ For 5 Hours } \\
\hline & $\% \mathrm{C}$ & $\% \mathrm{H}$ & $\% \mathrm{~N}$ & $\% \mathrm{~S}$ & $\% \mathrm{O}$ \\
\hline & 90.4553 & 5.42546 & 1.60515 & 0.313701 & 2.479589 \\
\hline & 89.98824 & 5.364038 & 1.474416 & 0.29052 & 2.484793 \\
\hline & 90.11885 & 5.388947 & 1.529301 & 0.297538 & 2.461563 \\
\hline Average & 90.18746 & 5.392815 & 1.536289 & 0.300586 & 2.475315 \\
\hline & & & & & \\
\hline & H/C Atomic & O/C Atomic & $1 / \mathrm{C}$ & C/H Atomic & \\
\hline & 0.717547 & 0.020585 & 0.133056 & 1.393636 & \\
\hline
\end{tabular}

\begin{tabular}{|c|c|c|c|c|c|}
\hline \multicolumn{6}{|c|}{ Coal-Extract pitch $\mathrm{AB} 2 \mathbf{2 7}^{\circ} \mathrm{C}$ For 2 Hours } \\
\hline & $\% \mathrm{C}$ & $\% \mathrm{H}$ & $\% \mathrm{~N}$ & $\% \mathrm{~S}$ & $\% \mathrm{O}$ \\
\hline & 88.9819 & 5.337453 & 1.468444 & 0.284579 & 2.500674 \\
\hline & 88.41658 & 5.327549 & 1.44669 & 0.283922 & 2.486718 \\
\hline & 89.01871 & 5.336147 & 1.449285 & 0.282177 & 2.503982 \\
\hline Average & 88.80573 & 5.333716 & 1.454806 & 0.28356 & 2.497125 \\
\hline & & & & & \\
\hline & H/C Atomic & O/C Atomic & $1 / \mathrm{C}$ & C/H Atomic & \\
\hline & 0.720726 & 0.021089 & 0.135126 & 1.38749 & \\
\hline
\end{tabular}

\begin{tabular}{|c|c|c|c|c|c|}
\hline \multicolumn{6}{|c|}{ Coal-Extract pitch AB $275^{\circ} \mathrm{C}$ For 5 Hours } \\
\hline & $\% \mathrm{C}$ & $\% \mathrm{H}$ & $\% \mathrm{~N}$ & $\% \mathrm{~S}$ & $\% \mathrm{O}$ \\
\hline & 89.98801 & 5.16705 & 1.436412 & 0.289748 & 2.495997 \\
\hline & 90.4936 & 5.220552 & 1.530075 & 0.28454 & 2.483145 \\
\hline & 90.01949 & 5.195322 & 1.536638 & 0.287466 & 2.484428 \\
\hline Average & 90.16704 & 5.194308 & 1.501042 & 0.287251 & 2.487857 \\
\hline & & & & & \\
\hline & H/C Atomic & O/C Atomic & $1 / \mathrm{C}$ & C/H Atomic & \\
\hline & 0.691291 & 0.020694 & 0.133086 & 1.446568 & \\
\hline
\end{tabular}

\begin{tabular}{|c|c|c|c|c|c|}
\hline \multicolumn{6}{|c|}{ Coal-Extract pitch $\mathrm{AB} \mathbf{3 0 0 ^ { \circ } \mathrm { C } \text { For } 1 \text { Hours }}$} \\
\hline & $\% \mathrm{C}$ & $\% \mathrm{H}$ & $\% \mathrm{~N}$ & $\% \mathrm{~S}$ & $\% \mathrm{O}$ \\
\hline & 89.45058 & 5.319645 & 1.409332 & 0.326213 & 2.513641 \\
\hline & 89.77666 & 5.355975 & 1.434553 & 0.294751 & 2.445212 \\
\hline & 90.05719 & 5.354958 & 1.454286 & 0.281988 & 2.445063 \\
\hline Average & 89.76148 & 5.343526 & 1.432723 & 0.300984 & 2.467972 \\
\hline & & & & & \\
\hline & H/C Atomic & O/C Atomic & $1 / \mathrm{C}$ & C/H Atomic & \\
\hline & 0.714363 & 0.020621 & 0.133688 & 1.399848 & \\
\hline
\end{tabular}




\begin{tabular}{|c|c|c|c|c|c|}
\hline \multicolumn{7}{|c|}{ Coal-Extract pitch $\mathrm{AB} \mathbf{3 0 0}^{\circ} \mathrm{C}$ For $\mathbf{2}$ Hours } \\
\hline & $\% \mathrm{C}$ & $\% \mathrm{H}$ & $\% \mathrm{~N}$ & $\% \mathrm{~S}$ & $\% \mathrm{O}$ \\
\hline & 90.17432 & 5.192916 & 1.496782 & 0.293364 & 2.47224 \\
\hline & 89.98154 & 5.194839 & 1.454789 & 0.275541 & 2.4374 \\
\hline & 89.8064 & 5.167157 & 1.488963 & 0.282436 & 2.464901 \\
\hline Average & 89.98742 & 5.184971 & 1.480178 & 0.28378 & 2.458181 \\
\hline & & & & & \\
\hline & H/C Atomic & O/C Atomic & $1 / \mathrm{C}$ & C/H Atomic & \\
\hline & 0.691426 & 0.020488 & 0.133352 & 1.446286 & \\
\hline
\end{tabular}

\begin{tabular}{|c|c|c|c|c|c|}
\hline \multicolumn{6}{|c|}{ Coal-Extract pitch $\mathrm{AB} \mathbf{3 0 0 ^ { \circ } \mathrm { C } \text { For } 3 \text { Hours }}$} \\
\hline & $\% \mathrm{C}$ & $\% \mathrm{H}$ & $\% \mathrm{~N}$ & $\% \mathrm{~S}$ & $\% \mathrm{O}$ \\
\hline & 89.2807 & 5.103723 & 1.543809 & 0.28298 & 2.427017 \\
\hline & 89.49577 & 5.111496 & 1.600077 & 0.280145 & 2.454612 \\
\hline & 89.27948 & 5.127618 & 1.663877 & 0.282331 & 2.399748 \\
\hline Average & 89.35198 & 5.114279 & 1.602588 & 0.281818 & 2.427125 \\
\hline & & & & & \\
\hline & H/C Atomic & O/C Atomic & $1 / \mathrm{C}$ & C/H Atomic & \\
\hline & 0.686849 & 0.020373 & 0.1343 & 1.455923 & \\
\hline
\end{tabular}

\begin{tabular}{|c|c|c|c|c|c|}
\hline \multicolumn{6}{|c|}{ Coal-Extract pitch $\mathrm{AB} \mathbf{3 0 0}^{\circ} \mathrm{C}$ For 4 Hours } \\
\hline & $\% \mathrm{C}$ & $\% \mathrm{H}$ & $\% \mathrm{~N}$ & $\% \mathrm{~S}$ & $\% \mathrm{O}$ \\
\hline & 89.34852 & 5.038198 & 1.665455 & 0.241014 & 2.428588 \\
\hline & 89.37491 & 5.050701 & 1.92147 & 0.261109 & 2.427507 \\
\hline & 89.08163 & 5.013106 & 1.761702 & 0.247619 & 2.509608 \\
\hline Average & 89.26835 & 5.034002 & 1.782876 & 0.249914 & 2.455234 \\
\hline & & & & & \\
\hline & H/C Atomic & O/C Atomic & $1 / \mathrm{C}$ & C/H Atomic & \\
\hline & 0.676701 & 0.020628 & 0.134426 & 1.477757 & \\
\hline
\end{tabular}




\section{Appendix VI}

FTIR Data Tables 
Baseline corrected FTIR data for Ashland A240 petroleum pitch

\begin{tabular}{|c|c|c|c|c|c|c|c|c|}
\hline Sample \# & $\begin{array}{c}\text { Time } \\
\text { (hr) }\end{array}$ & $\begin{array}{c}\left(\mathrm{H}_{\mathrm{ar}}+\right. \\
\left.\mathrm{H}_{\mathrm{al}}\right)\end{array}$ & $\mathrm{H}_{\mathrm{al}}$ & $\mathrm{H}_{\mathrm{ar}}$ & $\begin{array}{c}\left(\mathrm{C}_{\mathrm{ar}}+\right. \\
\left.\mathrm{H}_{\mathrm{al}}\right)\end{array}$ & $C_{a r}$ & $\mathrm{H}_{\mathrm{al}}$ & $\mathrm{H}_{\mathrm{ar}}$ \\
\hline & - & $\begin{array}{c}2800- \\
3100\end{array}$ & $\begin{array}{c}2800- \\
3000\end{array}$ & $\begin{array}{l}3000- \\
3100\end{array}$ & $\begin{array}{c}1416- \\
1700\end{array}$ & $\begin{array}{c}1540- \\
1700\end{array}$ & $\begin{array}{c}1416- \\
1540\end{array}$ & $\begin{array}{l}700- \\
920\end{array}$ \\
\hline BC Feed A240 & 0 & 52.294 & 35.945 & 16.345 & 53.197 & 33.489 & 19.735 & 45.138 \\
\hline $\mathrm{BC}$ AB A240 $250^{\circ} \mathrm{C}$ & 9 & 45.733 & 30.262 & 15.471 & 41.87 & 24.145 & 22.242 & 39.419 \\
\hline $\mathrm{BC}$ AB A240 $250^{\circ} \mathrm{C}$ & 24 & 34.73 & 23.39 & 11.339 & 43.561 & 29.267 & 17.405 & 32.528 \\
\hline $\mathrm{BC}$ AB A240 $250^{\circ} \mathrm{C}$ & 30 & 35.183 & 23.329 & 11.862 & 48.827 & 31.529 & 17.3 & 33.236 \\
\hline $\mathrm{BC}$ AB A240 $250^{\circ} \mathrm{C}$ & 45 & 32.767 & 22.27 & 10.483 & 57.662 & 40.442 & 17.953 & 30.932 \\
\hline $\mathrm{BC}$ AB A240 $275^{\circ} \mathrm{C}$ & 9 & 48.42 & 32.999 & 15.413 & 51.586 & 30.85 & 21.403 & 46.545 \\
\hline $\mathrm{BC}$ AB A240 $275^{\circ} \mathrm{C}$ & 17 & 39.552 & 27.369 & 12.2 & 53.627 & 32.827 & 20.79 & 38.014 \\
\hline $\mathrm{BC}$ AB A240 $275^{\circ} \mathrm{C}$ & 24 & 18.674 & 12.136 & 6.54 & 37.774 & 29.423 & 8.639 & 18.214 \\
\hline $\mathrm{BC}$ AB A240 $275^{\circ} \mathrm{C}$ & 28 & 10.523 & 6.982 & 3.609 & 28.519 & 22.94 & 5.579 & 10.875 \\
\hline $\mathrm{BC}$ AB A240 $300^{\circ} \mathrm{C}$ & 6 & 13.223 & 8.698 & 4.523 & 22.733 & 17.151 & 5.582 & 13.265 \\
\hline$B C$ AB A240 $300^{\circ} \mathrm{C}$ & 8 & 10.509 & 6.993 & 3.515 & 22.213 & 17.366 & 4.847 & 12.693 \\
\hline$B C$ AB A240 $300^{\circ} \mathrm{C}$ & 14 & 14.184 & 9.572 & 4.607 & 23.633 & 17.486 & 6.147 & 14.442 \\
\hline $\mathrm{BC}$ AB A240 $300^{\circ} \mathrm{C}$ & 18 & 12.702 & 8.33 & 4.4 & 32.536 & 25.061 & 7.761 & 16.229 \\
\hline
\end{tabular}

Baseline corrected FTIR data for Koppers coal- tar pitch

\begin{tabular}{|c|c|c|c|c|c|c|c|c|}
\hline Sample \# & $\begin{array}{c}\text { Time } \\
(\mathrm{hr})\end{array}$ & $\begin{array}{c}\left(\mathrm{H}_{\mathrm{ar}}+\right. \\
\left.\mathrm{H}_{\mathrm{al}}\right)\end{array}$ & $\mathrm{H}_{\mathrm{al}}$ & $\mathrm{H}_{\mathrm{ar}}$ & $\begin{array}{c}\left(\mathrm{C}_{\mathrm{ar}}+\right. \\
\left.\mathrm{H}_{\mathrm{al}}\right)\end{array}$ & $\mathrm{C}_{\mathrm{ar}}$ & $\mathrm{H}_{\mathrm{al}}$ & $\mathrm{H}_{\mathrm{ar}}$ \\
\hline & - & $\begin{array}{l}2800- \\
3100\end{array}$ & $\begin{array}{c}2800- \\
3000\end{array}$ & $\begin{array}{c}3000- \\
3100\end{array}$ & $\begin{array}{c}1416- \\
1700\end{array}$ & $\begin{array}{c}1540- \\
1700\end{array}$ & $\begin{array}{c}1416- \\
1540\end{array}$ & $\begin{array}{l}700- \\
920\end{array}$ \\
\hline BC Feed CTP & 0 & 17.544 & 5.358 & 12.186 & 71.005 & 59.503 & 13.34 & 44.29 \\
\hline BC AB CTP $250^{\circ} \mathrm{C}$ & 8 & 3.14 & 0.661 & 2.481 & 7.855 & 6.487 & 1.368 & 9.127 \\
\hline BC AB CTP $250^{\circ} \mathrm{C}$ & 16 & 6.337 & 1.684 & 4.651 & 26.012 & 22.552 & 3.549 & 20.042 \\
\hline BC AB CTP $250^{\circ} \mathrm{C}$ & 24 & 8.538 & 0.246 & 8.042 & 30.578 & 25.455 & 5.123 & 24.604 \\
\hline BC AB CTP $250^{\circ} \mathrm{C}$ & 30 & 4.652 & -0.188 & 4.895 & 25.726 & 23.004 & 2.786 & 15.32 \\
\hline BC AB CTP $275^{\circ} \mathrm{C}$ & 5 & 7.477 & 1.513 & 5.926 & 26.031 & 22.154 & 4.383 & 20.623 \\
\hline BC AB CTP $275^{\circ} \mathrm{C}$ & 10 & 8.129 & 3.101 & 5.028 & 22.24 & 16.748 & 6.308 & 17.498 \\
\hline BC AB CTP $275^{\circ} \mathrm{C}$ & 15 & 5.984 & 1.744 & 4.242 & 30.963 & 27.446 & 3.644 & 18.359 \\
\hline BC AB CTP $275^{\circ} \mathrm{C}$ & 21 & 6.309 & 0.807 & 5.499 & 22.644 & 17.259 & 5.618 & 19.71 \\
\hline $\mathrm{BC}$ AB CTP $300^{\circ} \mathrm{C}$ & 3 & 8.222 & 1.819 & 6.402 & 23.828 & 18.857 & 6.119 & 22.206 \\
\hline BC AB CTP $300^{\circ} \mathrm{C}$ & 5 & 5.015 & 0.792 & 4.22 & 22.744 & 18.584 & 3.666 & 16.485 \\
\hline BC AB CTP $300^{\circ} \mathrm{C}$ & 8 & 6.286 & 0.461 & 5.825 & 30.095 & 24.859 & 5.236 & 20.686 \\
\hline $\mathrm{BC}$ AB CTP $300^{\circ} \mathrm{C}$ & 10 & 3.253 & -0.358 & 3.61 & 23.299 & 18.983 & 4.319 & 14.48 \\
\hline
\end{tabular}


Baseline corrected FTIR data for WVU coal-extract pitch

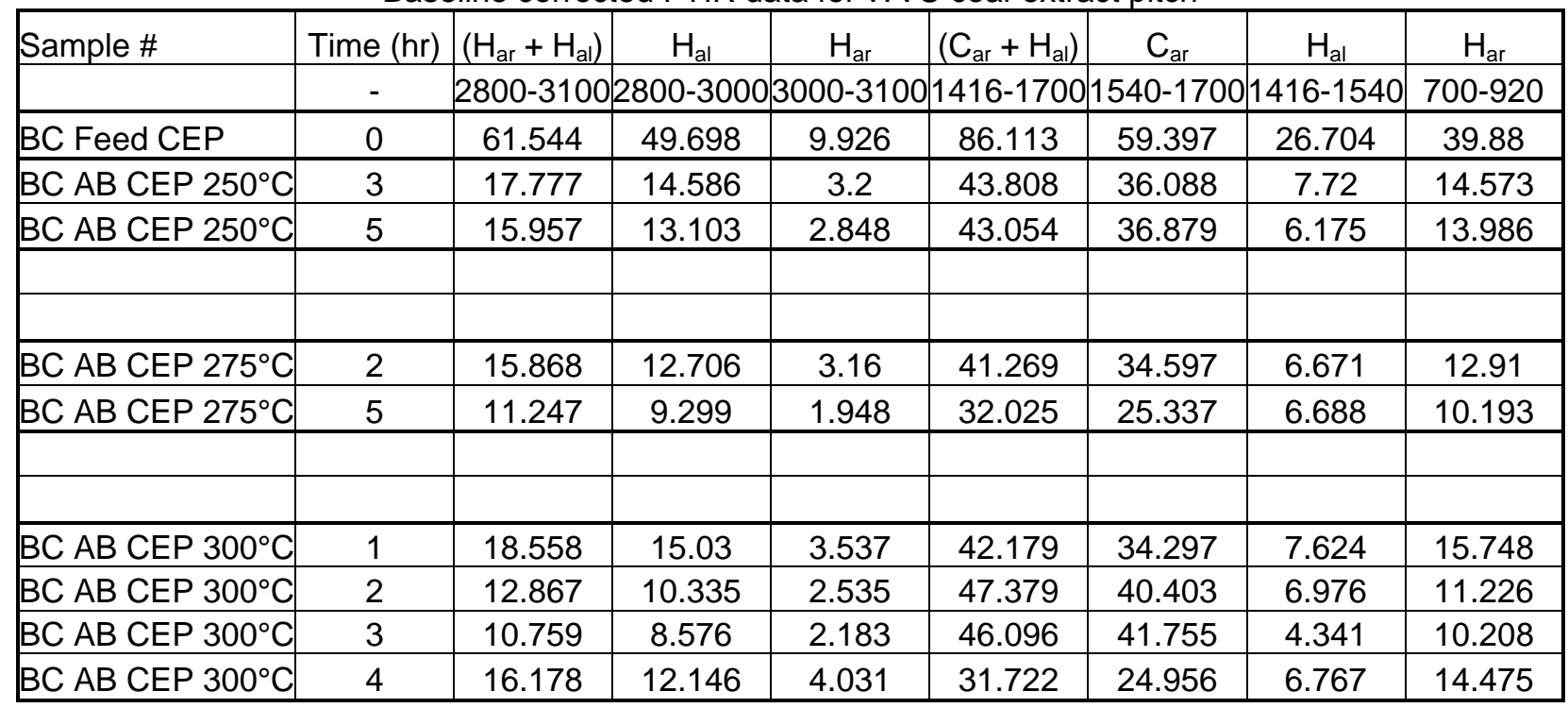


Appendix VII

MSDS Information 
PRODUCT NAME: MAPLLC A-240 PITCH

MSDS NO: 0224MAR019

THE FOLLOWING INFORMATION IS FURNISHED SUBJECT TO THE DISCLAIMER ON THE BOTTOM OF THIS FORM

\section{CHEMICAL PRODUCT AND COMPANY INFORMATION}

PRODUCT

NAME: MAPLLC A-240 PITCH

SYNONYMS:

A-240 PITCH; LPA PITCH 240; MAPLLC A-240

PITCH; PETROLEUM PITCH A-240

CHEMICAL FAMILY: PETROLEUM PITCH

CHEMICAL FORMULA: MIXTURE

PRODUCT CODE: NONE

INFORMATION SUPPLIED BY:
MANUFACTURER / DISTRIBUTOR:

MARATHON ASHLAND PETROLEUM LLC

539 SOUTH MAIN STREET

FINDLAY OH 45840

EMERGENCY PHONE NUMBERS:

(877) 627-5463

(800) 424-9300

MSDS INFORMATION: (419) 421-3070

MSDS REVISION DATE: 07/13/2001

CRAIG M. PARKER

MANAGER, TOXICOLOGY AND PRODUCT SAFETY

2. COMPOSITION / INFORMATION ON INGREDIENTS

PRODUCT INFORMATION:

MAPLLC A-240 PITCH (CAS \# 68187-58-6) IS A/AN COMPLEX MIXTURE OF THE RESIDUE FROM THE DISTILLATION OF THERMAL CRACKED RESIDUUM AND/OR CATALYTIC CRACKED CLARIFIED OIL WITH A SOFTENING POINT OF 104 TO 356 F. COMPOSED PRIMARILY OF A COMPLEX COMBINATION OF THREE OR MORE MEMBERED CONDENSED RING AROMATIC HYDROCARBONS.

$* * *$

MAPLLC A-240 PITCH WAS ANALYZED AND FOUND TO CONTAIN 1.7\% 4-6 MEMBERED CONDENSED RING POLYCYCLIC AROMATIC HYDROCARBONS.

COMPONENTS:

PETROLEUM PITCH

SULFUR COMPOUNDS

(EXPRESSED AS WT \% SULFUR)

5-METHYLCHRYSENE

BENZO(J)FLUORANTHENE

BENZO(A)PYRENE

BENZO(A)PHENANTHRENE

(COMPONENT ALSO KNOWN AS CHRYSENE)

BENZ(A)ANTHRACENE

\begin{tabular}{ll} 
PERCENT RANGE & CAS NUMBER \\
\hline 100.00 & MIXTURE \\
$0.50-4.00$ & \\
$0.10-0.40$ & $3697-24-3$ \\
$0.10-0.25$ & $205-82-3$ \\
$0.10-0.20$ & $50-32-8$ \\
$0.05-0.15$ & $218-01-9$ \\
$0.05-0.10$ & \\
$0.05-0.10$ & $56-55-3$ \\
\end{tabular}

BENZO(G,H,I)PERYLENE

191-24-2 
PRODUCT:

COMPONENTS:

\section{PETROLEUM PITCH}

SULFUR COMPOUNDS

5-METHYLCHRYSENE

BENZO(J)FLUORANTHENE

BENZO(A)PYRENE

BENZO(A)PHENANTHRENE

BENZ(A)ANTHRACENE

BENZO(G,H,I)PERYLENE
NONE ESTABLISHED

NONE ESTABLISHED

NONE ESTABLISHED

NONE ESTABLISHED

NONE ESTABLISHED

NONE ESTABLISHED

NONE ESTABLISHED

NONE ESTABLISHED

3. HAZARDS IDENTIFICATION

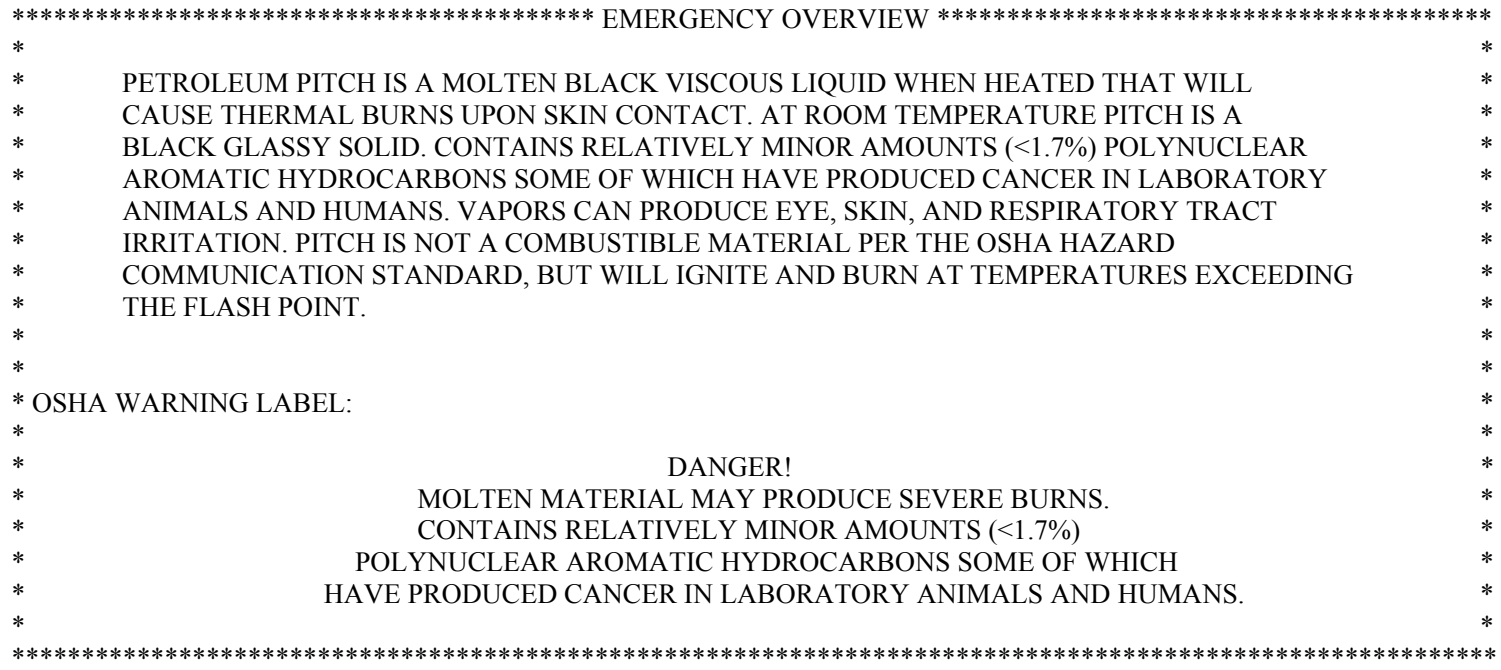

POTENTIAL HEALTH EFFECTS

EYE:

MOLTEN PITCH CAUSES SEVERE BURNS.

SKIN:

MOLTEN PITCH CAUSES SEVERE BURNS. FREQUENT OR PROLONGED CONTACT WITH COLD MATERIAL MAY CAUSE DERMATITIS. DERMAL EXPOSURE PLUS SUNLIGHT COULD CAUSE A PHOTOTOXIC REACTION THAT RESEMBLES EXAGGERATED SUNBURN. 
INHALATION:

VAPORS AND FUMES CAN CAUSE RESPIRATORY AND NASAL IRRITATION.

INGESTION:

COOLED PITCH HAS A LOW ORDER OF ACUTE ORAL TOXICITY.

CARCINOGEN LISTING:

THE INTERNATIONAL AGENCY FOR RESEARCH ON CANCER (IARC) CONCLUDED THAT THERE WAS SUFFICIENT EVIDENCE THAT AROMATIC OILS INCLUDING PETROLEUM PITCH (CLASS 6.1) ARE CARCINOGENIC TO ANIMALS.

THE INTERNATIONAL AGENCY FOR RESEARCH ON CANCER (IARC) AND THE NATIONAL TOXICOLOGY PROGRAM HAVE CONCLUDED THAT CERTAIN POLYCYCLIC AROMATIC HYDROCARBONS, I.E. BENZO(A)PYRENE, ENZ(A)ANTHRACENE, BENZO(A)PHENANTHRENE, BENZO(J)FLUORANTHENE, BENZO(G,H,I)PERYLENE AND 5METHYLCHRYSENE ARE PROBABLY CARCINOGENIC TO HUMANS (GROUP 2B).

MEDICAL CONDITIONS AGGRAVATED BY EXPOSURE:

PREEXISTING SKIN, EYE AND RESPIRATORY DISORDERS MAY BE AGGRAVATED BY EXPOSURE TO COMPONENTS OF THIS PRODUCT.

4. FIRST AID MEASURES

EYE:

FOR CONTACT WITH HOT MOLTEN MATERIAL, FLUSH WITH LARGE AMOUNTS OF TEPIDWATER FOR AT LEAST 15 MINUTES. IMMEDIATELY CALL A PHYSICIAN.

FOR CONTACT WITH VAPORS OR DUST, FLUSH WITH LARGE AMOUNTS OF TEPID WATER FOR AT LEAST 15 MINUTES. IF SYMPTOMS OR IRRITATION OCCUR, CALL A PHYSICIAN.

SKIN:

FOR CONTACT WITH HOT MOLTEN MATERIAL, IMMERSE OR FLUSH SKIN WITH COLD WATER FOR AT LEAST 15 MINUTES. CALL A PHYSICIAN. DO NOT ATTEMPT TO REMOVE SOLIDIFIED MATERIAL SINCE REMOVAL MAY CAUSE FURTHER TISSUE INJURY.

COLD MATERIAL OVER A BURN SHOULD NOT BE REMOVED EXCEPT BY A PHYSICIAN.REMOVE COLD MATERIAL (NOT ASSOCIATED WITH A BURN) WITH WATERLESS HANDCLEANER AND THEN WASH WITH SOAP AND WATER. IF SYMPTOMS OR IRRITATION OCCUR, CALL A PHYSICIAN.

INHALATION:

IF AFFECTED, MOVE PERSON TO FRESH AIR. IF BREATHING IS DIFFICULT, ADMINISTER OXYGEN. IF NOT BREATHING OR NO HEARTBEAT, GIVE ARTIFICIAL RESPIRATION OR CARDIOPULMONARY RESUSCITATION (CPR). IMMEDIATELY CALL A PHYSICIAN.

INGESTION:

INGESTION NOT LIKELY. IF LARGE AMOUNTS ARE SWALLOWED, IMMEDIATELY CALL A PHYSICIAN. 
NOTES TO PHYSICIAN:

RECOMMENDED PRACTICE IS TO NOT ATTEMPT TO REMOVE HOT MATERIAL ASSOCIATED WITH A BURN. ALLOW THE SOLIDIFIED MATERIAL TO REMAIN IN PLACE UNTIL COOLED SO IT CAN NATURALLY FALL OFF. NATURAL SEPARATION WILL OCCUR IN 48-72 HOURS. IF REMOVAL IS ATTEMPTED, MINERAL OIL MAY BE USED TO REMOVE PITCH ONCE IT IS COOLED. FOR BEST RESULTS, WORK IT INTO THE SKIN AROUND THE PITCH AND ALLOW THE MATERIAL TO "FLOAT" OFF.

5. FIRE FIGHTING MEASURES

FLAMMABLE PROPERTIES:

\begin{tabular}{|c|c|}
\hline FLASH POINT: & $518 \mathrm{~F} ; 270 \mathrm{C}(\mathrm{MIN})$ \\
\hline AUTOIGNITION TEMP: & NO DATA AVAILABLE \\
\hline EXPLOSIVE & OLU \\
\hline LOWER: & NO DATA AVAILABLE \\
\hline
\end{tabular}

FIRE AND EXPLOSION HAZARDS:

PITCH IS NOT A COMBUSTIBLE MATERIAL PER THE OSHA HAZARD COMMUNICATION STANDARD, BUT WILL IGNITE AND BURN AT TEMPERATURES EXCEEDING THE FLASH POINT.

EXTINGUISHING MEDIA:

FOR SMALL FIRES, CLASS B FIRE EXTINGUISHING MEDIA SUCH AS CO2, DRY CHEMICAL, FOAM (AFFF/ATC) OR WATER SPRAY CAN BE USED. FOR LARGE FIRES, WATER SPRAY, FOG OR FOAM (AFFF/ATC) CAN BE USED. FIRE FIGHTING SHOULD BE ATTEMPTED ONLY BY THOSE WHO ARE ADEQUATELY TRAINED AND EQUIPPED WITH PROPER PROTECTIVE EQUIPMENT.

SPECIAL FIRE FIGHTING INSTRUCTIONS:

AVOID USING STRAIGHT WATER STREAMS. WATER SPRAY AND FOAM (AFFF/ATC) MUST BE APPLIED CAREFULLY TO AVOID FROTHOVER. AVOID EXCESSIVE APPLICATION. USE WATER SPRAY TO COOL EXPOSED SURFACES FROM AS FAR A DISTANCE AS POSSIBLE. KEEP RUN-OFF WATER OUT OF SEWERS AND WATER SOURCES.

6. ACCIDENTAL RELEASE MEASURES

ISOLATE AND EVACUATE AREA. SHUT OFF SOURCE IF SAFE TO DO SO. ADVISE NATIONAL RESPONSE CENTER (800-424-8802) IF SUBSTANCE HAS ENTERED A WATERWAY. NOTIFY LOCAL HEALTH AND POLLUTION CONTROL AGENCIES, IF APPROPRIATE. CONTAIN LIQUID WITH SAND OR SOIL. RECOVER AND RETURN PRODUCT TO SOURCE. 
COMPLY WITH ALL APPLICABLE OSHA, NFPA AND CONSISTENT LOCAL REQUIREMENTS. USE APPROPRIATE GROUNDING AND BONDING PRACTICES. STORE IN PROPERLY CLOSED CONTAINERS THAT ARE APPROPRIATELY LABELED. DO NOT EXPOSE TO HEAT, OPEN FLAME, OXIDIZERS OR OTHER SOURCES OF IGNITION. DO NOT CUT, DRILL, GRIND OR WELD ON EMPTY CONTAINERS SINCE THEY MAY CONTAIN EXPLOSIVE RESIDUES.

AVOID SKIN CONTACT. WHEN OPENING COVERS AND OUTLET CAPS ON STORAGE TANKS, USE FACESHIELD AND GLOVES TO AVOID POSSIBLE INJURY FROM PRESSURIZED PITCH. KEEP HEATING COILS AND FLUES IN STORAGE TANKS, TRUCKS AND KETTLES COVERED WITH PITCH (8"). DO NOT OVERHEAT.

EXERCISE GOOD PERSONAL HYGIENE INCLUDING REMOVAL OF SOILED CLOTHING AND PROMPT WASHING WITH SOAP AND WATER.

\section{EXPOSURE CONTROL / PERSONAL PROTECTION}

ENGINEERING CONTROLS:

LOCAL OR GENERAL EXHAUST REQUIRED IN ENCLOSED AREAS OR WITH INADEQUATE VENTILATION.

PERSONAL PROTECTIVE EQUIPMENT:

RESPIRATORY PROTECTION:

NOT REQUIRED UNDER NORMAL CONDITIONS AND ADEQUATE VENTILATION. USE ATMOSPHERE SUPPLYING RESPIRATORS IN CONFINED SPACES OR WHEN FUMES EXCEED PERMISSIBLE LIMITS; OTHERWISE, AN ORGANIC VAPOR RESPIRATOR WITH PRE-FILTERFOR FUMES CAN BE USED. SELFCONTAINED BREATHING APPARATUS SHOULD BE USED FOR FIRE FIGHTING.

SKIN PROTECTION:

USE INSULATED GLOVES WHEN HANDLING HOT MATERIAL. IMPERMEABLE GLOVES (E.G NITRILE, VITON, TYVEK/SARANEX 23) SHOULD BE USED TO PREVENT SKIN CONTACT OF COLD MATERIAL.

EYE PROTECTION:

USE GOGGLES AND FACESHIELD WHEN HANDLING HOT MATERIAL.

OTHER PROTECTIVE EQUIPMENT:

RUBBERIZED SUITS OR COATS MAY BE NEEDED FOR SOME MAINTENANCE OPERATIONS IN HOT PITCH.

USE CHEMICAL RESISTANT APRON OR OTHER PROTECTIVE CLOTHING TO AVOID SKIN CONTACT WHEN HANDLING COLD MATERIAL. 


\section{PHYSICAL AND CHEMICAL PROPERTIES}

BOILING POINT:

MELTING POINT:

SPECIFIC GRAVITY $(\mathrm{H} 2 \mathrm{O}=1)$ :

NO DATA AVAILABLE

244-255 F; SOFTENS

1.22

NO DATA AVAILABLE

PACKING DENSITY (KG/M3):

NEGLIGIBLE

VAPOR DENSITY (AIR=1):

VAPOR PRESSURE:

PH INFORMATION:

$\%$ VOLATILES BY VOL:

EVAPORATION RATE:

APPEARANCE:

ODOR:

ODOR THRESHOLD (PPM):

NO DATA AVAILABLE

NEGLIGIBLE @ 77 F

NO DATA AVAILABLE

NO DATA AVAILABLE

NO DATA AVAILABLE

BLACK VISCOUS LIQUID, SOLID OR PELLETS

TAR

NO DATA AVAILABLE

ADDITIONAL PROPERTIES:

DENSITY: $\quad 10.2$ LBS/GALLON AT $60 \mathrm{~F}$

10. STABILITY AND REACTIVITY

STABILITY:

THE MATERIAL IS STABLE AT 70 F, 760MM PRESSURE.

CONDITIONS TO AVOID:

OVERHEATING, SOURCES OF IGNITION.

HAZARDOUS DECOMPOSITION PRODUCTS:

HYDROGEN SULFIDE, SULFUR DIOXIDE, CARBON MONOXIDE, HYDROCARBONS.

INCOMPATIBLE MATERIALS:

STRONG OXIDIZING AGENTS SUCH AS CHLORATES, NITRATES, PEROXIDES.

HAZARDOUS POLYMERIZATION:

WILL NOT OCCUR

CONDITIONS TO AVOID:

NO DATA AVAILABLE.

ADDITIONAL COMMENTS:

NO DATA AVAILABLE. 
LIFETIME SKIN PAINTING STUDIES IN MICE WITH PETROLEUM PITCH HAS PRODUCED CARCINOGENIC ACTIVITY FOLLOWING PROLONGED AND REPEATED EXPOSURE. PETROLEUM PITCH HAS BEEN FOUND TO BE POSITIVE IN A MODIFIED AMES MUTAGENICITY ASSAY.

\section{SUMMARY OF HEALTH EFFECT DATA ON PITCH COMPONENTS:}

THIS PRODUCT CONTAINS 1.7\% 4-6 MEMBERED CONDENSED RING POLYNUCLEAR AROMATIC HYDROCARBONS (PAH'S). SOME PAH'S SUCH AS BENZO(A)PYRENE, BENZ(A) ANTHRACENE, BENZO(A)PHENANTHRENE, BENZO(J)FLUORANTHENE, BENZO(G,H,I)-PERYLENE, AND 5-METHYLCHRYSENE HAVE BEEN SHOWN TO BE CARCINOGENIC IN EXPERIMENTAL ANIMALS. AN INCREASED RISK OF CANCER HAS BEEN OBSERVED IN WORKERS EMPLOYED IN THE ALUMINUM PRODUCTION, COAL GASIFICATION, COAL-TAR PITCH, COKE PRODUCTION AND IRON AND STEEL INDUSTRIES THAT HAD BEEN OCCUPATIONALLY EXPOSED TO POLYNUCLEAR AROMATIC HYDROCARBONS. SINCE THESE KINDS OF PAH'S HAVE BEEN MEASURED AT HIGH LEVELS IN AIR SAMPLES TAKEN IN THESE INDUSTRIES, IARC HAS CONCLUDED THAT THESE PAH'S ARE PROBABLY CARCINOGENIC TO HUMANS.

\section{ECOLOGICAL INFORMATION}

THERE IS NO POTENTIAL FOR FOOD CHAIN CONCENTRATION OR ACCUMULATION.

13. DISPOSAL CONSIDERATIONS

THIS PRODUCT AS SUPPLIED AND BY ITSELF, WHEN DISCARDED OR DISPOSED OF, IS NOT A RCRA HAZARDOUS WASTE. THIS MATERIAL COULD ALSO BECOME A HAZARDOUS WASTE IF MIXED OR CONTAMINATED WITH A LISTED HAZARDOUS WASTE. IT IS THE RESPONSIBILITY OF THE USER TO DETERMINE IF DISPOSAL MATERIAL IS HAZARDOUS ACCORDING TO FEDERAL, STATE AND LOCAL REGULATIONS.

\section{TRANSPORTATION INFORMATION}

49 CFR 172.101:

* FOR USE WITH MOLTEN LIQUID PITCH:

PROPER SHIPPING NAME:

DOT CLASSIFICATION:

ELEVATED TEMPERATURE LIQUID, N.O.S.

DOT IDENTIFICATION NUMBER: UN 3257

PACKING GROUP:

PG III

(HOT PETROLEUM PITCH)

THIS MATERIAL MUST NOT BE TRANSPORTED WHEN HEATED AT OR ABOVE ITS FLASH POINT.

* FOR USE WITH SOLID PITCH:

NOT REGULATED.

15. REGULATORY INFORMATION

THE FOLLOWING REGULATIONS APPLY TO THIS PRODUCT:

OSHA HAZARD COMMUNICATION STANDARD (29 CFR 1910.1200): 
THIS PRODUCT HAS BEEN EVALUATED AND DETERMINED TO BE HAZARDOUS AS DEFINED IN OSHA'S HAZARD COMMUNICATION STANDARD.

EPA TOXIC SUBSTANCES CONTROL ACT (40 CFR PART 710):

THIS PRODUCT AND/OR ITS COMPONENTS ARE LISTED ON THE TSCA CHEMICAL INVENTORY.

EPA SARA TITLE III SUPERFUND AMENDMENTS \& REAUTHORIZATION ACT - EMERGENCY PLANNING \& COMMUNITY RIGHT-TO-KNOW ACT OF 1986.

EXTREMELY HAZARDOUS SUBSTANCES (40 CFR PART 355):

THIS PRODUCT CONTAINS THE FOLLOWING COMPONENT(S) IDENTIFIED ON APPENDIX A AND B OF THE EXTREMELY HAZARDOUS SUBSTANCE LIST (AT A LEVEL OF $1 \%$ OR GREATER IF HAZARDOUS; $0.1 \%$ OR GREATER IF CARCINOGENIC): NONE.

EMERGENCY RELEASE NOTIFICATIONS (40 CFR PART 355):

THIS PRODUCT CONTAINS THE FOLLOWING COMPONENT(S) IDENTIFIED EITHER AS AN EXTREMELY HAZARDOUS SUBSTANCE (40 CFR 355) OR A CERCLA HAZARDOUS SUBSTANCE (40 CFR 302) WHICH IN CASE OF A SPILL OR RELEASE MAY BE SUBJECT TO EMERGENCY RELEASE REPORTING REQUIREMENTS:

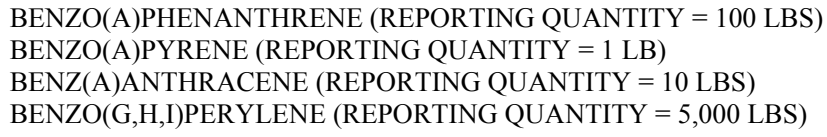

MATERIAL SAFETY DATA SHEET REQUIREMENTS (40 CFR PART 370):

THE FOLLOWING EPA HAZARD CATEGORIES APPLY TO THIS PRODUCT:

$$
\text { IMMEDIATE (ACUTE) HEALTH HAZARD }
$$

DELAYED (CHRONIC) HEALTH HAZARD

MSDS'S OR A LIST OF MSDS'S AND THEIR HAZARDS (SEE EPA HAZARD CATEGORIES ABOVE) MAY BE REQUIRED TO BE SUBMITTED TO THE STATE EMERGENCY RESPONSE COMMISSION (SERC), LOCAL EMERGENCY PLANNING COMMITTEE (LEPC) AND LOCAL FIRE DEPARTMENT (LFD).

IN ADDITION, A TIER II OR TIER I FORM MAY BE REQUIRED TO BE SUBMITTED ANNUALLY TO THE SERC, LEPC AND LFD IF APPLICABLE THRESHOLD REPORTING QUANTITIES ARE EXCEEDED. CURRENT FEDERAL THRESHOLDS ARE:

10,000 POUNDS OR MORE OF AN OSHA HAZARDOUS SUBSTANCE

OR

500 POUNDS OR THE THRESHOLD PLANNING QUANTITY, WHICHEVER IS LESS, OF AN EXTREMELY HAZARDOUS SUBSTANCE.

NOTE: THRESHOLDS MAY VARY ACCORDING TO LOCAL AND STATE REGULATIONS.

TOXIC CHEMICAL RELEASE REPORTING (40 CFR PART 372):

THIS PRODUCT CONTAINS THE FOLLOWING COMPONENT(S) (AT A LEVEL OF 1\% OR REATER IF HAZARDOUS; $0.1 \%$ OR GREATER IF CARCINOGENIC) THAT MAY BE SUBJECT TO REPORTING ON THE TOXIC RELEASE INVENTORY (TRI) FORM R:

$\begin{array}{lc}----C O M P O N E N T---- & ---C A S ~ N U M B E R---- \\ \text { BENZ(A)ANTHRACENE } & 56-55-3 \\ \text { BENZO(A)PYRENE } & 50-32-8 \\ \text { BENZO(A)PHENANTHRENE } & 218-01-9 \\ \text { BENZO(G,H,I)PERYLENE } & 191-24-2 \\ \text { BENZO(J)FLUORANTHENE } & 205-82-3 \\ \text { 5-METHYLCHRYSENE } & 3697-24-3\end{array}$

STATE AND COMMUNITY RIGHT-TO-KNOW REGULATIONS:

THIS MATERIAL MAY BE REGULATED BY LOUISIANA'S RIGHT-TO-KNOW LAW (REGULATORY STATUTE 30:2361). 
16. OTHER INFORMATION

NFPA CLASSIFICATION

HEALTH: 2

FIRE: 1

REACTIVITY: 1

OTHER: -
HMIS CLASSIFICATION

HEALTH: 2

FIRE: 1

REACTIVITY: 1

PERSONAL PROTECTION: *
HAZARD RATING

0 - LEAST

1 - SLIGHT

2 - MODERATE

3 - $\mathrm{HIGH}$

4 - EXTREME

COMMENTS:

* SEE SECTION 8 FOR GUIDANCE IN SELECTION OF PERSONAL PROTECTIVE EQUIPMENT.

\section{*** DISCLAIMER ***}

THIS INFORMATION RELATES ONLY TO THE SPECIFIC MATERIAL DESIGNATED AND MAY NOT BE VALID FOR SUCH MATERIAL USED IN COMBINATION WITH ANY OTHER MATERIALS OR IN ANY PROCESS. SUCH INFORMATION IS, TO THE BEST OF MARATHON ASHLAND PETROLEUM LLC'S KNOWLEDGE AND BELIEF, ACCURATE AND RELIABLE AS OF THE DATE INDICATED. HOWEVER, NO REPRESENTATION, WARRANTY OR GUARANTEE IS MADE AS TO ITS ACCURACY, RELIABILITY OR COMPLETENESS. IT IS THE USER'S RESPONSIBILITY TO SATISFY HIMSELF AS TO THE SUITABLENESS AND COMPLETENESS OF SUCH INFORMATION FOR HIS OWN PARTICULAR USE. 


\section{KOPPERS}

\section{MATERIAL SAFETY DATA SHEET}

$\begin{array}{llllll}\text { MATERIAL K O P P E R S } & \text { MEDICAL EMERGENCIES: } 1 & 800 & 553-5631 \\ \text { SAFETY } & & \text { OUTSIDE U.S.A.: } & 412 & 227-2001 \\ \text { DATA } & & \text { GENERAL INFORMATION : } & 412 & 227-2424 \\ \text { SHEET } & & & & \\ & & & & & \\ \text { KOPPERS INDUSTRIES, INC. } & & \text { CHEMTREC ASSISTANCE } & 1800 & 424-9300 \\ 436 \text { SEVENTH AVENUE } & \text { CANUTEC: } & 1613996-6666\end{array}$

\section{SECTION I - PRODUCT IDENTIFICATION}

PRODUCT NAME: Industrial Pitch/Coal Tar - Petroleum

SYNONYM: None

PRODUCT USE :

CHEMICAL FAMILY: Aromatic Hydrocarbon

FORMULA: Complex mixture of hydrocarbons

CAS NUMBER: 68187-57-5

$\begin{array}{ccrrr}\text { NFPA 704M/HMIS RATING: } 2 / 2 \mathrm{HEALTH} & 1 / 1 \text { FLAMMABILITY } & 1 / 1 \text { REACTIVITY } \\ 0=\text { Least } & 1=\text { slight } & 2=\text { Moderate } 3=\text { High } & 4 \text { Extreme }\end{array}$

CANADIAN PRODUCT CLASSIFICATION: Class D, Division 2, Subdivision A, Very Toxic Material

\section{SECTION II - HEALTH/SAFETY ALERT}

CHRONIC OVEREXPOSURE (as defined by OSHA recommended standards) MAY CAUSE CANCER WARNING

HARMFUL TO THE SKIN, OR IF INHALED OR SWALLOWED

CAUSES EYE AND SKIN IRRITATION AVOID PROLONGED OR REPEATED CONTACT

OBSERVE GOOD HYGIENE AND SAFETY PRACTICES WHEN HANDLING THIS PRODUCT DO NOT USE THIS PRODUCT UNTIL MSDS HAS BEEN READ AND UNDERSTOOD

SECTION III - HEALTH HAZARD INFORMATION 
EYE: Overexposure to vapor can result in irritation and/or corneal changes. Direct eye contact may cause irritation. Contact with heated material may cause thermal burns.

SKIN: Contact with skin can result in irritation which when accentuated by sunlight may result in a phototoxic skin reaction. Repeated and/or prolonged contact may cause more serious skin disorders including cancer. Contact with heated material may cause thermal burns.

INHALATION: Overexposure to vapor may result in respiratory tract irritation. Repeated and/or prolonged contact to high concentrations of vapor may result in respiratory difficulties, central nervous system (CNS) effects and possiblecardiovascular collapse.

INGESTION: Ingestion of material is unlikely, but may cause gastrointestinal disturbances including irritation, nausea, vomiting, abdominal pain and, in extreme cases, cardiovasular involvement.

OTHER: See Section XII (Comments) for additional information on health effects.

\title{
SECTION IV - EMERGENCY AND FIRST AID PROCEDURES
}

EYE CONTACT: Immediately flush with large amounts of water for 15 minutes. Immediately seek medical aid.

SKIN CONTACT: Wash thoroughly with waterless hand cleaner. For contact with molten product, do not remove contaminated clothing. Flush skin immediately with large amounts of cold water. If possible, submerge area in cold water. Pack with ice. Seek medical aid.

INHALATION: Remove from exposure. If breathing has stopped or is difficult, administer artificial respiration or oxygen as indicated. Seek medical aid.

INGESTION: Ingestion is unlikely. If it occurs, seek medical aid.

\section{SECTION V - FIRE AND EXPLOSION HAZARD INFORMATION}

\author{
FLASH POINT \& METHOD: >150C (>302F) COC AUTOIGNITION TEMP : ND \\ FLAMMABLE LIMITS (\% BY VOLUME/AIR): LOWER: NA UPPER: NA
}

TDG FLAMMABILITY CLASSIFICATION: None

EXTINGUISHING MEDIA: Use dry chemical, carbon dioxide, foam or water spray. Water or foam may cause frothing.

FIRE-FIGHTING PROCEDURES: Wear complete fire service protective equipment, including full-face MSHA/NIOSH approved self-contained breathing apparatus. Use water to cool fire-exposed container/structure/protect personnel. Toxic vapors may be given off in a fire. 
FIRE AND EXPLOSION HAZARDS: When heated (fire conditions), vapors/decomposition products may be released and may add to the intensity of the fire. Closed containers may explode when exposed to extreme heat (fire). Dust may form explosive mixture with air.

Combustible at high temperatures.

SENSITIVITY TO MECHANICAL IMPACT: ND

SENSITIVITY TO STATIC DISCHARGE: ND

\section{SECTION VI - SPILL, LEAK AND DISPOSAL INFORMATION}

SPILL OR LEAK PROCEDURES (PRODUCT): Solidified spills: Shovel into dry containers and cover. Flush area with water. Contain runoff from fire control and dilution water. Release or spillage of solid can be treated as a coal spillage and recovery made avoiding skin and eye irritation. If hot liquid is spilled, contain with sand, ashes, etc. Allow to cool, scrape up and dispose. Avoid contact with hot liquid and fumes.

WASTE DISPOSAL: If disposing in a state other than California, dispose of as an industrial waste in accordance with local, state, and federal regulations. Place in tightly sealed labeled containers. This product contains coal tar constituents, which have been determined by IARC to be a carcinogen. According to California hazardous waste regulations, substances posing a hazard to human health because of carcinogenicity are hazardous wastes. Dispose of as a hazardous waste in the state of California.

\section{SECTION VII - RECOMMENDED EXPOSURE LIMIT/HAZARDOUS INGREDIENTS}

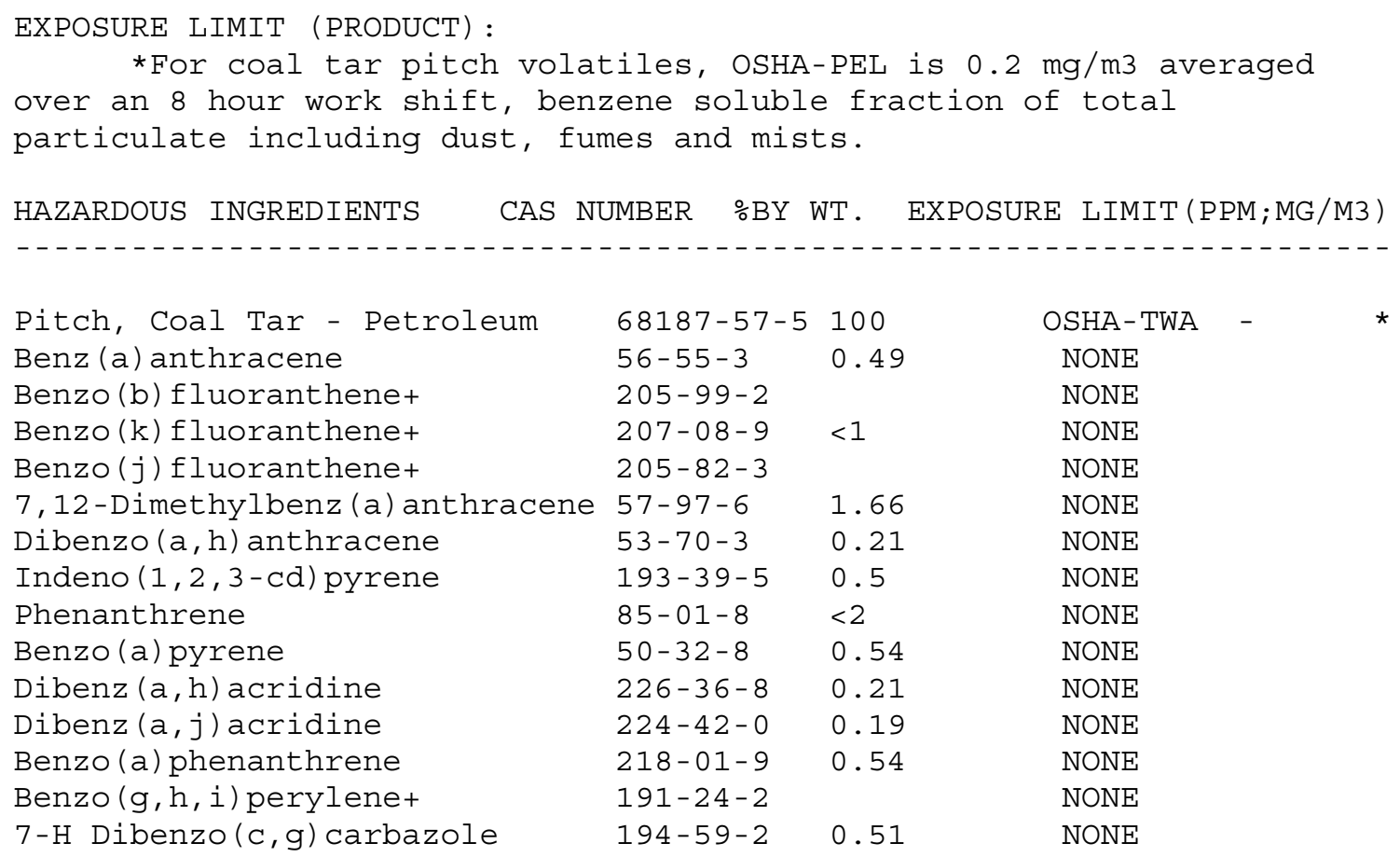




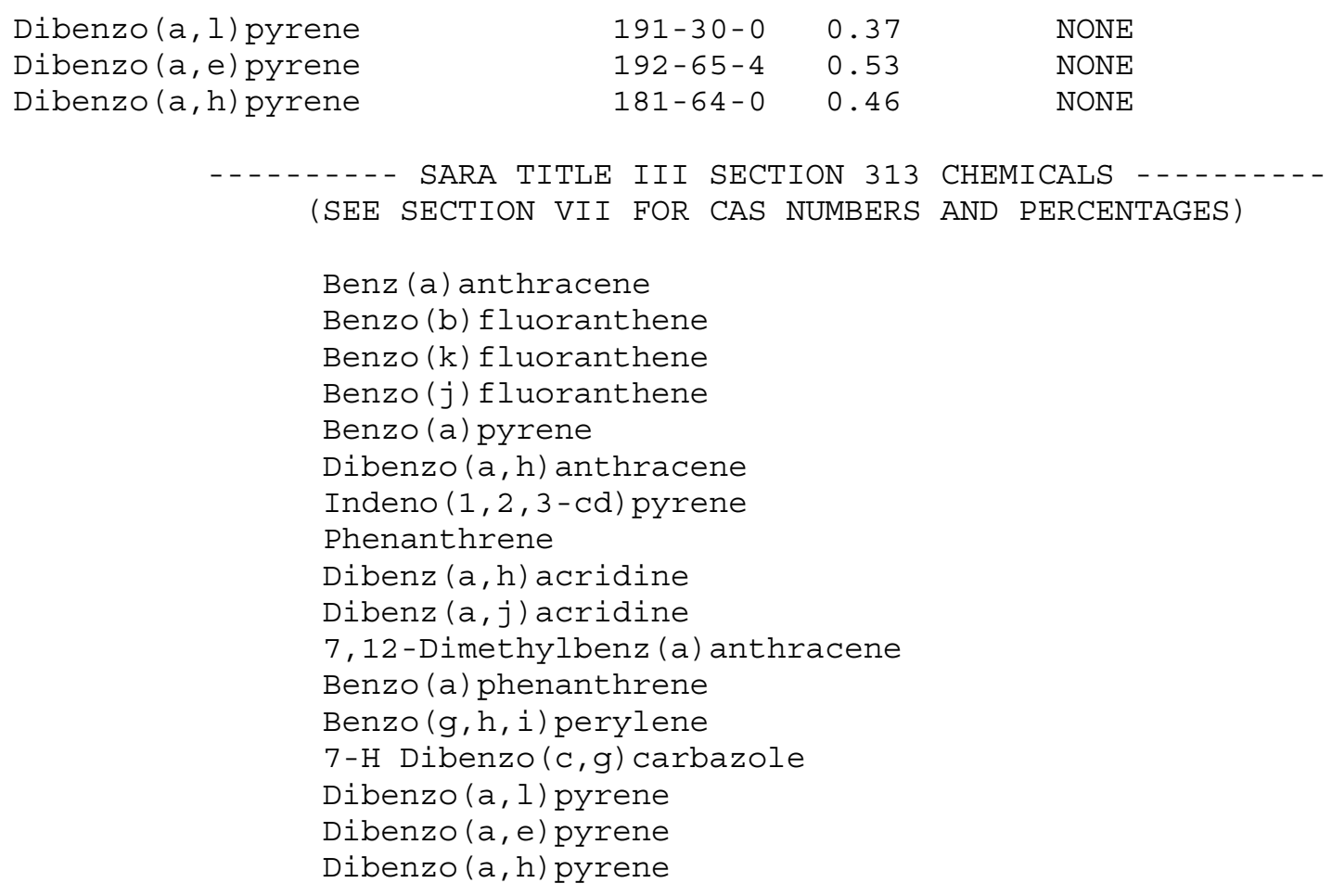

\section{SECTION VIII - PERSONAL PROTECTION INFORMATION}

EYE PROTECTION: Industrial safety glasses, minimum. As necessary to comply with 29 CFR 1910.133 and work area conditions: use side shields, goggles or face shield. Chemical goggles; face shield (if handling molten material).

SKIN PROTECTION: As required, industrial resistant, flexible-type gloves (nitrile, neoprene, PVC, NBR (Buna-N) or equal). Wear industrial-type work clothing and safety footwear. Depending on working conditions, i.e., contact potential, wear resistant protective garments such as aprons, jackets, pants, coveralls, boots, etc. See sect. XIII Comments for additional information on skin protection recommendations.

RESPIRATORY PROTECTION: If ventilation does not maintain inhalation exposures below TLV(PEL), use MSHA/NIOSH approved units as per current 29 CFR1910.134 and manufacturers' "Instructions" and "Warnings". Combination filter/organic vapor cartridges or canister may be used. Full-face piece respiratory protective units required.

VENTILATION: Provide sufficient general/local exhaust ventilation in pattern/volume to control inhalation exposures below current exposure limits and areas below flammable vapor/explosive dust concentrations. Local exhaust is necessary for use in enclosed or confined spaces. See OSHA Requirement/NIOSH Pub. 80-106 "Working in a Confined Space".

\section{SECTION IX - PERSONAL HANDLING INSTRUCTIONS}


HANDLING: Avoid prolonged or repeated breathing of vapors, mists or fumes. Avoid prolonged or repeated contact with skin or eyes. Application of certain protective creams (sun screens for coal tar products) before working/several times during work may be beneficial.

STORAGE: Keep in a closed, labeled container within a cool (well shaded), dry ventilated area. Protect from physical damage. Keep containers closed when material is not in use. Maintain good housekeeping.

OTHER: Showering and clothing change recommended at the end of each shift. Do not use until manufacturer's precautions have been read/understood.DO NOT TAKE INTERNALLY. Wash exposed areas promptly and thoroughly after skin contact and before eating, drinking, using tobacco products or rest rooms. Do not wear contaminated clothing. Discard contaminated footwear.

\title{
SECTION X - REACTIVITY DATA
}

CONDITIONS CONTRIBUTING TO INSTABILITY: None. Avoid overheating.

INCOMPATIBILITY: None

HAZARDOUS REACTIONS/DECOMPOSITION/COMBUSTION PRODUCTS: MaY emit toxiC fumes upon decomposition.

CONDITIONS CONTRIBUTING TO HAZARDOUS POLYMERIZATION: NONe

\section{SECTION XI - PHYSICAL DATA}

\author{
MELTING POINT: $\quad 40-180 \mathrm{C} \quad \%$ VOLATILE BY VOL: \\ VAPOR PRESSURE: $\quad<1 \mathrm{~mm} \mathrm{HG} \quad$ EVAPORATION RATE $($ ETHER=1): NA \\ VAPOR DENSITY $(A I R=1):>1 \quad$ VISCOSITY: Sold at room temp. \\ SOLUBILITY: $\quad$ Negligible $\quad \mathrm{pH}: \quad$ NA \\ (WATER) \\ VOC : NA \\ COEFFICIENT OF WATER/OIL DISTRIBUTION: ND \\ APPEARANCE/ODOR: Black solid with no odor at 21C; aromatic odor after \\ melting.
}

\section{SECTION XII - TRANSPORT INFORMATION}


RQ ELEVATED TEMPERATURE LIQUID, N.O.S.

(CONTAINS BENZO (A) PYRENE, DIBENZ (A, H) ANTHRACENE)

CLASS 9 UN3257 PG III

ELECTRODE BINDER

MARKED: HOT 3257

\author{
-....... PRODUCT PACKAGED IN TANK TRUCK -...... \\ RQ ELEVATED TEMPERATURE LIQUID, N.O.S. \\ (CONTAINS BENZO (A) PYRENE, DIBENZ (A, H) ANTHRACENE) \\ CLASS 9 UN3257 PG III \\ PITCH, COAL \\ MARKED: HOT 3257
}

\title{
SECTION XIII - COMMENTS
}

This product contains petroleum pitch. The IARC Monographs (Vol. 33) state that there is sufficient evidence for the carcinogenicity in experimental animals of untreated vacuum distilates, acid-treated oils, and aromatic oils, including extracts from solvent treatment of distillates and the high-boiling fraction of catallytically-cracked oils.

This product contains coal tar pitch. The IARC monographs (Vol. 35) state that there is sufficient evidence that coal tar pitches are carcinogenic in humans and that there is sufficient evidence that occupational exposure to coal tars as it occurs during the destructive distillation of coal is causally associated with the occurrence of skin cancers in humans. It is also listed in NTP and in OSHA subpart Z Table.

Persons with a history of liver/kidney/skin/CNS/respiratory disease or exposure to materials harmful to these systems are at a greater than normal risk of developing adverse health effects when working with this product.

No known ingredients which occur at greater than $0.1 \%$, other than those listed above, are listed as a carcinogen in the IARC Monographs on the Evaluation of the Carcinogenic Risk of Chemicals to Humans, the NTP Annual Report on Carcinogens or OSHA 29 CFR 1910.1001-1047 subpart Z Toxic and Hazardous Substances (Specifically Regulated Substances).

SKIN PROTECTION (protective material): Permeation/degradation values of chemical mixtures cannot be predicted from pure components or chemical classes. Thus, these materials are normally best estimates based on available pure component data. A significant difference in chemical breakthrough time has been reported for generically similar gloves from different manufacturers (AIHA J., 48, 941-947 1987).

Do not use until manufacturer's precautions have been read/understood. Wash exposed areas promptly and thoroughly after skin contact from working with this product and before eating, drinking, using tobacco products or rest rooms.

Prepared By: Safety and Health Department

REVISION DATE: 11/00

CODE NUMBER :

IND00140NO0011 
SPECIFICATION SHEET NUMBER: None

REPLACES SHEET:

IND00140DE9710

SUPPLIER INFORMATION: Same as manufacturer.

NOTICE: While the information and recommendations set forth herein are believed to be accurate as of the date hereof, Koppers Industries makes no warranty with respect thereto and disclaims all liability from reliance thereon. 


\section{MSDS}

Part Number/Trade Name: n-Methyl-2-Pyrrolidone This MSDS is valid for all grades and catalog numbers

General Information

Company's Name: PHARMCO PRODUCTS,INC.

Company's Street: 58 VALE RD.

Company's City: BROOKFIELD

Company's State: CT

Company's Zip Code: 06804

Company's Emerg Ph \#: (203) 740-3471

Company's Info Ph \#: (203) 740-3471

Date MSDS Revised: Nishant-8/23/99

Safety Data Review Date: 8/23/99

Preparer's Company: PHARMCO PRODUCTS,INC.

Preparer's St Or P. O. Box: 58 VALE RD.

Preparer's City: BROOKFIELD

Preparer's State: CT

Preparer's Zip Code: 06804

Ingredients/Identity Information

Ingredient: N-METHYL PYRROLIDONE

Ingredient Sequence Number: 01

Percent: $100 \%$

NIOSH (RTECS) Number: UY5790000

CAS Number: 872-50-4

Physical/Chemical Characteristics

Appearance And Odor: WATER-LIKE LIQUID, MILD AMINE-LIKE ODOR.

Boiling Point: 202C

Vapor Pressure (MM Hg/70 F): 0.2

Vapor Density (Air=1): 3.40

Specific Gravity: 1.03

Evaporation Rate And Ref: (BU AC = 1) 0.06

Solubility In Water: MISCIBLE

Percent Volatiles By Volume: 100\%

Fire and Explosion Hazard Data

Flash Point: 199F CC

Lower Explosive Limit: 1.30

Upper Explosive Limit: 9.50

Extinguishing Media: WATER, ALCOHOL FOAM, DRY CHEMICAL, CO2

MSDS 144, Rev 2.0 12/18/01 JC

N Methyl Pyrrolidone/Page 2 of 3

Special Fire Fighting Proc: FIREFIGHTERS SHOULD BE EQUIPPED WITH SCBA/

TURN OUT GEAR. 
Unusual Fire And Expl Hazrds: MODERATE FIRE HAZARD WHEN EXPOSED TO HEAT OR FLAME.

Reactivity Data

Stability: YES

Materials To Avoid: STRONG OXIDIZING OR REDUCING AGENTS

Hazardous Decomp Products: CO/NOX FUMES EMITTED WHEN HEATED TO

DECOMPOSITION. Hazardous Poly Occur: NO

Health Hazard Data

Signs/Symptoms Of Overexp: INHALATION: HEADACHE/GIDDINESS/CONFUSION/

NAUSEA. SKIN: REDNESS/SWELLING/CRACKING/EYE BURNS.

Emergency/First Aid Proc: INHALATION: REMOVE TO FRESH AIR. GIVE ARTIFICIAL

RESPIRATION. GIVE OXYGEN. CALL A PHYSICIAN. EYES: IMMEDIATELY FLUSH W/WATER

FOR 15 MINUTES. CALL A PHYSICIAN. SKIN: FLUSH WITH WATER. INGESTION: INDUCE

VOMITING IMMEDIATELY. CALL A PHYSICIAN.

Precautions for Safe Handling and Use

Steps If Matl Released/Spill: ELIMINATE SOURCES OF IGNITION. ABSORB WITH EARTH, SAND, OR SIMILAR INERT MATERIAL ANDISPOSE OF ACCORDING TO FEDERAL, STATE, AND LOCAL REGULATIONS. FLUSH AREWITH WATER.

Waste Disposal Method: DISPOSE OF WITH LIQUID WASTE ACCORDING TO FEDERAL, STATE AND LOCAL REGULATIONS.

Precautions-Handling/Storing: AVOID CONTACT WITH EYES/SKIN. WASH THOROUGHLY AFTER HANDLING. AVOID BREATHING VAPORS. USE WITHDEQUATE VENTILATION.

Other Precautions: KEEP THIS CONTAINER AND VAPOR FROM THIS CONTAINER AWAY

FROM HEAT AND FLAME. KEEP CONTAINER CLOSED.

Control Measures

Respiratory Protection: NIOSH APPROVED

RESPIRATOR

Ventilation: LOCAL EXHAUST: WELL

VENTILATED AREA

Protective Gloves: NEOPRENE

Eye Protection: CHEMICAL GOGGLES

Other Protective Equipment: IMPERVIOUS

GLOVES SUCH AS "SCORPIO \#8-352"

Suppl. Safety \& Health Data: MSDS DATE:

MAR 86.

Transportation Data 
Disposal Data

Landfill Ban Item: YES

Disposal Supplemental Data: MSDS DATE: MAR 86. IN CASE OF ACCIDENTAL

EXPOSURE OR DISCHARGE, cONSULT HEALTH AND SAFETY FILE FOR PRECAUTIONS.

1st EPA Haz Wst Name New: NOT REGULATED

1st EPA Haz Wst Char New: NOT REGULATED BY RCRA

1st EPA Acute Hazard New: NO

Label Data

Common Name: N-METHYL PYRROLIDONE

Special Hazard Precautions: INHALATION: HEADACHE/

GIDDINESS/CONFUSION/NAUSEA. SKIN: REDNESS/SWELLING/CRACKING/EYE BURNS.

The information contained herein is based on data considered to be accurate. However, no warranty is expressed regarding the accuracy of these data or the results to be obtained from the use thereof. It is the user's obligation to determine the conditions of safe use of the product. 


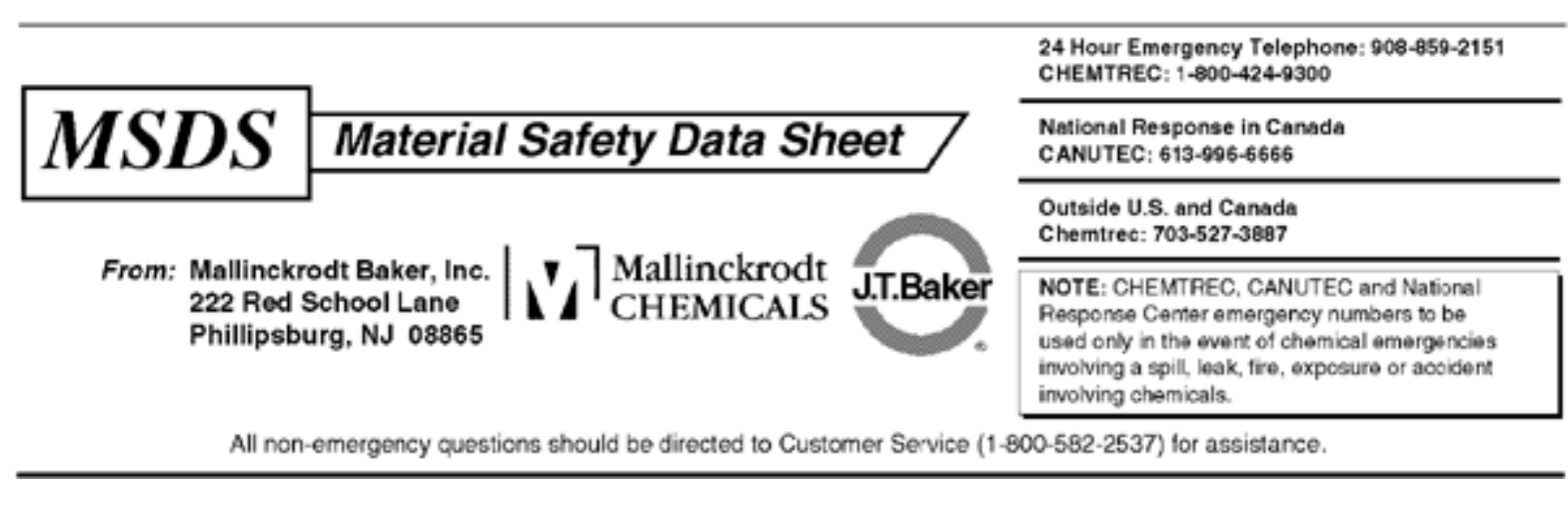

\section{1,2,3,4-TETRAHYDRONAPHTHALENE}

\section{Product Identification}

Synonyms: Naphthalene, 1,2,3,4-tetrahydro-; TETRALIN

CAS No.: 119-64-2

Molecular Weight: 132.21

Chemical Formula: $\mathrm{C} 10 \mathrm{H} 12$

Product Codes:

J.T. Baker: V577

Mallinckrodt: 2717

\section{Composition/Information on Ingredients}

\begin{tabular}{|c|c|c|c|}
\hline Ingredient & CAS No & Percent & Hazardous \\
\hline $\begin{array}{l}-------------------------------- \\
-\end{array}$ & -------- & --------- & ---------- \\
\hline Naphthalene, $1,2,3,4$-tetrahydro- & $119-64-2$ & $97 \%$ & Yes \\
\hline Decahydronaphthalene & $91-17-8$ & $2 \%$ & Yes \\
\hline Naphthalene & $91-20-3$ & $1 \%$ & Yes \\
\hline
\end{tabular}

\section{Hazards Identification}

Emergency Overview

WARNING! HARMFUL IF SWALLOWED OR INHALED. CAUSES IRRITATION TO SKIN, EYES AND RESPIRATORY TRACT. COMBUSTIBLE LIQUID AND VAPOR. CONTAINS NAPHTHALENE WHICH MAY CAUSE ALLERGIC SKIN REACTION AND MAY AFFECT LIVER, KIDNEY, BLOOD AND CENTRAL NERVOUS SYSTEM.

J.T. Baker SAF-T-DATA ${ }^{(\mathrm{tm})}$ Ratings (Provided here for your convenience) 
Health Rating: 2 - Moderate

Flammability Rating: 2 - Moderate

Reactivity Rating: 0 - None

Contact Rating: 2 - Moderate

Lab Protective Equip: GOGGLES; LAB COAT; VENT HOOD; PROPER GLOVES;

CLASS B EXTINGUISHER

Storage Color Code: Red (Flammable)

\section{Potential Health Effects}

\section{Inhalation:}

Inhalation of vapor or mist is irritating to the respiratory tract. May produce headache, nausea, vomiting. High concentrations can produce central nervous system depression. The predominant reaction of overexposure from the naphthalene component is delayed intravascular hemolysis with symptoms of anemia, fever, jaundice and kidney or liver damage.

\section{Ingestion:}

May cause nausea, headache, vomiting and intragastric discomfort. Major hazard (from the decahydronaphthalene component) is aspiration into lungs, which may result in pulmonary edema or chemical pneumonia.

\section{Skin Contact:}

Causes skin irritation with discomfort, rash. Sensitized individuals (from naphthalene exposure) may suffer a severe dermatitis.

\section{Eye Contact:}

Vapor causes irritation, redness and pain. The naphthalene component, at very high concentrations, can damage the nerves of the eye.

\section{Chronic Exposure:}

May cause cataract and kidney and liver damage. Chronic naphthalene exposure has led to cataract formation and may cause skin allergy.

\section{Aggravation of Pre-existing Conditions:}

Persons with pre-existing skin, eye, kidney or liver, blood or vascular disorders or impaired respiratory function may be more susceptible to the effects of the substance. Particularly susceptible individuals (for naphthalene exposure) are found in the general population, most commonly in dark skinned races.

\section{First Aid Measures}

\section{Inhalation:}

Remove to fresh air. If not breathing, give artificial respiration. If breathing is difficult, give oxygen. Get medical attention.

\section{Ingestion:}

Do NOT induce vomiting. Give large amounts of water. Never give anything by mouth to an unconscious person. Get medical attention.

\section{Skin Contact:}

Immediately flush skin with plenty of soap and water. Remove contaminated clothing and shoes. Get medical attention. Wash clothing before reuse. Thoroughly clean shoes 
before reuse.

Eye Contact:

Immediately flush eyes with plenty of water for at least 15 minutes, lifting lower and upper eyelids occasionally. Get medical attention immediately.

\section{Fire Fighting Measures}

Fire:

Flash point: 71C (160F) CC

Autoignition temperature: $385 \mathrm{C}(725 \mathrm{~F})$

Flammable limits in air $\%$ by volume:

lel: 0.8 ; uel: 5.0

Combustible Liquid and Vapor!

\section{Explosion:}

Above flash point, vapor-air mixtures are explosive within flammable limits noted above. Vapors can flow along surfaces to distant ignition source and flash back. Can form explosive peroxides which may be concentrated by evaporation or distillation.

\section{Fire Extinguishing Media:}

Water spray, dry chemical, alcohol foam, or carbon dioxide. Water may be ineffective. Water spray may be used to keep fire exposed containers cool.

\section{Special Information:}

In the event of a fire, wear full protective clothing and NIOSH-approved self-contained breathing apparatus with full facepiece operated in the pressure demand or other positive pressure mode.

\section{Accidental Release Measures}

Ventilate area of leak or spill. Remove all sources of ignition. Wear appropriate personal protective equipment as specified in Section 8. Isolate hazard area. Keep unnecessary and unprotected personnel from entering. Contain and recover liquid when possible. Use nonsparking tools and equipment. Collect liquid in an appropriate container or absorb with an inert material (e. g., vermiculite, dry sand, earth), and place in a chemical waste container. Do not use combustible materials, such as saw dust. Do not flush to sewer! For the naphthalene component: US Regulations (CERCLA) require reporting spills and releases to soil, water and air in excess of reportable quantities. The toll free number for the US Coast Guard National Response Center is (800) 424-8802.

J. T. Baker SOLUSORB ${ }^{\circledR}$ solvent adsorbent is recommended for spills of this product.

\section{Handling and Storage}

Protect against physical damage. Outside or detached storage is preferred. Inside storage should be in a standard flammable liquids storage room or cabinet. Separate from oxidizing materials. Storage and use areas should be No Smoking areas. Containers of 
this material may be hazardous when empty since they retain product residues (vapors, liquid); observe all warnings and precautions listed for the product.

\section{Exposure Controls/Personal Protection}

\section{Airborne Exposure Limits:}

For Naphthalene:

-OSHA Permissible Exposure Limit (PEL):

TWA $=10 \mathrm{ppm}, 50 \mathrm{mg} / \mathrm{m} 3$

-ACGIH Threshold Limit Value (TLV):

TWA $=10 \mathrm{ppm}, 52 \mathrm{mg} / \mathrm{m} 3$;

$\mathrm{STEL}=15 \mathrm{ppm}, 79 \mathrm{mg} / \mathrm{m} 3$

\section{Ventilation System:}

A system of local and/or general exhaust is recommended to keep employee exposures below the Airborne Exposure Limits. Local exhaust ventilation is generally preferred because it can control the emissions of the contaminant at its source, preventing dispersion of it into the general work area. Please refer to the ACGIH document, Industrial Ventilation, A Manual of Recommended Practices, most recent edition, for details.

\section{Personal Respirators (NIOSH Approved):}

If the exposure limit is exceeded, a half-face respirator with an organic vapor cartridge and particulate filter (NIOSH type P95 or R95 filter) may be worn for up to ten times the exposure limit or the maximum use concentration specified by the appropriate regulatory agency or respirator supplier, whichever is lowest. A full-face piece respirator with an organic vapor cartridge and particulate filter (NIOSH P100 or R100 filter) may be worn up to 50 times the exposure limit, or the maximum use concentration specified by the appropriate regulatory agency or respirator supplier, whichever is lowest. Please note that $\mathrm{N}$ series filters are not recommended for this material. For emergencies or instances where the exposure levels are not known, use a full-face piece positive-pressure, airsupplied respirator. WARNING: Air-purifying respirators do not protect workers in oxygen-deficient atmospheres.

\section{Skin Protection:}

Wear impervious protective clothing, including boots, gloves, lab coat, apron or coveralls, as appropriate, to prevent skin contact.

\section{Eye Protection:}

Use chemical safety goggles and/or a full face shield where splashing is possible. Maintain eye wash fountain and quick-drench facilities in work area.

\section{Physical and Chemical Properties}

\section{Appearance:}

Clear, colorless liquid.

Odor:

Like a mixture of benzene and menthol; a moldy turpentine odor. 


\section{Solubility:}

Insoluble in water.

Specific Gravity:

$0.970 @ 20 \mathrm{C} / 4 \mathrm{C}$

pH:

No information found.

\% Volatiles by volume @ 21C (70F):

100

\section{Boiling Point:}

207C (405F)

Melting Point:

$-35.8 \mathrm{C}(-33 \mathrm{~F})$

Vapor Density (Air=1):

4.55

Vapor Pressure (mm Hg):

$1 @$ 38C; $0.368 @ 25 \mathrm{C}$

Evaporation Rate (BuAc=1):

$<1$

\section{Stability and Reactivity}

\section{Stability:}

Stable under ordinary conditions of use and storage. Contact with air may cause formation of tetralin peroxide. Potentially explosive peroxides can form on long-term storage in contact with air. Light and heat accelerate peroxide formation.

Hazardous Decomposition Products:

Carbon dioxide and carbon monoxide may form when heated to decomposition. Under pyrolysis at 700C yields tars that contain 3,4-benzopyrene.

\section{Hazardous Polymerization:}

Will not occur.

Incompatibilities:

Strong oxidizers.

Conditions to Avoid:

Heat, flame, ignition sources, air, light and incompatibles.

\section{Toxicological Information}

For Tetrahydronaphthalene:

Oral Rat LD50: 1620 ul/kg; Skin Rabbit LD50: 17 gm/kg. Irritation Data (skin, rabbit): std Draize $=100 \mathrm{mg} / 24 \mathrm{H}$, moderate; open Draize $=500 \mathrm{mg}$, severe. Investigated as a tumorigen.

For Decahydronaphthalene:

Oral Rat LD50: 4170 mg/kg; Skin Rabbit LD50: 5900 mg/kg; Inhalation Rat LC50: 710 $\mathrm{ppm} / 4 \mathrm{H}$; Investigated as a tumorigen.

For Naphthalene: 
Oral Rat LD50: 490 mg/kg; Skin Rabbit LD50: > 20 g/kg; Inhalataion rat LC50: 340 $\mathrm{mg} / \mathrm{m} 3 / 1 \mathrm{H}$. Investigated as a tumorigen, mutagen $\&$ reproductive effector.

\begin{tabular}{|c|c|c|c|}
\hline Ingredient & $\begin{array}{l}-- \text {-NTP } \\
\text { Known }\end{array}$ & $\begin{array}{l}\text { Carcinogen--- } \\
\text { Anticipated }\end{array}$ & IARC \\
\hline \multicolumn{4}{|l|}{ Category } \\
\hline $\begin{array}{l}\text { Naphthalene, } 1,2,3,4 \text {-tetrahydro- } \\
(119-64-2)\end{array}$ & No & No & None \\
\hline Decahydronaphthalene (91-17-8) & No & No & None \\
\hline Naphthalene $(91-20-3)$ & No & No & None \\
\hline
\end{tabular}

\section{Ecological Information}

\section{Environmental Fate:}

When released into water, this material is expected to readily biodegrade. When released to water, this material is expected to quickly evaporate. When released into the water, this material is expected to have a half-life of less than 1 day. This material is expected to significantly bioaccumulate. When released into the air, this material is expected to be readily degraded by reaction with photochemically produced hydroxyl radicals. When released into the air, this material is expected to have a half-life of less than 1 day.

\section{Environmental Toxicity:}

No information found.

\section{Disposal Considerations}

Whatever cannot be saved for recovery or recycling should be handled as hazardous waste and sent to a RCRA approved waste facility. Processing, use or contamination of this product may change the waste management options. State and local disposal regulations may differ from federal disposal regulations. Dispose of container and unused contents in accordance with federal, state and local requirements.

\section{Transport Information}

Not regulated.

\section{Regulatory Information}

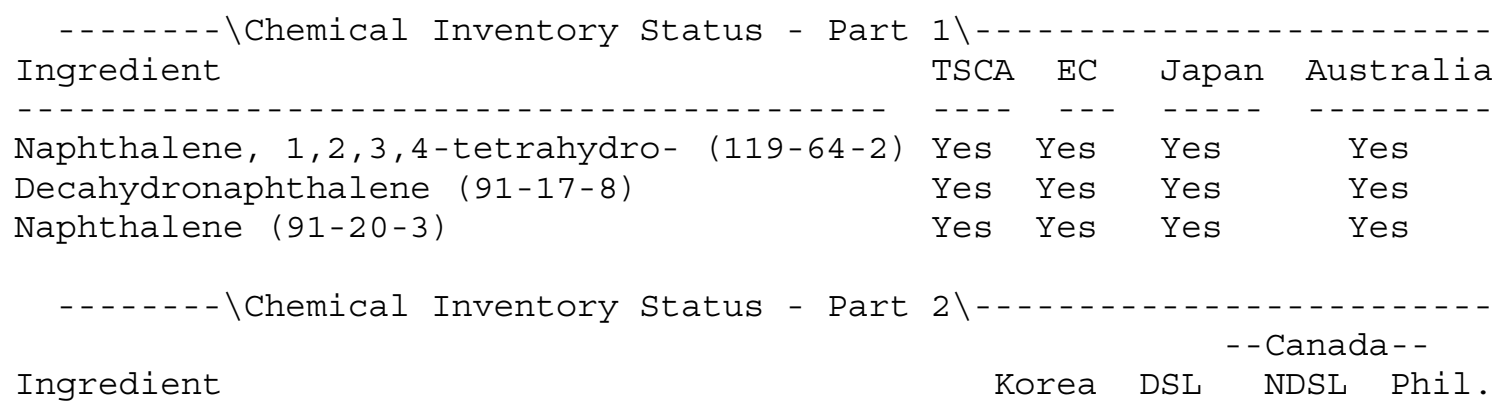


Naphthalene, 1,2,3,4-tetrahydro- (119-64-2)

Decahydronaphthalene (91-17-8)

Naphthalene (91-20-3)

$\begin{array}{llll}---- & --- & --- & ---- \\ \text { Yes } & \text { Yes } & \text { No } & \text { Yes } \\ \text { Yes } & \text { Yes } & \text { No } & \text { Yes } \\ \text { Yes } & \text { Yes } & \text { No } & \text { Yes }\end{array}$

\begin{tabular}{|c|c|c|c|c|}
\hline \multirow{4}{*}{ 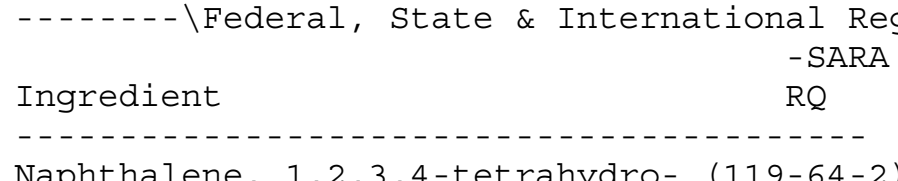 } & \multicolumn{4}{|c|}{ 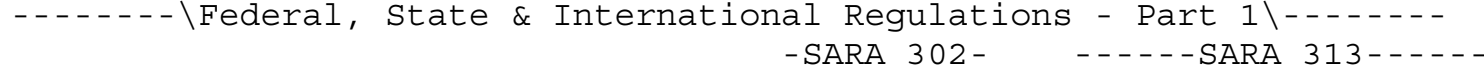 } \\
\hline & $\mathrm{TPQ}$ & List & \multirow{2}{*}{$\begin{array}{c}\text { Chemical } \\
----\end{array}$} & \multirow{2}{*}{1 Catg. } \\
\hline & --- & ---- & & \\
\hline & ) No & No & No & No \\
\hline Decahydronaphthalene (91-17-8) & No & No & No & No \\
\hline Naphthalene (91-20-3) & No & No & Yes & No \\
\hline 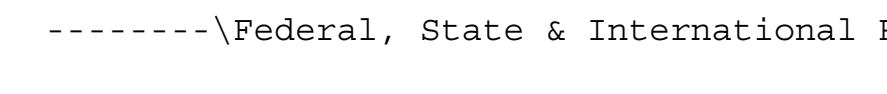 & Regulat & Eions & $\begin{array}{l}-\operatorname{Part} 2 \backslash \\
- \text { RCRA- }\end{array}$ & $-\mathrm{TSCA}-$ \\
\hline Ingredient & CERCLA & & 261.33 & $8(d)$ \\
\hline $\begin{array}{l}\text { Naphthalene, } 1,2,3,4 \text {-tetrahydro- } \\
\quad(119-64-2)\end{array}$ & No & & No & No \\
\hline Decahydronaphthalene (91-17-8) & No & & No & No \\
\hline Naphthalene (91-20-3) & 100 & & U165 & No \\
\hline Chemical Weapons Convention: & $12(\mathrm{~b}):$ & No & CDTA: & No \\
\hline $\begin{array}{l}\text { SARA 311/312: Acute: Yes Chronic: No } \\
\text { Reactivity: No } \\
\text { (Mixture / Liquid) }\end{array}$ & Fire & e: Yes & Pressure & No \\
\hline
\end{tabular}

Australian Hazchem Code: None allocated.

Poison Schedule: S6

WHMIS:

This MSDS has been prepared according to the hazard criteria of the Controlled Products Regulations (CPR) and the MSDS contains all of the information required by the CPR.

\section{Other Information}

NFPA Ratings: Health: 1 Flammability: 2 Reactivity: 0

\section{Label Hazard Warning:}

WARNING! HARMFUL IF SWALLOWED OR INHALED. CAUSES IRRITATION

TO SKIN, EYES AND RESPIRATORY TRACT. COMBUSTIBLE LIQUID AND VAPOR. CONTAINS NAPHTHALENE WHICH MAY CAUSE ALLERGIC SKIN REACTION AND MAY AFFECT LIVER, KIDNEY, BLOOD AND CENTRAL NERVOUS SYSTEM..

\section{Label Precautions:}

Avoid contact with eyes, skin and clothing.

Avoid prolonged or repeated contact with skin.

Avoid breathing vapor or mist.

Keep container closed.

Use only with adequate ventilation. 
Wash thoroughly after handling.

Keep away from heat, sparks and flame.

Label First Aid:

In case of skin contact, immediately flush skin with plenty of soap and water. Remove contaminated clothing and shoes. Wash clothing before reuse. In case of eye contact, immediately flush eyes with plenty of water for at least 15 minutes. If inhaled, remove to fresh air. If not breathing, give artificial respiration. If breathing is difficult, give oxygen. If swallowed, DO NOT INDUCE VOMITING. Give large quantities of water. Never give anything by mouth to an unconscious person. In all cases, get medical attention. Product Use:

Laboratory Reagent.

Revision Information:

MSDS Section(s) changed since last revision of document include: 8 .

Disclaimer:

$* * * * * * * * * * * * * * * * * * * * * * * * * * * * * * * * * * * * * * * * * * * * * * * * * * * * * * * * * * * * * * * * * * * * * * * *$ $* * * * * * * * * * * * * * * * * * * * * * * *$

Mallinckrodt Baker, Inc. provides the information contained herein in good faith but makes no representation as to its comprehensiveness or accuracy. This document is intended only as a guide to the appropriate precautionary handling of the material by a properly trained person using this product. Individuals receiving the information must exercise their independent judgment in determining its appropriateness for a particular purpose. MALLINCKRODT BAKER, INC. MAKES NO REPRESENTATIONS OR WARRANTIES, EITHER EXPRESS OR IMPLIED, INCLUDING WITHOUT LIMITATION ANY WARRANTIES OF MERCHANTABILITY, FITNESS FOR A PARTICULAR PURPOSE WITH RESPECT TO THE INFORMATION SET FORTH HEREIN OR THE PRODUCT TO WHICH THE INFORMATION REFERS. ACCORDINGLY, MALLINCKRODT BAKER, INC. WILL NOT BE RESPONSIBLE FOR DAMAGES RESULTING FROM USE OF OR RELIANCE UPON THIS INFORMATION.

*************************************************************************** $* * * * * * * * * * * * * * * * * * * * * * * *$

Prepared by: Environmental Health \& Safety Phone Number: (314) 654-1600 (U.S.A.) 